Portland State University

PDXScholar

Fall 10-28-2015

\title{
Effective Technology Implementation in Schools: Differing Perceptions of Teachers, Administrators, and Technology Staff
}

Joseph Stephen Morelock

Portland State University

Follow this and additional works at: https://pdxscholar.library.pdx.edu/open_access_etds

Part of the Educational Administration and Supervision Commons, and the Educational Leadership Commons

Let us know how access to this document benefits you.

\section{Recommended Citation}

Morelock, Joseph Stephen, "Effective Technology Implementation in Schools: Differing Perceptions of Teachers, Administrators, and Technology Staff" (2015). Dissertations and Theses. Paper 2626.

https://doi.org/10.15760/etd.2622

This Dissertation is brought to you for free and open access. It has been accepted for inclusion in Dissertations and Theses by an authorized administrator of PDXScholar. Please contact us if we can make this document more accessible: pdxscholar@pdx.edu. 
Effective Technology Implementation in Schools: Differing Perceptions of Teachers, Administrators, and Technology Staff

\author{
by \\ Joseph Stephen Morelock
}

A dissertation submitted in partial fulfillment of the requirements for the degree of

Doctor of Education

in

Educational Leadership: Administration

Dissertation Committee:

Deborah Peterson, Chair

Swapna Mukhopadhyay

Gayle Thieman

Margaret Everett

Portland State University

2015 


\begin{abstract}
This study examined the connection between perceptions of teacher self-efficacy, professional development, and leadership practices and attitudes as it relates to successful implementation of technology for student learning in K-12 schools. As external pressures exhort schools to transform the learning environment and to include more meaningful applications of technology in the learning experiences for all students, issues which create barriers to a successful implementation of new practices must be examined.
\end{abstract}

This study examined the responses of teachers, school and district administrators, and technology support personnel in a stratified random sample from 37 school districts in the state of Oregon to analyze the combined effects of teacher self-efficacy perceptions, leadership practices, and professional development as they relate to the implementation of classroom educational technology.

The study revealed perceptual differences between staff roles of what teachers know about technology and how they use technology. School contexts, such as percentages of disadvantaged or non-White students, and teacher factors, such as age and gender, affected participant perception of technology implementations and of professional development opportunities. 
The researcher proposes a new framework for understanding school contexts and for planning successful technology implementations based upon a review of literature and original research. 


\section{DEDICATIONS}

I dedicate this study to my family, from whom I have received so much patience and support over the last several years as I completed this journey. I am especially indebted to my wonderful wife and partner, Elaine, who dealt with late nights, multiple revisions, piles of papers strewn about, and myriad grammar doubts all while managing the busy lives of our two boys, Lorenzo and Fernando. Thank you also to my parents who showed me the value of education and of the importance of being involved in the lives of children.

I also dedicate this study to the teachers, administrators, and support personnel who work tirelessly on a daily basis to provide the best educational experience they can for students of all ages. 


\section{ACKNOWLEDGEMENTS}

In the doctoral studies process, there are so many people who support and encourage you along the way. I would like to express my gratitude and thanks to some of those amazing people here:

First, to my advisor, Deborah Peterson, without whose guidance, pressure, patience, advice, editing, cups of coffee and cheerleading this dissertation would not have been remotely possible. It impossible to put into words how much I appreciate her support and dedication to helping me completing this scholarly work.

To Swapna Mukhopadhyay, who invited me to tea one day after a long stretch of me being uninvolved in my doctoral studies and convinced me that this path was the right one. I'd like to also thank her for continuing on my committee and providing support and key human behavior insights.

To Gayle Thieman, not only for serving as a part of my committee and being a keen editor and advisor, but also for putting up with me for so many years throughout my work at Portland State, starting with my administrative licensure so many years ago and throughout my doctoral studies.

To Stefanie Randol, whose organizational skills, patient reminders and responses to my questions made it possible to navigate the proper university roads to achieve my goals. 
Lastly, I'd like to thank Margaret Everett for her willingness to serve and represent the Office of Graduate Studies, and whose keen insights helped me develop a stronger theory of action. 


\section{TABLE OF CONTENTS}

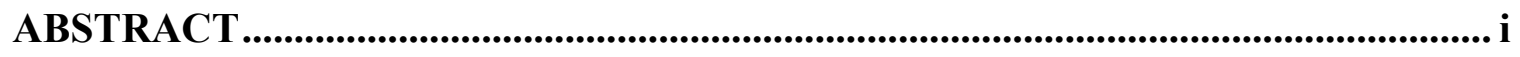

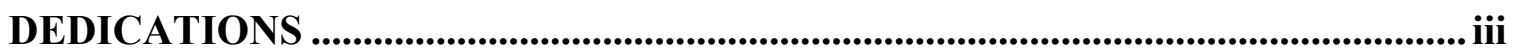

ACKNOWLEDGEMENTS ............................................................................. iv

LIST OF TABLES ................................................................................................... viii

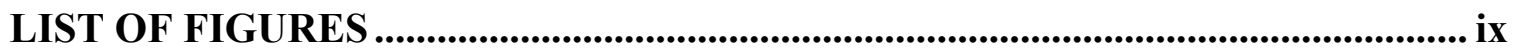

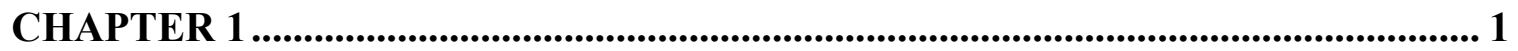

INTRODUCTION ................................................................................................. 1

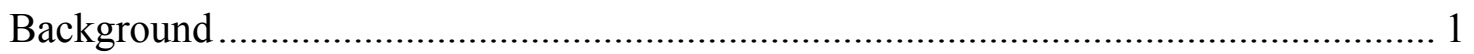

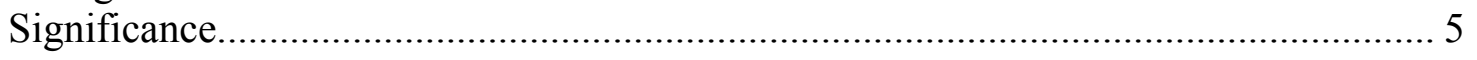

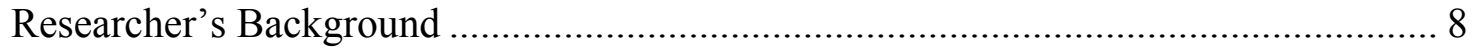

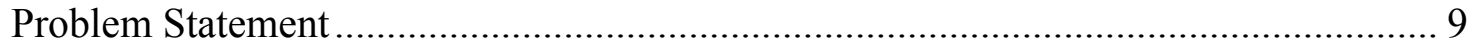

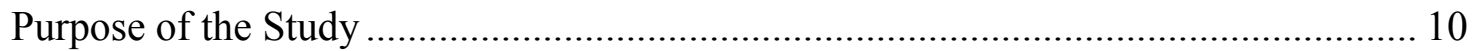

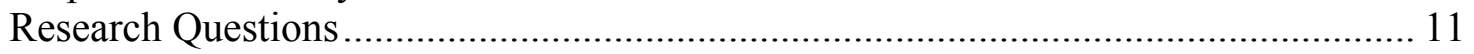

Limitations and Key Assumptions .................................................................. 12

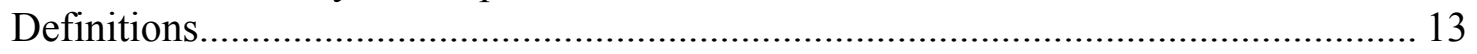

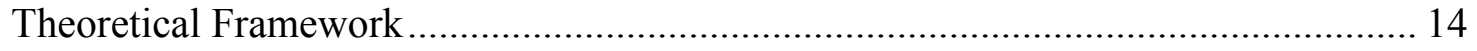

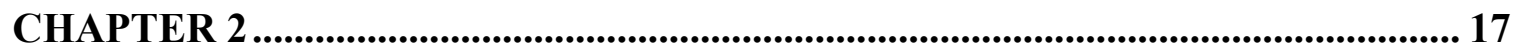

A REVIEW OF RELATED LITERATURE.......................................................... 17

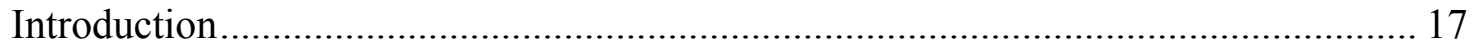

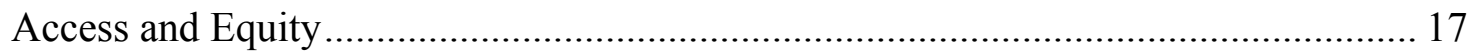

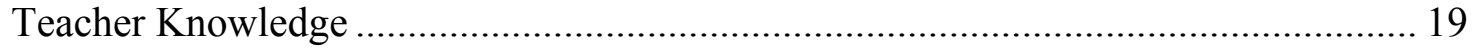

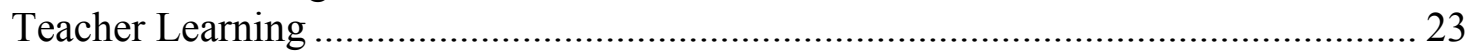

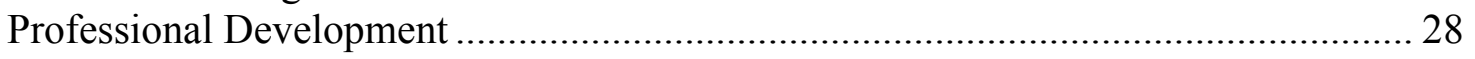

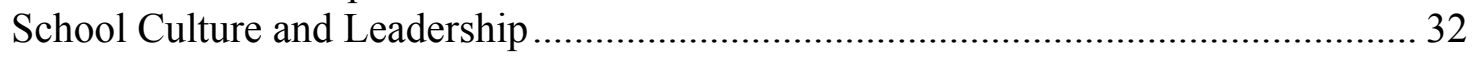

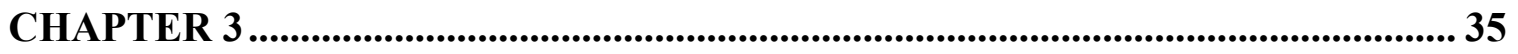

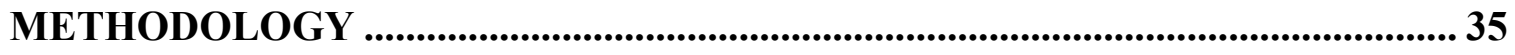

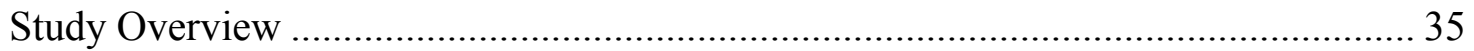

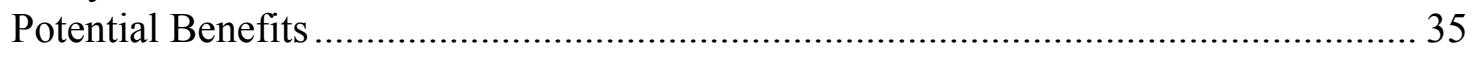

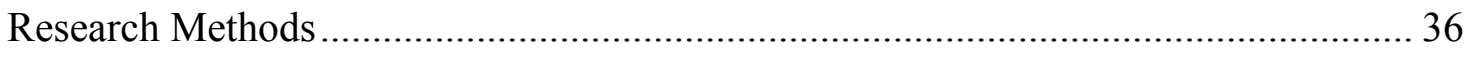

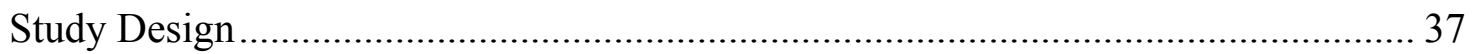

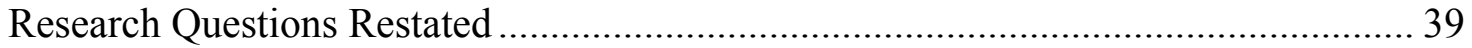

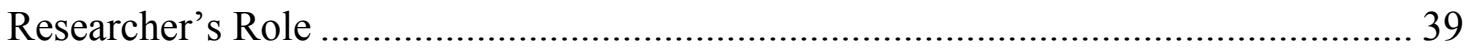

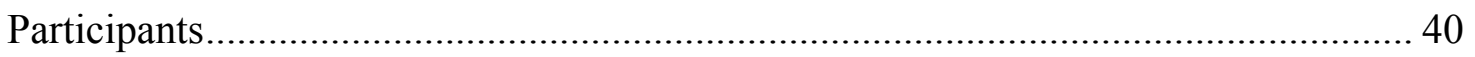

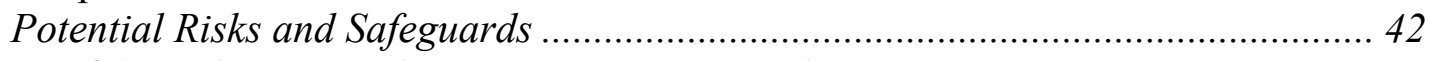

Confidentiality, Records Management \& Distribution .................................... 43

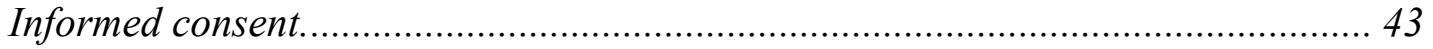




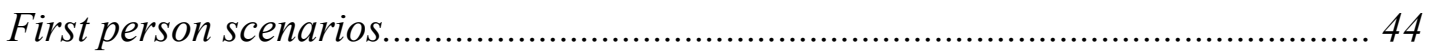

Discussion of the instrument's questions........................................................... 48

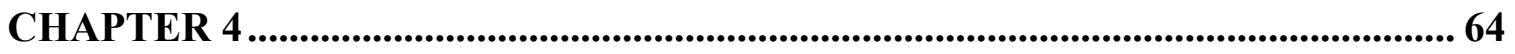

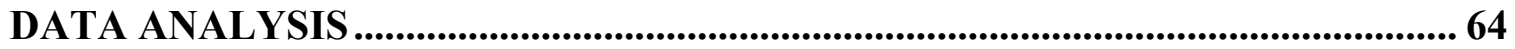

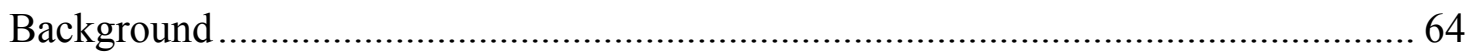

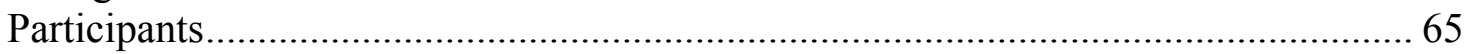

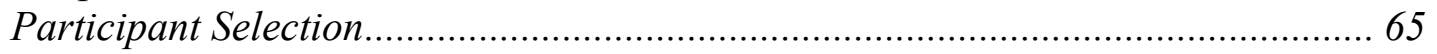

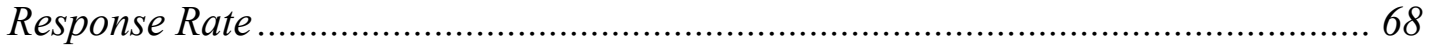

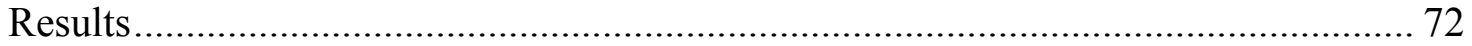

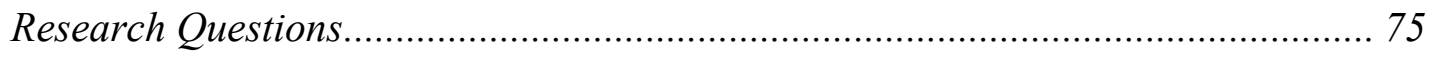

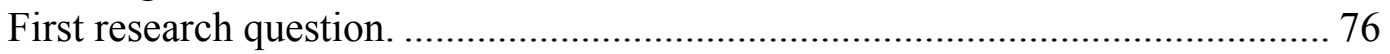

Second research question.................................................................... 90

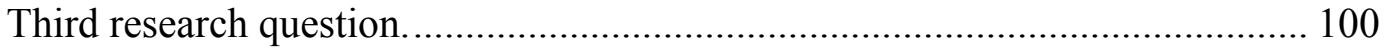

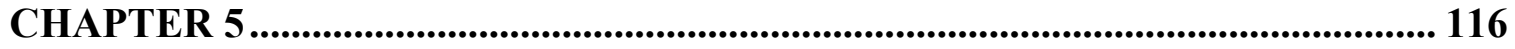

DISCUSSION \& CONCLUSION....................................................................... 116

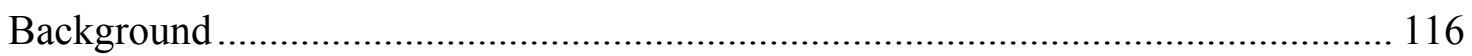

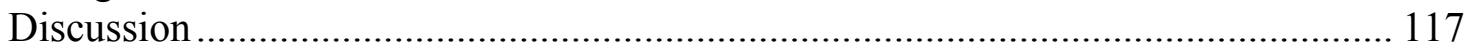

Differences of Opinion About Professional Development .................................... 117

Teacher Knowledge and Learning ................................................................... 119

Perceptions of Teacher Use of Technology .................................................... 123

Factors Affecting the Use of Technology ....................................................... 125

Perceptions of Technology's Advantages and Disadvantages ............................ 126

Opportunities for Further Study ................................................................ 128

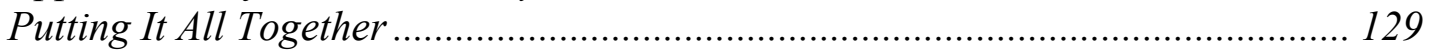

Successful Technology Implementation Cycle (STIC): A Theory of Action ........... 131

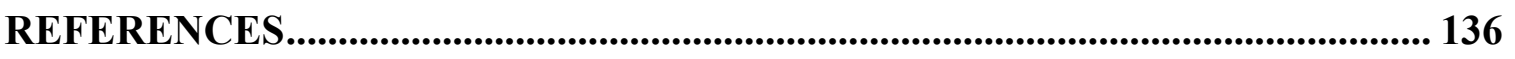

APPENDIX A - Email Invitation/Collection Correspondence ............................... 151

APPENDIX B - Additional Results Tables .................................................................. 156

APPENDIX C - Figures for Quantitative Results .................................................. 192

APPENDIX D - Correlation Matrices for Quantitative Results.............................. 214

APPENDIX E - Survey Instrument .......................................................................... 228 


\section{LIST OF TABLES}

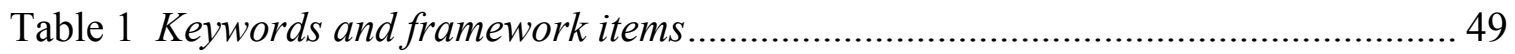

Table 2 List of tables with matching theoretical framework items ............................... 51

Table 3 Participant demographic information ............................................................ 52

Table 4 Technology ratios, usage, and frequency ....................................................... 53

Table 5 Technological Pedagogical Content Knowledge items by participant role ........ 54

Table 6 Influence of interpersonal pressures to incorporate technology ........................ 56

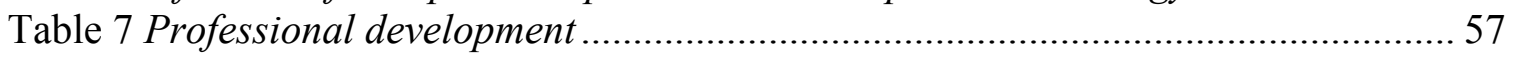

Table 8 Influences of leadership, peer support and teacher inclusion ........................... 58

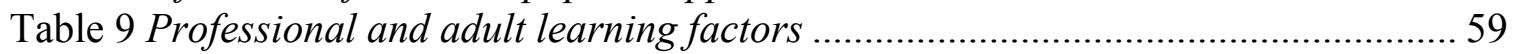

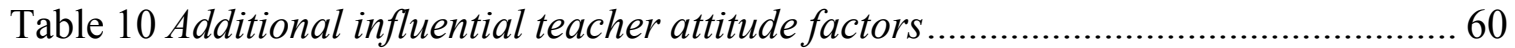

Table 11 Systemic and support barriers to incorporate technology............................... 61

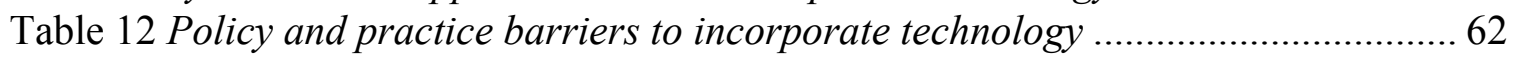

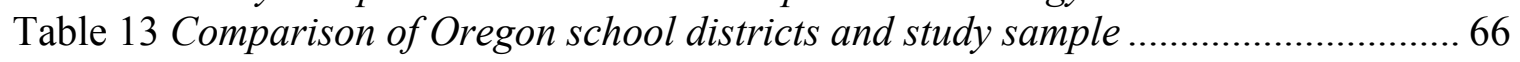

Table 14 Percentage of economically disadvantaged students as reported by study

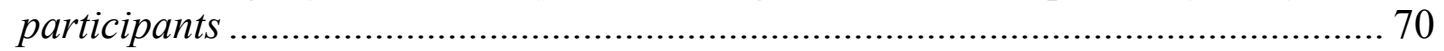

Table 15 Research questions and related questions ...................................................... 75

Table 16 Variables and their measures for the first research question........................... 76

Table 17 Significant covariates for Professional Development (Combined) ................... 79

Table 18 Significant covariates for Professional Development Relevancy (Combined).. 81

Table 19 Significant covariates for Technology Frequency ........................................... 87

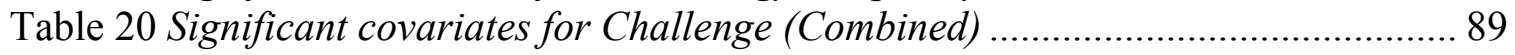

Table 21 Research question 2 and its related questions .............................................. 90

Table 22 Variables and their measures for the second research question ...................... 91

Table 23 Significant covariates for Technological Knowledge (TK) ............................. 92

Table 24 Significant covariates for Technological Content Knowledge (TCK) ............... 94

Table 25 Significant covariates for Technological Pedagogical Knowledge (TPK)....... 95

Table 26 Significant covariates for Technological Pedagogical Content Knowledge

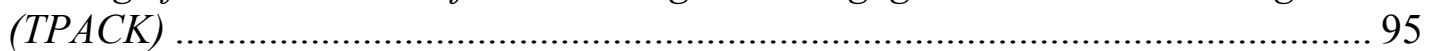

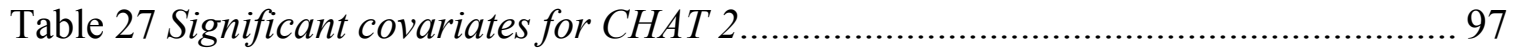

Table 28 Significant covariates for CHAT 3................................................................ 98

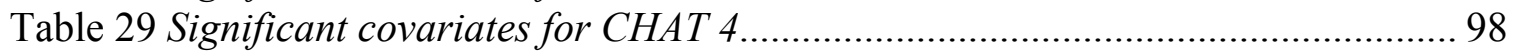

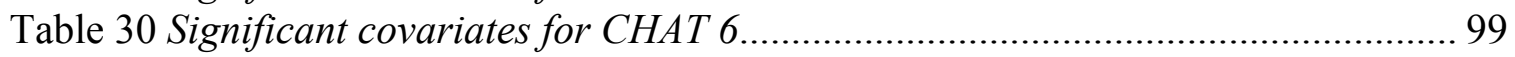

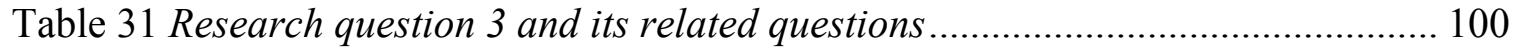

Table 32 Variables and their measures for the third research question ........................ 101

Table 33 Significant covariates for Usage 1.............................................................. 102

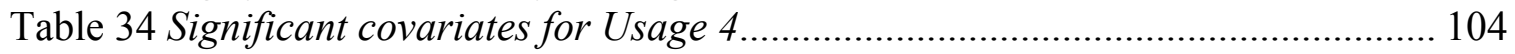

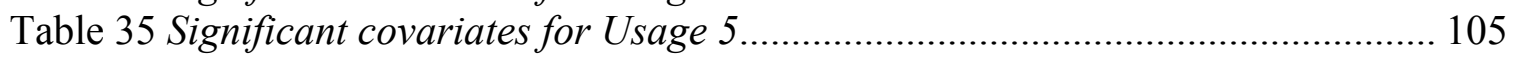

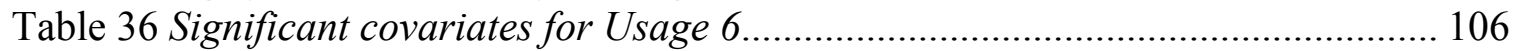

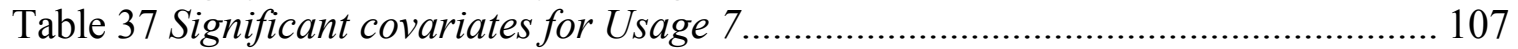

Table 38 Significant covariates for Usage 9............................................................... 108 


\section{LIST OF FIGURES}

Figure 1. Components of the TPACK framework........................................................ 20

Figure 2. Basic structure of the Activity Theory framework ........................................ 24

Figure 3. Expanded structure of the Activity Theory framework ................................ 25

Figure 4. Cultural Historical Activity Theory framework........................................... 27

Figure 5. Ratios of technology devices to students based upon attendance in schools with listed percentages of students who participate in the Federal Free and Reduced

Lunch Program as reported by study participants............................................ 72

Figure 6. Successful Technology Implementation Cycle (STIC). ............................... 132 


\section{CHAPTER 1 \\ INTRODUCTION \\ Background}

As the world around us goes through a period of rapid technology iterations and disruptive change, the pressure on schools to keep up has never been greater (Cummins, Brown, \& Sayers, 2007; National Association of State Boards of Education [NASBE], 2012). American public schools have been under fire for not innovating enough, not providing individualized instruction and for not changing in a relevant way to prepare students for the world of work and additional educational opportunities (Culp, Honey, \& Mandinach, 2005). Education technology policy papers in the last two decades have suggested that technology, in general, will either drive educational change, make the traditional model of school irrelevant, or provide students with the access they need to be successful in the future and to level the playing field for all students (Culp, Honey, \& Mandinach, 2005). Those policies often have used either a symbolic approach to play to the societal values, whether those are economic stability or global competitiveness, or they have focused on the rational perspective, using technology to solve or substantially alleviate problems or issues known to researchers and practitioners in the education field. School systems have been slow to adopt emerging technologies or make the changes to keep up with changing demands. Several studies of access issues and of relevant pedagogical shifts have been done as well as research into when and how classroom teachers adopt technology and how school and district leaders support those efforts.

Even while budgets tighten, stakeholders are demanding innovation in the classroom and technology access for students (Culp, Honey, \& Mandinach, 2005). 
Teachers, who may have been educated themselves in a completely different era of schooling, are being asked to engage students in new ways with little access to training and professional development. Meanwhile, superintendents are responding to requests from school boards and patrons to individualize instruction for all students (Judge, Puckett, Cabuk, 2004; NASBE, 2012). Often, teachers or administrators are seen as the ones holding back the technology adoption in schools, and in turn they respond to the public that there is not enough money, or time, or commitment by the district or state to comply (NASBE; Sugar, Crawley, \& Fine, 2004; Warschauer \& Ware, 2008). In some schools and classrooms, low-income students are missing the educational opportunities that newer technologies can provide, while in others, those who do have access begin to "check out" of traditional school and look for alternatives, possibly due to the archaicness of what they are expected to endure (Collins, 1991; Toffler, 1981; Prensky, 2008). Clearly, there is a need for research to find solutions to some of these seemingly dichotomous viewpoints and situations.

Schools, and the very necessity of education, are being seen in a new light as well. While the current structure of the vast majority of public schools was created in a response to the Industrial Revolution and before there was an organized public schooling system in place (Collins \& Halverson, 2010), the technological innovations of more recent history and the pressures to integrate them into schools are happening at a time when school systems already exist, albeit still a reflection of their original intent: reacting to a changing cultural and world-of-work landscape of the late 1800s (Collins \& Halverson, 2010). The structures of the past were developed around the concept of an 
educator holding and delivering all the knowledge students would need to master (Dewey, 1938; Halverson \& Shapiro, 2013). By contrast, information technologies, when accessed and employed by students, give them "control of relevant information and provide systems to manage cognitive load so that users can focus on the appropriate information to facilitate activities" (Halverson \& Shapiro, 2013, p.168). To clarify, students in schools today are learning previously curated information on the off-chance they may need to recall it later, instead of learning to "crisscross" the information landscape in order to practice learning structures which help them acquire deeper knowledge of complex concepts from multiple perspectives now and in the future (Spiro, Coulson, Feltovich, \& Anderson, 1988). Collins and Halverson succinctly state this difference as "schools foster just-in-case learning; information technologies foster just-intime learning" (p. 20).

The number of students who do have access to technology in order to engage in just-in-time learning is increasing nationally, in spite of the dearth of access at school. According to a Pew Internet \& American Life Project study (Madden, Lenhart, Duggan, Cortesi, \& Gasser, 2013)

- $78 \%$ of teens now have a cell phone, and almost half (47\%) of them own smartphones.

- $23 \%$ of teens have a tablet computer, a level comparable to the general adult population.

- $95 \%$ of teens use the Internet.

- $93 \%$ of teens have a computer or have access to one at home. 
- $71 \%$ of teens with home computer access say the laptop or desktop they use most often is one they share with other family members.

Other studies show the desire of teachers to incorporate more technology-rich resources in order to foster just-in-time learning is thwarted by technology access barriers in school. In a study by the Pew Research Center (Purcell, Heaps, Buchanan, \& Friedrich, 2013), researchers found that

- $56 \%$ of teachers of the lowest income students say that a lack of resources among students to access digital technologies is a "major challenge" to incorporating more digital tools into their teaching; $21 \%$ of teachers of the highest income students report that problem;

- $49 \%$ of teachers of students living in low income households say their school's use of internet filters has a major impact on their teaching, compared with $24 \%$ of those who teach better off students who say that.

The rapidly expanding availability of information and our exposure to it require researchers to consider additional theoretical frameworks for knowledge and skill acquisition on the part of both students and teachers. The role of leadership in removing barriers, providing vision and support, as well as demanding equity for all students is also in need of clarity and definition.

Access barriers to technology tools, information resources, and creative opportunities remain stubbornly large for many lower-income students in schools. Further, many schools reflect an image of what was created in the past as a response to a 
different technology (industrial) revolution (Collins \& Halverson, 2010). Transformation of school practices must begin to more closely mirror the technology revolution currently underway. It is imperative we understand the issues and pathways to meaningful action. At this time of rapid change in the world outside the classroom, we need critical research in successful practices in order to transform what is happening within its walls.

\section{Significance}

Studies of access equity have pervaded educational research for decades. Throughout much of Krashen's work (1989, 1995, 1997) detailing reading skill improvement and bilingual education, he posits that access to a text-rich environment that has materials of interest to the students is a key factor in improving reading and literacy skills and attitudes. His research showed that one of the best predictors of reading ability scores on the 1992 National Assessment of Educational Progress (NAEP) was the ratio of books per student in their school libraries (Krashen, 1995). In schools where there was a higher book-to-student ratio, both nationally and in California, their achievement scores outpaced other schools by a significant amount (Krashen, 1997). There are multiple levels to consider in this research. First, if schools do not spend some of their budget purchasing reading materials, then no students will have high access to those materials. Without access to reading materials in the library, where most low socio-economic status (SES) students can get to them, the chance that they will spend more time outside of class reading decreases. In turn, as the NAEP assessment shows, without more practice reading, both student scores and skills are destined to falter. In summary, one might say 
that without expanded access to reading materials, students from a lower SES or underserved school are at a distinct disadvantage.

Additionally, the current state of available and extensive text opportunities is presenting new issues of access barriers to literacy development. The term "literacy" is difficult to define, and there is a movement among the literature to redefine it completely (Warschauer \& Ware, 2008). Some argue that literacy extends well beyond the decoding of words and texts toward a contextual, personal, social, and economic understanding of the concepts and ideas (Frechette, 2002; Kress, 2003, Warschauer \& Ware). Kress asserts that "it is no longer possible to think about literacy in isolation from a vast array of social, technological, and economic factors" (p. 1). Frechette (2002) agrees and adds that traditional approaches to literacy in a text environment have been changed to reflect the understanding that "the function and the purpose of text is contextual, historical, cultural, and personal" (p. 24). She goes on to describe that the shift from a traditionally textual world to an increasingly multimedia-rich one requires the vital skill of "media literacy" (p. 24). These issues, of learning to navigate, discern, and dissect that which can be found online, may well be an insurmountable hurdle for those who have little access to the tools, or the experience or instruction required to develop those "new media" literacy skills. Additionally, Dewey's work (1938) details the importance of providing educational opportunities through experiences of importance and interest to the student. For those learners who have restricted access to online or outside reading opportunities or less experience with decoding and defining what they read in context of their own 
heritage or social history, there is a growing problem of inequitable access to the learning experience.

Taken together, the research into student access of text materials and the development of a modern understanding of literacy and media literacy (Frechette, 2002; Kress, 2003, Warschauer \& Ware) point to the necessity of providing a learning environment replete with access to texts in a variety of formats, student interest levels, and from widely varied sources. Of course, in order for students to gain access to such experiences and reading opportunities, they must have access to the tools that can take them there. These tools can be as small and mobile as a phone, to the more complex tools, such as a tablet or state-of-the-art computer center with high-level creation and collaboration tools. Therefore, the access roadblock is the simplest to understand. Fewer tools equals less access. Less access means less opportunity for outside-school or highinterest resources.

Beyond simply spending money and deploying devices in a willy-nilly fashion, leaders must understand the importance of modern technology in schools and teachers must be given the opportunities to learn and to practice with those technologies so that their pedagogical power might be unleashed. Careful attention to professional development, decision-making opportunities about purchases, and an understanding of how adults perceive their own abilities may be the crucial factors in a successful educational technology implementation.

This study investigated three primary areas related to the use of technology in schools: (1) teachers' perception of their own levels of technological, pedagogical, and 
content knowledge (Mishra \& Koehler, 2006); (2) critical leadership actions and styles which influence technology integration by teachers; and (3) factors which influence teachers' willingness or ability to learn to use and to integrate technology in their classroom. Each of these perspectives was seen through three sets of respondent group lenses: teachers, administrators, and technology support staff. This research examined the relationship among perception of abilities and knowledge of teachers by different groups, the leadership actions and styles that inhibit or encourage teacher technology integration, and other factors impacting teacher willingness to employ technology with students.

\section{Researcher's Background}

In my current role as a curriculum director and district technology leader for a medium-sized school district, the importance of successfully implementing technology resources as a support for improving the achievement and the opportunities of all students in schools is my daily concern. As available funds are reduced, the strategic and purposeful engagement of technology in classrooms must show signs of improving the experience and the achievement of both students and staff. In the last decade in Oregon, monies from the state's general fund for K-12 public schools in Oregon has grown at a rate of 15\% (Oregon Department of Education, 2014a) while the costs of the Public Employee Retirement System (PERS) rose 47\% between 2007 and 2012 (Oregon Health Sciences University, 2012). With the rising costs of healthcare and the unpredictable rise and fall of school funding since 2003 (Oregon Department of Education, 2014a), coupled with the possibility of PERS costs nearly doubling in the next two years, school systems are wary of any purchase without measurable and direct impact on student engagement 
and achievement. With the increasing need for shrinking budgets to be carefully and wisely spent, discovering the essential success factors of leadership practice in technology implementation as well as core practices exhibited by teachers in improving the achievement of their students while employing technology in a meaningful way is of great interest to both the researcher and to other school and district leaders across the country.

\section{Problem Statement}

Technologies available for student learning vary so widely across the United States that it is nearly impossible for any researcher to present a histogram of the current state of technology use in schools. Access barriers for many of the lower-income students in schools to technology tools, information resources, and creative opportunities remain daunting. While many schools reflect an image of what was created in the past as a response to the Industrial Revolution (Collins \& Halverson, 2010), the world around us has changed exponentially. The rapidly expanding availability of information and students' and teachers' constant exposure to it requires researchers to consider additional theoretical frameworks for knowledge and skill acquisition. Activity theory as a learning framework may help researchers understand how both groups, adults and students, become comfortable and eventually proficient in new skills and capabilities (Jonassen \& Rohrer-Murphy, 1999). Further, it is important to understand how teachers view professional development and change (Guskey, 2002) and how their views and their commitment to it shifts over the course of their career (Vermunt \& Endedijk, 2011). It is 
also important to understand how teachers view their own abilities (Mishra \& Koehler, 2006) as we design professional development for their benefit.

Teacher empowerment in technology purchasing decisions is an area with scant research, though there is a plethora of research on the need for being an inclusive and engaging leader (Deal \& Peterson, 2009; Marzano, Waters, \& McNulty, 2005; Schmoker, 1999; Anderson \& Dexter, 2000; Becker, 1992; Cordeiro \& Cunningham, 2013; Davies, 2010; Lecklider, Britten, Clausen, \& Muncie, 2009). The role leadership provides in removing barriers (Ertmer, 1999), providing vision and support (Anderson \& Dexter, 2000), as well as demanding equity for all students in technology implementations requires clarity of purpose. Prior studies showed that administrative direction and control over budgets proved to be the most important factor in technology use in schools (Becker, 1992). However, since technology devices have become ever easier to use by a broader audience and the pressure to use technology in schools has increased, the prior research may not apply under current and ever-changing circumstances.

By using a mix of both closed-ended quantitative survey responses and qualitative open-ended responses from three primary groups of educators- teachers, administrators, and technology staff, the researcher hoped to provide insight into certain existing conditions and leadership practices which support well-implemented technologies for learners and directions for leaders to consider in order to harness these conditions to enhance teacher acumen and increase student access to technology and the meaningful opportunities it can provide in the learning environment.

\section{Purpose of the Study}


The purpose of this study was to explore the effects of leadership practice upon the successful integration of technology in the learning environment. A second purpose of this study was to understand the interplay of theories of learning, frameworks for understanding how teachers feel about their own abilities and comfort with technology, and the practices and attitudes of leadership. Finally, this study proposed to present the data collected in a format that can be easily understood and applied by leaders and teachers in schools today.

\section{Research Questions}

While there are thousands of articles, books, and conference proceedings that deal with technology use in the classroom, strikingly few specifically unite the impact on student access of leadership practices, student (child) and teacher (adult) learning frameworks, and stakeholder input on purchasing decisions related to classroom technology.

This paper examines core issues surrounding the changing nature of learning and acquiring knowledge and structures, the impact of leadership at various levels within the organization, and how well-implemented, highly-available technologies may improve student opportunity. The researcher then proposes a theory of action in order to address some of the key findings of the research. Following the review of literature, this paper describes a mixed-methods survey using a primarily quantitative survey of thirty-five items with an additional three simultaneously-collected supporting qualitative items (Morgan, 1998) to answer the following questions: 
1. How do leadership styles and/or practices impact the implementation of technology initiatives?

2. What factors specific to teacher characteristics inhibit or encourage their application of technology in learning experiences for students?

3. What additional factors related to the beliefs, attitudes or policies of schools and school personnel influence the implementation of technology?

\section{Limitations and Key Assumptions}

The proposed study has the following limitations:

1. The survey instrument collected self-perception data and as such, is limited to how the respondents view their own work and the work of others.

2. There are some issues with correlating data elements which come from the same self-reporting source (Podsakoff \& Organ, 1986).

3. The study primarily focuses on participants whose central or building-level administration has given permission to the researcher to make contact with the teachers (and other administrators and support staff), so the study may not represent a true random sample.

4. The bulk of the data collected will be quantitative in an effort to reduce the effects of researcher bias, as the researcher is a professional in the area of district and technology leadership.

5. The researcher is a White male with an advanced education employed in a public school system as a central office administrator. As such, the scope of 
what defines equity and other concepts in this study are based upon this perspective.

The proposed study includes the following key assumptions: (a) the selected participants responded to the survey accurately and of their own free will; (b) the selected participants understood the questions presented, in vocabulary, scope, and intent; (c) the data collected largely represents self-perception and opinion data by three distinct groups who function in the same environment but who have very different roles; and (d) the interpretation of the data best approximates the intent of the respondents and makes connections based upon that data and not upon researcher bias.

\section{Definitions}

For the purpose of this study, the following definitions are used:

1. Teacher: a classroom teacher, not including instructional "coaches" nor teacher assistants;

2. Administrator: may include any school official not directly tied to technology support, including principals, area managers, district directors, superintendents;

3. Personal Learning Network (PLN): informal professional social groups and collegial relationships formed by teachers (usually through electronic means) as a way to explore their profession, gather wisdom and information about issues, and share their own expertise;

4. Staff: teachers, support personnel, or others under the direction of a school-based or a district-based administrator; 
5. Technology staff: may include technology support staff, technology coaches, technology managers, directors, $\mathrm{CIO} / \mathrm{CTO}$, or other technology administrator;

6. Technological Pedagogical Content Knowledge (TPACK): a framework describing the intersection of knowledge of technological, pedagogical, and content by teachers.

\section{Theoretical Framework}

This study is structured to examine the impact of teacher self-efficacy, professional development, theories of activity and learning, and actions and perceptions of leadership factors in a connected way that allows for significant discussion on the impact of each one, both individually and as a whole. The theoretical framework is comprised primarily of the following theories of measuring what teachers know and describing how they learn:

1. Teachers arrive at a new learning task, such as attempting to integrate technology into their daily work with students, with perceptions of their own personal level of technological, pedagogical, and content (TPACK) knowledge;

2. Cultural-Historical Activity Theory (CHAT) helps the researcher describe learning actions in the classroom context, including the role of the community, division of labor, and rules. This study examines leadership and support personnel actions and perceptions through the lens of CHAT.

Additionally, a review of literature caused the researcher to develop predispositions to guide the research. The predispositions include the following: 
1. Reducing opportunity or production gaps between upper income and lower income students in schools is a worthwhile goal and schools should be providing those rich, technology-supported educational experiences for all students (Attwell \& Battle, 1999; Becker, 2000; Cummins, Brown, \& Sayers, 2007; Goode, 2010; Graham, 2011; Jackson, Zhao, Kolenic, Fitzgerald, Harold, \& Von Eye, 2008; Judge, Puckett, \& Cabuk, 2004; Norris, 2003; Rogoff \& Wertsch, 1984; Selwyn, 2003; Warschauer, Knobel, \& Stone, 2004; Warschauer \& Ware, 2008);

2. Integrating technology in classrooms, schools, and districts is a difficult endeavor and there are many factors which affect its effective implementation (Abbitt, 2011; Erdogan \& Sahin, 2010; Ertmer, 1999 \& 2005; Ertmer, Ottenbreit-Leftwich, Sadik, Sendurur, \& Sendurur, 2012; Jordan, 2013; Koehler \& Mishra, 2009; Koh \& Chai, 2011; Lin, Tsai, Chai, \& Lee, 2013; Mishra \& Koehler, 2006);

3. Teachers are the primary source of educational opportunities for students in schools and will be the persons responsible for the majority of the pedagogical changes that occur in order to adjust for classroom technology integration (Clark \& Hollingsworth, 2002; Guskey 1986 \& 2002; Schmoker, 1999);

4. Teachers (and administrators) will need additional and ongoing professional development in order to integrate technology resources in a powerful way in their classrooms (Cummins, Brown, \& Sayers, 2007; Deal \& Peterson, 2009; Fullan, 2010; Guskey 1986 \& 2002; Hattie, 2009; Parrett \& Budge, 2012; Reeves, 2009; Tharp \& Gillimore, 1988); 
5. Professional development opportunities has different meaning to teachers at different times in their careers, and that perception of the abilities to use technology (of themselves and by others) will have an impact on their success (Clarke \& Hollingsworth, 2002; Guskey 1986 \& 2002; Huberman, 1989; Richter, Kunter, Klusmann, Lüdtke, \& Baumert, 2011; Vermunt \& Endedijk, 2011);

6. Additional data about events and processes that teachers, leaders, and support personnel perceive as barriers to classroom technology integration may inhibit increased access to students in order to provide equity in their school opportunities (Judge, Puckett, Cabuk, 2004; Madden, Lenhart, Duggan, Cortesi, \& Gasser, 2013; NASBE, 2012; Purcell, Heaps, Buchanan, \& Friedrich, 2013; Sugar, Crawley, \& Fine, 2004; Warschauer \& Ware, 2008).

By using the theoretical framework outlined above along with the predispositions developed from the review of literature, this study highlights additional domains of research to be explored as well as tangible, usable action items for both administrators and support personnel to use in their work designing professional development, technology deployments, and action for equity. 


\section{CHAPTER 2 \\ A REVIEW OF RELATED LITERATURE \\ Introduction}

The review of related research is separated into a discussion of access and equity, teacher knowledge, teacher learning, professional development, and school culture and leadership. In each section, the researcher will describe current literature supporting various aspects of the concepts in the framework as well as detailing some of the limitations of the research recommendations.

\section{Access and Equity}

The "digital divide" has been a term used to define the difference between the "haves" and the "haves not" groups of individuals who have or do not have access to modern technology tools (Goode, 2010; Jackson, Zhao, Kolenic, Fitzgerald, Harold, \& Von Eye, 2008; Judge, Puckett, \& Cabuk, 2004; Norris, 2003; Warschauer \& Ware, 2008). While the tools that allow students to create, collaborate, share, search, read and learn have become readily available for some, there is a chasm between those who can afford to purchase such tools personally and those who cannot (Lievrouw \& Farb, 2003). This includes individuals and schools alike. So while some students will be afforded the opportunity to develop their media literacy skills because of their socioeconomic status, others will not, either because of their income level or the state of technology availability in their schools.

Among those students who can get access to technology tools, there are other issues in the "digital divide" that are cause for alarm. How the computer or other information tool is used can be as important as who has access to use it (Attwell \& Battle, 
1999; Selwyn, 2003; Warschauer, Knobel, \& Stone, 2004). If a computer is primarily used at school for drill and practice activities or mandated assessments only, then the level of usage outside school has the propensity to be very perfunctory (Attwell \& Battle, 1999; Cummins, Brown, \& Sayers, 2007; Warschauer, Knobel, \& Stone, 2004). Without regular access and opportunities to use the computer for activities beyond electronic textbooks or testing machines, what chance do learners have outside the school day to understand the power of the tools and to develop their personal media literacy skills? This has also been called an opportunity or production gap and can be considered a secondlevel digital divide (Attwell, 2001; Graham, 2011; Norris, 2003). The importance of an adult guide to help students develop an understanding of how to use tools and resources beyond the classroom is critical in a constructivist approach to teaching and learning (Rogoff \& Wertsch, 1984). Without a rich experience using and learning the power of the tools while in school with a knowledgeable guide to help scaffold the learner's understanding of how to use tools to create, research, or collaborate, a poor experience outside of school with similar tools will likely be the result. If the gap remains between those who have and those who do not have access to modern technology outside school, the inequity of more intellectual and creative uses of technology will remain unchanged (Becker, 2000).

We know technology access and usage models affect lower socio-economic (SES) students differently than higher SES students (Cummins, Brown, \& Sayers, 2007; Warschauer, Knobel, \& Stone, 2004), and that low-income schools suffer from computer use as performativity, i.e., computer technology used in a way to learn to use the tool 
itself, not the application of the tool for higher-order learning. Warschauer, Knobel, and Stone also found that in schools with high numbers of low SES students, combined with the additional pressure of scoring well on high stakes tests and with policy shifts to move to standards-based learning, teachers often feel the need to use technology to prepare students for a test or rote skill rather than using it for expanding and extending the learning environment. We can see that policy changes at the national level, e.g. highstakes testing and standards-based teaching models, affect students from lower income families much more than those from higher income environments (Cummins, Brown, \& Sayers). The most recent Oregon Department of Education's (2013) statistics for the 2011-2012 school year show a state average of 53\% of students enrolled in the federal Free \& Reduced Lunch Program, with several districts and schools reporting numbers in the $80-90 \%$ range. These Oregon students will feel the effects of national and state policy differently than other populations within the school who will not (Ruiz-de-Velasco, Fix, \& Clewell, 2000; Wenglinsky, 1998). It is important that we craft policy that allows for and encourages technology use to engage students in higher-level learning opportunities both in and out of school and to understand the reality of numbers of kids living in poverty among us who may only have this chance if school provides it. Every aspect of these issues and others will require thoughtful policy planning, extensive dialog, and careful curation.

\section{Teacher Knowledge}

Among the factors that can contribute to the lower availability of technology for students in classrooms and schools, clearly some stand out in the professional research. 
The first factor, successful integration of technology by the teacher, can best be described via the TPACK framework developed by Mishra and Koehler (2006). The framework is a way to understand the relationship between and among three specific components of teacher knowledge: technology, pedagogy, and content. TPACK helps us understand the complex nature of those relationships and the difficulty in getting them all to interact in a balanced, powerful way.

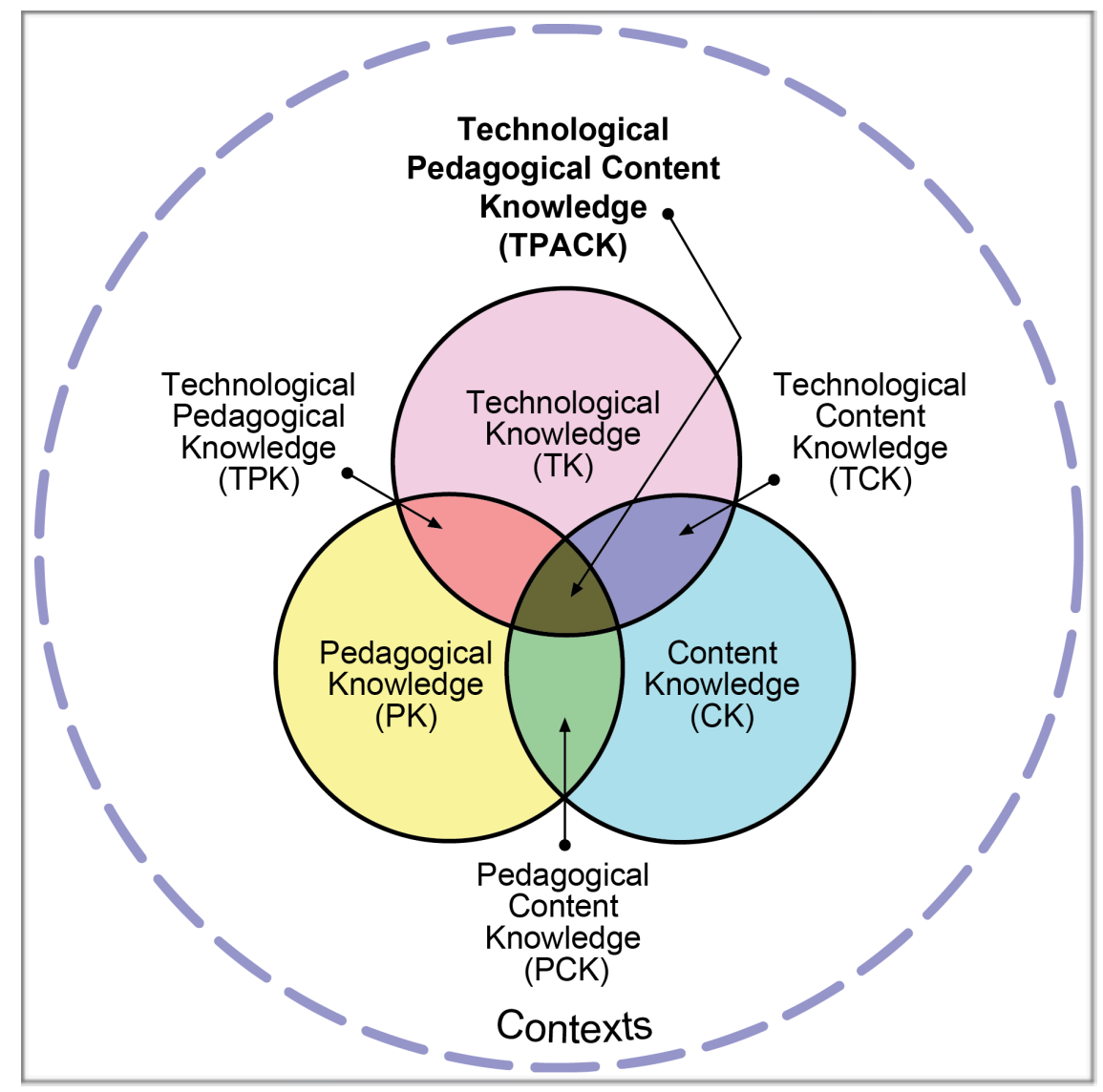

Figure 1. Components of the TPACK framework Reproduced by permission of the publisher, (C) 2012 by tpack.org

In terms of teacher knowledge as described by Koehler and Mishra (2009), there are three core areas, each of which has an equal weight in the success of teachers 
integrating technology effectively: content, pedagogy, and technology. TPACK does not make the argument for or against using technology in an integrated way per se, but that the framework should be used as a medium for understanding some of the connections and the complexities between following areas as described by Mishra and Koehler (2006):

1. Content knowledge (CK) refers to the material to be taught and learned, and Koehler and Mishra (2009) make the argument that teacher subject-area content knowledge is important in successful integration.

2. Pedagogical knowledge $(\mathrm{PK})$ is the awareness and understanding the teacher has of those practices which influence teaching and learning, including techniques and approaches.

3. Pedagogical content knowledge (PCK) is the interpretation and presentation of the subject matter being taught and learned and includes much of the teacher's craft in determining how and how much students are taught about that subject.

4. Technology knowledge (TK) refers to the teacher's awareness of different technologies and their usage; TK will be a difficult area to be specific about, as technology tools are rapidly outdated and updated.

5. Technological content knowledge (TCK) refers to the teacher's understanding of how technology can create new representations of the content being explored.

6. Technological pedagogical knowledge (TPK) refers to the teacher's knowledge of how teaching and learning can be changed by the application of technology; and, it 
also refers to his/her understanding of how to use technology tools in a pedagogical way for which they were not necessarily designed.

7. Technological pedagogical content knowledge (TPACK), then, is the intersection of knowledge about teaching and learning, subject matter expertise, and the rapidly changing landscape of technology.

The TPACK framework appears straightforward when described and/or put into pictorial representations. However, effectively teaching with technology is a challenging process, and the framework should be seen as a fluid representation as strengths and weaknesses of teachers change depending upon their comfort level with any of the three core areas $(\mathrm{PK} / \mathrm{CK} / \mathrm{TK})$ and the instructional task in which they are involved (Koehler \& Mishra, 2009).

It is important to note that some research makes the connection between teacher knowledge and teacher self-efficacy when it comes to using the TPACK framework as a measurement instrument (Abbitt, 2011; Ertmer, 2005). It is possible that teacher selfefficacy is one of the barriers to technology integration in classrooms because of the teacher's level of confidence in either choosing or using a technology tool (Abbitt, 2011; Ertmer, 1999 \& 2005; Ertmer, Ottenbreit-Leftwich, Sadik, Sendurur, \& Sendurur, 2012). How teachers feel about their own technological, content, or pedagogical abilities have shown to be strong indicators of successful technology integration and powerful usage by teachers (Ertmer et al., 2012; Abbitt, 2011). There are studies that have shown both age and gender effects on the TPACK self-assessment as well (Erdogan \& Sahin, 2010; Jordan, 2013; Koh \& Chai, 2011; Lin, et al., 2013). 
As part of the research framework for this study, there is a focus on teacher perception of their self-efficacy in the seven areas detailed by the TPACK framework.

These indicators are one of the focus areas of the data and have been shown in the past to be key insights into both the how and the why of teacher technology integration. The TPACK framework, however, is only a method by which to measure and understand the complex connections between the areas of content, pedagogy, and technology.

Additionally, though it has been shown to be a tool that can measure progress in the areas via a pre and post test measurement (Schmidt, Baran, Thompson, Mishra, Koehler, \& Shin, 2009; Chai, Koh, Tsai, \& Tan, 2011), the TPACK framework is not meant to be used as a tool to discover how teachers gain more knowledge in the seven areas. In order to understand how teachers learn instead of what they know, we will need to examine other frameworks.

\section{Teacher Learning}

In order to describe the process of teacher learning, the researcher has selected Activity Theory, detailed by a number of authors as way to understand and measure complex learning processes (Engeström, 2000 \& 2001; Jonassen \& Rohrer-Murphy, 1999; Feldman \& Weiss, 2010; Daniels, 2004; Koszalka \& Wu, 2004; Nardi, 1996). Jonassen and Rohrer-Murphy (1999) describe the purpose of the theory thusly:

Activity cannot be understood or analyzed outside the context in which it occurs. So when analyzing human activity, we must examine not only the kinds of activities that people engage in but also who is engaging in that activity, what their goals and intentions are, what objects or products 
result from the activity, the rules and the norms that circumscribe that activity, and the larger community in which the activity occurs (p. 62).

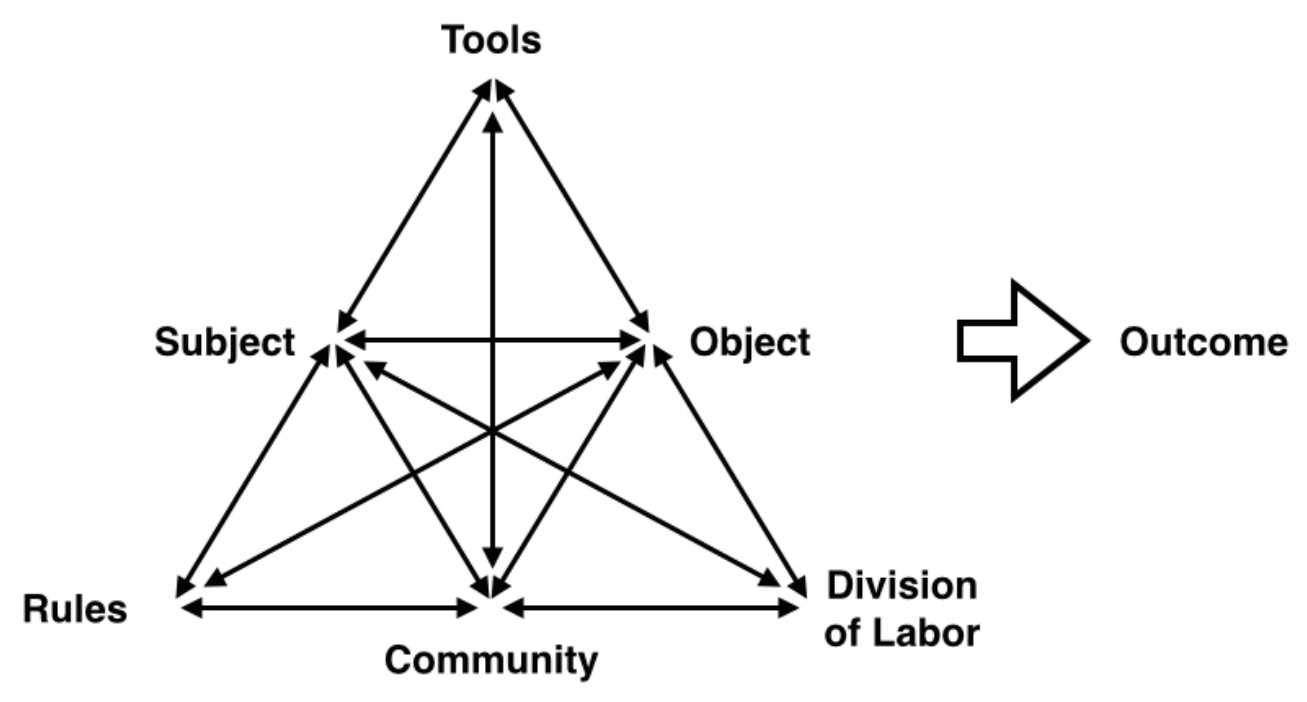

Figure 2. Basic structure of the Activity Theory framework (Adapted from Engeström, 2000; Feldman \& Weiss, 2010)

Figure 2 is a commonly-used graphic to describe the core framework of Activity Theory as generally two triangles, showing the relationship between the subject, the object, tools, community, rules, division of labor, and an outcome (Engeström, 2000; Koszalka \& Wu, 2004; Jonassen \& Roher-Murphy, 1999). Jonassen and Rohrer-Murphy (1999) say that Activity Theory "posits that conscious learning emerges from activity (performance), not as a precursor to it" (p. 62). 


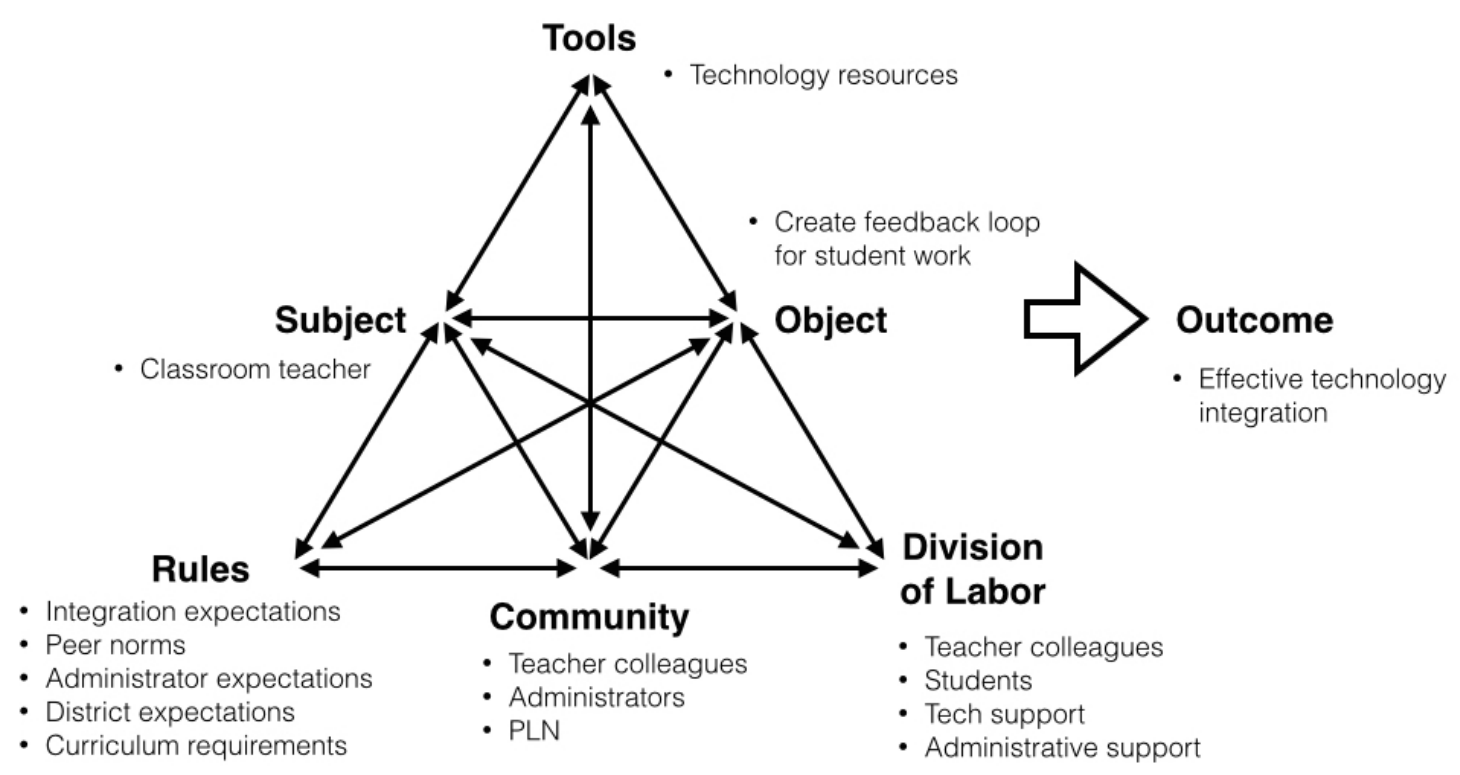

Figure 3. Expanded structure of the Activity Theory framework (Adapted from Engeström, 2000; Feldman \& Weiss, 2010)

Figure 3 describes the framework of Activity Theory in the manner in which it is used for the study. The "subject" in Activity Theory is the central active learner or actor. In most instances, these learners will not be acting alone (Engeström, 2001), so the subject would possibly have the support of the greater learning community around her, and/or a person or group of persons with whom to share the learning work. So, in Figure 3, then, the subject is the classroom teacher engaged in the work, who is supported by her “community" which may include her teacher colleagues, building or district-level administrators who provide support, or her personal learning network (PLN). Further, she may be dividing the labor of the learning task by calling on her colleagues to possibly codesign a lesson, or asking her students to provide feedback to her, or sharing the workload with an administrator or technology support personnel. Additionally, "rules" or norms may guide in what manner the subject learns. School and district culture norms, 
technology policy, and possibly supervisor expectations all play a role in how the subject will approach the task.

Jonassen and Rohrer-Murphy (1999) inform us that a "fundamental assumption of Activity Theory is that tools mediate or alter the nature of human activity" (p. 67). That is, the tools we learn to use for a task impact the way we think about the task, thereby fundamentally changing the way we learn. However, tools also go through changes over a period of time as their capabilities are constantly being discovered and rediscovered in response to how we humans use them and are changed themselves; in Activity Theory, they are explained as "a reflection of their historical development- they change the process and are changed by the process" (p. 67).

The "object" refers to the learning task or the "constantly reproduced purpose of a collective activity system that motivates and defines the horizon of possible goals and actions" (Daniels, 2004, p. 190). In the example shown in Figure 3, it could be the development or implementation of or the learning about a manner in which to provide students better feedback on their work and progress. Daniels differentiates goals from objects by saying that "goals are primarily conscious, relatively short-lived and finite aims of individual actions" (p. 61).

The outcome should be seen as the point at which the subject has finally made sense and meaning. The outcome in Figure 3 above is "effective technology integration," which guides the task learning work the subject is doing. That is, if successful in the work of developing or learning a process by which to give students more appropriate feedback. 
Activity Theory was first developed in Russia during the 1920s and 1930s, but has seen a large amount of study and adjustment over time (Engeström, 2000; Jonassen \& Rohrer-Murphy, 1999; Nardi, 1996). In the later years of development, "culturalhistorical activity theory" (CHAT) gained popularity as a way to describe what innate and learned experiences the subject (and other actors) bring to the learning task at hand (Feldman \& Weiss, 2010; Koszalka \& Wu, 2004).

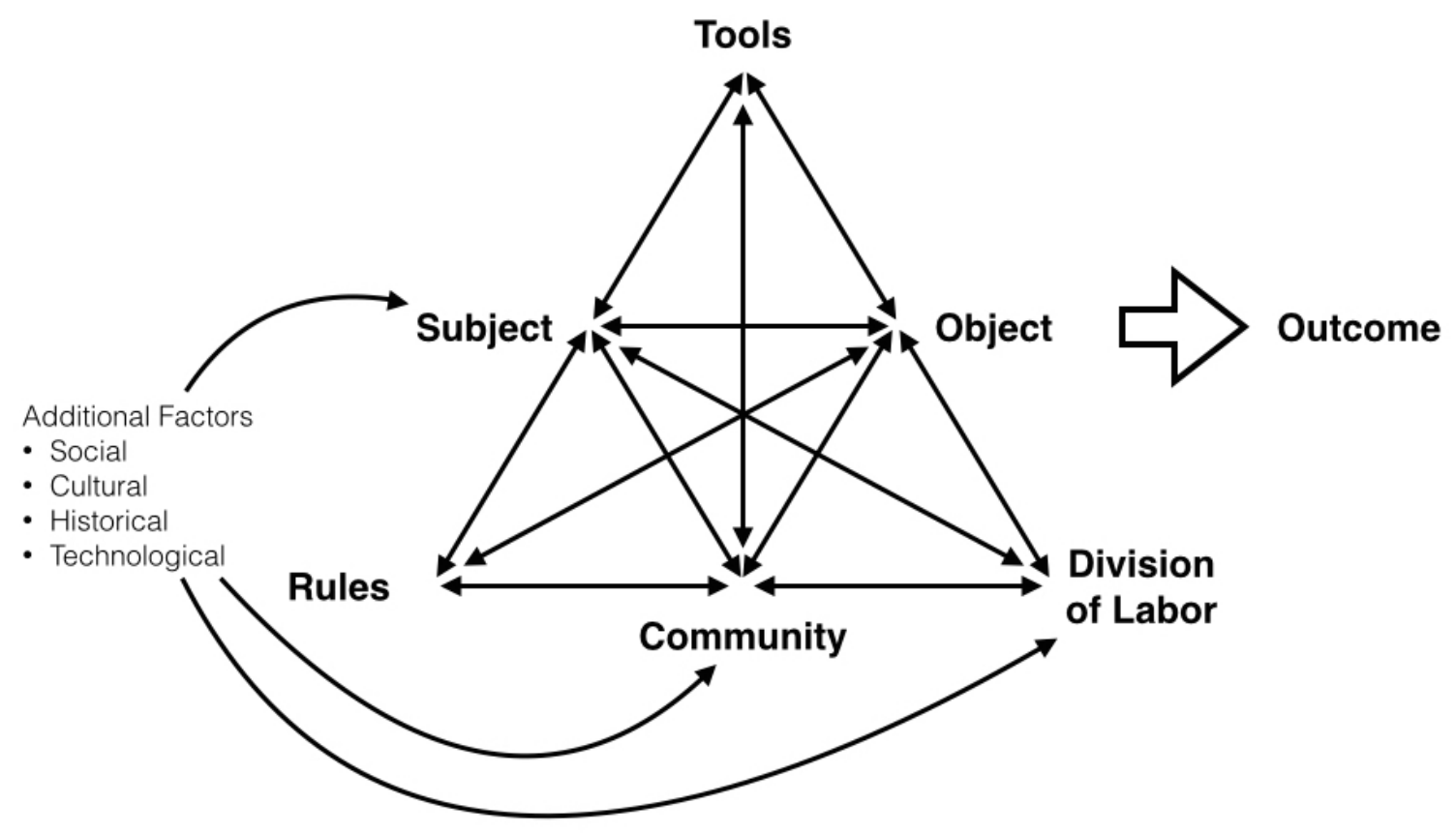

Figure 4. Cultural Historical Activity Theory framework (Adapted from Koszalka \& Wu, 2004)

Considering the additional factors as seen on the left of Figure 4, each subject brings to the task their social-cultural perspective, their personal history, and in this case, their abilities and beliefs about technology tools. The same could be true for those in the supporting community (administrators, peers) or in the group with whom the teacher will 
share the task (technology support, students, peers), thereby providing additional complex factors to study and to understand by research.

It is important to remember both Activity Theory and Cultural-Historical Activity Theory frameworks are meant to describe the learning activity as a continual process, not as a singular event. Further, it is critical to understand that much of Activity Theory and its offshoots see learning as a social activity; learning is rarely done by individuals on their own without connecting with other humans in the knowledge and experiencebuilding process (Engeström, 2001; Feldman \& Weiss, 2010).

While Activity Theory and Cultural-Historical Activity Theory can provide us a framework to understand how humans interact with mediating tools and with the support of others and the rules and norms by which they are bound, we also must consider how to reach those learners when we attempt to provide them the learning opportunities they may need.

\section{Professional Development}

The primary method of changing pedagogical practices and pedagogical knowledge growth is professional development. Among much of the literature, there is clear consensus that the need for continuous professional development is a necessary and worthwhile endeavor (Cummins, Brown, \& Sayers, 2007; Deal \& Peterson, 2009; Fullan, 2010; Guskey 1986 \& 2002; Hattie, 2009; Parrett \& Budge, 2012; Reeves, 2009; Tharp \& Gillimore, 1988). As there are several aspects of professional development to consider, only a few of those will be presented here. 
Using professional development activity as a way to improve teacher effectiveness is a generally accepted goal (Guskey 2002). In order to understand what makes professional development effective, we must understand:

1. when and why teachers engage in it and how it affects them (Clarke \& Hollingsworth, 2002; Guskey 1986 \& 2002; Richter, Kunter, Klusmann, Lüdtke, \& Baumert, 2011; Vermunt \& Endedijk, 2011);

2. which models make it most effective (Clarke \& Hollingsworth, 2002; Glazer \& Hannafin, 2006; Guskey, 2002); and

3. which additional types of activities can have effect on teacher practice and student outcomes (Jurasaite-Harbison \& Rex, 2005; Rathgen, 2006; Voogt, Westbroek, Handelzalts, Walraven, McKenney, Pieters, \& de Vries, 2011).

For teachers, the value in professional development is found when they believe it will help them improve their knowledge and skills to a point that they will be able to notice a measurable difference in student achievement (Guskey, 2002). According to some research, development activities which fail are often geared toward changing teacher attitudes and beliefs before getting teachers to try techniques first to change their practice and affect student outcomes (Clark \& Hollingsworth, 2002; Guskey 1986 \& 2002). In simpler terms, "seeing is believing," and according to research on professional development, that statement holds mostly true. To further explore the role of change in teacher practice leading to a change in teacher beliefs and attitudes, Clark and Hollingsworth (2002) note that the actual change occurs through the mediating process of "reflection" and "enaction" by the teacher. That is to say that the actual change in 
practice happens when teachers attempt a new practice and then spend time thinking about it or sharing it with colleagues in order to look for patterns of success or failure. All of the authors agree that professional development is an ongoing and fluid process, making it difficult to define in a straightforward manner.

To further complicate designing school and teacher change-making resources, teachers tend to use professional development activities, collaborate with their peers, and read professional literature in differing patterns over the course of their careers (Richter et al., 2011; Vermunt \& Endedijk, 2011). As for inservice or traditional professional development, teachers tend to use it less at the beginning of their careers, peak in their mid-career, and then tapering off sharply in the latter part of their years working (Huberman, 1989; Richter et al., 2011).

In contrast, teacher collaboration follows a more linear path, with peer collaboration starting at a high level in their career and steadily decreasing over the years (Richter et al., 2011). Somewhat paradoxically, teachers appear to read less professional literature at the beginning of their careers and increasingly more over the course of their years in the profession, in a linear trajectory opposite that of the collaboration line (Richter et al., 2011). Taken together, it would appear that teachers begin their career as more collaborative professionals and then as they mature in their profession, they increasingly become more individualistic relying less on their peers and more on their own information gathering. As influences from the outside put pressure on the school system (i.e., technology and the expectations of its use in school), these competing 
factors challenge leaders to develop meaningful and engaging professional development opportunities.

The research into professional development models varies greatly as to structure, timing, and content. Practices such as a collaborative apprenticeship, whereby teachers support their peers as coaches and modelers of successful strategies, show promise as teams of teachers collaborate with each other during the school day rather than as part of a disconnected event (Glazer \& Hannafin, 2006). Another study showed that taking an active role as a classroom researcher played a role in changing their practice and was a powerful way to take part in professional learning to improve teacher knowledge (Rathgen, 2006). Other studies have shown that teachers can improve their knowledge of content and pedagogy, both individually and as a group of teachers, when they collaboratively build curriculum (Voogt et al., 2011). Following up on what Clark and Hollingsworth (2002) call the Interconnected Model of Professional Growth, Voogt et al. state, "from the perspective of the team, the interaction reflects the reflection and enactment processes that foster the learning of individuals and the team (p. 1243)."

It is important to note that in the research reviewed, most mentioned the importance of professional development in the improvement of teacher practice and student achievement. Primarily, teachers believe that their students will benefit and so they "participate in staff development activities primarily because they believe such activities will help them to become better teachers" (Guskey, 1986). 


\section{School Culture and Leadership}

The research is clear about several teaching and learning factors which impact the integration and usage of technology resources by teachers with students in classrooms: 1) teacher attitudes and beliefs (Abbitt, 2011; Cope \& Ward, 2002; Ertmer, 2005; Ertmer, et al., 2012; Kim, Kim, Lee, Spector, \& DeMeester, 2013; Ottenbreit-Leftwich, Glazeweski, Newby, \& Ertmer, 2010), 2) teacher instruction and instructional models (Inan \& Lowther, 2010; Keengwe, Pearson, \& Smart, 2009; Koehler \& Mishra, 2009; Land \& Greene, 2000), 3) teacher knowledge of technology (Margerum-Leys, 2004; Mueller, Wood, Willoughby, Ross, \& Specht, 2008), and 4) the cultures and ecologies of schools, including social capital resources (Frank, Zhao, \& Borman, 2004; Zhao \& Frank, 2003).

In spite of the research mentioned above, there is a dearth of research into technology and its connection to school culture by the currently-popular school improvement authors. Technology and its use by students, teachers, or administrators is rarely if ever mentioned or discussed in depth in the literature on teaching (Danielson, 2007; Marzano, 2007), or teacher supervision (Danielson \& McGreal, 2000; Downey, Poston Jr, Steffy, English, \& Frase, 2004; Marshall, 2009; Marzano, Frontier, \& Livingston, 2011; Tucker, \& Stronge, 2005), or school leadership and culture development (Deal \& Peterson, 2009; Marzano, Waters, \& McNulty, 2005; Schmoker, 1999).

The role of the principal and of district leadership has been well documented as a key factor in the implementation of technology resources in schools (Anderson \& Dexter, 
2000; Becker, 1992; Cordeiro \& Cunningham, 2013; Davies, 2010; Lecklider, Britten, Clausen, \& Muncie, 2009). Anderson and Dexter (2005) found that at the school level, technology efforts were "seriously threatened unless key administrators become active technology leaders in school" (p.74). They also found that even though principals may lag behind teachers or others in their own ability to use technology, they "tend to recognize their need to be involved and involve others with technology use in classrooms" (p.55). Another surprising facet of their research discovered that technology leadership had in fact more impact on the outcomes they measured than classroom technology and infrastructure purchases did (2005). That is, leadership at the local level (which could include policy as well as personnel) was more important to a wellimplemented technology integration effort than was purchasing and deploying devices even to a wide group of teacher recipients.

Becker (1992) noted that a trend existed to decentralize decision-making among teachers and building-level administrators in terms of technology purchasing and usage. However, his research showed that if the goals of technology in schools were explicitly to use them to engage students in higher-order thinking learning tasks and be used for more than just basic computer skills training, then it was not a decentralized approach that work best, "but (a) substantial district-level involvement in school-level decision-making and (b) the active presence and leadership of a school-level computer coordinator" (p. 25). Since the time of Becker's research cited above, many changes have happened in terms of available technologies for schools. In most cases, the complexities of technology have fallen away as more powerful and far simpler devices have been brought to market. 
There is a need to update this research area in light of the probable increased number of teachers using technology in their daily lives as well as in their classrooms.

In some cases, the need for leadership in technology is more about removing obstacles (Ertmer, 1999) or being able to ask the right questions (Heifetz \& Laurie, 1996) than it is to be a good role model for using technology (Anderson \& Dexter, 2000). Unfortunately, without additional publications talking deeply about the role technology has as a necessary instructional tool in student engagement, as a tool for equity in information access, or as a key aspect of 21 st Century learning (United States Department of Education, 2010; Partnership for 21st Century Skills, 2013), schools may find themselves having a more difficult time explaining their financial investment in technology for education. Of course, public education is not solely about using technology in school. However, if today's educational experience does not include technology as a meaningful and integrated learning tool for students, the world and the learning outside the school walls will supersede that which happens within, and schools will be on a path of eventual irrelevancy. In schools today, we are essentially preparing students who will either live into the 22 nd Century or at a minimum, have a major impact upon it. We need to find additional motivational opportunities for schools to engage in the work of transforming themselves into relevant and vibrant institutions that serve the public good and prepare students for the world in which they live now and for the world they will find in their future. 


\section{CHAPTER 3 \\ METHODOLOGY}

\section{Study Overview}

This mixed methods study uses Morgan's (2014) model of supplementing quantitative data with qualitative data, both of which are collected simultaneously. Morgan states that this quadrant of the sequential priorities model has as its goal " to create a sense of how real people are connected to the findings from quantitative methods" (p. 173). I used stratified random sampling (Borg \& Gall, 1983; Fraenkel \& Wallen, 1996) to identify 37 districts that represent the size, location, socio-economic, and racial/ethnic background of $18.8 \%$ of schools in Oregon (NCES, 2014). I requested participation from this stratified sample of districts using NCES district classifications to determine a sample that represented districts that mirror the state percentage of students who attend schools in or near cities, suburbs, towns, and rural settings. Data was collected from three types of respondents: classroom teachers, administrators, and technology support personnel. The purpose of the study was to examine core issues surrounding the impact of leadership attitudes and practices at various levels within the organization as well as the attitudes instructional staff have about their ability and usage of technology with students during technology implementations. The data provides insight into conditions that support optimal implementation of technology initiatives and a potential theory of action for school leaders.

\section{Potential Benefits}

Schools and the people who work in them are increasingly under pressure to 
incorporate and infuse technology tools in order to produce higher achieving pupils and a more relevant educational environment (Culp, Honey, \& Mandinach, 2005; Cummins, Brown, \& Sayers, 2007; NASBE, 2012). Often, the difficulty in implementing technology initiatives lies in deciding what the most effective tools are and how to deploy them. By analyzing how teachers feel about the ways technology is presented to them, the opportunities they may be offered, and the leadership structures and practices which either enable or inhibit the delicate balance of the integration of technology for learning, we may be better understand the procedures and the planning necessary to implement such changes. The results of this study may assist schools and districts in their communication strategies and planning efforts with staff in order to ensure technology integration projects produce better achievement results and have a lasting, long-term impact.

\section{Research Methods}

This is an illustrative study from a single point in time survey in an attempt to surface key indicators that signal successful actions and attitudes in the implementation of technology for students. The study did not focus on whether or not technology helps students in their studies specifically, rather it proposed to provide insight into the factors that allow technology integration efforts to flourish.

Participants were confidential, as respondents were asked to select their district from a list of potential choices. Since the study did not ask for school names, district name was the most locally identifying factor. There was no further coding that could have allowed connecting survey responses with the respondents. The stratified sample 
(Borg \& Gall, 1983) targeted districts that mirror the population centers and areas of the state of Oregon. That is, the researcher attempted to collect data from a representative sample of districts to include the same relative percentage of schools in or near city, suburb, town, and rural settings as there are in the state (Borg \& Gall, 1983).

A mixed methods research approach was used in this study. It was primarily a quantitative data collection with supplemental qualitative data elements, and its goal is to provide education leaders insight into the attitudes and actions that have the most impact upon technology integration. Quantitative data was the bulk of the data collected and qualitative data elements were used to gain further insight into why participants responded the way they did in the quantitative section (Creswell \& Clark, 2007; Miles \& Huberman, 1994; Morgan 2014). Morgan calls this putting "a human face on the data" (p. 155), and the researcher feels mixed methods is a necessary research method design in order to more fully understand both self-efficacy issues for teachers and leadership and technology support actions and attitudes.

\section{Study Design}

A single online survey was used for this study. The survey instrument delivery tool was chosen as Portland State University provides a license for all staff and students and the data can also easily be exported to popular data analysis tools (see Appendix E for the full survey). The online survey tool also has data safeguards for security and there are tools available for general data analysis. By using an initial crosstab review of the data, I was able to develop additional correlation tests beyond those listed below which 
were processed in another data modeling software package. Some correlation tests used to study student technology implementations included:

1. demographic trends (gender, race, ethnicity, age);

2. technology usage trends (see Table 5 below);

3. teacher self-efficacy beliefs (see Table 6 below);

4. leadership actions or attitudes (see Tables 9 and 12 below);

5. beliefs and attitudes of technology support personnel (see Tables 9, and 12 below) and

6. professional development opportunities (see Table 7 below).

A single survey was developed and had three distinct sections which were visible to the participants depending upon the role the participant selected which described their normal daily work. The participant roles included: teachers, administrators, and technology support personnel. The survey included an informed consent response, three quantitative school information questions, five personal demographic responses, 24 Likert scale questions, and three supplemental qualitative open-ended response items (see Appendix E). Schools and districts across Oregon were contacted in order to recruit participants for the study.

The survey was comprised of adapted quantitative items from a TPACK survey (Schmidt et al., 2009), a technology purchase decision-making survey from Becker (1992), a teacher and their home use of technology survey (Purcell et al., 2013), and quantitative and qualitative items developed by the researcher and based on a literature review of successful technology implementation strategies. In this mixed methods 
approach to research, the simultaneously collected qualitative items were intended to provide illustrative insight into the quantitative data.

\section{Research Questions Restated}

The primary questions this research study targeted are as follows:

1. How do leadership styles and/or practices impact the implementation of technology initiatives?

2. What factors specific to teacher characteristics inhibit or encourage their application of technology in learning experiences for students?

3. What additional factors related to the beliefs, attitudes or policies of schools and school personnel influence the implementation of technology?

\section{Researcher's Role}

In my current role as a curriculum director and district technology leader for a medium-sized school district, the importance of successfully implementing technology resources as a support for improving the achievement and the opportunities of all students in schools is my daily concern. As the researcher for this study, I gathered previously used survey instrument items and merged them with additional items I developed based upon the review of literature. I designed and distributed the instrument myself, and it was through collegial relationships I have in schools and districts across the state that I was able to collect a wide range of data. 
This study is a survey research project using primarily a quantitative survey with qualitative open-ended questions informed by mixed-methods methodology to support the findings of the quantitative data. A fixed mixed methods approach using a supplemental qualitative extension to core quantitative design as described by Morgan $(1998,2014)$ was chosen to inform the study's design in order to increase the capacity of the quantitative items as well as to reduce researcher bias in the study. Because my work involves direct contact with teachers, administrators, and technology support personnel on a daily basis, I chose to use deductive quantitative research for the primary data analysis in order to foster both objectivity and enhance the study's generality. However, due to the review of literature discussed in Chapter 2, which described deeply human aspects of adult learning, as well as the perceived need to humanize the data in order to better understand attitudes and actions of teachers and leaders, I felt the need to use the strength of qualitative items to give the study better depth and detail in its context (Creswell \& Clark, 2011; Morgan, 2014). Both the quantitative and qualitative data were collected simultaneously.

\section{Participants}

This study used a stratified sampling approach, with a goal to strengthen the data collection and analysis by reaching beyond a single school or district (Lunenburg \& Irby, 2008). The districts were selected by targeting schools and districts who represent the percentage of schools located in or near city, suburb, town and rural settings (as defined by the National Center for Education Statistics) in Oregon. By using a large stratified 
sampling, the goal was to draw out more generalizable conclusions about access, equity, and the importance of the teacher and leadership factors upon the integration of technology in classrooms. Also, by using statewide stratified data rather than a smaller case study model, the goal was to reach a wide range of teacher, administrator and technology support personnel in order to better understand their attitudes, actions, and answers to the research questions proposed by this study.

\section{Participant Selection}

There are three distinct groups who participated in this study. The first participant group was comprised of pre-kindergarten through twelfth grade teachers, including general education, special education, teachers of English Language Learners and Teachers on Special Assignment (TOSAs). The second participant group included both district and building-level administrators (not including administrators associated with technology). The third group participant group was comprised of technology support personnel, including technology administrators, at both building and district levels.

Administrators, teachers, and support personnel from across Oregon were recruited to participate in the survey. In order to contact districts in Oregon, the researcher used the Oregon School Directory and the October 2014 enrollment report, both published by the Oregon Department of Education, to locate the proper email contact information for schools. Then, an email communication was sent to thirty-five superintendents requesting permission to contact teachers, administrators, and support personnel to participate in the study (see Appendix A). A follow up email to the superintendent request was made ten days from the initial request if there was no response as a reminder and as additional 
recruitment. If there were no responses from districts included in the first or second round of email invitations, other districts which fit the criteria according to their NCES uLocale grouping were contacted in order to build a proper stratified sample. Due to some delays in responses from districts, or to complications related to receiving permission to conduct the research project, the sample was not a perfectly matching stratified sample according to the original intent. In the end, there were 37 districts who participated to varying degrees. At the outset of the study, it was anticipated that there would minimally be 50 responses from the teacher participant group, 25 responses from the building and district level leadership group, and 25 responses from the technology support personnel group. Email lists were then generated either via the school's public web site listings or by lists provided by the district or schools and school personnel were contacted directly requesting their participation in the study starting in the fall of 2014 and finishing in the winter of 2015 (see Appendix A).

\section{Potential Risks and Safeguards}

There was little potential risk associated for participants in this study. To ensure there was no potential risk of supervisor retaliation, all data collected is published in an aggregate form only. Respondents were asked to select their district from a list of possible choices in the state, but any other information that could be used to identify the location of the respondent was removed (e.g. location-based data). Email messages that were sent to all three participant groups contained a generic web site address that sent them to a single survey with skip logic built in to take them to the correct questions most related to their position of teacher, administrator, or support personnel. Once the email 
was sent to the potential participants, there was no way to know whether or not they personally participated in the survey nor which answers corresponded to them. No coding occurred to tie responses to specific email addresses, IP (Internet Protocol) addresses, or location-based data.

\section{Confidentiality, Records Management \& Distribution}

All lists of email addresses are stored in an electronic document that requires a password and is backed up to an electronic service that requires a password. Survey results are confidential and the link that was sent to all participants in all groups was generic and cannot be linked in any way to their individual responses. For the purposes of data analysis, the results of the survey from the university-supplied research tool were downloaded and stored on the secure device and backed up to the secure electronic backup service. Survey results also remain inside the online survey tool, which are only accessible via the researcher's login and password. Email lists, survey results, and any other information received during the data collection phase will be available on these secured devices for a minimum of three years following my dissertation defense.

\section{Informed consent.}

Participation in this study was voluntary, and by participating, respondents did not gain benefit in their workplace. Supervisors do not know who has or has not done survey, and all data presented is in aggregate form. There were two opportunities for participants in the study to review the rules of informed consent. The first opportunity the participant had to review informed consent was in the email sent to them recruiting them for the study which included detailed information of the kinds of information which would be 
collected, how it would be stored and how it would be used (see Appendix A). The second opportunity that potential participants had to review informed consent was in the initial page of the survey before questions are asked of them (see Appendix E). In order to assure that all participants reviewed and understood informed consent, a required question at the beginning of the survey requested that the participant acknowledge that they have read and understood informed consent and the nature of the study. All responses from all participants who select that they understand and agree with the informed consent question were used. Participants who selected that they do not wish to be included will not be used in the data as the survey tool ended the survey immediately and they were not able to continue with the survey or provide responses.

\section{First person scenarios.}

\section{Teachers and teachers on special assignment.}

The following is the first-person scenario for teachers and teachers on special assignment.

I received an email this week from an education researcher that described a study about measuring the impact of leadership practices upon the successful integration of technology in the classroom. The email also described what informed consent was and how the data from the study would be used. The email also said that if I wished to participate in the study, my responses would be confidential and could not be attributed to me in any way. The researcher also stated the final dissertation project would be publicly available and that I could receive an electronic copy if I requested it after its publication. The email included a link that I clicked once I decided that I wanted to 
participate in the study and it sent me to a web page on a survey tool site. The first page I was presented with when I clicked the link restated the informed consent information that I had already received in the email about the study, and since I had already read it in the email, I understood what it meant and I selected the option that stated that I agreed to participate in the study and that I understood the informed consent, and then it took me to the first questions on the survey. The survey included a series of questions related to my work and to the work of administrators, other school leaders, and support personnel. The survey then asked me about my perceptions of my use of technology, the level to which I am comfortable using it in the classroom, and if there are any barriers to using it more effectively that I could describe. Finally, the survey ended with some questions that asked me my opinion about certain leadership practices, school culture, and my and my students' interest in technology using a scale, a short answer, and an open-ended format. After the last question, the survey tool thanked me for my participation and provided an email link to the researcher that I could use in case I wanted to contact them about the final study.

\section{School and district-level administrators.}

The following is the first-person scenario for school-level and district-level administrators.

I received an email this week from an education researcher that described a study about measuring the impact of leadership practices upon the successful integration of technology in the classroom. The email also described what informed consent was and how the data from the study would be used. The email also stated that my responses 
would be confidential and could not be attributed to me in any way. The researcher stated the final dissertation project would be publicly available and that I could receive an electronic copy if I requested it after its publication. The email included a link that I clicked once I decided that I wanted to participate in the study and it sent me to a web page on a survey tool site. The first page I was presented with when I clicked the link restated the informed consent information that I had already received in the email about the study, and since I had already read it in the email, I understood what it meant and I selected the option that stated that I agreed to participate in the study and that I understood the informed consent, and then it took me to the first questions on the survey. The survey included a series of questions related to my work and to the work of other school leaders, teachers, and support personnel. The survey then asked me about my perceptions of my use of technology, the level to which I believe teachers are comfortable using technology in the classroom, and if there are any barriers for schools or teachers to use technology more effectively that I could describe. Finally, the survey ended with some questions that asked me my opinion about certain leadership practices, school culture, and teacher and student interest in technology using a scale, a short answer, and an open-ended format. After the last question, the survey tool thanked me for my participation and provided an email link to the researcher that I could use in case I wanted to contact them about the final study.

\section{Support personnel.}

The following is the first-person scenario for technology support personnel. I received an email this week from an education researcher that described a study 
about measuring the impact of leadership practices upon the successful integration of technology in the classroom. The email also described what informed consent was and how the data from the study would be used. The email stated that my responses would be confidential and could not be attributed to me in any way. It also stated the final dissertation project would be publicly available and that I could receive an electronic copy if I requested it after its publication. The email included a link that I clicked once I decided that I wanted to participate in the study and it sent me to a web page on a survey tool site. The first page I was presented with when I clicked the link restated the informed consent information that I had already received in the email about the study, and since I had already read it in the email, I understood what it meant and I selected the option that stated that I agreed to participate in the study and that I understood the informed consent, and then it took me to the first questions on the survey. The survey included a series of questions related to my work and to the work of administrators, other school leaders, and teachers. The survey then asked me about my perceptions of my use of technology, the level to which I believe teachers comfortable using it in the classroom, and if there are any barriers for them to use it more effectively that I could describe.

Finally, the survey ended with some questions that asked me my opinion about certain leadership practices, school culture, and teacher and student interest in technology using a scale, a short answer, and an open-ended format. After the last question, the survey tool thanked me for my participation and provided an email link to the researcher that I could use in case I wanted to contact them about the final study. 


\section{Discussion of the instrument's questions}

In the section that follows, the survey instrument's questions are discussed in

order to understand the flow of the instrument for participants and the relative need of each grouping of questions and their source if not produced by the researcher. The instrument in its entirety is located in Appendix E.

The study was primarily a quantitative data collection with supplemental qualitative data elements and was informed by mixed-methods methodologies, with its goal being to provide education leaders insight into the attitudes and actions that have the most impact upon technology integration. Quantitative data was the bulk of the data collected, however because the answers can be highly subjective based upon how the respondents feel, qualitative data elements were used to gain further insight into why participants responded the way they did in the quantitative section.

The quantitative data was collected via the instrument, which was cleaned, and in some cases recoded, in order to be used in the statistical modeling software package. The $\mathrm{R}$ project for statistical computing, a freely available, open source package was selected to run the models and produce the results. Multiple statistical tests were run using the data (including MANOVA, ordinary least squares, Levene's test, Box test, quantile regression, and Tukey’s Honestly Significant Difference).

The three qualitative items of the survey were meant to, as Morgan (2014) states, "put a human face on the data" (p. 155), and to provide further insight into the quantitative items which preceded them. The qualitative items were put through a multistep process in order to organize it in such a way as to be understandable and usable. 
First, all responses on each of the three questions from 641 participants were read through once in order to gain a sense of themes that may emerge. Next, a pattern code process was used in order to reduce the large amount of open-ended textual data into smaller clustered groups to be analyzed (Miles \& Huberman, 1994) by then coding into categories that were built during the second reading in order to place every written response into a matching category. Finally, for each of the three qualitative questions, a third reading was done, checking the marked categories for appropriateness and consolidating rarely-used categories into slightly broader ones. In the end, each research question had 24-26 categories in which participant responses were grouped. By then noting the recurrence of certain major themes within the larger cluster of data elements, the goal was to determine patterns that could be used as illustration to the quantitative data analysis. This convergent parallel design, with both quantitative and qualitative data being collected simultaneously, is a "data-validation variant" (Creswell \& Clark, 2011). The open-ended data was used to determine emergent themes, validate or confirm the analysis of the quantitative data, and to add details for more complete findings from the statistical analysis of closed-ended data.

Table 1

Keywords and framework items

\begin{tabular}{ll}
\hline Keyword & Framework Item \\
\hline Equity & Reducing opportunity or production gaps between upper \\
& income and lower income students in schools is a \\
& worthwhile goal and schools should be providing those \\
& rich, technology-supported educational experiences for all \\
& students. \\
Factors & Integrating technology in classrooms, schools, and districts
\end{tabular}


Teachers

TPACK

Pro Dev

CHAT

Barriers is a difficult endeavor and there are many factors which affect its effective implementation.

Teachers are the primary source of educational opportunities for students in schools and will be the persons responsible for the majority of the pedagogical changes that occur in order to adjust for classroom technology integration.

Teachers arrive at a new learning task, such as attempting to integrate technology into their daily work with students, with perceptions of their own personal level of technological, pedagogical, and content (TPACK) knowledge.

Teachers (and administrators) will need additional and ongoing professional development in order to integrate technology resources in a powerful way in their classrooms.

Pro Dev Professional development opportunities have different meaning to teachers at different times in their careers, and that perception of the abilities to use technology (of themselves and by others) have an impact on their success. Cultural-Historical Activity Theory (CHAT) can help the research describe learning actions in the classroom context, including the role of the "community" and "rules" concepts by studying leadership and support personnel actions and perceptions.

Additional data about events and processes that teachers, leaders, and support personnel perceive as barriers to classroom technology integration which may inhibit increased access to students in order to provide equity in their school opportunities.

This study was structured to examine the impact of teacher self-efficacy,

professional development, theories of activity and learning, and actions and perceptions

of leadership factors in a connected way that allows for significant discussion on the impact of each one, both individually and as a whole. The theoretical framework was built from these factors and is presented in Table 1. Additionally, a framework 
"keyword" is listed on the left side of Table 1, which will be used to describe the groups of questions found in Table 3 through Table 12 that are matched with it.

In each of the tables from 3 through 12, groups of questions were presented which come directly from the survey instrument. In order to understand how each group of questions matches up with a part of the theoretical framework, a "meta" table of the groups of questions and their framework "keywords" is found in Table 2.

Table 2

List of tables with matching theoretical framework items

\begin{tabular}{lll}
\hline Table & Name & Keyword \\
\hline Table 3 & Participant demographic information & Factors \\
Table 4 & Technology ratios, usage, and frequency & Factors, Equity \\
Table 5 & Technological Pedagogical Content Knowledge items & TPACK \\
Table 6 & $\begin{array}{l}\text { Influence of interpersonal pressures to incorporate } \\
\text { technology }\end{array}$ & Teachers \\
Table 7 & Professional development & Pro Dev \\
Table 8 & $\begin{array}{l}\text { Influences of leadership, peer support and teacher } \\
\text { inclusion }\end{array}$ & CHAT \\
Table 9 & Professional and adult learning factors & CHAT \\
Table 10 & Additional influential teacher attitude factors & Teachers \\
Table 11 & $\begin{array}{l}\text { Systemic and support barriers to incorporate } \\
\text { technology }\end{array}$ & Barriers \\
Table 12 & Policy and practice barriers to incorporate technology & Barriers, Equity \\
\hline
\end{tabular}

For the participant demographics, listed in Table 3, school staff were asked about their teaching expertise level (if they are or have been a teacher and for how long) and their age (grouped by the categories used in the 2000 US Census) in order to relate to the 
review of literature into professional development. Other demographic information, such as race and ethnicity, were also collected.

Table 3

Participant demographic information

\begin{tabular}{ll}
\hline Demographic & Item choices \\
\hline Participant race & American Indian or Alaska native; Asian; Black or \\
& African American; Native Hawaiian or Other Pacific \\
& Islander; White \\
& Hispanic or Latino: A person of Cuban, Mexican, Puerto \\
Rarticipant ethnicity & Latino culture or origin, regardless of race (including \\
& Brazil); Not Hispanic or Latino \\
& Male; Female \\
Participant gender & $20-24 ; 25-34 ; 35-44 ; 45-54 ; 55-64 ;$ over 65 \\
Participant age & $1-3 ; 4-6 ; 7-18 ; 19-30 ;$ More than 30 years; Never \\
Number of years as a & \\
classroom teacher &
\end{tabular}

The survey then asked a role-based question, upon the answer of which the instrument selected which next group of questions the participant answered.

After determining their role (teacher, administrator, technology support), the instrument took them through a group of questions, broken into groups by participant role, which were all similar to the questions asked of the participants who selected a different role. They were broken into the following three groups: teacher, administrator (not related to technology), and technology support (including administrators and other staff attributed to technology). The purpose was to gather similar data about attitudes and actions of both teachers and leaders but from three unique perspectives. 
The following survey items, listed in Table 4, were used to gather data about the student-to-device ratio, the frequency of technology use, and some general types of technology usage activities in order to gain a more complete picture of the classrooms and schools who are represented by those who participated in the survey. The questions are listed in the left column of the Table 4 below, with the possible selections for participants on the right. In addition to the quantitative items in this section of the instrument, Table 4 includes a qualitative item that was used to gather data that may have been outside the quantitative items' scope, or that might have been better explained by a participant in their own words.

Table 4

Technology ratios, usage, and frequency

\begin{tabular}{ll}
\hline Instrument item topic & Response options \\
\hline Ratio of technology devices to & 1 student per 1 device; 2 students per 1
\end{tabular}

students

Technology devices general classroom usage

Frequency technology is used by students in school or district

Description of the major advantages device; more than 2 students per 1 device

Reward for completing other work; Understanding their academic work; Supplementary or enrichment tool; Teaching about computers and other technology tools and how to use them; Remediation of academic deficiencies; Challenging the brightest students; State or local assessments; Motivating interest in school, schoolwork, or class projects; Significantly changing the nature of learning projects and the way students interact with information, contexts, and real-world projects

Every day / every day the class meets; nearly every day / nearly every day the class meets; throughout the school year, but not every day; intensively, but only for certain units; once or twice per week; less than once per week

[Qualitative item, open-ended essay or 
and/or disadvantages the participant sees in the use of technology with

paragraph response] students

Following these instrument items were questions related to their opinion about their own technological pedagogical content knowledge (TPACK) if they are a teacher, or their opinion about the TPACK levels of teachers in their schools or district if they are an administrator or a technology support staff member. The rationale for choosing to use similar questions was to explore how teachers see themselves and how others see them as users or implementers of technology in student learning activities. These items, detailed in Table 5, were rated by the participant on a 5-point Likert scale selecting from "strongly agree," "agree," "neither agree or disagree," "disagree," and "strongly disagree." In the table below, the left hand column, "item domain," indicates under which TPACK domain the item fell. The middle column, "teacher item," contains the instrument item for teachers, and the last column, "administrator or support personnel" shows the similar item with the differentiated language.

Table 5

Technological Pedagogical Content Knowledge items by participant role

\begin{tabular}{lll}
\hline TPACK domain & Teacher item & $\begin{array}{l}\text { Administrator or technology } \\
\text { support personnel item }\end{array}$ \\
\hline $\begin{array}{l}\text { Technological } \\
\text { Knowledge }\end{array}$ & $\begin{array}{l}\text { I know how to solve my own } \\
\text { technical problems. }\end{array}$ & $\begin{array}{l}\text { The majority of the teachers in } \\
\text { my school or district know how } \\
\text { to solve their own technical } \\
\text { problems. }\end{array}$ \\
$\begin{array}{ll}\text { Technological } \\
\text { Knowledge }\end{array}$ & $\begin{array}{l}\text { I can learn technology } \\
\text { easily. }\end{array}$ & $\begin{array}{l}\text { my school or district can learn } \\
\text { technology easily. }\end{array}$
\end{tabular}


Technological

Knowledge

Technological

Knowledge

Technological-

Content

Knowledge

Technological-

Pedagogical

Knowledge

Technological-

Pedagogical

Knowledge

Technological-

Pedagogical

Content

Knowledge

Technological-

Pedagogical

Content

Knowledge

Technological-

Pedagogical

Content

Knowledge
I have the technical skills I need to use technology.

I have had sufficient opportunities to work with different technologies.

I know about technologies that I can use for understanding and working in the primary subject area(s) or grade level(s) I teach.

I can choose technologies that enhance the teaching approaches for a lesson.

I can choose technologies that enhance students' learning for a lesson.

I can choose technologies that enhance the content for a lesson.

I can select technologies to use in my classroom that enhance what I teach, how I teach, and what students learn.

I can teach lessons that appropriately combine my subject area(s) or grade level(s), technologies, and teaching approaches.
The majority of the teachers in my school or district have the technical skills I need to use technology.

The majority of the teachers in my school or district have had sufficient opportunities to work with different technologies.

The majority of the teachers in my school or district know about technologies that they can use for understanding and working in the primary subject area(s) or grade level(s) they teach.

The majority of the teachers in my school or district can choose technologies that enhance the teaching approaches for a lesson.

The majority of the teachers in my school or district can choose technologies that enhance students' learning for a lesson.

The majority of the teachers in my school or district can choose technologies that enhance the content for a lesson.

The majority of the teachers in my school or district can select technologies to use in their classroom that enhance what they teach, how they teach, and what students learn.

The majority of the teachers in my school or district can teach lessons that appropriately combine their subject area(s) or grade level(s), technologies, and teaching approaches.

Note. These survey instrument items adapted from Schmidt, Baran, Thompson, Mishra, Koehler \& Shin (2009). 
Following those items on the instrument were questions designed to discover perceptions of leadership, support, professional development, and rationales that each of the three groups report are driving factors for teachers to use technology in the classroom. In the left column in Table 6 are the items formatted for teacher responses, and on the right side are the items formatted for administrators or support personnel. These items were rated by the participant on a 5-point Likert scale selecting from "strongly agree," “agree," "neither agree or disagree," “disagree," and "strongly disagree."

Table 6

Influence of interpersonal pressures to incorporate technology

Teacher item Administrator or technology support personnel item

I use technology in my instruction because it's my own choice to do so. The majority of teachers in my school or district use technology in their instruction because it's their own choice to do so.

I use technology in my instruction because it's expected by school or district leaders.

The majority of teachers in my school or district use technology in my instruction because it's expected by school or district leaders.

I use technology in my instruction The majority of teachers in my school or because some/many of my peers do so.

I use technology in my instruction because students request it. district use technology in their instruction because some/many of their peers do so. The majority of teachers in my school or district use technology in their instruction because students request it.

I use technology in my instruction because families or parents expect it. The majority of teachers in my school or district use technology in their instruction because families or parents expect it.

Note. These survey instrument items adapted from Becker (1992).

The next group of items in the instrument were meant to gather data about professional development opportunities, and included four quantitative items and one 
qualitative item. In the left column of Table 7 are the quantitative items formatted for teacher responses, and on the right side, the items formatted for administrators or support personnel. The quantitative items in this section were rated by the participant on a 5-point Likert scale selecting from "strongly agree," "agree," "neither agree or disagree," “disagree," and "strongly disagree." The qualitative question follows and is an openended essay or paragraph form response.

Table 7

Professional development

\begin{tabular}{|c|c|}
\hline Teacher item & $\begin{array}{l}\text { Administrator or technology support } \\
\text { personnel item }\end{array}$ \\
\hline $\begin{array}{l}\text { The school leadership or district } \\
\text { leadership provides adequate training } \\
\text { or professional development for using } \\
\text { technology in instruction. }\end{array}$ & $\begin{array}{l}\text { The school leadership or district leadership } \\
\text { provides adequate training or professional } \\
\text { development for using technology in } \\
\text { instruction. }^{\text {a }}\end{array}$ \\
\hline $\begin{array}{l}\text { The school leadership or district } \\
\text { leadership provides training or } \\
\text { professional development which } \\
\text { directly influences my use of } \\
\text { technology in instruction. }\end{array}$ & $\begin{array}{l}\text { The school leadership or district leadership } \\
\text { provides training or professional } \\
\text { development which directly influences the } \\
\text { use of technology in instruction. }{ }^{\text {a }}\end{array}$ \\
\hline $\begin{array}{l}\text { The professional development } \\
\text { activities for teachers to learn to use } \\
\text { technology in the classroom with } \\
\text { students are relevant and useful. }\end{array}$ & $\begin{array}{l}\text { The professional development activities for } \\
\text { teachers to learn to use technology in the } \\
\text { classroom with students are relevant and } \\
\text { useful. b }\end{array}$ \\
\hline $\begin{array}{l}\text { There should be more professional } \\
\text { development opportunities for teachers } \\
\text { to learn to use technology in the } \\
\text { classroom with students. }\end{array}$ & $\begin{array}{l}\text { There should be more professional } \\
\text { development opportunities for teachers to } \\
\text { learn to use technology in the classroom } \\
\text { with students. }\end{array}$ \\
\hline $\begin{array}{l}\text { [Qualitative open-ended essay or } \\
\text { paragraph response] Think about } \\
\text { positive experiences you had in a staff } \\
\text { development session. Think about why } \\
\text { these sessions were so memorable to } \\
\text { you. What made those staff } \\
\text { development sessions successful? Or, } \\
\text { what were the best things about those }\end{array}$ & $\begin{array}{l}\text { [Qualitative open-ended essay or paragraph } \\
\text { response] Think about positive experiences } \\
\text { you had in a staff development session. } \\
\text { Think about why these sessions were so } \\
\text { memorable to you. What made those staff } \\
\text { development sessions successful? Or, what } \\
\text { were the best things about those staff } \\
\text { development sessions? }\end{array}$ \\
\hline
\end{tabular}
staff development sessions? 
Note. ${ }^{\text {a }}$ These survey instrument items adapted from Becker (1992).

${ }^{\mathrm{b}}$ These survey instrument items adapted from Purcell, Heaps, Buchanan \& Friedrich (2013).

The items that followed the professional development questions in Table 8 are linked to cultural-historical activity theory (CHAT) and were meant to shed light upon the influences of the concepts of "community" "rules" and "division of labor" within the CHAT model. In the left column are the items formatted for teacher responses, and on the right side, are the items formatted for administrators or support personnel. These items were rated by the participant on a 5-point Likert scale selecting from "strongly agree," “agree," "neither agree or disagree," “disagree," and "strongly disagree."

Table 8

Influences of leadership, peer support and teacher inclusion

Teacher item Administrator or technology support personnel item

I feel that I am able to influence Teachers are able to influence technology technology purchasing decisions in my purchasing decisions in our school/district. school/district.

My school/district has an effective Our school or district has a effective method for me to apply for funding a technology project in my classroom. method for teachers to apply for funding a I feel that my school leadership supports my use of technology with students

I feel that my teaching peers support my use of technology with students. technology project in their classroom. I feel that my leadership supports our teachers' use of technology with students

I can get adequate technology support for issues that arise for me or for my students.

I feel that teachers' peers support their use of technology with students.

I feel that teachers can get adequate technology support for issues that arise for themselves or for their students.

Note. These survey instrument items adapted from Becker (1992). 
The next group of instrument items were used to measure the concepts of the "subject" and their interaction with the "tools" within the CHAT model. In Table 9, the left column are the items formatted for teacher responses, and on the right side are the items formatted for administrators or support personnel. These items were rated by the participant on a 5-point Likert scale selecting from "strongly agree," "agree," "neither agree or disagree," “disagree," and "strongly disagree."

Table 9

Professional and adult learning factors

\begin{tabular}{|c|c|}
\hline Teacher item & $\begin{array}{l}\text { Administrator or technology support } \\
\text { personnel item }\end{array}$ \\
\hline $\begin{array}{l}\text { I learn by doing and/or by using } \\
\text { technology tools in an active way on } \\
\text { my own. }\end{array}$ & $\begin{array}{l}\text { The majority of teachers in my school or } \\
\text { district by doing and/or by using technology } \\
\text { tools in an active way on their own. }\end{array}$ \\
\hline $\begin{array}{l}\text { I learn by researching or learning } \\
\text { about using technology tools before I } \\
\text { start doing it or using it in my } \\
\text { classroom/school. }\end{array}$ & $\begin{array}{l}\text { The majority of teachers in my school or } \\
\text { district learn by researching or learning } \\
\text { about using technology tools before they } \\
\text { start doing it or using it in their } \\
\text { classroom/school. }\end{array}$ \\
\hline $\begin{array}{l}\text { I look for models of effective or } \\
\text { appropriate use BEFORE I start } \\
\text { using technology tools with my } \\
\text { students. }\end{array}$ & $\begin{array}{l}\text { The majority of teachers in my school or } \\
\text { district look for models of effective or } \\
\text { appropriate use BEFORE they start using } \\
\text { technology tools with their students. }\end{array}$ \\
\hline $\begin{array}{l}\text { I prefer to use technology tools in a } \\
\text { similar way as my peers or leaders } \\
\text { do. }\end{array}$ & $\begin{array}{l}\text { The majority of teachers in my school or } \\
\text { district prefer to use technology tools in a } \\
\text { similar way as their peers or leaders do. }\end{array}$ \\
\hline $\begin{array}{l}\text { I need to know how to fully use a } \\
\text { technology tool (device or } \\
\text { application) BEFORE my students } \\
\text { begin using it. }\end{array}$ & $\begin{array}{l}\text { The majority of teachers in my school or } \\
\text { district need to know how to fully use a } \\
\text { technology tool (device or application) } \\
\text { BEFORE their students begin using it. }\end{array}$ \\
\hline $\begin{array}{l}\text { I prefer to try out different techniques } \\
\text { of using technology tools with } \\
\text { students regardless of how my peers } \\
\text { or leaders do so. }\end{array}$ & $\begin{array}{l}\text { The majority of teachers in my school or } \\
\text { district prefer to try out different techniques } \\
\text { of using technology tools with students } \\
\text { regardless of how their peers or leaders do } \\
\text { so. }\end{array}$ \\
\hline
\end{tabular}


From items listed in both Table 9 above and Table 10 below, some of the variables the data produced have been identified in previous research specific to teachers who incorporate technologies at a higher rate than other teachers (Mueller, Wood, Willoughby, Ross \& Specht, 2008). As above, these questions are listed with teacherformatted items on the left, and administrator and support personnel on the right side. By asking all three respondent groups, these items were intended as a way to explore differences in the way teachers view themselves and their actions and the ways that others view them. These items were rated by the participant on a 5-point Likert scale selecting from "strongly agree," "agree," "neither agree or disagree," "disagree," and “strongly disagree."

Table 10

Additional influential teacher attitude factors

\begin{tabular}{ll}
\hline Teacher item & $\begin{array}{l}\text { Administrator or technology support } \\
\text { personnel item }\end{array}$ \\
\hline $\begin{array}{l}\text { I only use technology tools with my } \\
\text { students when I know their learning } \\
\text { product will be significantly enhanced. }\end{array}$ & $\begin{array}{l}\text { The majority of teachers in my school or } \\
\text { district only use technology tools with their } \\
\text { students when they know their learning } \\
\text { product will be significantly enhanced. } \\
\text { Knowing the outcomes and/or the student } \\
\text { knowing the outcomes and/or the }\end{array}$ \\
$\begin{array}{l}\text { student products or goals for using } \\
\text { technology is important to me }\end{array}$ & $\begin{array}{l}\text { important to the majority of teachers in my } \\
\text { school or district BEFORE they start doing } \\
\text { BEFORE I start doing so. }\end{array}$ \\
$\begin{array}{l}\text { so. } \\
\text { The majority of teachers in my school or } \\
\text { do with technology in the classroom }\end{array}$ & $\begin{array}{l}\text { district like to show others what their } \\
\text { students do with technology in the } \\
\text { classroom }\end{array}$ \\
\hline
\end{tabular}


The next group of quantitative items in the survey instrument focused on perceived barriers for teachers to incorporate digital technologies into their instruction and the learning tasks of their students. These items, shown in Table 11, were presented to all three groups of participants and again focused on the possible differences noted by each of the three groups from the other groups. All respondents were asked to comment on how teachers (or themselves, if they were teachers) rate certain systemic and support barriers (selected by the researcher) to incorporate technology tools into the classroom and with students selecting whether each of the barriers listed presents a "major challenge," "minor challenge," or "not a challenge."

Table 11

Systemic and support barriers to incorporate technology

\begin{tabular}{ll}
\hline & $\begin{array}{l}\text { Time constraints } \\
\text { Pressure to "teach to the test" }\end{array}$ \\
Systemic Barriers & $\begin{array}{l}\text { Common Core State Standards requirements } \\
\text { Lack of access to technology resources for your students } \\
\text { Your own lack of knowledge about or comfort with technology }\end{array}$ \\
\hline Support Barriers & $\begin{array}{l}\text { Lack of technology support for issues that arise } \\
\text { Lack of support (or a general resistance) by school or district } \\
\text { leadership }\end{array}$
\end{tabular}

Note. These survey instrument items adapted from Purcell, Heaps, Buchanan \& Friedrich (2013).

The group of quantitative items following the items listed in Table 11 also focused on perceived barriers for teachers to incorporate digital technologies into their instruction and the learning tasks of their students. These items were presented to all 
three groups of participants and again focused on the possible differences noted by each of the three groups from the other groups. All respondents were asked to comment on how teachers (or themselves, if they were teachers) felt certain policies and practices are barriers to incorporating technology tools into the classroom by selecting whether each of the items listed has a "major impact," "minor impact," or "no impact," (with an option to select if the school or district does not have that particular policy or practice).

Additionally, Table 12 includes the final item in the survey instrument focused on the perception of the school's or district's efforts to support teachers trying to effectively to incorporate digital technologies into their instruction and the learning tasks of their students. This item was presented to all three groups of participants and again focused on the possible differences noted by each of the three groups from the other groups. All respondents were also asked to rate the district's or school's efforts to support teachers integrating technology by selecting from "great job," "good job," "neither good nor bad," "mediocre," or "poor job." Table 12, which includes items related to policy and practice barriers to incorporating technology in the learning environment is organized by items which used the 3-point Likert scale, an item which used the 5-point Likert scale, and the final qualitative item which relates to perceived barriers.

Table 12

Policy and practice barriers to incorporate technology

\begin{tabular}{ll}
\hline Likert scale & Instrument items \\
\hline 3-point Likert scale, "major impact, & Filters blocking access to certain websites \\
minor impact, no impact, school/district & or online content \\
does not have this in place" $a$ & Rules governing students using personal
\end{tabular}


technology devices on school grounds

Lack of access to technology resources for your students

Acceptable Use Policy governing how and for what purpose students shall be granted access to the school's network resources (i.e. Internet, email, etc)

5-point Likert scale, "great job, good job, neither good nor bad, mediocre, poor job" $a$

Qualitative item, open-ended response District/school provides proper resources and supports

What are the major obstacles to more effective use of technology with students?

Note. ${ }^{a}$ These survey instrument items adapted from Purcell, Heaps, Buchanan \& Friedrich (2013).

By using a combination of survey items which centered on teacher self-efficacy, views of leadership and professional development, and perceived barriers to technology use in the same data collection activity, the researcher planned to discover both correlations and trends which could be illustrative into how each of those impacts successful and meaningful implementations of technology for students. 


\section{CHAPTER 4 \\ DATA ANALYSIS \\ Background}

The purpose of this study was to explore the effects of leadership practice upon the successful integration of technology in the learning environment. A second purpose of this study was to understand the interplay of theories of learning, frameworks for understanding how teachers feel about their own abilities and comfort with technology, and the practices and attitudes of leadership upon teacher attitudes toward technology.

This study examined core issues surrounding the changing nature of learning and acquiring knowledge and structures, the impact of leadership at various levels within the organization, and how well implemented, highly available technologies may improve student opportunity. The researcher will use the findings of the study to propose a theory of action in order to address some of the key findings of the research. The instrument for collecting data for this study was primarily a quantitative survey of 29 items with three additional simultaneously collected supporting qualitative items (Morgan, 1998) to answer the following questions:

4. How do leadership styles and/or practices impact the implementation of technology initiatives?

5. What factors specific to teacher characteristics inhibit or encourage their application of technology in learning experiences for students?

6. What additional factors related to the beliefs, attitudes or policies of schools and school personnel influence the implementation of technology? 
In the pages that follow, I will describe the participants in the study, their responses to the survey instrument, correlations in the data, and how the responses relate to the questions detailed above.

\section{Participants}

\section{Participant Selection}

Participants for the study were selected by using a stratified random sampling technique, which allowed the researcher to more closely mirror the approximate number and proportions of teachers, administrators, and technology support personnel in the varied geographical areas in Oregon.

In order to contact districts in Oregon, the researcher used a report, which was provided to school district personnel by the Office of the Deputy Superintendent (Oregon Department of Education, 2014) with achievement and demographic information. This report was sent in the fall of 2014 and included district demographic, achievement, and contact information for the 2013-2014 school year.

According to the data files provided publicly by the National Center for Education Statistics (NCES), districts in each state have been coded to identify their locations based upon their proximity along an urban continuum that ranges from "large city" to "rural" (NCES, 2014). New codes were developed after the 2000 Census to be more accurate in their definitions of location. Data from the newest available report from NCES (2014) was for the 2005-06 school year and included each district's "uLocale" code (uLocale is 
defined as "urban-centric"). This file was merged with the ODE's achievement and demographic data to create a master list of all school districts in Oregon, which included each district's NCES “uLocale” code (their relationship to city, suburb, town, rural locations). This list was used to determine the overall number of districts in each category. Then, using randomized numbering (with rounding) in a spreadsheet, districts were selected from each set of the uLocale-defined groups. The groups selected through this random process were placed on an ordinal list used by the researcher to contact the districts in the order of their random selection. Table 13 represents the percentages of districts grouped by their urban proximity in the population of K-12 public school districts of Oregon and the stratified sample of districts who participated.

Table 13

Comparison of Oregon school districts and study sample

\begin{tabular}{cccccc}
\hline & \multicolumn{2}{c}{ Oregon $(N=197)$} & & \multicolumn{2}{c}{ Sample $(n=37)$} \\
\cline { 2 - 3 } \cline { 5 - 5 } $\begin{array}{c}\text { Urban } \\
\text { Proximity }\end{array}$ & Districts & $\%$ & & Districts & $\%$ \\
\hline City & 11 & $5.6 \%$ & & 4 & $10.8 \%$ \\
Suburb & 19 & $9.6 \%$ & & 6 & $16.2 \%$ \\
Town & 55 & $27.9 \%$ & & 9 & $24.3 \%$ \\
Rural & 112 & $56.9 \%$ & & 18 & $48.7 \%$ \\
\hline
\end{tabular}


The sample included $10.8 \%$ districts located in or near cities, compared to Oregon's 5.6\%. For districts located in suburbs, Oregon lists 9.6\% while the sample included responses from $24.3 \%$. The "town" classification saw the closest representation with $27.9 \%$ in the state and $24.3 \%$ in the stratified sample. Finally, the most challenging districts from which to collect participants, rural, came in at $48.7 \%$ of the sample while Oregon classifies more than half of its districts as rural with $56.9 \%$ total. A full breakdown of both the districts in Oregon and in the sample, including their NCES urban proximity codes, and their percentages is available in Table B1 in Appendix B.

Email communication was the primary mode of contacting district superintendents for permission to contact their school and district staff for participation in the study. Emails were sent to the first thirty-five superintendents who were on the data collection list in order and according to the participation goals originally proposed by the study. It was anticipated at the outset of the study that there would minimally be 50 responses from the teacher participant group, 25 responses from the building and district level leadership group, and 25 responses from the technology support personnel group. A follow up email to the superintendent request was made five to seven days from the initial request if there was no response as a reminder and as an additional recruitment method. If permission by the superintendent (or his/her designee) was granted, email lists were generated either via the school's public web site listings or by lists provided by the district or schools, and school personnel were contacted directly requesting their participation in the study starting in the fall of 2014 and finishing in the winter of 2015. 


\section{Response Rate}

As a way to represent the breadth of the study, the student population served by the number of districts represented was used. Although imperfect in terms of actual numbers of staff ratios (i.e. exact numbers of staff per district per role was unavailable at the time of the study), these numbers paint a fair picture of the statewide coverage of staff responses. In all, 7,383 email invitations were sent to staff in 142 districts in Oregon, with 744 participants in 37 districts starting the survey and 641 completing it $(86.2 \%$ completion rate). Participants included 537 teachers, 78 administrators, and 26 technology support personnel. Overall, of the 197 districts in Oregon, 37 districts $(18.8 \%)$ participated in the study, representing $28.1 \%$ of the students in the state served by those districts (approximately 156,200).

Some challenges were presented during the process of contacting the superintendents in the lists of districts who were selected via the random sampling. It was most difficult to get responses from superintendents who serve rural districts not located close to a metro area. Further, delays in responses from or research request procedures in several districts caused an oversampling in some of the NCES uLocale categories, particularly in the metro area among suburban school districts, as seen in Table B1 previously.

The participants were asked to mark their ethnicity, race, age, and years of experience as a teacher (if any). Table B2 in Appendix B shows the complete demographic breakdown by role served in the district (administrator, teacher, technology staff). The sample was compared to a database report from the Oregon Department of 
Education with data current for the 2006 calendar year (Oregon Department of Education, 2015). For Oregon, $67.8 \%$ of educators were reported as female and in the sample, $70.9 \%$ were female. According to a report provided by the Oregon Education Investment Board (2014), the non-Hispanic ethnicity rate for teachers in 2013-14 was $96.4 \%$ and white teachers was $91.7 \%$ of the teacher workforce. The study's sample included $97.9 \%$ White and $96.2 \%$ non-Hispanic participants. The sample had similarities in age breakdown among teachers and administrators, but more than a third of the technology support staff selected 55 to 64 as their age category (see Table B2 in Appendix B). Nearly half of the teacher and administrator group reported having between 7 and 18 years of classroom experience, while unsurprisingly, $58 \%$ of technology staff report not having any teaching experience. One of the limitations of the study was the ability to break down the technology staff group into administrators, who may have had classroom experience, and more traditional technology staff, who are less likely to have had any formal teaching experience.

Additionally, since many of the results and regression tests relied on looking for relationships between the ratio of devices and/or the poverty level of students, it is important to understand the breakdown of technology availability and the number of students who are economically disadvantaged in the schools in which the participants work. In the results section of this study below, the variable Free/Reduced Lunch Students reflects what the participants believe the percentage of students to be in their building (or district). Since there was no way to know from which building a participant was, the researcher decided to ask participants to give their best answer along a scale of 
percentages. The same is true for Non-White Students, so those numbers are also estimates given by each participant in the study. While it would be possible to match a participant's district with the proper district-wide free and reduced percentage and the percentage of non-White students, there would not be a way to account for different schools and their differing demographics within each district. For that reason, these two variables are a participant perception variable, not necessarily a factual variable based upon available data.

In Table 14 below, the count of participants is matched with their estimate of the percentage of economically disadvantaged students.

Table 14

Percentage of economically disadvantaged students as reported by study participants

\begin{tabular}{cc}
$\begin{array}{c}\text { Number of } \\
\text { participants }\end{array}$ & $\begin{array}{r}\text { \% of students in Federal Free \& } \\
\text { Reduced Lunch Program }\end{array}$ \\
\hline 62 & Fewer than $10 \%$ \\
76 & Fewer than $20 \%$ \\
98 & Fewer than $40 \%$ \\
69 & Fewer than $50 \%$ \\
\hline 142 & More than $50 \%$ \\
107 & More than $70 \%$ \\
57 & More than $80 \%$ \\
30 & More than $90 \%$ \\
\hline
\end{tabular}

In Figure 5 below, the participant-provided percentage of students who take part in the Federal free and reduced lunch program are along the x-axis, and the ratio of devices to 
students is on the y-axis. For each bar representing a percentage level of students living in poverty, the relative percentages of technology ratios in the school or district (devices per student) serving that student can be determined by the patterns within the bar. It is important to note that in the study's sample, students who are from a lower socioeconomic are not being denied the opportunity to attend a school with high availability of student technology, nor are the majority of children who attend schools with a higher overall socio-economic level always receiving the benefit of using district-provided technology devices. 


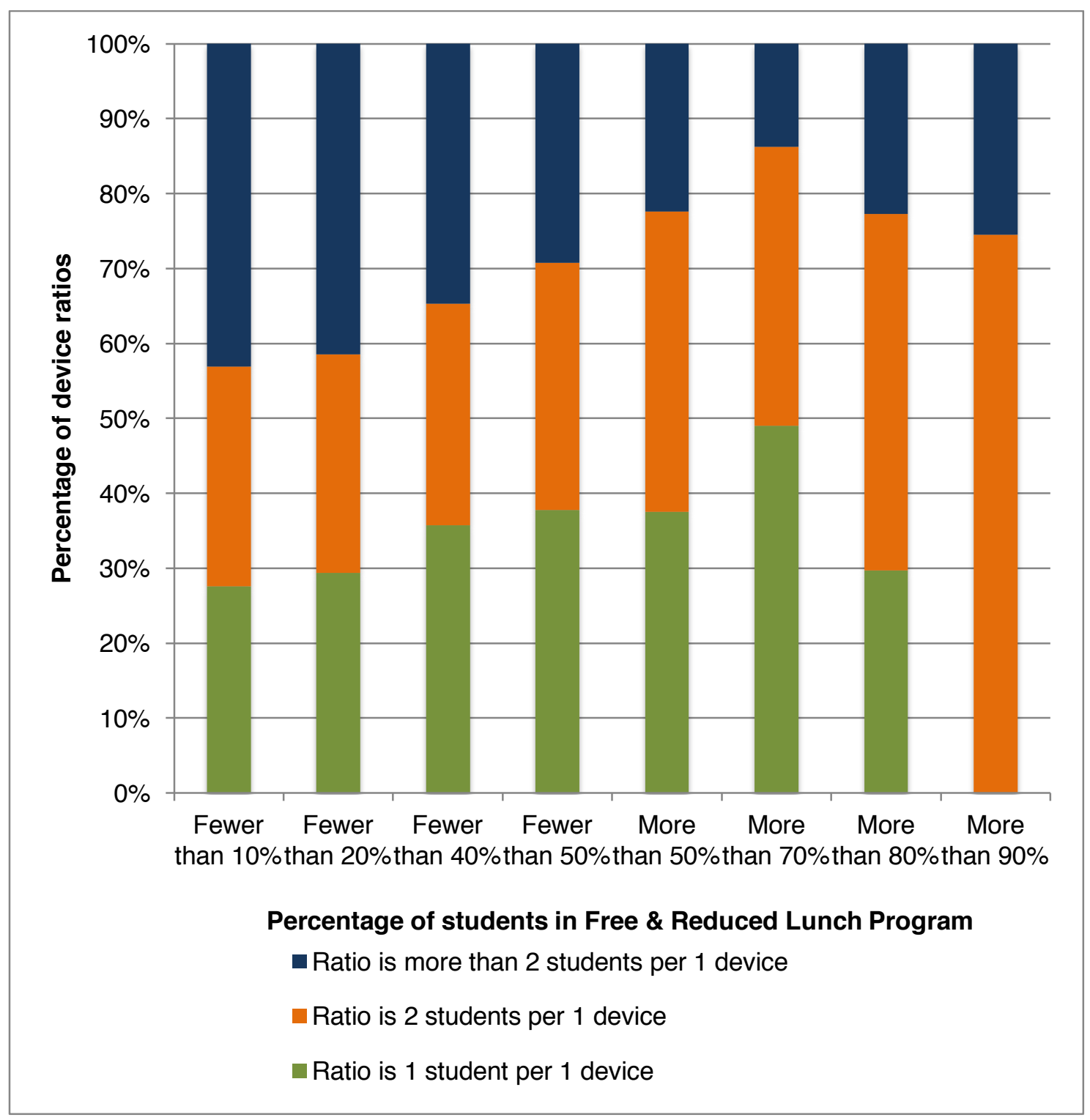

Figure 5. Ratios of technology devices to students based upon attendance in schools with listed percentages of students who participate in the Federal Free and Reduced Lunch Program as reported by study participants.

\section{Results}

The survey instrument was based upon a literature review of successful technology implementation strategies and was comprised of adapted quantitative items from a 
TPACK survey (Schmidt et al., 2009), a technology purchase decision-making survey from Becker (1992), a teacher and their home use of technology survey (Purcell et al., 2013), and quantitative and qualitative items developed by the researcher. In this primarily qualitative study informed by a mixed-methods approach to research, the simultaneously collected qualitative items were intended to provide illustrative insight into the quantitative data.

The qualitative items were put through a multistep process in order to organize it in such a way as to be understandable and usable. First, all responses on each of the three questions from 641 participants were read through once in order to gain a sense of themes that may emerge. The responses were then coded into categories that were built during the second reading in order to place every written response into a matching category. Finally, for each of the three qualitative questions, a third reading was done, checking the marked categories for appropriateness and consolidating rarely-used categories into slightly broader ones. In the end, each research question had 24-26 categories in which participant responses were grouped.

The quantitative data was collected via the instrument, which was cleaned, and in some cases recoded, in order to be used in the statistical modeling software package. The $\mathrm{R}$ project for statistical computing, a freely available, open source package was selected to run the models and produce the results. Multiple statistical tests were run using the data (including MANOVA, ordinary least squares, Levene's test, Box test, quantile regression, and Tukey's Honestly Significant Difference). The descriptive statistics (means and standard deviations) for the all of the variables used from the quantitative 
data in the analysis of the three primary research questions are located in Table B3 in Appendix B.

In this study, with the large data set and the intricacies of analyzing different types of data (including quantitative, qualitative, data with different Likert scales), the researcher decided to work closely with a research analyst to assist in the process and analysis of the entire data set. The researcher and data analyst designed specific tests for the data and worked together to ensure the validity of the results by using several different methods of analysis. The R Project statistical analysis software (R Development Core Team, 2015) was selected for the needs of the statistical computing that would be necessary to understand the quantitative data collected by the survey instrument. The researcher developed the research questions and the supporting questions and decided upon the variables and the statistical tests that would be used to answer each of the questions. The research analyst, over the period of several weeks, worked in conjunction with the researcher to better understand the data set, run initial tests, and make suggestions for modifying the statistical tests run in order to produce more reliable results.

The following sections will describe the survey results as they relate to each of the research questions. For each research question, related questions were developed to clarify the statistical tests that would be run on the data in order to understand the results. In the pages that follow, each primary research question will be followed by related questions and then both the quantitative and/or qualitative findings are presented. 


\section{Research Questions}

In order to answer the research questions more clearly, the researcher developed additional related questions. The research questions and their related questions are found below in Table 15.

Table 15

Research questions and related questions

Research Question Related Questions

\begin{tabular}{|c|c|}
\hline \multirow{3}{*}{$\begin{array}{l}\text { How do leadership styles and/or } \\
\text { practices impact the } \\
\text { implementation of technology } \\
\text { initiatives? }\end{array}$} & $\begin{array}{l}\text { How do provided professional development } \\
\text { activities impact classroom use of technology? }\end{array}$ \\
\hline & $\begin{array}{l}\text { Can we predict a change in the frequency of } \\
\text { technology use based upon teacher choice, teacher } \\
\text { influence, and/or the ratio of devices? }\end{array}$ \\
\hline & $\begin{array}{l}\text { To what extent do certain internal and external } \\
\text { pressures impact teacher and student technology } \\
\text { use? }\end{array}$ \\
\hline \multirow{2}{*}{$\begin{array}{l}\text { What factors specific to teacher } \\
\text { characteristics inhibit or } \\
\text { encourage their application of } \\
\text { technology in learning } \\
\text { experiences for students? }\end{array}$} & $\begin{array}{l}\text { How do teacher self-efficacy perceptions (using } \\
\text { TPACK to measure) vary among each respondent } \\
\text { group? What is the relationship between age and } \\
\text { experience factors upon teachers' confidence with } \\
\text { technology and teaching? }\end{array}$ \\
\hline & $\begin{array}{l}\text { How do teachers see themselves as learners, and } \\
\text { how do others perceive them? What is the } \\
\text { relationship between age and experience factors } \\
\text { upon how teachers perceive their own learning } \\
\text { styles? }\end{array}$ \\
\hline \multirow{3}{*}{$\begin{array}{l}\text { What additional factors related to } \\
\text { the beliefs, attitudes or policies } \\
\text { of schools and school personnel } \\
\text { influence the implementation of } \\
\text { technology? }\end{array}$} & $\begin{array}{l}\text { How do teachers use technology with students and } \\
\text { how do others perceive they do? Does the } \\
\text { frequency with which teachers report they use } \\
\text { devices have an impact upon how the devices are } \\
\text { used with students? }\end{array}$ \\
\hline & $\begin{array}{l}\text { What attitudes about the advantages and } \\
\text { disadvantages of using technology with students } \\
\text { do staff in different roles and at differing age and } \\
\text { experience levels have? }\end{array}$ \\
\hline & How much do systemic barriers and supports \\
\hline
\end{tabular}


influence the incorporation of technology into the educational experience of students?

\section{First research question.}

The first research question relates to leadership styles and practices and their impacts on technology use in teaching and learning environments, specifically surrounding the impact of school or district provided professional development activities, technology usage frequencies, teacher choice, technology ratios, and external pressures or challenges. The variables used in the first research question and what they measure are found in Table 16 below.

Table 16

Variables and their measures for the first research question

\begin{tabular}{|c|c|}
\hline Variable & Measure \\
\hline Professional Development 1 & $\begin{array}{l}\text { Whether or not the school leadership or district } \\
\text { leadership provides adequate training or } \\
\text { professional development for using technology in } \\
\text { instruction. }\end{array}$ \\
\hline Professional Development 2 & $\begin{array}{l}\text { Whether or not the school leadership or district } \\
\text { leadership provides training or professional } \\
\text { development that directly influences the use of } \\
\text { technology in instruction. }\end{array}$ \\
\hline $\begin{array}{l}\text { Professional Development } \\
\text { (Combined) }\end{array}$ & $\begin{array}{l}\text { Combination of Professional Development } 1 \text { and } \\
\text { Professional Development } 2\end{array}$ \\
\hline $\begin{array}{l}\text { Professional Development } \\
\text { Relevancy } 1\end{array}$ & $\begin{array}{l}\text { Whether or not the professional development } \\
\text { activities for teachers to learn to use technology } \\
\text { in the classroom with students are relevant and } \\
\text { useful }\end{array}$ \\
\hline $\begin{array}{l}\text { Professional Development } \\
\text { Relevancy } 2\end{array}$ & $\begin{array}{l}\text { Whether or not there should be more professional } \\
\text { development opportunities for teachers to learn } \\
\text { to use technology in the classroom with students }\end{array}$ \\
\hline
\end{tabular}




\begin{tabular}{|c|c|}
\hline $\begin{array}{l}\text { Professional Development } \\
\text { (Combined) }\end{array}$ & $\begin{array}{l}\text { Combination of Professional Development } \\
\text { Relevancy } 1 \text { and Professional Development } \\
\text { Relevancy } 2\end{array}$ \\
\hline Choice & $\begin{array}{l}\text { Whether or not teachers use technology in their } \\
\text { instruction because it is their own choice to do so }\end{array}$ \\
\hline Teacher Influence & $\begin{array}{l}\text { Whether or not teachers believe they have an } \\
\text { influence on technology purchasing. }\end{array}$ \\
\hline Technology Frequency & $\begin{array}{l}\text { How often technology is used in schools or in a } \\
\text { teacher's classroom }\end{array}$ \\
\hline Technology Ratio & Describes the relative ratio of students to devices \\
\hline Minority & Racial/Ethnic minority of staff member \\
\hline Gender & Gender of staff member \\
\hline Age & Age of staff member \\
\hline Free/Reduced Lunch Students & $\begin{array}{l}\text { Participant-reported percentage of students living } \\
\text { in poverty }\end{array}$ \\
\hline Non-White students & $\begin{array}{l}\text { Participant-reported percentage of non-White } \\
\text { students }\end{array}$ \\
\hline
\end{tabular}

\section{Related question: Professional development.}

The first related question is focused on how school staff perceive the value and the relevancy of professional development. The first variable, Professional Development 1 , indicated that the district or school leadership provides inadequate training for instructional use of technology. Administrators as a group were slightly less critical of the adequacy of the training, while technology staff were the most critical. The next variable, Professional Development 2, presented a similar result to Professional Development 1 and indicated that the training or professional development does not have a direct influence on how teachers use technology in their instructional practices. The teachers were the most critical of the influence of the training, followed by the technology staff, with the administrators again being the least critical. 
Results of both the omnibus multivariate (MANOVA) test (Table B4 in Appendix B), and of the univariate (ANOVA) test (Table B5 in Appendix B) were able to determine that there are statistically significant differences in how professional development is perceived by different personnel groups. The results of the MANOVA test allowed us to reject the multivariate null hypothesis since all four of the test criteria were statistically significant at $\alpha=0.05$. Both of the ANOVA tests indicate that at least one statistically significant difference exists among the participant roles (i.e. teachers, administrator, technology support staff).

In order to test for simultaneous inference for multiple comparisons, Tukey's Honestly Significant Difference (HSD) post hoc test was used and those results are found in Table B6 in Appendix B. In this test, there were statistically significant pair-wise comparisons at $\alpha=0.05$. Administrators have significantly higher values of Professional Development 1 than teachers, which indicates that administrators believe the provided professional development to be more adequate than teachers do. For the variable Professional Development 2, administrators have significantly higher values than teachers, which indicates that administrators believe that the training influences technology use in the classroom more than teachers believe it does. No differences between teachers and technology support staff or between administrators and technology support staff were found in either variable.

Although there were statistically significant differences presented in the data using both ANOVA and MANOVA, the magnitude of each was small. So, in order to look more closely at this analysis, the researcher and the research analyst decided upon 
using quantile regression which would allow for adjusting for covariates and possibly uncover other variables which impact the differences in how staff in different roles view professional development. Professional Development 1 and Professional Development 2 were combined and used as the dependent variable in the model.

As a combined variable in the quantile analysis, Professional Development (Combined) suggests that in general, teachers, administrators, and technology support staff agree that the training and/or professional development they receive is inadequate and has a minor influence on the way teachers use technology with students. Teachers found the least value in the training, while administrators found the most value among the three groups. The results of this quantile regression can be found in Table B7 in Appendix B, while Table 17 below shows the significant covariates only.

Table 17

Significant covariates for Professional Development (Combined)

\begin{tabular}{|c|c|c|c|c|}
\hline \multirow{2}{*}{ Covariates } & \multirow{2}{*}{$\begin{array}{c}\text { OLS } \\
\text { Estimate }\end{array}$} & \multicolumn{3}{|c|}{$\tau=0.50$} \\
\hline & & $\beta$ & $S E$ & $p$ \\
\hline Intercept & $2.046 * * *$ & $1.821 * * *$ & 0.373 & .000 \\
\hline Free/Reduced Lunch Students & $0.084 * * *$ & $0.107^{*}$ & 0.055 & .040 \\
\hline
\end{tabular}

Professional Development (Combined) was tested with several other variables, including Age, Gender, Minority, Free/Reduced Lunch Students, and Non-White Students in the regression model. The coefficient for Free/Reduced Lunch Students had the strongest influence on how teachers, administrators, and technology support staff view 
professional development implying that as the percentage of students living in poverty increases, the value of provided professional development increases for all staff. Professional Development Relevancy 1 suggests that the professional development sessions staff are involved in are both relevant and useful. Technology staff here was the least critical, and again, the teachers the most critical. There was a noticeable difference, however, in Professional Development Relevancy 2. Across the board, there was an indication that more professional development for using technology with students was needed.

When Professional Development Relevancy 1 and Professional Development Relevancy 2 are combined, it still implies that staff believe the training to be relevant to their needs and/or they believe more is needed. Teachers were again the least positive in the combined variable, with technology staff coming in as the most supportive of the professional development.

The variables Professional Development Relevancy 1 (professional development for technology is relevant and useful), Professional Development 2 (should be more professional development for technology use), were combined into Professional Development (Combined). Because of the results of the quantile regression for Professional Development 1 and Professional Development 2 above, the researcher and the research analyst decided to again use quantile regression. 
Table 18

Significant covariates for Professional Development Relevancy (Combined)

\begin{tabular}{lcccc}
\hline & \multirow{2}{*}{$\begin{array}{c}\text { OLS } \\
\text { Estimate }\end{array}$} & \multicolumn{3}{c}{$\tau=0.50$} \\
\cline { 3 - 5 } & & $\beta$ & $S E$ & $p$ \\
\hline & $3.471^{* * *}$ & $3.254^{* * *}$ & 0.314 & .000 \\
Intercept & $0.393^{* * *}$ & $0.381^{*}$ & 0.178 & .027 \\
Administration & $0.590^{* * *}$ & $0.611^{* *}$ & 0.207 & .004 \\
Technology Support Staff & & & &
\end{tabular}

Note. Model quality indicators for the OLS regression are $\mathrm{R}^{2}=0.058$ and $F(7,524)=4.584, p<.001$. $* \mathrm{p}<.05 . * * \mathrm{p}<.01 . * * * \mathrm{p}<.001$.

The full results of this regression model can be found in Table B8 in Appendix B, while the statistically significant results are shown in Table 18 above. Using this model for Professional Development Relevancy (Combined), there are statistically significant differences among teachers, administrators, and technology support staff in terms of how they view the value of the provided professional development. The views of administrators and technology support staff are significantly more favorable towards the value of the provided professional development than those of teachers.

In order to better understand the quantitative data in this study, particularly surrounding professional development, the researcher used a convergent parallel design, with both quantitative and qualitative data collected simultaneously. Since the qualitative data was used to determine emergent themes as well as illustrate and validate the results from the quantitative, closed-ended questions, this convergent parallel design is known as a "data-validation variant" (Creswell \& Clark, 2011).

Table B9 in Appendix B presents qualitative data surrounding district-provided professional development opportunities simultaneously collected from the participants 
using the instrument. The open-ended survey item asked participants to "think about positive experiences you had in a staff development session [...] why were these sessions were so memorable to you [...] what were the best things about those staff development sessions?" All written answers were coded into 24 categories which developed over the course of three complete readings of the collected qualitative data. There are several notable differences among the participant groups in terms of what they found to be the most important parts of quality professional development experiences.

The top priority for professional development activities for administrators (30.8\%) and teachers (28.3\%) was "Direct application to the classroom or relevant/effective use strategies," and was third for technology support staff at a far lower rate $(15.4 \%)$. "Collaborating or talking with peers and sharing ideas" was the secondmost important thing for teachers (18.1\%) and third for administrators $(21.8 \%)$. Technology support personnel, however, reported it in nearly one-third of their total responses $(30.8 \%)$. "Time to practice or time to plan" was more important to teachers as a whole $(17.1 \%)$ than for technology support staff $(11.5 \%)$ or administrators $(9.0 \%)$. Technology support personnel reported "Hands-on or real-world" far lower (3.8\%) than administrators (15.4\%) and teachers (12.8\%). Administrators reported that "Follow up sessions or coaching model" in their top categories $(9.0 \%)$, but not teachers $(3.9 \%)$ nor technology personnel (0.0\%). "Participants choose topics or session choice" was more important to technology support personnel (11.5\%) than it was to teachers $(3.4 \%)$ or to administrators $(0.0 \%)$. Technology support personnel mentioned that "Staff concerns or interests or input for content" was important (11.5\%) more than administrators did $(2.6 \%)$ 
or teachers $(1.1 \%)$. "Engaging sessions or content" was among the top nine categories reported by administrators $(12.8 \%)$, but far less for technology support personnel $(3.8 \%)$ and for teachers $(2.6 \%)$.

Although the qualitative items asked the participants to report positive experiences they had in a staff development sessions and to recall what made the sessions memorable, several staff reported that they could not recall a positive experience or that the district lacks good professional development. Technology support personnel were the most critical (23.1\%), followed by teachers (9.7\%) and then administrators $(2.6 \%)$.

Another way to consider the qualitative responses surrounding professional development is to break them down into groups related to the amount of teaching experience each participant has. Table B10 in Appendix B shows the top responses sorted by experience categories similar to those described by Huberman (1989). In all of the experience groups except "no teaching experience," participants made statements that fell into the category of "direct application to the classroom or relevant-effective use strategies" more than any other category. Having "time to practice or time to plan" became more important to teachers as their years of teaching experience increased. At 1-3 years of experience, 3.4\% reported items that fell into that category, and from 4-6 years of experience, it nearly doubles to $6.1 \%$. After that, however, when participants have from 7-30 years of experience, having time to practice what they learn or time to plan jumps to a reported average of $19.8 \%$ of the time.

“Collaborating with peers" was reported by participants with 7-18 years of teaching experience at a higher rate $(21.8 \%)$ than staff with 1-6 years of experience 
(16.9\%) or by staff with $19-30$ years of experience (13.0\%). Only those participants with more than 30 years of teaching experience reported the need for collaboration higher $(27.6 \%)$. Staff who have no teaching experience also reported collaboration at a higher rate $(22.6 \%)$ than staff with 1-6 or 19-30 years of teaching experience.

Participants with 1-3 years of teaching experience answered with statements that reflected the need for "hands-on or real-world" at a similar rate $(19.0 \%)$ as their colleagues at the other end of the experience spectrum (more than 30 years of teaching experience) who reported it $20.7 \%$ of the time. Between 4 and 30 years experience, however, it was only reported an average $11.3 \%$ of the time. Participants with no teaching experience only reported hands-on experience at a rate of $9.7 \%$.

When participants responded with information that fit into the "access/exposure to new resource/tools/skills/techniques/strategies" category of statements, teachers with 1-3 years of experience reported that at higher levels $(19.0 \%)$ than their peers. Teachers with 4-18 years of experience reported it $6.4 \%$ of the time, and from 19 to more than 30 years of teaching experience, it was reported by $10.4 \%$ of the participants.

An additional method of looking at differences in the qualitative data about professional development would be to break it down by age groups. The top categories of the statements made by participants, grouped by age, is presented in Table B11 in Appendix B. In all of age groups except "65 years or older," participants made statements that fell into the category of "direct application to the classroom or relevant-effective use strategies" more than any other category. Having "time to practice or time to plan" was also as apparent in the age groupings as it had been in the experience breakdown in Table 
24 above, showing up $21.2 \%$ of the time for 35 to 44 year olds, $18.3 \%$ for 45 to 54 year olds, and $16.0 \%$ of the time for 55 to 64 year olds. For the younger teachers, aged 25-34, it was reported only $5.5 \%$ of the time, and not at all $(0.0 \%)$ for the youngest teachers at 20 to 24 years of age.

“Collaborating with peers" was reported higher by participants aged 35 to 44 $(23.3 \%)$ than for the 25 to 34 year olds $(20.5 \%)$ and significantly higher than the 20 to 24 year olds (8.3\%) and the 65 years and older staff members (11.1\%). From age 45 to 54 , the responses for collaboration appeared $13.9 \%$ of the time and for 55 to 64 year olds, slightly higher at $23.4 \%$.

"Well-prepared or expert presenters" was a category that had an interesting spread across the age groups. For the 20-24 year olds, it was $16.7 \%$ and for the $25-34$ year olds, the rate was $15.7 \%$. However in the next group ( 35 to 44 years old) its importance dips to $11.1 \%$ and stays near that in the following group (45 to 54 years old) at $11.4 \%$. It returns to a higher level in the 55 to 64 age group, reported at $14.9 \%$. The 65 years and older category of personnel reported expert presenters $44.4 \%$ of the time.

Hands-on or real-world experiences in a professional development session were mentioned by the 25 to 34 year old age group more than any other group (16.5\%). Younger teachers (20 to 24$)$ didn't mention it at all (0.0\%), but teachers from ages 35 to 65 and older reported it an average of $12.1 \%$ of the time.

Finally, "practical/meaningful information or grade/content area appropriate" professional development sessions appeared in the top 3 categories of our two oldest age groupings. It was listed second-most (19.1\%) by both the age 55 to 64 staff members and 
those who are over 65 years old $(22.2 \%)$ and it ranked third overall $(14.5 \%)$ for staff development categories in the qualitative data.

\section{Related question: Teacher choice, teacher influence, and ratio of devices.}

The second related question to the first research question is, "Can we predict a change in the frequency of use based upon teacher choice, teacher influence, and/or the ratio of devices?" Returning to the data collected in the closed-ended quantitative portion of the survey instrument, the researcher and the data analyst decided to use quantile regression with Technology Frequency (how often technology is used with students), Choice (teacher choice in selecting/using technology), Technology Ratio (ratio of students to devices), and Teacher Influence (teacher influence on selection/purchase of technology).

The teacher Choice variable indicated that teachers as a whole felt it is their own choice to use technology with students, while administrators and technology support staff were slightly less positive about the amount of choice teachers have to implement technology than the teachers. For the Teacher Influence variable, teachers mostly disagreed that they had any influence on technology purchasing at their school or district.

The variable Technology Frequency presented a perception of more frequent use of the technology by the teachers than the views of the technology support staff or administrators. After frequency, the variable for Technology Ratio describes the relative ratio of students to devices, with more teachers and technology support staff selecting ratios which are 2 students per device or having only shared devices across a school. Administrators tended to choose a ratio closer to 2 students per device. 
For the regression model, the dependent variable is Technology Frequency, and the independent variables are Choice, Technology Ratio, Teacher, Minority, Female, Age, Free/Reduced Lunch Students, and Non-White Students.

Table 19

Significant covariates for Technology Frequency

\begin{tabular}{llllr}
\hline & OLS & & \multicolumn{3}{c}{$\tau=0.50$} \\
\cline { 3 - 5 } Covariates & Estimate & \multicolumn{1}{c}{$\beta$} & $S E$ & $p$ \\
\hline & & $1.500^{* * *}$ & 0.302 & .000 \\
Intercept & $0.911^{* *}$ & $0.500^{*}$ & 0.232 & .032 \\
Technology Ratio & $0.515^{* * *}$ & 0.000 & 0.021 & 1.000 \\
Teacher Influence & $0.103^{* *}$ & & & \\
\hline
\end{tabular}

Note. Model quality indicators for the OLS regression are $\mathrm{R}^{2}=0.203$ and $F(9,457)=13.010, p<.001$. $* \mathrm{p}<.05 . * * \mathrm{p}<.01 . * * * \mathrm{p}<.001$.

The full results for this quantile regression at the median value for Technology Frequency are in Table B12 in Appendix B, while the statistically significant results are found in Table 19 above. The OLS estimates indicated that the ratio of technology devices has a moderately large statistically significant influence on the frequency of technology use. As the number of devices available for students increases, so does their employment by teachers in the classroom. Additionally, when teachers have some influence in technology purchasing plans, there is a statistically significant increase in the frequency of their classroom application and use of technology with students. 


\section{Related question: Differences in how varying roles view challenges.}

The third related question is, "To what extent do certain internal and external pressures impact teacher and student technology use?" The challenges to incorporating technology in the classroom presented to the participants in the study included:

- Time constraints;

- Pressure to "teach to the test";

- Lack of access to technology resources for students;

- Lack of technology support for issues that arise;

- Lack of support (or a general resistance) by school or district leadership;

- Personal lack of knowledge about or comfort with technology;

- Common Core State Standards.

Individually, time constraints (Challenge 1) and lack of access to technology resources for students (Challenge 3) were the most difficult challenges reported by all participants, while lack of support (or a general resistance) by school or district leadership (Challenge 5) and personal lack of knowledge about or comfort with technology (Challenge 6) were the least difficult. Pressure to "teach to the test" (Challenge 2), lack of technology support for issues that arise (Challenge 4) and Common Core State Standards (Challenge 7) were normally distributed variables.

By combining all of the Challenge variables, Challenge (Combined), we can create a reasonably normal distribution to use as a dependent variable in the regression model. The results for this quantile regression are in Table B13 in Appendix B and the statistically significant covariates are in Table 20 below. 
Table 20

Significant covariates for Challenge (Combined)

\begin{tabular}{lcccc}
\hline & & & \multicolumn{3}{c}{$\tau=0.50$} \\
\cline { 3 - 5 } Covariates & Estimate & $\beta$ & $S E$ & $p$ \\
\hline & & & & \\
Intercept & $1.860^{* *}$ & $1.799^{* * *}$ & 0.128 & .000 \\
Age & $0.048^{* *}$ & $0.081^{* *}$ & 0.027 & .003 \\
Free/Reduced Lunch & $-0.024^{*}$ & -0.035 & 0.019 & .063 \\
Students & $0.036^{* *}$ & 0.037 & 0.026 & .147 \\
Non-White Students & & & & \\
\hline
\end{tabular}

Note. Model quality indicators for the OLS regression are $\mathrm{R}^{2}=0.036$ and $F(7,525)=2.835, p=.007$. $* \mathrm{p}<.05 . * * \mathrm{p}<.01 . * * \mathrm{p}<.001$.

Age was one of the covariates that had a statistically significant relation with Challenge (Combined). It suggests that older teachers view some of the challenges presented in the instrument as more difficult to overcome than younger teachers do. The coefficient for Free/Reduced Lunch Students indicates that as the number of students living in poverty increases, the external and internal pressures have less of an effect upon educational technology usage. The coefficient for Non-White Students suggests that as the number of non-White students increases, external and internal pressures have more of an effect on how teachers use technology with students.

Overall, there are no statistically significant differences among teachers, administrators, and technology support staff in terms of how they view internal and external challenges. The age of the individual and the context of his/her school (i.e., Free/Reduced Lunch Students and Non-White Students) have the strongest influence on how teachers, administrators, and technology support staff view internal and external challenges (among the variables in the model). Nonetheless, it is important to note that 
the size of these influences is moderately small. In effect, these challenges were minor for teachers, administrators, or technology support staff as they attempted to incorporate digital technologies into the classroom or their district.

\section{Second research question.}

The second research question relates to teacher practices and the perception of their abilities to use technology in the educational environment. Further, the second research questions aims to discover which factors from the Cultural Historical Activity Theory (CHAT) may have an influence as well. In order to answer this research question more clearly, the researcher developed additional related questions as a guide for the data analysis. The second research question and its related questions are in Table 21 below.

Table 21

Research question 2 and its related questions

\begin{tabular}{|c|c|}
\hline Research Question & Related Questions \\
\hline \multirow{2}{*}{$\begin{array}{l}\text { What factors specific to teacher } \\
\text { characteristics inhibit or } \\
\text { encourage their application of } \\
\text { technology in learning } \\
\text { experiences for students? }\end{array}$} & $\begin{array}{l}\text { How do teacher self-efficacy perceptions (using } \\
\text { TPACK to measure) vary among each respondent } \\
\text { group? What is the relationship between age and } \\
\text { experience factors upon teachers' confidence with } \\
\text { technology and teaching? }\end{array}$ \\
\hline & $\begin{array}{l}\text { How do teachers see themselves as learners, and } \\
\text { how do others perceive them? What is the } \\
\text { relationship between age and experience factors } \\
\text { upon how teachers perceive their own learning } \\
\text { styles? }\end{array}$ \\
\hline
\end{tabular}

All of the variables and the descriptive statistics (means and standard deviations) for the second research question are in Table B3 in Appendix B. Below, in Table 22, are the variables and the measures used in the second research question. 
Table 22

Variables and their measures for the second research question

\begin{tabular}{|c|c|}
\hline Variable & Measure \\
\hline $\begin{array}{l}\text { Technological Knowledge } \\
(T C K)\end{array}$ & Level of comfort with technology \\
\hline $\begin{array}{l}\text { Technological Content } \\
\text { Knowledge (TCK) }\end{array}$ & $\begin{array}{l}\text { Level of knowledge related to selecting } \\
\text { technology to enhance lesson content }\end{array}$ \\
\hline $\begin{array}{l}\text { Technological Pedagogical } \\
\text { Knowledge (TPK) }\end{array}$ & $\begin{array}{l}\text { Level of knowledge related to using } \\
\text { technology to enhance teaching practices }\end{array}$ \\
\hline $\begin{array}{l}\text { Technological Pedagogical } \\
\text { Content Knowledge } \\
\text { (TPACK) }\end{array}$ & $\begin{array}{l}\text { Level of comfort and/or knowledge related to } \\
\text { using technology to enhance lesson content } \\
\text { and teaching practices }\end{array}$ \\
\hline CHAT 1 & $\begin{array}{l}\text { Teachers prefer to learn by doing or by using } \\
\text { technology tools in an active way on their own }\end{array}$ \\
\hline CHAT 2 & $\begin{array}{l}\text { Teachers prefer to try out different techniques } \\
\text { with their students no matter how their peers } \\
\text { use it }\end{array}$ \\
\hline CHAT 3 & $\begin{array}{l}\text { Teachers prefer to review usage models before } \\
\text { using technology with their own students }\end{array}$ \\
\hline СHAT 4 & $\begin{array}{l}\text { Teachers prefer to research best practices } \\
\text { before using technology with their own } \\
\text { students }\end{array}$ \\
\hline CHAT 5 & $\begin{array}{l}\text { Teachers prefer to know how to fully use the } \\
\text { tech before students begin using it }\end{array}$ \\
\hline СHAT 6 & $\begin{array}{l}\text { Teachers tend to use technology in the same } \\
\text { way their peers or leaders do }\end{array}$ \\
\hline Minority & Racial/Ethnic minority of staff member \\
\hline Gender & Gender of staff member \\
\hline Age & Age of staff member \\
\hline $\begin{array}{l}\text { Free/Reduced Lunch } \\
\text { Students }\end{array}$ & $\begin{array}{l}\text { Participant-reported percentage of students } \\
\text { living in poverty }\end{array}$ \\
\hline Non-White students & $\begin{array}{l}\text { Participant-reported percentage of non-White } \\
\text { students }\end{array}$ \\
\hline
\end{tabular}




\section{Related question: How teacher self-efficacy perceptions vary.}

To aid in answering the second research question, data was analyzed regarding how teachers view their own self-efficacy, using parts of the TPACK model and corresponding survey items, and how others (i.e. administrators and technology support personnel) perceive them. In general, across all areas of the TPACK model, teachers rated themselves higher than the administrators or technology support staff in terms of their knowledge of technology, ability to choose the right technology, and/or how to teach using technology. This indicates that for the most part, teachers feel more confident than the other role groups (i.e. administrators or technology support staff) feel about their ability to employ well-chosen technology tools in their work with students.

A quantile regression model was applied for each of the TPACK areas measured (TK, TCK, TPK, TPACK) in order to measure the differences in perception as well as measure other factors such as technology ratio, technology frequency, gender, age, minority status or the school context (i.e. free and reduced lunch students or non-White student population pecentages), and the impact of each of these factors on TPACK selfassessment.

Table 23

Significant covariates for Technological Knowledge (TK)

\begin{tabular}{lcccc}
\hline & & & & $\tau=0.50$ \\
& OLS & & & \\
\cline { 3 - 5 } & Estimate & $\beta$ & $S E$ & $p$ \\
\hline & & & & \\
Intercept & $3.884^{* * *}$ & $3.749^{* * *}$ & 0.206 & .000 \\
Administration & $-0.700^{* * *}$ & $-0.697^{* * *}$ & 0.126 & .000 \\
Technology Support Staff & $-1.056^{* * *}$ & $-1.249^{* * *}$ & 0.245 & .000 \\
\hline
\end{tabular}




\begin{tabular}{lcccc}
\cline { 1 - 1 } Technology Frequency & $0.130^{* * *}$ & $0.149^{* *}$ & 0.053 & .005 \\
Female & $-0.372^{* * *}$ & $-0.370^{* * *}$ & 0.093 & .000 \\
Age & $-0.161^{* * *}$ & $-0.123^{* *}$ & 0.046 & .008 \\
Free/Reduced Lunch & $0.058^{* *}$ & $0.065^{*}$ & 0.030 & .032 \\
Students & & & &
\end{tabular}

Note. Model quality indicators for the OLS regression are $\mathrm{R}^{2}=0.200$ and $F(9,588)=16.400, p<.001$. ${ }^{*} \mathrm{p}<.05 .{ }^{* *} \mathrm{p}<.01 .{ }^{* * *} \mathrm{p}<.001$.

The results of the quantile regression model for Technical Knowledge (TK in the TPACK model) are detailed in Table B14 in Appendix B, and the significant results only are in Table 23 above.

Six covariates had a statistically significant relation with Technological Knowledge at the $50^{\text {th }}$ percentile. Generally, the results of the quantile regression analysis indicate statistically significant differences between administrators and teachers and between technology support staff and teachers in terms of the Technological Knowledge self-assessment. Administrators and technology support staff reported significantly smaller values in technological knowledge than teachers, pointing to a belief by these individuals that teachers have a lower level of technological knowledge than teachers see in themselves. Additional factors, including frequency of use, gender and age of the individual, and the context of his/her school (i.e., Free/Reduced Lunch Students) appear to influence the overall technological knowledge of teachers.

The coefficient for Technology Frequency indicates that as the frequency of technology use increases, teachers report having more technological knowledge. Female staff members report lower levels of Technological Knowledge than males. The coefficient for Age implies that older teachers have a more negative view of their knowledge of technology than younger teachers do. The coefficient for Free/Reduced 
Lunch Students indicates that teachers who have more students in poverty feel more confident about their knowledge of technology.

The results of the quantile regression model for Technological Content Knowledge (TCK in the TPACK model) are detailed in Table B15 in Appendix B. The statistically significant covariates are in Table 24 below.

Table 24

Significant covariates for Technological Content Knowledge (TCK)

\begin{tabular}{lcccc}
\hline & & & \multicolumn{3}{c}{$\tau=0.50$} \\
\cline { 3 - 5 } Covariates & Estimate & $\beta$ & $S E$ & $p$ \\
\hline & & & & \\
& & & & \\
Intercept & & & & \\
Administration & $-0.643^{* * * *}$ & $-1.000^{* * *}$ & 0.107 & .000 \\
Technology Support & $-0.974^{* * *}$ & $-1.000^{*}$ & 0.317 & .008 \\
Staff & & & 0.458 & .029 \\
\hline
\end{tabular}

Note. Model quality indicators for the OLS regression are $\mathrm{R}^{2}=0.160$ and $F(9,583)=12.340, p<.001$. $* \mathrm{p}<.05 . *{ }_{\mathrm{p}}<.01 . * * * \mathrm{p}<.001$.

Two covariates had a statistically significant relation with Technological Content Knowledge at the $50^{\text {th }}$ percentile. These two covariates imply that both administrators and technology support staff believe teachers have a lower level of knowing how to choose technologies that will enhance lesson content (TCK) than the teachers themselves believe.

The results of the quantile regression model for Technological Pedagogical Knowledge (TPK in the TPACK model) are detailed in Table B16 in Appendix B. 
Table 25

Significant covariates for Technological Pedagogical Knowledge (TPK)

\begin{tabular}{lrrrr}
\hline & OLS & & \multicolumn{2}{c}{$\tau=0.50$} \\
\cline { 3 - 5 } Covariates & Estimate & $\beta$ & $S E$ & $p$ \\
\hline & $3.308^{* * *}$ & $4.000^{* * *}$ & 0.181 & .000 \\
Intercept & $-0.867^{* * *}$ & $-1.000^{* * *}$ & 0.229 & .000 \\
Technology Support Staff & & & \\
\hline
\end{tabular}

Note. Model quality indicators for the OLS regression are $\mathrm{R}^{2}=0.165$ and $F(9,583)=12.830, p<.001$. $* \mathrm{p}<.05 . * * \mathrm{p}<.01 . * * \mathrm{p}<.001$.

The significant covariates only are shown in Table 25 above. Only one covariate had a statistically significant relation with Technological Pedagogical Knowledge at the $50^{\text {th }}$ percentile. This covariate indicates that teachers believe they have more technological pedagogical knowledge than technology support personnel believe they have.

The complete results of the quantile regression model for Technological Pedagogical Content Knowledge (TPACK) can be found in Appendix B in Table B17. The significant covariates only are shown in Table 26 below.

Table 26

Significant covariates for Technological Pedagogical Content Knowledge (TPACK)

\begin{tabular}{lcccc} 
& & & $\tau=0.50$ \\
Covariates & Estimate & $\beta$ & $S E$ & $p$ \\
\cline { 3 - 4 } & & & & .000 \\
Intercept & $3.242^{* * *}$ & $3.714^{* * *}$ & 0.212 & .023 \\
Administration & $-0.562 * * *$ & $-0.500^{*}$ & 0.219 & .002 \\
Technology Support & $-0.872 * * *$ & $-0.762^{* *}$ & 0.239 & \\
Staff & & & &
\end{tabular}

Note. Model quality indicators for the OLS regression are $\mathrm{R}^{2}=0.167$ and $F(9,578)=12.860, p<.001$. $* \mathrm{p}<.05 . * \mathrm{p}<.01 . * * \mathrm{p}<.001$ 
Two covariates had a statistically significant relationship with Technological Pedagogical Content Knowledge at the $50^{\text {th }}$ percentile. Overall, the statistically significant differences are between technology support staff and teachers and between administrators and teachers in terms of the Technological Pedagogical Content Knowledge self-assessment. Technology support staff and administrators hold significantly lower opinions of the levels of teachers' Technological Pedagogical Content Knowledge than teachers do of themselves.

\section{Related question: How teachers see themselves as learners, and how others} perceive them.

The next set of factors which may have an impact on how teachers use technology with students in their learning experiences are related to how teachers perceive their own learning styles (when it comes to tool usage) and how other personnel groups see them. To aid in answering this related question, data was analyzed that centers on ideas presented by the Cultural Historical Activity Theory (CHAT) as discussed in Chapter 2. Table B3 in Appendix B lists the descriptive statistics for all of the CHAT variables used in the quartile regression models.

For the CHAT 1 (actively learning on their own) variable, no covariates had a statistically significant relation with $C H A T 1$ at the $50^{\text {th }}$ percentile. Table B18 in Appendix B shows the results of this quantile regression model. There are no statistically significant differences between administrators and teachers or between technology 
support staff and teachers in terms of CHAT 1. Further, none of the other covariates have statistically significant relations with $C H A T 1$. The response distribution shows that teachers, administrators and technology support staff mostly agree with the idea that teachers learn to use technology best in an active way.

In Table B18 in Appendix B, the results for the quartile regression model for the CHAT 2 (trying out different techniques) are listed. Table 27 below has the significant covariates only. There are statistically significant differences between administrators and teachers and between technology support staff and teachers in terms of CHAT 2. Teachers reported they prefer to try out different techniques of using technology tools with students regardless of how their peers or leaders do more than administrators and technology support staff believe they do.

Table 27

Significant covariates for CHAT 2

\begin{tabular}{lrr}
\hline & \multicolumn{2}{c}{ CHAT 2 } \\
\cline { 2 - 3 } Covariates & $\tau=0.50$ & OLS \\
\hline & & $3.505(0.188)^{* * *}$ \\
Intercept & $4.000(0.257)^{* * * *}$ & $-0.640(0.129)^{* * *}$ \\
Administration & $-1.000(0.163)^{* * *}$ & $-0.811(0.220)^{* * *}$ \\
Technology Support Staff & $-1.000(0.330)^{* *}$ & \\
& & \\
Note. Model quality indicators for the CHAT 2 OLS regression are $\mathrm{R}^{2}=0.078$ and $F(7,540)=6.507, p<$ \\
.001. Values in parentheses are standard errors.
\end{tabular}

There are statistically significant differences between administrators and teachers and between technology support staff and teacher in terms of CHAT 3 (reviewing usage models). 
Table 28

Significant covariates for CHAT 3

\begin{tabular}{lcc}
\hline & \multicolumn{2}{c}{ CHAT 3} \\
\cline { 2 - 3 } Covariates & $\tau=0.50$ & OLS \\
\hline Intercept & $4.000(0.000)^{* * *}$ & $3.496(0.186)^{* * *}$ \\
Administration & $-1.000(0.308)^{* *}$ & $-0.444(0.127)^{* * *}$ \\
Technology Support Staff & $-1.000(0.351)^{* *}$ & $-0.396(0.218)$ \\
& \\
\hline Note. Model quality indicators for the CHAT 3 OLS regression are $\mathrm{R}^{2}=0.030$ and $F(7,540)=2.39, p=$ \\
.021. Values in parentheses are standard errors. \\
${ }^{*} \mathrm{p}<.05 . * * \mathrm{p}<.01 .{ }^{* * *} \mathrm{p}<.001$.
\end{tabular}

Teachers believe they need to look for effective models of technology usage before they employ it with students more than administrators and technology support staff believe do. In Appendix B in Table B19, the results of this regression model are found, while the statistically significant variables are listed in Table 28 above.

Table 29

Significant covariates for CHAT 4

\begin{tabular}{lrr} 
& \multicolumn{2}{c}{ CHAT 4} \\
\cline { 2 - 3 } Covariates & $\tau=0.50$ & OLS \\
\hline Intercept & $4.000(0.078)^{* * *}$ & $3.661(0.205)^{* * *}$ \\
Administration & $-1.000(0.131)^{* * *}$ & $-0.561(0.140)^{* * *}$ \\
Technology Support Staff & $-1.000(0.263)^{* * *}$ & $-0.566(0.240)^{*}$ \\
\hline Note. Model quality indicators for the CHAT 4 OLS regression are $\mathrm{R}^{2}=0.047$ and $F(7,540)=3.844, p<$ \\
.001. Values in parentheses are standard errors. \\
${ }^{*} \mathrm{p}<.05 .{ }^{* *}<.01 . * * * \mathrm{p}<.001$.
\end{tabular}

For CHAT 4 (researching best practices), the results of the quantile regression model used for the data analysis of CHAT 4 are found in Table B19 in the Appendix and the significant covariates are in Table 29 above. There are statistically significant 
differences between administrators and teachers and between technology support staff and teachers in terms of CHAT 4 (trying out techniques). Administrators and technology support staff have significantly smaller values of CHAT 4 than teachers, implying that teachers believe they have a need to learn by researching or learning about using technology tools before they start using it in their classroom or school more than administrators and technology support personnel believe they do.

The results of the quantile regression for CHAT 5 (knowing how to fully use the technology) are in Table B20 in the Appendix B. No covariates had a statistically significant relation with CHAT 5 at the mean. Chat 5 is a reasonable approximation of normal distribution meaning that all staff either agreed or disagreed relatively equally with the idea that teachers needed to know how to fully use the technology before their students use it.

Finally, for CHAT 6 (using the technology similarly to my peers or leaders), Table B20 in the Appendix has the results of the quantile regression for this variable, and Table 30 below shows only the significant covariates.

Table 30

Significant covariates for CHAT 6

\begin{tabular}{lcc}
\hline & \multicolumn{2}{c}{ CHAT 6} \\
\cline { 2 - 3 } Covariates & $\tau=0.50$ & OLS \\
\hline & $3.000(0.000)^{* * *}$ & $3.253(0.154)^{* * *}$ \\
Intercept & $1.000(0.109)^{* * *}$ & $0.522(0.105)^{* * *}$ \\
Administration & $1.000(0.334)^{* *}$ & $0.571(0.180)^{* *}$ \\
Technology Support Staff & & \\
\hline
\end{tabular}

Note. Model quality indicators for the CHAT 6 OLS regression are $\mathrm{R}^{2}=0.060$ and $F(7,540)=4.929, p<$ .001 . Values in parentheses are standard errors.

$* \mathrm{p}<.05 . * * \mathrm{p}<.01 . * * * \mathrm{p}<.001$ 
There are statistically significant differences at the mean between administrators and teachers and between technology support staff and teacher in terms of CHAT 6 . In the largest difference among all the CHAT variables, CHAT 6 indicates that teachers do not prefer to use technology in a similar way to their peers or their leaders as much as than administrators believe they do. Technology support staff view CHAT 6 similarly to administrators but to a slightly lesser extent.

\section{Third research question.}

The third research question relates to beliefs, attitudes, and policies of the people who work in schools and the impact of each upon the use of technology resources for teaching and learning. In order to answer this research question more fully, the researcher developed additional related questions, located in Table 31 below.

Table 31

Research question 3 and its related questions Research Question Related Questions

How do teachers use technology with students and how do others (administrators and technology support personnel) perceive they do? Does the frequency with which teachers report they use devices have an impact upon how the

What additional factors related to the beliefs, attitudes or policies of schools and school personnel influence the implementation of technology? devices are used with students?

What attitudes about the advantages and disadvantages of using technology with students do staff in different roles and at differing age and experience levels have?

How much do systemic barriers and supports influence the incorporation of technology into the educational experience of students? 
All of the variables and the descriptive statistics (means and standard deviations) for the third research question are in Table B3 in Appendix B. Below, in Table 32, are the variables and the measures used in the second research question.

Table 32

Variables and their measures for the third research question

\begin{tabular}{|c|c|}
\hline Variable & Measure \\
\hline Usage 1 & Technology is used as/for reward for completing other work \\
\hline Usage 2 & $\begin{array}{l}\text { Technology is used as/for understanding their academic } \\
\text { work }\end{array}$ \\
\hline Usage 3 & Technology is used as/for supplementary or enrichment tool \\
\hline Usage 4 & $\begin{array}{l}\text { Technology is used as/for teaching about computers or other } \\
\text { technology tools and how to use them }\end{array}$ \\
\hline Usage 5 & $\begin{array}{l}\text { Technology is used as/for remediation of academic } \\
\text { deficiencies }\end{array}$ \\
\hline Usage 6 & Technology is used as/for challenging the brightest students \\
\hline Usage 7 & Technology is used as/for state or local assessments \\
\hline Usage 8 & $\begin{array}{l}\text { Technology is used as/for motivating interest in school, } \\
\text { schoolwork, or class projects }\end{array}$ \\
\hline Usage 9 & $\begin{array}{l}\text { Technology is used as/for significantly changing the nature } \\
\text { of learning projects and the way students interact with } \\
\text { information, contexts, real-world projects }\end{array}$ \\
\hline Minority & Racial/Ethnic minority of staff member \\
\hline Gender & Gender of staff member \\
\hline Age & Age of staff member \\
\hline $\begin{array}{l}\text { Free/Reduced Lunch } \\
\text { Students }\end{array}$ & Participant-reported percentage of students living in poverty \\
\hline Non-White students & Participant-reported percentage of non-White students \\
\hline
\end{tabular}




\section{Related question: How teachers use technology with students.}

The following set of models describe how teachers use technology with students in their learning experiences and how other personnel groups believe they do. Table B3 in Appendix B contains the descriptive statistics for all of the "usage" variables used in the quartile regression models that are presented below. Generally speaking, in all but one usage area (Usage 2), teachers as a group were more apt to select "always used for" or "most likely used for" than administrators and technology support staff were.

All staff reported Usage 1 (reward for completing other work) as one of the least likely uses of technology in the classroom. Teachers reported its use as a reward less often than administrators and technology support staff did. There are statistically significant differences between administrators and teachers and between technology support staff and teachers in terms of Usage 1 (reward for completing other work), listed in the quantile regression model results in Table B21 in Appendix B. The significant covariates are shown in Table 33 below. Administrators and technology support staff have significantly larger values of Usage 1 than teachers suggesting those two personnel groups believe technology is used as a reward more than teachers report it is.

Table 33

Significant covariates for Usage 1

\begin{tabular}{|c|c|c|}
\hline \multirow{2}{*}{ Covariates } & \multicolumn{2}{|c|}{ Usage 1} \\
\hline & $\tau=0.50$ & OLS \\
\hline Intercept & $0.412(0.181)^{*}$ & $0.795(0.142)^{* * *}$ \\
\hline Administration & $0.635(0.117)^{* * *}$ & $0.527(0.089) * * *$ \\
\hline Technology Support Staff & $0.973(0.149)^{* * *}$ & $0.771(0.139) * * *$ \\
\hline Technology Frequency & $0.135(0.053)^{*}$ & $0.157(0.032)^{* * *}$ \\
\hline Female & $0.162(0.081)^{*}$ & $0.172(0.064)^{* *}$ \\
\hline
\end{tabular}


Free/Reduced Lunch Students $0.122(0.034) * * *$ $0.106(0.017)^{* * *}$

Note. Model quality indicators for the Usage 1 OLS regression are $\mathrm{R}^{2}=0.206$ and $F(9,595)=17.190, p<$ .001 .

Values in parentheses are standard errors.

$* \mathrm{p}<.05 . * * \mathrm{p}<.01 . * * * \mathrm{p}<.001$.

The frequency of use, gender of the individual, and the context of his/her school (i.e., Free/Reduced Lunch Students) also influence the technology usage of teachers. The coefficient for Technology Frequency suggests that as technology is used more frequently by students in their educational setting, it is also used more frequently as a reward for completing other work.

The data also implies that female teachers are more apt to use technology as a reward more than male teachers are. Additionally, the coefficient for Free/Reduced Lunch Students indicates that teachers who work with higher populations of students living in poverty use technology more as a reward than teachers who work in schools who have lower numbers of economically disadvantaged students.

In contrast to Usage 1, the Usage 2 variable indicates that participants perceive the use of technology for students to better understand their academic work as likely. In Table B21, located in Appendix B, the results of the quantile regression for Usage 2 (understanding their academic work) can be found. No covariates had a statistically significant relation with Usage 2 at the $50^{\text {th }}$ percentile. In general, all personnel groups agree that technology is being used as an academic support regardless of the ratio of devices to students, the frequency of technology use, the school's context (i.e. percentage of economically disadvantaged students), or the teacher's gender, age, or minority status. 
The responses for Usage 3 indicate that most participants see technology as a likely supplementary or enrichment tool. For Usage 3 (supplementary or enrichment tool), the results for the regression analysis can be found in Table B22 in Appendix B. No covariates had a statistically significant relation with Usage 3 at the $50^{\text {th }}$ percentile suggesting that there are no statistically significant differences between administrators and teachers or between technology support staff and teachers in terms of Usage 3.

The quartile regression results for Usage 4 (teaching about how to use computers and technology tools), are located in Table B22, in Appendix B, and the significant covariates only are listed in Table 34 below. Using the OLS estimates for Usage 4, the regression model indicates that teachers report using technology with students as a way to teach technology tools and computer use in general less than either administrators or technology support personnel believe they do.

Table 34

Significant covariates for Usage 4

\begin{tabular}{llc}
\hline & \multicolumn{2}{c}{ Usage 4} \\
\cline { 2 - 3 } Covariates & \multicolumn{1}{c}{$\tau=0.50$} & OLS \\
\hline & & \\
Intercept & $1.500(0.319)^{* * *}$ & $1.795(0.189)^{* * *}$ \\
Administration & $0.663(0.277)^{*}$ & $0.426(0.118)^{* * *}$ \\
Technology Support Staff & $0.939(0.156)^{* * *}$ & $0.837(0.184)^{* * *}$ \\
Technology Ratio & $0.276(0.191)$ & $0.127(0.058)^{*}$ \\
\hline
\end{tabular}

Note. Model quality indicators for the Usage 4 OLS regression are $\mathrm{R}^{2}=0.087$ and $F(9,595)=6.327, p<$ .001 . Values in parentheses are standard errors.

$* \mathrm{p}<.05 . * * \mathrm{p}<.01 . * * * \mathrm{p}<.001$

Further, the coefficient for Technology Ratio suggests that schools or classrooms with more devices available for students spend more time teaching students about general 
computer use or how to use technology tools than those schools with a higher student-todevice ratio.

Usage 5 (remediation of academic deficiencies), was reported by teachers as a less likely usage scenario than technology support and administrators reported. For Usage 5, the regression model results are found in Table B23 in Appendix B. For the significant covariates, see Table 35 below. The model suggests that administrators believe teachers are using technology to remediate academic deficiencies much more than teachers report they are. Technology support staff also perceive teachers as using technology as a remediate tool for students more than teachers report they do. The coefficient for Technology Frequency implies that as the frequency of technology use increases, so does the use of technology for remediating academic deficiencies. Female teachers also report using technology for student remediation more than males do.

Table 35

Significant covariates for Usage 5

\begin{tabular}{lcc}
\hline & \multicolumn{2}{c}{ Usage 5 } \\
\cline { 2 - 3 } Covariates & $\tau=0.50$ & OLS \\
\hline & & $1.423(0.174)^{* * *}$ \\
Intercept & $1.333(0.268)^{* * *}$ & $0.621(0.109)^{* * *}$ \\
Administration & $0.667(0.137)^{* * *}$ & $0.463(0.169)^{* *}$ \\
Technology Support Staff & $0.667(0.173)^{* * *}$ & $0.226(0.039)^{* * *}$ \\
Technology Frequency & $0.333(0.079)^{* * *}$ & $0.217(0.078)^{* *}$ \\
Female & $0.333(0.134)^{*}$ & \\
\hline Note. Model quality indicators for the Usage 5 OLS regression are $\mathrm{R}^{2}=0.136$ and $F(9,595)=10.380, p<$ \\
.001. Values in parentheses are standard errors. \\
$* \mathrm{p}<.05 . * * \mathrm{p}<.01 . * * * \mathrm{p}<.001$.
\end{tabular}


Usage 6 (challenging the brightest students) has a reasonably normal distribution. The results for the regression model for the variable Usage can be found in Appendix B, in Table B23. The significant covariates are found in Table 36 below.

Table 36

Significant covariates for Usage 6

\begin{tabular}{lcc}
\hline & \multicolumn{2}{c}{ Usage 6} \\
\cline { 2 - 3 } Covariates & $\tau=0.50$ & OLS \\
\hline & $1.188(0.348)^{* * *}$ & $1.557(0.179)^{* * *}$ \\
Intercept & $0.312(0.301)$ & $0.353(0.112)^{* *}$ \\
Administration & $0.312(0.162)$ & $0.187(0.040)^{* * *}$ \\
Technology Frequency & $0.188(0.169)$ & $0.119(0.055)^{*}$ \\
Technology Ratio & & \\
\hline
\end{tabular}

Note. Model quality indicators for the Usage 6 OLS regression are $\mathrm{R}^{2}=0.095$ and $F(9,595)=6.918, p<$ .001 . Values in parentheses are standard errors.

$* \mathrm{p}<.05 . * * \mathrm{p}<.01 . * * * \mathrm{p}<.001$

The OLS estimates show that there are statistically significant differences between administrators and teachers in terms of Usage 6. The model suggests that administrators believe teachers are challenging the brightest students more than they report they are. The frequency of use and the ratio of technology devices influences how staff report teachers using technology with students; however, it is important to note that the magnitude of influence is moderate for frequency of use and small for the ratio of technology devices. The coefficients for Technology Frequency and Technology Ratio indicate that with either more frequent use of technology with students or more devices available for student use, more teachers use the technology to challenge bright and highflying students. 
Of all the usage variables, technology staff reported Usage 7 (state or local assessments) as the most likely usage of classroom technology. Both administrators and technology staff reported state or local assessments more often than teachers did. According to the regression model, those differences between administrators and teachers and between technology support staff and teachers for Usage 7 are statistically significant. The results of the regression model for Usage 7 are found in Table B24 in Appendix B and the significant covariates are shown in Table 37 below.

Table 37

Significant covariates for Usage 7

\begin{tabular}{lrr}
\hline & \multicolumn{2}{c}{ Usage 7} \\
\cline { 2 - 3 } Covariates & $\tau=0.50$ & OLS \\
\hline & & $2.717(0.226)^{* * *}$ \\
Intercept & $3.500(0.280)^{* * * *}$ & $0.859(0.141)^{* * *}$ \\
Administration & $1.000(0.120)^{* * *}$ & $0.975(0.220)^{* * *}$ \\
Technology Support Staff & $1.000(0.110)^{* * *}$ & $-0.328(0.070)^{* * *}$ \\
Technology Ratio & $-0.500(0.243)^{*}$ & \\
& & \\
Note. Model quality indicators for the Usage 7 OLS regression are $\mathrm{R}^{2}=0.138$ and $F(9,595)=10.570, p<$ \\
.001. Values in parentheses are standard errors.
\end{tabular}

The ratio of technology devices influences the way teachers, administrators, and technology support staff view technology usage (i.e., Usage 7). With more available devices for students, teachers report using them even less for state and local assessments. For Usage 8 (motivating interest in school or schoolwork), the results from the regression model are found in Table B24 in Appendix B. The distribution suggests that staff perceive the use of technology as a likely tool for motivating interest in school or schoolwork. No covariates had a statistically significant relation with Usage 8 at the $50^{\text {th }}$ 
percentile indicating that all three personnel groups have a similar outlook on Usage 8 , and that other factors (school context, gender, technology ratio, etc.) have no influence on the use of technology for motivation.

The regression results for Usage 9 (significantly changing the nature of learning projects) are shown in Table B25 in Appendix B and the significant covariates are in Table 38 below.

Table 38

Significant covariates for Usage 9

\begin{tabular}{lllcc}
\hline & & & \multicolumn{3}{c}{$\tau=0.50$} \\
\cline { 3 - 5 } Covariates & Estimate & $\beta$ & $S E$ & $p$ \\
\hline & & & & \\
Intercept & $1.591^{* * *}$ & $1.219^{* * *}$ & 0.323 & .000 \\
Technology Frequency & $0.217^{* * *}$ & $0.324^{* * *}$ & 0.057 & .000 \\
Technology Ratio & $0.254^{* * *}$ & $0.274^{* *}$ & 0.082 & .001 \\
Age & $0.070^{*}$ & $0.119^{*}$ & 0.046 & .010 \\
\hline
\end{tabular}

Note. Model quality indicators for the OLS regression are $\mathrm{R}^{2}=0.143$ and $F(9,595)=11.050, p<.001$. $* \mathrm{p}<.05 . * * \mathrm{p}<.01 . * * * \mathrm{p}<.001$.

Using the OLS estimates, given that Usage 9 has a reasonably normal distribution, the frequency of use, the ratio of technology devices, and the age of the individuals show an influence upon how teachers, administrators, and technology support staff see the use of technology for changing the core nature of student projects (i.e., Usage 9). The moderate influence of the coefficient for Technology Frequency implies that teachers who use technology more often with students report using them more for significantly changing the kinds of educational projects in which students are engaged than teachers use technology with less frequency. The moderate influence of the coefficient for Technology Ratio implies that teachers whose students have more devices 
available to them report using them more for significantly changing the nature of the learning projects and the way students interact with information, contexts, and real-world projects. The coefficient for Age indicates a small influence that as teachers age, they are more apt to use technology to modify the educational tasks more than younger teachers are.

\section{Related question: Advantages and disadvantages to technology use in school.}

Table B26 in Appendix B presents qualitative data surrounding staff beliefs about the advantages and disadvantages of using technology with students collected from the participants using the instrument. The open-ended survey item asked participants to "describe in your own words the major advantages and/or disadvantages that you see in the use of technology with students." All written answers were coded into 25 categories which developed over the course of three complete readings of the collected qualitative data. There are several notable differences as well as interesting similarities among the participant groups in terms of what they found to be advantages and disadvantages.

For the responses coded into the advantage categories, many of the most frequent answers fit into the same ones for teachers, administrators, and technology personnel. One striking difference was that technology personnel ranked "building student skills/preparing for the future" as the highest advantage (34.6\%), while teachers $(19.0 \%)$ and administrators $(21.8 \%)$ reported it as the fourth-highest. The category of "access information easily/current resources" was reported approximately $30 \%$ of the time across all personnel groups. Administrators reported (32.1\%) that "student academics/organization" was the most important, while teachers placed it second $(26.6 \%)$ 
and technology personnel put it third (26.9\%). Using technology for "student individualization/personalization" was more important for technology support personnel $(26.9 \%)$ than it was for administrators $(23.1 \%)$ and for teachers $(19.6 \%)$. The category in the sixth spot for all three groups was different, and each had very different response percentages: "student communication or collaboration tool" for administrators $(9.0 \%)$, "student practice" for teachers (12.5\%), and "student project creation/demonstration of learning" for technology support personnel (19.2\%).

Disadvantages, when grouped by participant role, have both a range of different responses as well as similar responses at differing levels of importance. Those are listed alongside the advantages in Table B26 in Appendix B. The "availability of technology/money/funding" was at the top of the list for teachers $(29.4 \%)$ and for administrators $(23.1 \%)$, but near the end of the top six for technology personnel $(3.8 \%)$. For administrators (15.4\%) and teachers (22.2\%), "tech support lacking/tech not working/network slow/tech is old" was the second-most reported item, while technology support mentioned it far less (3.8\%). Administrators (12.8\%) and technology personnel (11.5\%) reported that "teacher PD (training) needed/low teacher ability with tech," while teachers only reported it $2.8 \%$ of the time. The technology "not being used effectively for teaching/learning" came up for technology personnel the most and as their top disadvantage (23.1\%), while administrators mentioned it $11.5 \%$ and teachers only $7.8 \%$ of the time. Technology support personnel reported that "distractions/inappropriate use/social media" was their second-most critical disadvantage (19.2\%), while teachers reported it $17.5 \%$ of the time, and administrators far less $(10.3 \%)$. Teachers reported 
$(8.8 \%)$ that "students have low tech skill level" while technology personnel mentioned it $7.7 \%$ of the time, and administrators very rarely (1.3\%). Administrators had "equity (low access) to tech or tech experience (home) in their top six reported disadvantages at $7.7 \%$ of their responses, while teachers only reported it 3.5\% of the time, and technology support personnel did not mention it at all. Teachers also reported "less teacher control/supervision or management issues" among their top six disadvantages (7.8\%) while administrators reported it $5.1 \%$ of the time, and technology personnel only $3.8 \%$.

In Table B27, found in Appendix B, the responses of reported advantages to using technology with students are grouped by the participant's reported age category. Many of the top responses in each age group fell into the same categories ("access information easily/current resources," "student engagement/interest/motivation," and "student academics/organization"). There were a few notable exceptions. First, "building student skills/preparing for the future" was in the top three for staff aged 25 to 34,55 to 64 , and 65 years and older but not for the other age groups. Secondly, "student individualization/personalization" was in the top three (44.4\%) for participants 65 years and older but again, not in other age groups.

As for disadvantages listed by age categories, Table B27 in Appendix B has those results. All age groups listed “distractions/inappropriate use/social media” and "availability of technology/money/funding" among their top three responses. The "tech support lacking/tech not working/network slow/tech old" category appeared in the top three for all age groups except 20 to 24 years old $(0.0 \%)$ and 65 years or older $(0.0 \%)$. In 
fact, of all responses from the study's oldest participants, only two disadvantages were reported in total (availability, 33.3\% and distractions, 11.1\%).

When the categories are grouped by years of teaching experience, "student engagement/interest/motivation" , "access information easily/current resources" and "student academics/organization" appear among the top advantages for all experience levels, including those participants with no teaching experience. Advantages to using technology with students, grouped by years of teaching experience, can be found in Table B28 in Appendix B.

For participants with 4-6 years and more than 30 years of teaching experience, "student individualization/personalization" appears as one of the top 3 advantages. Then, "building student skills/preparing for future" is in the top 3 advantages for participants with 1-3 years of experience, more than 30 years of experience, and no teaching experience (where it came in at the top of that group's responses).

For disadvantages to using technology with students, found in Table B28 in Appendix B, "availability of technology/money/funding”, "distractions/inappropriate use/social media" and "tech support lacking/tech not working/network slow/ tech old" appear across all experience groups, except those participants with more than 30 years of experience. For that group, "students have low tech skill” rounds out the top 3 appearing $17.2 \%$ of the time.

\section{Related question: Systemic barriers and supports.}

Table B29 in Appendix B presents qualitative data related to staff viewpoints about obstacles or barriers to using technology with students grouped by participant role. 
The open-ended survey item asked participants "what are the major obstacles to more effective use of technology with students?" All written answers were coded into 975 separate items and placed into 26 categories which developed over the course of three complete readings of the simultaneously collected qualitative data.

Teachers (35.2\%) and administrators (24.4\%) reported "lack of access" as their top obstacle, and technology support staff reported it as their second-most important obstacle (23.1\%). For technology support personnel (38.5\%) and administrators $(23.1 \%)$, "teacher professional development missing" was in the top two for reported obstacles. Teachers, however, only reported it $11.7 \%$ of the time. Teachers $(17.5 \%)$ and technology staff $(19.2 \%)$ reported "lack of time" far more than administrators did (10.3\%). Teachers reported "Internet/network slow/unreliable" much lower (5.8\%) than either administrators (9.0\%) or technology support staff (23.1\%). For teachers and technology staff, “costs/funding”, "outdated/old technology”, "tech support/lack of” all were reported among the top 8 obstacles, while those did not appear in the top responses for administrators. For administrators "equity of student access" was reported $9.0 \%$ of the time while it was lower for teachers $(6.0 \%)$ and non-existent for technology personnel $(0.0 \%)$

In Table B30 in Appendix B, the top reported obstacles to using technology with students, grouped by years of teaching experience are listed. Across all teaching experience groups, "lack of access to devices" was reported as the largest obstacle to effectively using technology with students. For all teaching experience groups, "lack of time" was reported in the top 3 categories, increasing in its importance as staff were in 
teaching roles longer (from $12.1 \%$ at $1-3$ years of teaching increasing to $24.1 \%$ for more than 30 years of teaching experience). Even for those participants who have no teaching experience, it was reported among the top 3 at 12.9\% tied with "lack of resource."

Teachers with 1-3 years of experience (12.1\%) and teachers with more than 30 years of experience (13.8\%) felt that "costs/funding" was a major obstacle. For teachers with 4-6 years, 19-30 years, and no teaching experience, "teacher professional development" was reported among the top 3 obstacles to effective technology integration efforts. Finally, teachers in their mid-career (7-18 years of experience) felt that "teacher knowledge of technology and pedagogy" was a major obstacle (14.9\%). The complete list of obstacles to effective use of technology with students is included in Appendix B in Table B30.

For variables related to supports for teachers to use technology in the classroom, the quantitative items from the instrument are listed in a cross tabulation in Table B31 in Appendix B. For the first Support question directly related to school or district leadership, teachers (77.3\%), administrators (78.0\%), and technology support personnel (76.9\%) were overwhelmingly positive about the support for technology exhibited by the leadership of the school. In a similar way, teachers $(78.4 \%)$, and administrators $(83.6 \%)$ felt that teachers were supported by their peers in their work with technology while technology support personnel (65.4\%) felt slightly less that way and almost a third of them reporting "neither agree nor disagree" (30.8\%). Those who disagreed were in the small minority on this question among their peers, with teachers at $4.4 \%$, administrators at $5.5 \%$, and technology support personnel at $11.6 \%$. 
The widest discrepancies fell into the last support item surrounding teachers getting technology support for themselves or their students. The positive responses were significantly lower for teachers (49.1\%) and for administrators (56.2\%), and slightly higher for technology support staff (61.6\%). On the negative side, participants were more likely to select "disagree" or "strongly disagree" in much larger numbers, especially among the teachers $(33.5 \%)$. Administrators were also likely to rate it lower $(23.3 \%)$, and even technology support personnel implied (19.2\%) that it was difficult for staff to get support for issues that arises with either their or their student's technology support issues.

In the next chapter, I will discuss the major findings of the data analyses, detail implications for policy and practice around technology, leadership, and teacher selfefficacy, and posit further opportunities for research in this dynamic area of our educational practice. 


\section{CHAPTER 5 \\ DISCUSSION \& CONCLUSION \\ Background}

Schools are going through a challenging reorganization during a time of rapid change in the world around them. Technology is advancing out of its traditional work and home spaces and into the daily, personal spaces of every individual's life. Meanwhile, schools are struggling to find ways to incorporate inside school what is increasingly becoming part of every individual's day outside of school. While schools are working through the details of that balance, our need to educate our own workforce and to transition our systems looms large. Without understanding the needs of staff in terms of their learning styles and the kinds of professional development they desire, and without the context of why closing the opportunity gap for our most underserved students must be a priority, traditional public schools will continue to become less relevant in the fastpaced time in which we find ourselves. For school and district leaders, the pressure is intense to reimagine how schools ought to look and to operate as they prepare students for the $22^{\text {nd }}$ Century. With a workforce that tends to stay in a career that spans decades (if they continue past their first few years) the need to understand the influence of leadership practices and the constant training and retraining of school professionals is paramount.

It is within this context that this study came to be. The purpose of this study was to explore the effects of leadership practice upon the successful integration of technology in the learning environment. The study did not seek to judge the worthiness of the activities or of the role of technology in a student's school experience per se, but it did 
consider that as technology had more of an impact upon life outside of school, certain equity issues will arise in terms of opportunity if not paid their due attention. Because retraining a workforce is one of the most challenging tasks facing school and district leaders, a second purpose of this study was to understand how teachers feel about their own abilities and comfort with technology, how teachers see their own training needs, and how theories of learning impact the planning and delivery of professional development activities.

\section{Discussion}

\section{Differences of Opinion About Professional Development}

When reviewing the responses from the different personnel groups there is a clear difference of opinion as to the relevance, adequacy, and structure of professional development. Although as a group, all staff agreed that more professional development for integrating technology is needed, there are different viewpoints as to its focus and value. Technology support staff were the most critical of the adequacy of the professional development, while teachers regularly reported that the training activities do not have a direct impact on their teaching. Also, teachers reported one of their obstacles to using technology more effectively with students was the lack of professional development available. Moreover, administrators mentioned this lack of professional development for teachers twice as often as teachers did, and technology staff more than three times as often. 
As for technology-specific professional development, teachers voiced their discontent the loudest about its relevancy to their daily work with students. The top priority for teachers as a whole was professional development that had an immediate and direct impact on their work in the classroom and with students. Further, the results of this study indicate that as teachers remain in the profession longer, their needs change over time. This has been referenced in prior research studies (Huberman, 1989; Guskey, 1986) and was reported in a similar way by participants in this study. Early-career teachers (with 1 to 6 years of teaching experience) felt it was most important to get access or exposure to new resources, tools, or strategies and that professional development should focus on hands-on and real-world activities. Mid- to late-career teachers (from 7 to 30 years) requested more collaboration time to talk with peers and share ideas, time to practice what they learn, and time to plan with the technologies they learn about in the professional development sessions.

Interestingly, staff who work in buildings with higher numbers of economically disadvantaged students rate professional development higher than those whose percentages are lower. Whether that speaks to the fact that teachers in underserved environments are more cognizant of the needs of high-quality training in order to reach their students better, or that they are simply undertrained in providing an opportunity for students to close the opportunity gap, is an exciting area for future research.

Keeping these aspects of perception in mind when designing professional development should be in the forefront of the planning stages of the activities. After direct application to the classroom or student learning, what teachers really requested 
most was the gift of time. Not necessarily unstructured time, but dedicated time to collaborating with peers, sharing what they know, and practicing what they learn. What administrators, and in many cases, technology staff, believe teachers want or need for professional development is not necessarily what teachers believe is necessary or useful. This is an important reminder for leaders to consider both the experience levels of teachers as well as their desires about the styles and structures of the professional development activities.

\section{Teacher Knowledge and Learning}

This study used two frameworks to help structure the survey instrument and to better understand what adults know how to do and how they sense their own learning needs and styles. Specifically on the technology knowledge side, the Technological Pedagogical Content Knowledge (TPACK) framework (Mishra and Koehler, 2006) was the primary way to probe teachers about their depth of knowledge in several aspects of the model and also to ask how other personnel perceived teacher knowledge. In general, teachers rated their own knowledge of technology, the ability to choose the right technology, and/or how to teach using technology higher than the administrators or technology support staff rated them. This discrepancy may help illuminate the disconnect between the kind of professional development teachers receive from the district or school and the type they actually need.

Other factors affected the teachers' TPACK scores as well, such as the socioeconomic level of their students, the teachers' age or gender, and the frequency with 
which they used technology with students. According to the results of this study, older teachers increasingly feel less confident in their ability to use technology. This mirrors other studies (Koh and Chai, 2011; Lin, et al., 2013) on the role of age in TPACK selfassessments. This may be due to the fact that they have grown up in a time before many of the technologies used in schools were even imagined, or it could be that with more life experience, they have a better understanding of what they do not know. While the former seems more likely, the researcher believes that this is a possible avenue of further research with far-reaching ramifications for professional development. If, for instance, it is discovered that older teachers have a better grasp on their depth of knowledge than they report, professional development will have to be more targeted to reach their specific pedagogical needs. If, on the other hand, it is simply a matter of teachers needing basic technology training, leaders would need to adjust those sessions accordingly.

Female teachers were also more critical as a group of their own TPACK levels of knowledge than male teachers. Again, this could be a perception issue, where females either have a better understanding of what they know and do not know, or that male teachers simply report a higher opinion of their depth of experience and knowledge of using technology with students as a general rule. While some research into this phenomenon has taken place (Erdogan \& Sahin, 2010; Jordan, 2013), more dedicated study into the role of gender and comfort with technology and the TPACK selfassessment is needed to better understand these results.

Other factors affecting the TPACK self-assessment, including the frequency of technology usage and higher numbers of economically disadvantaged students, have also 
been discovered by this study. Unsurprisingly, when teachers use technology more frequently, they report higher confidence in their TPACK scores. However, a curious result is that teachers who work with more students from a lower socio-economic background report that their knowledge and skill with technology is higher than those who work with students of a higher economic status. This result is another opportunity for study into the effects of school contexts (i.e., economically disadvantaged students, higher numbers of minority students, etc.) upon teacher knowledge and comfort with integrated technologies.

On the teacher learning side, this study used the Cultural Historical Activity Theory (CHAT) as the framework for understanding how teachers learn to use technology tools. Overall, there were significant differences in the ways that teachers saw themselves as learners and how others perceived them. In four of the six variables tested, teachers disagreed with the assessment that both administrators and technology support personnel made about teachers' learning style. Understanding how teachers learn and what kinds of activities are most efficacious for teachers is key to designing professional development opportunities.

When asked about whether they prefer to try out different techniques with students, or look for effective models of use, or learn by researching best practices before they begin, or if they use technology in a similar way to their peers or leaders, teachers generally answered in the negative. Administrators and technology support staff, on the other hand, regularly disagreed with the majority of those responses related to teacher learning styles. 
Based upon the results of this study, it is clear that administrators and technology support staff are not aware of the kinds of activities and experiences teachers require or desire in order to improve their practice using technology more effectively with students. This is a major finding, and one that needs to be better understood and more deeply researched so that professional development design can provide what teachers need in order to be better learners and use technology more effectively for teaching.

In one area of agreement, when asked if teachers learn by being actively engaged in the learning task, all groups (teachers, administrators, and technology staff) agreed that it was a good method for them to learn about technology and how to use it with students. This study's results reflect the core idea of CHAT as described by other researchers (Engeström, 2001; Feldman and Weiss, 2010; Koszalka and Wu, 2004) in that learning happens through activity (with the tools) to produce the outcomes. Additionally, in the qualitative responses for professional development, teachers repeatedly asked for time to collaborate, talk, and share ideas with peers. As one of the key aspects of CHAT, leaders should be aware of the expressed need for both structured and unstructured "community" collaboration time and its importance in learning.

Another key tenet of the CHAT model is the "division of labor" which includes support from peers, leaders, and other staff. Teachers (and administrators) reported that they have high levels of support from both their school leaders as well as from their peers. Conversely, although about half of teachers report technology support as helpful to their work, one-third of teachers rate technology support very low. Interestingly, about one-fifth of technology staff also rate the ability of teachers to get technology support as 
low. Since there is a struggle between some of the groups that make up the important “division of labor" part of the CHAT model for teacher learning, concentrated work must be done in order to keep some balance in the model and to allow teachers to flourish as learners. Efforts by teachers to acquire new technology skills may be helped by peer and leadership support only to be hampered again by a lack of support for technology problems that arise for which they cannot get help.

\section{Perceptions of Teacher Use of Technology}

When it comes to the ways teachers employ technology in their instructional day and the ways in which they use it with students, there are again perceptual differences among the personnel groups in this study. In general, the trend to use technology as a reward for completing other work was low, however, as the frequency of technology use increases, so does the propensity to use it as a reward. Additionally, administrators and technology support staff believe that teachers use it as a reward more than teachers report doing so. When asked about using technology to teach about technology tools themselves, using technology for state or local assessments, or its use as a remediation tool, administrators and technology staff implied teachers were using it far more for those activities than teachers reported doing so. Teachers also indicated that they use technology to challenge the brightest students less than administrators believe they do. The models of technology use (and its frequency of access) for students is important, as previous research has indicated that students from lower socio-economic backgrounds are affected by access and usage models differently than their higher SES peers (Cummins, 
Brown, and Sayers, 2007; Warschauer, Knobel, and Stone, 2004). Prior research has determined that perfunctory technology use such as for assessment, learning about technology itself, or its use as a remediation tool can limit students' ability to use it for other activities without dedicated practice and high levels of access (Attwell and Battle, 1999; Selwyn, 2003; Warschauer, Knobel, and Stone, 2004)

In several use cases, as the frequency of technology use increased (daily, weekly, etc.), so did the tendency to use it more for each specified activity. This includes its use as a remediation tool, as a reward for completing other work, challenging the brightest students, and significantly changing the nature of learning projects. Additionally, as the number of available technology devices per student increased, so did its use in challenging the brightest students and in changing the nature of learning tasks. Interestingly, the opposite of that was true for state and local assessments: as more devices were available, staff reported it used less for testing rather than more. This is a major finding, as it suggests that only with more time available with technology for students is it possible to move the classroom technology activities beyond test preparation and completion, which tend to require a significant amount of the available technology time during the assessment window, and into more significant and pedagogically sound applications of the resource.

Areas of agreement among the three personnel groups include using technology to support a student's academic work, as a supplementary or enrichment tool, and for motivating student interest or engagement in school and schoolwork. Those three areas trended toward the affirmative, indicating that teachers, administrators, and technology 
support staff agree that those are regular uses of technology in their classrooms, school, and districts.

As the amount of time students are using technology and the amount of available devices increases, all staff must be mindful of its use and its place in the educational setting in order to narrow the opportunity gap between students of different economic, social, and cultural backgrounds.

\section{Factors Affecting the Use of Technology}

Several additional factors that could affect teacher use of technology were tested using the data collected via the instrument. As the amount of devices available for students increases, predictably so does the frequency of technology use in the educational setting. Furthermore, when teachers feel they have a choice of which technologies to employ and that it is their own choice to use technology with students, the frequency of use also increases. Interestingly, teachers implied they have more choice than either administrators or technology staff report they do.

The most difficult obstacles and challenges staff face in attempting to use technology with students include time constraints and a lack of access to devices. Teachers and technology staff also report costs or funding of technology as one of their top obstacles, while administrators do not. The importance of time (or lack thereof) increases over time for teachers as they advance across their career. This reflects the statements they made regarding professional development and the need for time to work with what they learn. When the challenge factors were grouped as one and tested against 
other factors, the regression models discovered that as teachers age, the challenges become more difficult to overcome. Also, as the percentage of non-White students increases, staff report that challenges are harder to work through. Curiously, participants reported that as the number of economically disadvantaged students increases, the perception of those same challenges decreases. That may be because teachers already deal with a number of other challenges when working with low SES students, the challenges in using technology rate relatively low on their professional scale. This is an interesting avenue for further research as there were more than half of this study's participants $(52.4 \%)$ who work in schools and districts with more than $50 \%$ of their students participating in the Federal free and reduced lunch program. Knowing why they determine certain barriers, obstacles, or challenges as less difficult to overcome than those who work with higher SES students could have wide applications to professional development and school improvement efforts.

\section{Perceptions of Technology's Advantages and Disadvantages}

There was general agreement among the administrators, teachers, and technology staff when it came to the advantages of using technology with students. Accessing up-todate information, supporting student academics, and individualization and/or personalization of the learning environment mentioned by all personnel groups among the very top responses. Only technology staff included "building future skills or preparing for the future" higher than all of those, and teachers and administrators mentioned the same advantage directly after the others listed above. After these top responses, in which 
there was general agreement, different advantages were named by each of the personnel groups in very different orders. For teachers, their next priority advantage was its use as a "student practice tool," while administrators saw technology being used as a "communication and collaboration tool." Technology support staff indicated that its use for "student project creation and presentation" was their next highest advantageous use of technology for students.

Administrators and teachers reported a lack of funding or available technologies as their top disadvantage and a lack of technology support or technology not in working order as their second-highest disadvantage in using technology with students. Interestingly, technology support staff reported both of those areas very low, and instead concentrated on technology not being used effectively for teaching and learning as their most pressing disadvantage. For participants between 20 and 24 years of age or 65 years and older, technology support was not a concern. For all three respondent groups, distractions, inappropriate use and social media were in the top three disadvantages for technology integration. In fact, for the oldest participant group in the study, only two disadvantages were named: availability of technology devices and distractions or social media.

Overall, technology use in the educational environment was described as a great support tool for information access, student academic support, and for individualization and personalization. Frustrations were reported in the availability of devices for student use, old or non-functioning devices, and the inevitable distractions of inappropriate use and attractions of social media. This balance will not be foreign to school staff, but their 
presence is part of the ongoing work leaders must be aware of in order to create successful opportunities for the implementation of technology resources for students.

\section{Opportunities for Further Study}

Several implications for further research were surfaced by this study. Each implication on its own is a significant avenue for deeper examination of what can make a technology initiative or implementation more effective and, when aggregated, may paint a clearer picture of what practices encourage a successful technology integration cycle. Those areas of research include the following:

- Staff who work in buildings with higher numbers of economically disadvantaged students rated professional development higher than those whose percentages are lower. Is this due to teachers in underserved environments being more cognizant of the needs of high-quality training in order to reach their students better, or do they believe they are undertrained in providing an opportunity for students to close the opportunity gap?

- There were significant differences between what administrators and technology staff believe teachers want or need for professional development and what teachers themselves believe is necessary or useful. What are the most efficacious professional development opportunities and activities for teachers that lead to more successful technology implementations? 
- Age and gender factors were shown to have a statistically significant impact on teacher TPACK perceptions. How impactful are these two factors on teacher self-perception and their use of technology with students?

- Teachers who work with more students from a lower socio-economic background reported that their knowledge and skill with technology is higher than those who work with students of a higher economic status. How do school contexts (i.e., economically disadvantaged students, higher numbers of minority students, etc.) impact teacher knowledge and comfort with classroom-integrated technologies?

These opportunities for further research are exciting avenues for further study into the "why" and "how" of powerful leadership practices for successful technology implementations.

\section{Putting It All Together}

The purpose of this study was to understand a small portion of the myriad factors that affect school change and in this specific case, the challenges of integrating technology into the learning environment. It is clear from the results of this study that there is a disconnect between what leaders believe teachers need and want in terms of professional development and what teachers state they need and want. Finding the right balance between training and professional development that meets the needs of both teachers and of the overall school (or district) mission and vision will be a monumental 
leadership challenge. Based upon the responses to the qualitative portion of the instrument, it is clear that the negative comments about professional development, its structure, and its methodology are not limited to technology-specific sessions and activities. This portion of the study's results may have more far-reaching impact upon how people in leadership positions decide to form and to provide professional development for a whole host of topics for maximum impact in the classroom.

Moreover, there is a striking difference of the perception of technological capacity and ability among the different personnel groups included in this study. Teachers believed themselves to be more capable with technology resources than either leaders or technology support staff did. Teasing out from where this difference of opinion comes must be part of a shared leadership model wherein teachers and school and district leaders can engage in open dialogue to better understand where teachers are and where schools want them to be when it comes to technology opportunities for students beyond testing and remediation activities. If different models of technology use are needed in order for schools to help close the opportunity gap for students, then an understanding of what teachers already know and how teachers engage in learning new pedagogical practices will be necessary.

Finally, it is clear from both the qualitative and quantitative data in this study that some obstacles and/or barriers must be overcome before schools can continue to move forward. Several of the barriers this researcher believed would have an impact upon technology integration, including filtering policies, pressure to "teach to the test," or a general lack of support by leadership, were not factors that affected teacher use of 
technology with students at all. In fact, it was the simpler, more obvious things that created the most angst and frustration among the study's participants: lack of access to devices, outdated or non-functional technology, lack of time to practice and plan, and support for technology issues when they arise for staff or students. As leaders toil to create better professional development opportunities based upon what teachers report they need and how they need it to be offered, they must also find budget opportunities to engage in sustainable technology fleet management to keep devices up to date and to provide the technology support necessary required to maintain that fleet.

\section{Successful Technology Implementation Cycle (STIC): A Theory of Action}

By combining the results of the survey instrument and the review of literature, the researcher has developed a theory for successful technology implementations. The theory of action to ensuring a successful and scalable technology implementation at the school or district level has five critical aspects: mission and vision, goals, contexts, resource commitment, and evaluation and adjustment. These can be seen as a cycle as in Figure 6 below. 


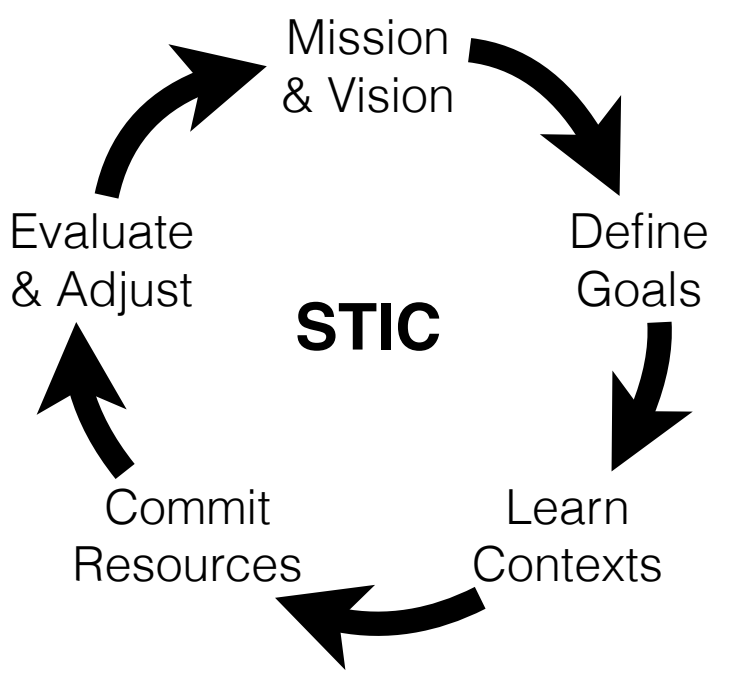

Successful Technology Implementation Cycle

Figure 6. Successful Technology Implementation Cycle (STIC).

The school or district's mission and vision must provide direction for all aspects of the implementation, as they are described as critical organizational success factors in both the literature (Cordeiro \& Cunningham, 2013; Deal \& Peterson, 2009; Kotter, 1996; Morgan, 1997), and by the survey participants in this study. From the organization's mission and vision, a set of goals should be developed in order to provide short and long-term milestones (Kotter, 1996) which can be measured in the evaluation step of the implementation cycle to determine success relative to the mission and vision.

In order to understand the ways teachers learn, what they know, and what barriers they perceive, schools or districts need tools (such as TPACK) and theoretical 
frameworks (such as CHAT) to learn the contexts in which the implementation's adult learning requirements will take place so that professional development can best serve those needs. Gathering data about what teachers perceive their knowledge and skill level with technology, pedagogy and content by using Koehler and Mishra's TPACK framework can help school and district leaders understand what topics are required for professional development. However, in order to provide the right kind of learning opportunities for teachers, leaders must also understand the school contexts (technology supports, peer supports, perceived barriers, student demographics, technology resource availability, etc.) for which the professional development is provided. Cultural Historical Activity Theory provides a framework for describing those contexts and a way to understand how they influence teacher learning.

After learning about the contexts in which teachers perceive themselves teaching and attempting to implement technology successfully within their curriculum, leaders must be willing to commit resources to the implementation. In the review of literature, the importance of properly budgeting for both capital and non-capital resources for the long-term success of an implementation cycle (technology or otherwise) were described as paramount (Cordeiro \& Cunningham, 2013; Deal \& Peterson, 2009; Marzano, Waters $\&$ McNulty, 2005). The participants in the study also revealed that resource commitment was a critical barrier to success in procuring and supporting technology usage with students. The resource commitment should reflect the elements of long-term device fleet management, instructional and technical supports available, and the reduction of barriers for quality instructional utilization. 
Finally, in order to measure the success of the implementation, the organization must be ready to evaluate the process and adjust as necessary if the results of the evaluation indicate the process is not meeting its specified goals or is not in line with the district or school's mission and vision. Evaluation can include follow up TPACK measurement, feedback from professional development sessions, or checking alignment with the vision and goals.

The STIC theory describes the entire process as a cycle that is constantly renewing itself. This is similar to CHAT, in which learning is described as a constant process and not a singular event (Engeström, 2001; Feldman \& Weiss, 2010). Each part of the STIC theory is dependent upon each of the others. That is, without a mission and/or vision, goals for the implementation cannot be developed. Without long and shortterm goals, the contexts and the needs of teachers cannot be fully understood nor can proper professional development be provided. If leaders do not commit resources, including devices, infrastructure, and personnel, the implementation has a far smaller chance of success. Without an evaluation of the implementation's successes and challenges, adjustments cannot be made in order to reach the stated goals nor stay focused on the core mission of the school and district.

The proposed Successful Technology Implementation Cycle (STIC) theory can be used as an implementation framework for planning a new technology initiative or for adjusting one currently in process. The researcher plans to develop the theory further in order to help districts collect the contextual information they need in order to plan and implement technology successfully in their respective districts. 
This study addressed the very important issue of the effective implementation of technology in schools. As our world changes more rapidly and schools rush to implement technology initiatives, this study points to the need to understand the specific needs of teachers in our schools. By spending time to better understand the learning needs of our teacher professionals, providing opportunities for them to share what they know and to grow together, and by providing more students the chance to use technological resources in a truly powerful way, we can help students access and make sense of the informationrich world in which they live and become more engaged and empowered citizens. 


\section{References}

Abbitt, J. T. (2011). An Investigation of the relationship between self-efficacy beliefs about technology integration and technological pedagogical content knowledge (TPACK) among preservice teachers. Journal of Digital Learning in Teacher Education, 27(4), 134-143. Available at:

http://www.eric.ed.gov/PDFS/EJ936541.pdf

Anderson, R. E., \& Dexter, S. L. (2000). School technology leadership: Incidence and impact. Center for Research on Information Technology and Organizations, University of California, Irvine. Retrieved February 4, 2013 from http://escholarship.org/uc/item/76s142fc

Attwell, P. \& Battle, J. (1999). Home computers and school performance. The Information Society, 15, 1-10. doi: 10.1080/019722499128628

Attwell, P. (2001). The first and second digital divides. Sociology of Education, 74(July), 252-259. Available online: http://www.jstor.org/stable/2673277

Becker, H. J. (1992). Top down versus grass roots decision making about computer acquisition and use in American schools. Center for Social Organization of Schools Report, Johns Hopkins University.

Becker, H. J. (2000). How exemplary computer-using teachers differ from other teachers: Implications for realizing the potential of computers in schools. Contemporary Issues in Technology and Teacher Education, 1(2), 274-293. 
Retrieved from

http://www.citejournal.org.proxy.lib.pdx.edu/vol1/iss2/seminal/article1.htm

Borg, W. R. \& Gall, M. D. (1983). Educational research: An introduction, $4^{\text {th }}$ Ed. New York: Longman

Chai, C. S., Koh, J. H. L., Tsai, C.-C., \& Tan, L. L. W. (2011). Modeling primary school pre-service teachers' Technological Pedagogical Content Knowledge (TPACK) for meaningful learning with information and communication technology (ICT). Computers \& Education, 57(1), 1184-1193. doi:10.1016/j.compedu.2011.01.007

Clarke, D., \& Hollingsworth, H. (2002). Elaborating a model of teacher professional growth. Teaching and Teacher Education, 18(8), 947-967.

Collins, A. (1991). The role of computer technology in restructuring schools. Phi Delta Kappan, 73(1), 28-36. Retrieved March 17, 2013 from: http://www.project2061.org/publications/designs/online/pdfs/reprints/4_collin.pdf

Collins, A., \& Halverson, R. (2010). The second educational revolution: rethinking education in the age of technology. Journal of Computer Assisted Learning, 26(1), 18-27. doi:10.1111/j.1365-2729.2009.00339.x

Cope, C., \& Ward, P. (2002). Integrating learning technology into classrooms: The importance of teachers' perceptions. Educational Technology \& Society, 5(1), 67-74. Retrieved February 4, 2013 from http://www.ifets.info.proxy.lib.pdx.edu/journals/5_1/cope.html Cordeiro, P. A. \& Cunningham, W. G. (2013). Educational Leadership: A Bridge 
To Improved Practice, 5th Ed. Pearson Education.

Creswell, J. W., \& Clark, V. L. P. (2007). Designing and conducting mixed methods research. Thousand Oaks, CA: Sage publications.

Culp, K. M., Honey, M., \& Mandinach, E. (2005). A retrospective on twenty years of education technology policy. Journal of Educational Computing Research, 32(3), 279-307. doi: 10.2190/7W71-QVT2-PAP2-UDX7

Cummins, J., Brown, K., \& Sayers, D. (2007). Literacy, technology, and diversity. Teaching for success in changing times. Pearson Education.

Daniels, H. (2004). Cultural historical activity theory and professional learning. International Journal of Disability, Development and Education, 51(2), 185-200. doi:10.1080/10349120410001687391

Danielson, C., \& McGreal, T. L. (2000). Teacher evaluation to enhance professional practice. Alexandria, VA: Association for Supervision and Curriculum Development.

Danielson, C. (2007). Enhancing professional practice: A framework for teaching. Alexandria, VA: Association for Supervision and Curriculum Development. Davies, P. M. (2010). On school educational technology leadership. Management in education 24(2). doi: 10.1177/0892020610363089

Deal, T. E., \& Peterson, K. D. (2009). Shaping school culture: Pitfalls, paradoxes, and promises. San Francisco: Jossey-Bass.

Dewey, J. (1938). Experience and education. New York: The Macmillan company. Downey, C. J., Poston Jr, W. K., Steffy, B. E., English, F. W., \& Frase, L. E. (Eds.). 
(2004). The three-minute classroom walk-through: Changing school supervisory practice one teacher at a time. Corwin Press.

Engeström, Y. (2000). Activity theory as a framework for analyzing and redesigning work. Ergonomics, 43(7), 960-974. doi:10.1080/001401300409143

Engeström, Y. (2001). Expansive Learning at Work: Toward an activity theoretical reconceptualization. Journal of Education and Work, 14(1), 133-156. doi:10.1080/13639080020028747

Erdogan, A., \& Sahin, I. (2010). Relationship between math teacher candidates' Technological Pedagogical And Content Knowledge (TPACK) and achievement levels. Procedia-Social and Behavioral Sciences, 2(2), 2707-2711.

Ertmer, P. A. (1999). Addressing first-and second-order barriers to change: Strategies for technology integration. Educational Technology Research and Development, 47(4), 47-61. Retrieved February 22, 2013 from http://www.jstor.org/stable/30221096

Ertmer, P. A., Ottenbreit-Leftwich, A. T., Sadik, O., Sendurur, E., \& Sendurur, P. (2012). Teacher beliefs and technology integration practices: A critical relationship. Computers \& Education, 59(2), 423-435.

Feldman, A., \& Weiss, T. (2010). Understanding change in teachers' ways of being through collaborative action research: a cultural-historical activity theory analysis. Educational Action Research, 18(1), 29-55. doi:10.1080/09650790903484517

Frank, K. A., Zhao, Y., \& Borman, K. (2004). Social capital and the diffusion of 
innovations within organizations: The case of computer technology in schools. Sociology of Education, 77(2), 148-171. doi: 10.1177/003804070407700203

Fraenkel, J. R. \& Wallen, N. E. (1996). How to design and evaluate research in education, 3rd Ed. McGraw-Hill.

Frechette, J. D. (2002). Developing media literacy in cyberspace : Pedagogy and critical learning for the twenty-first-century classroom. Westport, Conn.: Praeger.

Fullan, M. (2010). Motion leadership: The skinny on becoming change savvy. Thousand Oaks: Corwin.

Glazer, E. M., \& Hannafin, M. J. (2006). The collaborative apprenticeship model: Situated professional development within school settings. Teaching and Teacher Education, 22(2), 179-193. doi:10.1016/j.tate.2005.09.004

Goode, J. (2010). The digital identity divide: how technology knowledge impacts college students. New Media \& Society, 12(3), 497-513. doi: 10.1177/1461444809343560

Graham, M. (2011). Time machines and virtual portals The spatialities of the digital divide. Progress in Development Studies, 11(3), 211-227. doi:10.1177/146499341001100303

Guskey, T. (1986). Staff Development and the Process of Teacher Change. Educational Researcher, 15(5), 5-12. doi:10.3102/0013189X015005005

Guskey, T. (2002). Professional Development and Teacher Change. Teachers and Teaching, 8(3), 381-391. doi:10.1080/135406002100000512

Halverson, R. \& Shapiro, R. B. (2013). Technologies for educators and technologies for learners: How information technologies are (and should be) changing schools. In 
S. Rutledge \& D. Anagnostopoulos (Eds.) The Infrastructure of Accountability. Harvard Education Press.

Hattie, J. (2009). Visible learning: A synthesis of over 800 meta-analyses relating to achievement. Routledge.

Heifetz, R. A., \& Laurie, D. L. (1997). The work of leadership. Harvard Business Review, 75, 124-134. Retrieved January 6, 2013 from http://mowgli.org.uk/wpcontent/uploads/2011/02/laurie-jump-off-balcony-leadership.pdf

Huberman, M. (1989). The professional life cycle of teachers. The Teachers College Record, 91(1), 31-57.

Inan, F. A., \& Lowther, D. L. (2010). Laptops in the K-12 classrooms: Exploring factors impacting instructional use. Computers \& Education, 55(3), 937-944. doi:10.1016/j.compedu.2010.04.004

Jackson, L. A., Zhao, Y., Kolenic III, A., Fitzgerald, H. E., Harold, R., \& Von Eye, A. (2008). Race, gender, and information technology use: the new digital divide. CyberPsychology \& Behavior, 11(4), 437-442. doi: 10.1089/cpb.2007.0157

Jordan, K. (2013). The influence of gender on beginning teachers' measurement of TPACK knowledge. Australian Educational Computing, 28(2).

Jonassen, D., \& Rohrer-Murphy, L. (1999). Activity theory as a framework for designing constructivist learning environments. Educational Technology Research and Development, 47(1), 61-79.

Judge, S., Puckett, K., \& Cabuk, B. (2004). Digital equity: New findings from the early 
childhood longitudinal study. Journal of Research on Technology in Education, 36, 383-396. Retrieved March 15, 2013 from: http://edinsanity.com/wpcontent/uploads/2008/02/digital-equity_ecls.pdf

Jurasaite-Harbison, E., \& Rex, L. A. (2005). Taking on a researcher's identity: Teacher learning in and through research participation. Linguistics and Education, 16(4), 425-454. doi:10.1016/j.linged.2006.05.004

Keengwe, J., Pearson, D., \& Smart, K. (2009). Technology Integration: Mobile devices (iPods), constructivist pedagogy, and student learning. AACE Journal, 17(4), $333-346$.

Kim, C., Kim, M. K., Lee, C., Spector, J. M., \& DeMeester, K. (2013). Teacher beliefs and technology integration. Teaching and Teacher Education, 29(C), 76-85. doi:10.1016/j.tate.2012.08.005

Koehler, M., \& Mishra, P. (2009). What is Technological Pedagogical Content Knowledge (TPACK)? Contemporary Issues in Technology and Teacher Education, 9(1), 60-70.

Kotter, J. P. (1996). Leading Change. Boston: Harvard Business School Press.

Krashen, S. D. (1989). We acquire vocabulary and spelling by reading: Additional evidence for the input hypothesis. The Modern Language Journal, 73, 440-464. doi: $10.2307 / 326879$

Krashen, S. D. (1995). School Libraries, Public Libraries, and the NAEP Reading Scores. School Library Media Quarterly, 23(4), 235-237. Retreived January 9, 2013 from http://www.eric.ed.gov/ERICWebPortal/detail?accno=EJ510341 
Krashen, S. D. (1997). Bridging inequity with books. [Electronic version]. Educational Leadership, 55, 18-22. Retrieved February 24, 2013 from http://go.galegroup.com.proxy.lib.pdx.edu/ps/i.do?id=GALE\%7CA20445484\&v= $2.1 \& \mathrm{u}=\mathrm{s} 1185784 \& \mathrm{it}=\mathrm{r} \& \mathrm{p}=\mathrm{PPPM} \& \mathrm{sw}=\mathrm{w}$

Kress, G. R. (2003). Literacy in the new media age. New York: Routledge.

Land, S., \& Greene, B. (2000). Project-based learning with the World Wide Web: A qualitative study of resource integration. Educational Technology Research and Development, 48(1), 45-66.

Lecklider, D., Britten, J. S., Clausen, J. M., \& Muncie, I. N. (2009). Principals priority for technology as an indicator of observed use in schools. American Association of School Administrators Journal of Scholarship and Practice 5(4), 27-33. Retrieved January 6th, 2013, from https://members.aasa.org/uploadedFiles/Publications/Journals/ AASA_Journal_of_Scholarship_and_Practice/Winter09FINAL.pdf\#page=27

Lievrouw, L. A., \& Farb, S. E. (2005). Information and equity. Annual review of information science and technology, 37(1), 499-540. doi:

10.1002/aris. 1440370112

Lin, T. C., Tsai, C. C., Chai, C. S., \& Lee, M. H. (2013). Identifying science teachers' perceptions of technological pedagogical and content knowledge (TPACK). Journal of Science Education and Technology, 22(3), 325-336. doi: $10.1007 / \mathrm{s} 10956-012-9396-6$

Lunenburg, F. C., \& Irby, B. J. (2008). Writing a successful thesis or dissertation: Tips 
and strategies for students in the social and behavioral sciences. Corwin Press.

Madden, M., Lenhart, A., Duggan, M., Cortesi, S., \& Gasser, U. (2013). Teens and Technology 2013, 1-19. Retrieved March 14, 2013 from http://www.pewinternet.org/ /media//Files/Reports/2013/PIP_TeensandTechnolo gy2013.pdf

Margerum-Leys, J. (2004). The nature and sharing of teacher knowledge of technology in a student teacher/mentor teacher pair. Journal of Teacher Education, 55(5), 421437. doi:10.1177/0022487104269858

Marshall, K. (2009). Rethinking teacher supervision and evaluation: How to work smart, build collaboration, and close the achievement gap. Jossey-Bass.

Marzano, R. J., Waters, T., \& McNulty, B. A. (2005). School leadership that works: From research to results. Alexandria, VA: Association for Supervision and Curriculum.

Marzano, R. J. (2007). The art and science of teaching: A comprehensive framework for effective instruction. Alexandria, VA: Association for Supervision and Curriculum Development.

Marzano, R. J., Frontier, T., \& Livingston, D. (2011). Effective supervision: Supporting the art and science of teaching. Alexandria, VA: Association for Supervision and Curriculum Development.

Miles, M. B., \& Huberman, A. M. (1994). Qualitative data analysis: An expanded sourcebook. Thousand Oaks, CA: Sage publications.

Mishra, P., \& Koehler, M. (2006). Technological pedagogical content knowledge: A 
framework for teacher knowledge. The Teachers College Record, 108(6), 10171054. doi:10.1111/j.1467-9620.2006.00684.X

Morgan, D. L. (1998). Practical strategies for combining qualitative and quantitative methods: Applications to health research. Qualitative health research, 8(3), 362376.

Morgan, D.L. (2014). Integrating qualitative and quantitative methods: A pragmatic approach. Thousand Oaks, CA: Sage Publications.

Morgan, G. (1997). Images of Organization. Thousand Oaks, CA: Sage Publications.

Mueller, J., Wood, E., Willoughby, T., Ross, C., \& Specht, J. (2008). Identifying discriminating variables between teachers who fully integrate computers and teachers with limited integration. Computers \& Education, 51(4), 1523-1537. doi:10.1016/j.compedu.2008.02.003

Nardi, B. A. (1996). Studying context: A comparison of activity theory, situated action models, and distributed cognition. In Nardi, B.A. (Ed.) Context and consciousness: Activity theory and human-computer interaction, 69-102. Cambridge, MA: The MIT Press.

National Association of State Boards of Education. (2012). Born in another time: Ensuring educational technology meets the needs of students today and tomorrow. The report of the NASBE study group on the role of technology in schools and communities. Retrieved March 4, 2013 from: http://blogs.edweek.org/edweek/DigitalEducation/NASBE.pdf National Center for Education Statistics (2014a). Local education agency (school district) 
locale code files, accessed October 12, 2014 at

https://nces.ed.gov/ccd/CCDLocaleCodeDistrict.asp

National Center for Education Statistics (2014b). Documentation to the NCES common core of data local education agency locale code file: School year 2005-06, accessed October 12, 2014 at https://nces.ed.gov/ccd/pdf/al051agen.pdf

Norris, P. (2003). Digital divide: Civic engagement, information poverty, and the Internet worldwide (Vol. 40). Cambridge: Cambridge University Press. doi: $10.1080 / 0810902032000118249$

Oregon Department of Education (2013). 2011-2012 Students eligible for free and reduced lunch (generated report). Reports: Table of contents. Generated online March 17, 2013 at http://www.ode.state.or.us/data/reports/toc.aspx

Oregon Department of Education (2014a). District estimates \& warrants, accessed February 21, 2014 at http://www.ode.state.or.us/search/results/?id=344

Oregon Department of Education (2014b). District media file, email attachment from Deputy Superintendent of Public Instruction, received October 7, 2014.

Oregon Department of Education (2015). Certificated Staff Summary, 2005-2006 (generated report). Generated online on May 11, 2015 at http://www.ode.state.or.us/sfda/reports/r0072rpt.asp

Oregon Education Investment Board (2014). 2014 Oregon Minority Teacher Act Status Report, accessed August 12, 2014 at http://education.oregon.gov/Documents/archive/Minority_Teacher_Report_FNL_ bkmarked.pdf 
Oregon Health Sciences University (2012). The next 5 years. Retrieved February 21, 2014 from: http://www.ohsu.edu/xd/about/vision/upload/TheNextFiveYears_full.pdf Ottenbreit-Leftwich, A. T., Glazewski, K. D., Newby, T. J., \& Ertmer, P. A. (2010). Teacher value beliefs associated with using technology: Addressing professional and student needs. Computers \& Education, 55(3), 1321-1335. doi:10.1016/j.compedu.2010.06.002

Partnership for 21st Century Skills (2013). P21 Framework Definitions. Retrieved January 13, 2012 from http://www.p21.org/storage/documents/P21_Framework_Definitions.pdf Podsakoff, P. M. (1986). Self-Reports in Organizational Research: Problems and Prospects. Journal of Management, 12(4), 531-544. doi: $10.1177 / 014920638601200408$

Parrett, W. H. \& Budge, K. M. (2012). Turning high-poverty schools into highperforming schools. Alexandria: ASCD.

Prensky, M. (2008). Turning on the lights. Educational Leadership, 65(6), 40-45. Retrieved February 9, 2013 from http://www.wit.edu/td/facultymentor/articles/ turningonthelights.pdf

Purcell, K., Heaps, A., Buchanan, J., \& Friedrich, L. (2013). How teachers are using technology at home and in their classrooms. Washington, DC: Pew Research Center's Internet \& American Life Project. Accessed February 10, 2014 from 
http://www.pewinternet.org/ /media/Files/Reports/2013/PIP_TeachersandTechno logywithmethodology_PDF.pdf

Rathgen, E. (2006). In the voice of teachers: The promise and challenge of participating in classroom-based research for teachers' professional learning. Teaching and Teacher Education, 22(5), 580-591. doi:10.1016/j.tate.2006.01.004

Reeves, D. B. (2009). Leading change in your school: How to conquer myths, build commitment, and get results. Alexandria, VA: Association for Supervision and Curriculum Development.

Richter, D., Kunter, M., Klusmann, U., Lüdtke, O., \& Baumert, J. (2011). Professional development across the teaching career: Teachers' uptake of formal and informal learning opportunities. Teaching and Teacher Education, 27(1), 116-126. doi:10.1016/j.tate.2010.07.008

Rogoff, B., \& Wertsch, J. V. (1984). Children's learning in the "zone of proximal development". San Francisco: Jossey-Bass.

Ruiz-de-Velasco, J., Fix, M., \& Clewell, B. (2000). Overlooked and underserved: Immigrant students in US secondary schools. Washington, D.C.: Urban Institute. Retrieved April 14, 2013 from http://www.urban.org/publications/310022.html

Selwyn, N. (2003). 'Doing IT for the Kids': Re-examining children, computers and the 'Information Society'. Media, Culture \& Society, 25(3), 351-378. doi: $10.1177 / 0163443703025003004$

Schmidt, D. A., Baran, E., Thompson, A. D., Mishra, P., Koehler, M. J., \& Shin, T. S. 
(2009). Technological pedagogical content knowledge (TPACK): The development and validation of an assessment instrument for preservice teachers. Journal of Research on Computing in Education, 42(2), 123.

Schmoker, M. J. (1999). Results: The key to continuous school improvement. Alexandria, VA: Association for Supervision and Curriculum Development.

Spiro, R. J., Feltovich, P. J., Coulson, R. L., Anderson, D. K. (1988). Cognitive Flexibility Theory: Advanced Knowledge Acquisition in Ill-Structured Domains. Technical Report No. 441, Illinois University, Urbana, Center for the Study of Reading. ERIC document ED302821.

Sugar, W., Crawley, F., \& Fine, B. (2004). Examining teachers' decisions to adopt new technology. Educational Technology and Society, 7(4), 201-213. Retrieved January 22, 2013 from http://www.ifets.info.proxy.lib.pdx.edu/others/journals/7_4/19.pdf

Tharp, R. \& Gallimore, R. (1988). Rousing minds to life. New York: Cambridge University Press.

Toffler, A. (1981). The third wave. New York: Bantam books.

Tucker, P. D., \& Stronge, J. H. (2005). Linking Teacher Evaluation and Student Learning. Alexandria: Association for Supervision and Curriculum Development.

United States Department of Education, Office of Educational Technology (2010). Transforming American education: Learning powered by technology. Retrieved December 12, 2012 from http://www.ed.gov/sites/default/files/netp2010.pdf Vermunt, J. D., \& Endedijk, M. D. (2011). Learning and Individual Differences. 
Learning and Individual Differences, 21(3), 294-302.

doi:10.1016/j.lindif.2010.11.019

Voogt, J., Westbroek, H., Handelzalts, A., Walraven, A., McKenney, S., Pieters, J., \& de Vries, B. (2011). Teacher learning in collaborative curriculum design. Teaching and Teacher Education, 27(8), 1235-1244. doi:10.1016/j.tate.2011.07.003

Warschauer, M., Knobel, M., \& Stone, L. (2004). Technology and equity in schooling: Deconstructing the digital divide. Educational Policy, 18(4), 562-588. doi: $10.1177 / 0895904804266469$

Warschauer, M., \& Ware, M. (2008). Learning, change, and power: Competing discourses of technology and literacy. In J. Coiro, M., Knobel, C. Lankshear, \& D. J. Leu (Eds.) Handbook of research on new literacies. New York: Lawrence Erlbaum Associates.

Wenglinsky, H. (1998). Does it Compute? The relationship between educational technology and student achievement in mathematics. Princeton: ETS Policy Information Center. Retrieved April 14, 2013 from http://www.ets.org/Media/Research/pdf/PICTECHNOLOG.pdf

Zhao, Y., \& Frank, K. A. (2003). Factors affecting technology uses in schools: An ecological perspective. American Educational Research Journal, 40(4), 807-840. doi: $10.3102 / 00028312040004807$ 
APPENDIX A - Email Invitation/Collection Correspondence 
[Email request of superintendents to request permission to contact staff in their district]

Date:

Dear

My name is Joe Morelock, and I am the Executive Director of Secondary Programs and Technology for the Lake Oswego School District in Lake Oswego, Oregon. I am also an Education Doctorate candidate at Portland State University, and it is for this purpose that I am reaching out to you. My dissertation is a study of the combined effects of teacher self-efficacy, leadership practices, and professional development as they relate to the implementation of classroom educational technology. The results of the study will be analyzed to determine which aspects of those three areas have the most impact upon a successful education technology implementation. The aggregate results will be published both in the final dissertation as well as in a short best-practices handbook for education leaders at all levels.

I am writing you to request permission to contact teachers, administrators, and technology support personnel in order to ask them to participate in my study. The participants will all be anonymous, and there will be no way to tie the responses to individuals or to schools/districts included in the study. There will be only one web link to the survey, and the questions will be tailored to each respondent depending upon the option they choose which best describes their role in the school or district.

I thank you for your assistance in my research and if allowable, the permission to contact your staff about their participation. If you have any questions whatsoever about this request or the research itself, please feel free to contact me, Joseph Morelock, at 503-305xxxx, morelock@pdx.edu or my Portland State University doctoral candidate supervisor, Deborah Peterson, at (503) 725-xxxx,dpeterso@pdx.edu .

Sincerely,

Joseph Morelock

Ed.D. Candidate

Portland State University

503-305-xxxx

morelock@pdx.edu 
[Email invitation for staff after receiving permission to contact them from superintendent or designee]

$<<$ District Name $>>$

Dear Educator,

My name is Joe Morelock, and I am the Executive Director of Secondary Programs and Technology for the Lake Oswego School District. I am also an Education Doctorate candidate at Portland State University, and it is for this purpose that I am reaching out to you. My dissertation is a study of the combined effects of teacher self-efficacy, leadership practices, and professional development as they relate to the implementation of classroom educational technology. The results of the study will be analyzed to determine which aspects of those three areas have the most impact upon a successful education technology implementation. The aggregate results will be published both in the final dissertation as well as in a short best-practices handbook for education leaders at all levels.

I am writing you to request your participation in my study. All your answers will be confidential, and there will be no way to tie the responses to you or to your schools/districts. There will be only one web link to the survey, and the questions will be tailored to each person depending upon the option they choose which best describes their role in the school or district. With your superintendent's permission, I am contacting teachers, administrators, and technology personnel in your district for participation in this study.

Again, your participation is voluntary. The researcher will not know if you have or have not participated. If you choose to participate, then let me thank you in advance for your assistance in my research. If you have any questions whatsoever about this request or the research itself, please feel free to contact me, Joe Morelock, at 503-305xxxx, morelock@pdx.edu or my Portland State University doctoral candidate supervisor, Deborah Peterson, at (503) 725-xxxx,dpeterso@pdx.edu .

Here is the link to the online survey for the study:

https://portlandstate.qualtrics.com//SE/?SID=SV_2a8cOV5MQynHPHT 
Joe Morelock

Ed.D. Candidate

Portland State University

morelock@pdx.edu

Below is your Informed Consent for participation in this study - you will see this again at the survey URL (link) above if you choose to participate in the study:

Introduction

This is a research study that will attempt to measure the impact of leadership practices and teacher knowledge upon the successful integration of technology in the classroom.

Procedures

You will take part in a 28-question survey that should take approximately 15 minutes to complete. This questionnaire will be conducted with an online Qualtrics survey.

Risks

Risks are minimal for involvement in this study. Supervisors will not know who has or has not done survey, and all data presented will be in an aggregate format (all the results will be combined, no individual responses will be reported). All participants will use the same link to complete the survey.

Benefits

There are no direct benefits for participants. Participation in this study is voluntary, and by participating, respondents will not gain benefit in their workplace. However, it is hoped that through your participation, researchers will learn more about which practices and actions from administrators and teachers result in more successful technology integration projects.

Confidentiality

All data obtained from participants will be confidential and will only be reported in an aggregate format (by reporting only combined results and never reporting individual ones). Survey items which ask for state and district names will only be used by the researcher to pair responses to student demographic information available from the National Center for Education Statistics (NCES) and the US Census Bureau. If any data collected using the online using password-protected Qualtrics survey system is downloaded to a local device, that data will be kept on a locally-accessible, encrypted and password protected data storage device and will be maintained for a three year period after the publication of the research before being securely destroyed by the researcher. 


\section{Compensation}

There is no direct compensation for participation in this study.

Participation

Participation in this research study is completely voluntary. You have the right to withdraw at anytime or refuse to participate entirely without jeopardy to your employment. If you desire to withdraw before finishing the survey, please close your internet browser and no other action is required. If you desire to withdraw after you have completed the questionnaire, please notify the principal investigator at this

email: morelock@pdx.edu with your approximate time and date of submission.

Questions about the Research

If you have questions regarding this study, you may contact the primary researcher, Joseph Morelock, at 503-305-xxxx, morelock@pdx.edu or his Portland State University doctoral candidate supervisor, Deborah Peterson, at (503) 725-xxxx, dpeterso@pdx.edu.

Questions about your Rights as Research Participants If you have questions you do not feel comfortable asking the researcher, you may contact Deborah Peterson, at (503) 725-xxxx, dpeterso@pdx.edu615 SW Harrison, Education Building, Office 506 U, Portland, OR 97207

Joe Morelock

Ed.D. Candidate

Portland State University

503-305-xxxx

morelock@pdx.edu

$<<$ District Name $>>$

Oregon District: $<<$ OR District ID $>>$

NCES ID: $<<$ LEAID $>>$ 
APPENDIX B - Additional Results Tables 


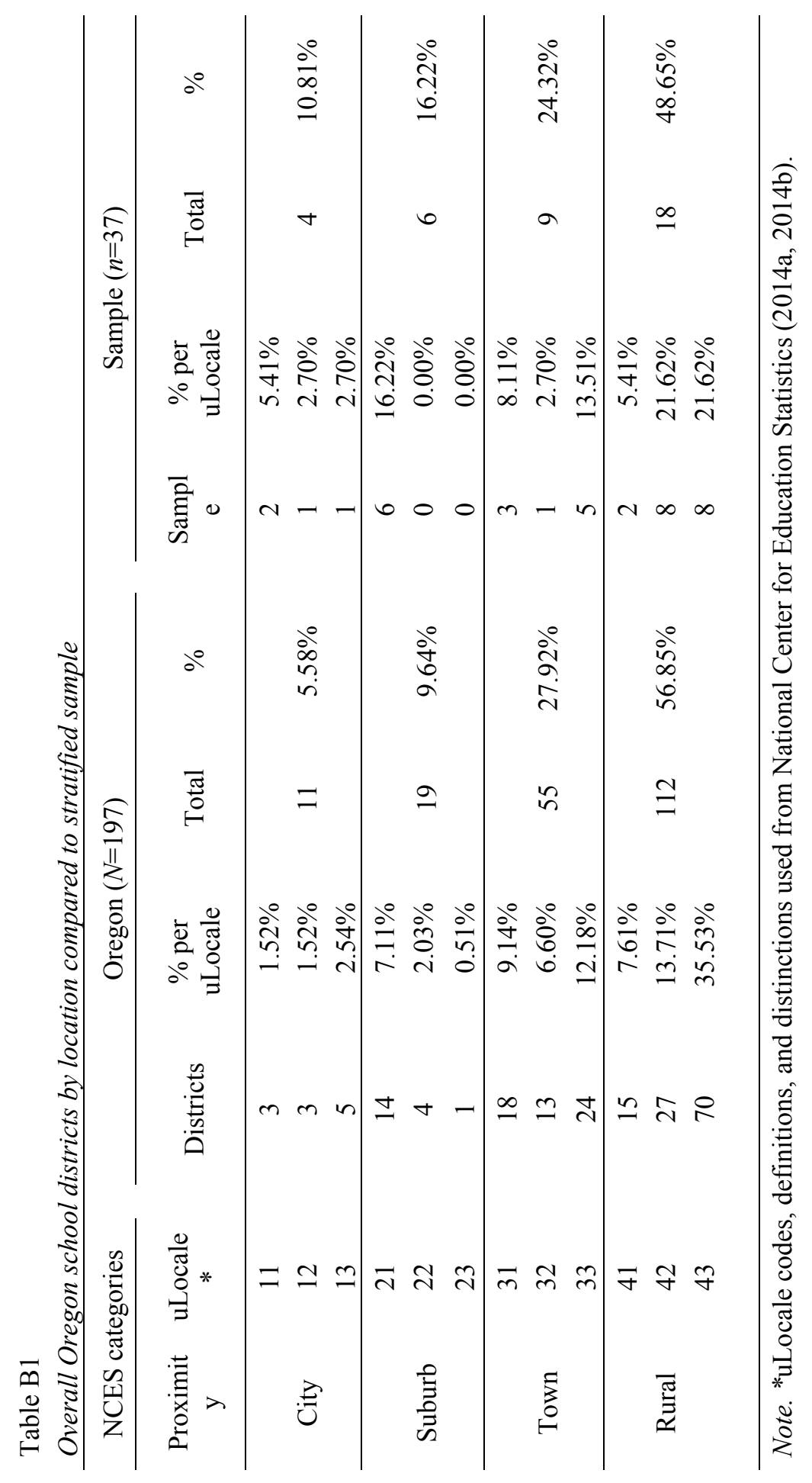


Table B2

Participant demographics and experience

\begin{tabular}{|c|c|c|c|c|c|}
\hline & & Teacher & Admin & Tech staff & Total \\
\hline \multirow{2}{*}{ Ethnicity } & $\begin{array}{l}\text { Hispanic or } \\
\text { Latino }\end{array}$ & $4.04 \%$ & $2.53 \%$ & $3.33 \%$ & $3.82 \%$ \\
\hline & $\begin{array}{l}\text { Not Hispanic or } \\
\text { Latino }\end{array}$ & $95.96 \%$ & $97.47 \%$ & $96.67 \%$ & $96.18 \%$ \\
\hline \multirow{5}{*}{ Race } & $\begin{array}{l}\text { American Indian } \\
\text { or Alaska Native }\end{array}$ & $2.40 \%$ & $3.75 \%$ & $3.33 \%$ & $2.61 \%$ \\
\hline & Asian & $1.66 \%$ & $1.25 \%$ & $0.00 \%$ & $1.53 \%$ \\
\hline & $\begin{array}{l}\text { Black or African } \\
\text { American }\end{array}$ & $0.55 \%$ & $0.00 \%$ & $0.00 \%$ & $0.46 \%$ \\
\hline & $\begin{array}{l}\text { Native Hawaiian } \\
\text { or Other Pacific } \\
\text { Islander }\end{array}$ & $0.37 \%$ & $1.25 \%$ & $6.67 \%$ & $0.77 \%$ \\
\hline & White & $98.15 \%$ & $97.50 \%$ & $93.33 \%$ & $97.85 \%$ \\
\hline \multirow{6}{*}{ Age category } & 20 to 24 & $2.19 \%$ & $0.00 \%$ & $3.33 \%$ & $1.97 \%$ \\
\hline & 25 to 34 & $22.04 \%$ & $10.00 \%$ & $10.00 \%$ & $20.03 \%$ \\
\hline & 35 to 44 & $29.33 \%$ & $37.50 \%$ & $23.33 \%$ & $30.05 \%$ \\
\hline & 45 to 54 & $30.97 \%$ & $38.75 \%$ & $26.67 \%$ & $31.71 \%$ \\
\hline & 55 to 64 & $13.84 \%$ & $12.50 \%$ & $36.67 \%$ & $14.72 \%$ \\
\hline & 65 or over & $1.64 \%$ & $1.25 \%$ & $0.00 \%$ & $1.52 \%$ \\
\hline \multirow{3}{*}{ Gender } & Male & $24.86 \%$ & $51.90 \%$ & $46.67 \%$ & $29.12 \%$ \\
\hline & Female & $75.14 \%$ & $48.10 \%$ & $53.33 \%$ & $70.88 \%$ \\
\hline & $1-3$ years & $10.41 \%$ & $4.94 \%$ & $9.68 \%$ & $9.72 \%$ \\
\hline \multirow{5}{*}{$\begin{array}{l}\text { Experience } \\
\text { as a teacher }\end{array}$} & 4-6 years & $8.98 \%$ & $20.99 \%$ & $0.00 \%$ & $10.01 \%$ \\
\hline & 7-18 years & $48.29 \%$ & $45.68 \%$ & $25.81 \%$ & $46.94 \%$ \\
\hline & $19-30$ years & $26.39 \%$ & $11.11 \%$ & $6.45 \%$ & $23.62 \%$ \\
\hline & $\begin{array}{l}\text { More than } 30 \\
\text { years }\end{array}$ & $4.49 \%$ & $4.94 \%$ & $0.00 \%$ & $4.33 \%$ \\
\hline & $\begin{array}{l}\text { I have never } \\
\text { been a classroom } \\
\text { teacher }\end{array}$ & $1.44 \%$ & $12.35 \%$ & $58.06 \%$ & $5.38 \%$ \\
\hline
\end{tabular}


PERCEPTIONS OF EFFECTIVE TECHNOLOGY IMPLEMENTATION

Table B3

Descriptive statistics (means and standard deviations)

\begin{tabular}{|c|c|c|c|}
\hline Variables & Teachers & Administrators & $\begin{array}{l}\text { Technology } \\
\text { Support Staff }\end{array}$ \\
\hline Minority & $0.08(0.27)$ & $0.09(0.28)$ & $0.13(0.35)$ \\
\hline Female & $0.75(0.43)$ & $0.48(0.50)$ & $0.53(0.51)$ \\
\hline Age & $3.37(1.09)$ & $3.58(0.88)$ & $3.83(1.15)$ \\
\hline Experience & $3.01(1.04)$ & $2.53(1.28)$ & $1.13(1.50)$ \\
\hline Free/Reduced Lunch Students & $4.35(1.95)$ & $4.20(2.04)$ & $4.23(1.89)$ \\
\hline Non-White Students & $3.01(1.72)$ & $2.72(1.48)$ & $3.19(1.42)$ \\
\hline Professional Development 1 & $2.41(1.11)$ & $2.78(1.03)$ & $2.27(0.96)$ \\
\hline Professional Development 2 & $2.47(1.14)$ & $2.95(1.05)$ & $2.77(1.18)$ \\
\hline Professional Development (Combined) & $2.44(1.05)$ & $2.86(0.98)$ & $2.52(0.99)$ \\
\hline Professional Development Relevancy 1 & $3.16(1.16)$ & $3.72(0.93)$ & $3.76(0.77)$ \\
\hline Professional Development Relevancy 2 & $4.31(0.85)$ & $4.49(0.70)$ & $4.86(0.36)$ \\
\hline $\begin{array}{l}\text { Professional Development Relevancy } \\
\text { (Combined) }\end{array}$ & $3.73(0.74)$ & $4.10(0.63)$ & $4.31(0.43)$ \\
\hline Choice & $4.15(0.83)$ & $3.77(0.77)$ & $3.64(0.68)$ \\
\hline Technology Frequency & $2.38(1.00)$ & $2.51(0.81)$ & $1.30(0.54)$ \\
\hline Technology Ratio & $1.45(0.75)$ & $2.54(0.79)$ & $1.45(0.78)$ \\
\hline Teacher Influence & $2.37(1.17)$ & & \\
\hline Challenge (Combined) & $2.06(0.44)$ & $2.13(0.47)$ & $2.08(0.42)$ \\
\hline Technological Knowledge & $3.59(0.91)$ & $2.99(0.75)$ & $2.60(0.61)$ \\
\hline Technological-Content Knowledge & $3.73(0.98)$ & $3.17(0.99)$ & $2.82(0.82)$ \\
\hline Technological-Pedagogical Knowledge & $3.73(0.90)$ & $3.25(0.92)$ & $3.00(0.86)$ \\
\hline \multirow{2}{*}{\multicolumn{4}{|c|}{ Knowledge }} \\
\hline & & & \\
\hline CHAT1 & $4.25(0.77)$ & $3.94(0.67)$ & $3.45(1.06)$ \\
\hline CHAT2 & $3.52(1.00)$ & $2.89(0.89)$ & $2.73(0.63)$ \\
\hline CHAT3 & $3.59(0.95)$ & $3.20(0.95)$ & $3.23(0.87)$ \\
\hline CHAT4 & $3.47(1.08)$ & $2.92(0.97)$ & $2.91(0.87)$ \\
\hline CHAT5 & $3.23(1.15)$ & $3.18(0.99)$ & $3.27(1.08)$ \\
\hline CHAT6 & $3.13(0.81)$ & $3.62(0.72)$ & $3.64(0.58)$ \\
\hline Usage 1 & $1.67(0.77)$ & $2.14(0.56)$ & $2.34(0.48)$ \\
\hline Usage 2 & $2.90(0.79)$ & $3.03(0.46)$ & $3.07(0.46)$ \\
\hline Usage 3 & $2.93(0.77)$ & $2.96(0.53)$ & $2.93(0.37)$ \\
\hline Usage 4 & $2.33(0.97)$ & $2.72(0.74)$ & $3.14(0.69)$ \\
\hline Usage 5 & $2.33(0.92)$ & $2.89(0.64)$ & $2.76(0.64)$ \\
\hline Usage 6 & $2.27(0.93)$ & $2.64(0.74)$ & $2.48(0.74)$ \\
\hline Usage 7 & $2.71(1.21)$ & $3.58(0.64)$ & $3.69(0.54)$ \\
\hline Usage 8 & $2.80(0.88)$ & $2.80(0.63)$ & $2.86(0.58)$ \\
\hline Usage 9 & $2.63(0.92)$ & $2.66(0.68)$ & $2.69(0.60)$ \\
\hline Support 1 & $3.92(0.94)$ & $3.86(0.79)$ & $3.96(1.08)$ \\
\hline Support 2 & $3.96(0.80)$ & $3.93(0.75)$ & $3.77(0.91)$ \\
\hline Support 3 & $3.20(1.21)$ & $3.34(1.03)$ & $3.50(0.91)$ \\
\hline Barrier 1 & $3.55(0.75)$ & $3.65(0.64)$ & $3.43(0.75)$ \\
\hline Barrier 2 & $3.30(0.68)$ & $3.56(0.68)$ & $3.52(0.81)$ \\
\hline Barrier 3 & $3.29(0.66)$ & $3.43(0.61)$ & $3.38(0.59)$ \\
\hline
\end{tabular}


Note. Values in parentheses are standard deviations.

Table B4

MANOVA results for Professional Development 1 and Professional Development 2

\begin{tabular}{lcccccc}
\hline & & & \multicolumn{2}{c}{ Degrees of Freedom } & & \\
Test Criteria & Values & $F$ & Hypotheses & Error & & $\eta^{2}$ \\
& & & & & & \\
Pillai's Trace & 0.032 & 4.666 & 4 & 1166 & .001 & 0.016 \\
Wilks' Lambda & 0.969 & 4.663 & 4 & 1164 & .001 & 0.016 \\
Hotelling's Trace & 0.032 & 4.660 & 4 & 1162 & .001 & 0.016 \\
Roy's Largest Root & 0.022 & 6.422 & 2 & 583 & .002 & 0.022 \\
\hline
\end{tabular}

Table B5

ANOVA results for Professional Development 1 and Professional Development 2

\begin{tabular}{lcccccc}
\hline \multirow{2}{*}{ Test Criteria } & $\begin{array}{c}\text { Type III } \\
\text { Sums of } \\
\text { Squares }\end{array}$ & $\begin{array}{c}\text { Degrees of } \\
\text { Freedom }\end{array}$ & $\begin{array}{c}\text { Mean } \\
\text { Square }\end{array}$ & $F$ & $p$ & $\eta^{2}$ \\
\hline Professional Development 1 & 9.513 & 2 & 4.756 & 3.986 & .019 & 0.013 \\
Professional Development 2 & 15.864 & 2 & 7.932 & 6.185 & .002 & 0.021 \\
\hline
\end{tabular}


PERCEPTIONS OF EFFECTIVE TECHNOLOGY IMPLEMENTATION

Table B6

Results of Tukey's HSD post hoc test

\begin{tabular}{|c|c|c|c|c|}
\hline Dependent Variable & Multiple Comparisons & $\begin{array}{c}\text { Mean } \\
\text { Difference }\end{array}$ & $S E$ & $p$ \\
\hline Professional & Teacher vs. Administrator & -0.37 & 0.137 & .020 \\
\hline \multirow{5}{*}{ Development 1} & Teacher vs. Technology Support Staff & 0.14 & 0.220 & .791 \\
\hline & Administrator vs. Teacher & 0.37 & 0.137 & .020 \\
\hline & $\begin{array}{l}\text { Administrator vs. Technology Support } \\
\text { Staff }\end{array}$ & 0.51 & 0.249 & .101 \\
\hline & Technology Support Staff vs. Teacher & -0.14 & 0.220 & .791 \\
\hline & $\begin{array}{l}\text { Technology Support } \quad \text { Staff } \quad \text { vs. } \\
\text { Administrator }\end{array}$ & -0.51 & 0.249 & .101 \\
\hline Professional & Teacher vs. Administrator & -0.48 & 0.142 & .002 \\
\hline \multirow[t]{5}{*}{ Development 2} & Teacher vs. Technology Support Staff & -0.30 & 0.228 & .384 \\
\hline & Administrator vs. Teacher & 0.48 & 0.142 & .002 \\
\hline & $\begin{array}{l}\text { Administrator vs. Technology Support } \\
\text { Staff }\end{array}$ & 0.18 & 0.259 & .775 \\
\hline & Technology Support Staff vs. Teacher & 0.30 & 0.228 & .384 \\
\hline & $\begin{array}{l}\text { Technology Support } \quad \text { Staff } \quad \text { vs. } \\
\text { Administrator }\end{array}$ & -0.18 & 0.259 & .775 \\
\hline
\end{tabular}

Table B7

Results of quantile regression model for Professional Development (Combined)

\begin{tabular}{lcccc}
\hline & \multirow{2}{*}{$\begin{array}{c}\text { OLS } \\
\text { Covariates }\end{array}$} & \multicolumn{3}{c}{$\tau=0.50$} \\
\cline { 3 - 5 } & & $\beta$ & $S E$ & $p$ \\
\hline & & & & \\
Intercept & $2.046^{* * *}$ & $1.821^{* * *}$ & 0.373 & .000 \\
Administration & $0.366^{* *}$ & 0.429 & 0.268 & .102 \\
Technology Support Staff & 0.004 & 0.393 & 0.337 & .235 \\
Minority & 0.077 & 0.071 & 0.240 & .775 \\
Female & -0.109 & -0.214 & 0.195 & .276 \\
Age & 0.048 & 0.071 & 0.072 & .328 \\
Free/Reduced Lunch Students & $0.084^{* * *}$ & $0.107^{*}$ & 0.055 & .040 \\
Non-White Students & -0.019 & -0.036 & 0.047 & .417 \\
& & & &
\end{tabular}

Note. Model quality indicators for the OLS regression are $\mathrm{R}^{2}=0.041$ and $F(7,559)=3.412, p=.001$. ${ }^{*} \mathrm{p}<.05 . * * \mathrm{p}<.01 . * * * \mathrm{p}<.001$ 
Table B8

Results of quantile regression model for Professional Development Relevancy (Combined)

\begin{tabular}{lcccc}
\hline & & & \multicolumn{3}{c}{$\tau=0.50$} \\
\cline { 3 - 5 } Covariates & Estimate & $\beta$ & $S E$ & $p$ \\
\hline & & & & \\
Intercept & $3.471^{* * *}$ & $3.254^{* * *}$ & 0.314 & .000 \\
Administration & $0.393^{* * *}$ & $0.381^{*}$ & 0.178 & .027 \\
Technology Support Staff & $0.590^{* * *}$ & $0.611^{* *}$ & 0.207 & .004 \\
Minority & -0.056 & -0.056 & 0.190 & .792 \\
Female & 0.024 & -0.056 & 0.167 & .714 \\
Age & 0.032 & 0.079 & 0.053 & .144 \\
Free/Reduced Lunch Students & 0.016 & 0.040 & 0.032 & .233 \\
Non-White Students & 0.026 & 0.024 & 0.036 & .491 \\
& & & & \\
\hline
\end{tabular}

Note. Model quality indicators for the OLS regression are $\mathrm{R}^{2}=0.058$ and $F(7,524)=4.584, p<.001$. $* \mathrm{p}<.05 . * * \mathrm{p}<.01 . * * * \mathrm{p}<.001$. 
Table B9

Frequency of responses about professional development sorted by all participants

\begin{tabular}{|c|c|c|c|c|}
\hline & $\begin{array}{l}\text { Admin } \\
(n=78)\end{array}$ & $\begin{array}{l}\text { Teacher } \\
(n=537)\end{array}$ & $\begin{array}{l}\text { Tech } \\
(n=26)\end{array}$ & $\underset{(n=641)}{\mathrm{A} 11}$ \\
\hline $\begin{array}{l}\text { Direct application to the classroom / relevant- } \\
\text { effective use strategies }\end{array}$ & $30.8 \%$ & $28.3 \%$ & $15.4 \%$ & $28.1 \%$ \\
\hline $\begin{array}{l}\text { Collaborating with peers / talk with peers / share } \\
\text { ideas }\end{array}$ & $21.8 \%$ & $18.1 \%$ & $30.8 \%$ & $19.0 \%$ \\
\hline Time to practice / time to plan & $9.0 \%$ & $17.1 \%$ & $11.5 \%$ & $15.9 \%$ \\
\hline $\begin{array}{l}\text { Practical/meaningful information / grade or } \\
\text { content area appropriate }\end{array}$ & $20.5 \%$ & $13.6 \%$ & $15.4 \%$ & $14.5 \%$ \\
\hline Well-prepared presenters / expert presenters & $11.5 \%$ & $13.2 \%$ & $15.4 \%$ & $13.1 \%$ \\
\hline Hands-on / real-world & $15.4 \%$ & $12.8 \%$ & $3.8 \%$ & $12.8 \%$ \\
\hline $\begin{array}{l}\text { Can't think of positive experience / district lacks } \\
\text { good PD }\end{array}$ & $2.6 \%$ & $9.7 \%$ & $23.1 \%$ & $9.4 \%$ \\
\hline $\begin{array}{l}\text { Access/exposure to new } \\
\text { resources/tools/skills/techniques/ strategies }\end{array}$ & $15.4 \%$ & $7.8 \%$ & $11.5 \%$ & $8.9 \%$ \\
\hline Relevant / useful / informative & $12.8 \%$ & $6.5 \%$ & $7.7 \%$ & $7.3 \%$ \\
\hline When peer teachers lead the sessions & $6.4 \%$ & $6.0 \%$ & $7.7 \%$ & $6.1 \%$ \\
\hline Talk with peers / share ideas & $5.1 \%$ & $5.8 \%$ & $15.4 \%$ & $6.1 \%$ \\
\hline Differentiation / leveled for skill/knowledge levels & $3.8 \%$ & $5.6 \%$ & $0.0 \%$ & $5.1 \%$ \\
\hline Follow up sessions / coaching model / feedback & $9.0 \%$ & $3.9 \%$ & $0.0 \%$ & $4.4 \%$ \\
\hline $\begin{array}{l}\text { Pro dev. better out of district / conferences / learn } \\
\text { on my own }\end{array}$ & $1.3 \%$ & $4.7 \%$ & $3.8 \%$ & $4.2 \%$ \\
\hline Engaging / engaging content & $12.8 \%$ & $2.6 \%$ & $3.8 \%$ & $3.9 \%$ \\
\hline $\begin{array}{l}\text { Learning to engage learners / student learning } \\
\text { outcomes }\end{array}$ & $6.4 \%$ & $3.4 \%$ & $0.0 \%$ & $3.6 \%$ \\
\hline Participants choose topics / session choice & $0.0 \%$ & $3.4 \%$ & $11.5 \%$ & $3.3 \%$ \\
\hline Learning to use tech from my own classroom & $0.0 \%$ & $2.4 \%$ & $0.0 \%$ & $2.0 \%$ \\
\hline Staff concerns/interests/input for content/needs & $2.6 \%$ & $1.1 \%$ & $11.5 \%$ & $1.7 \%$ \\
\hline Observing "master" or other teachers use tech & $2.6 \%$ & $0.9 \%$ & $0.0 \%$ & $1.1 \%$ \\
\hline Focus on one topic/school-wide focus/focused & $0.0 \%$ & $1.1 \%$ & $0.0 \%$ & $0.9 \%$ \\
\hline Teacher knowledge of tech and pedagogy & $1.3 \%$ & $0.6 \%$ & $0.0 \%$ & $0.6 \%$ \\
\hline $\begin{array}{l}\text { Content available online / convenience / time- } \\
\text { shifted }\end{array}$ & $0.0 \%$ & $0.6 \%$ & $0.0 \%$ & $0.5 \%$ \\
\hline Not focused on level I teach & $0.0 \%$ & $0.4 \%$ & $0.0 \%$ & $0.3 \%$ \\
\hline
\end{tabular}




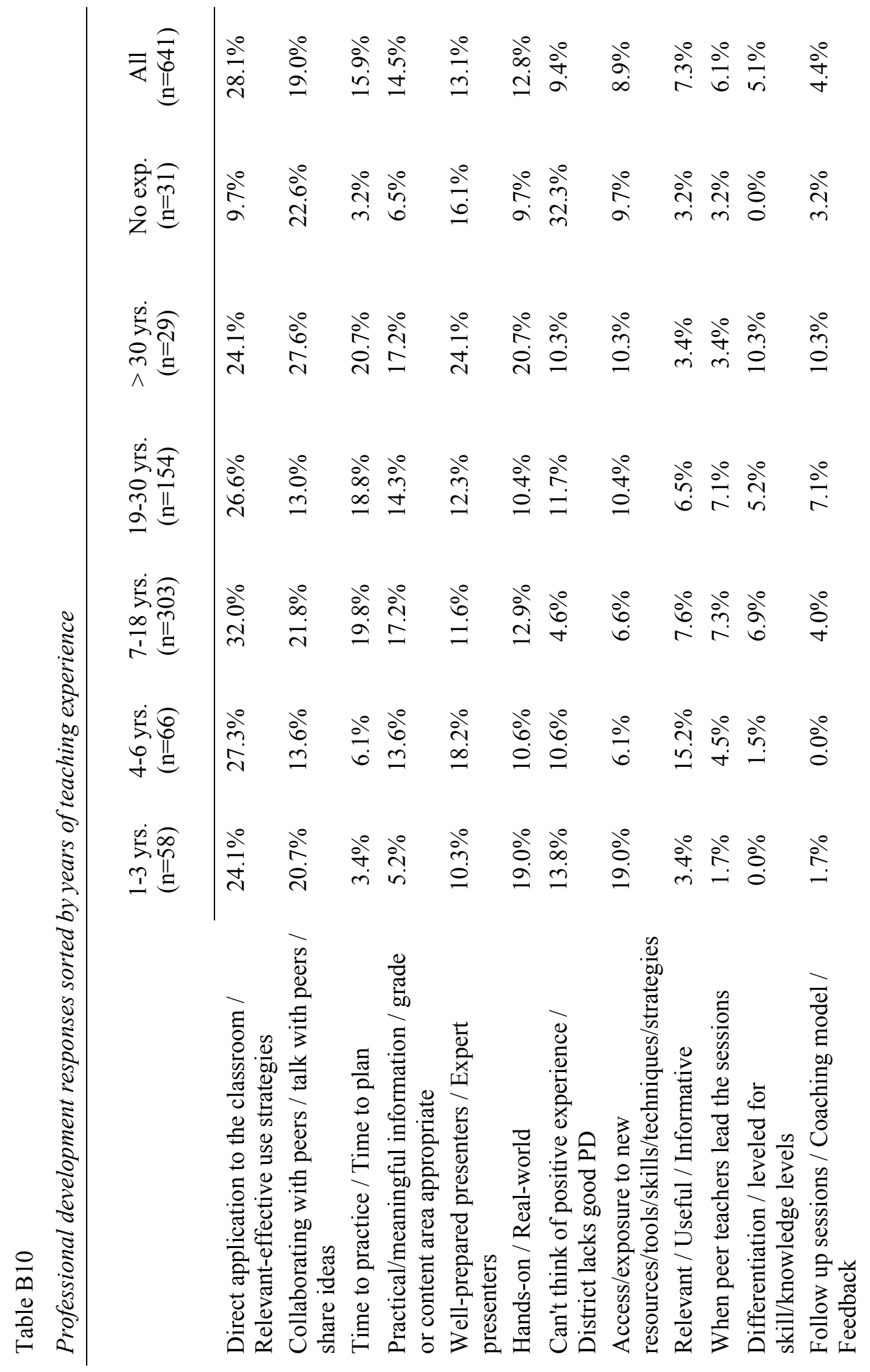


ஸे

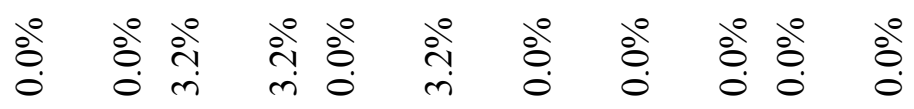

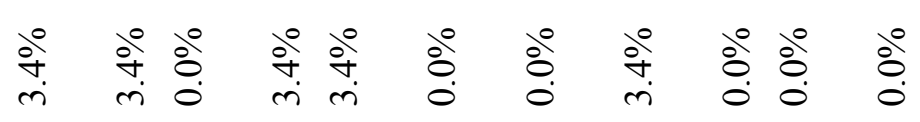

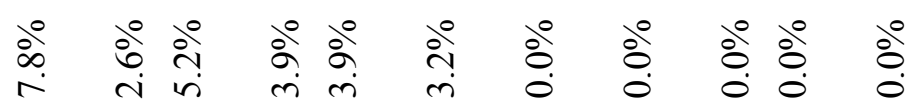

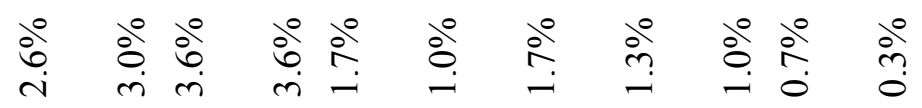

oें bें i̊̀

oे

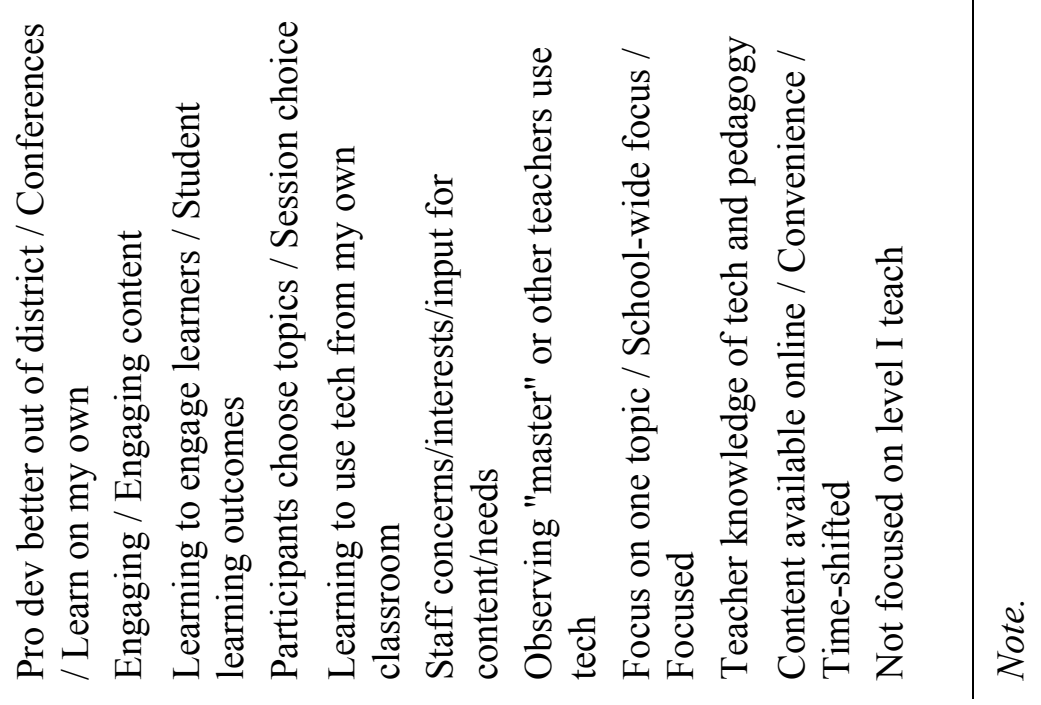




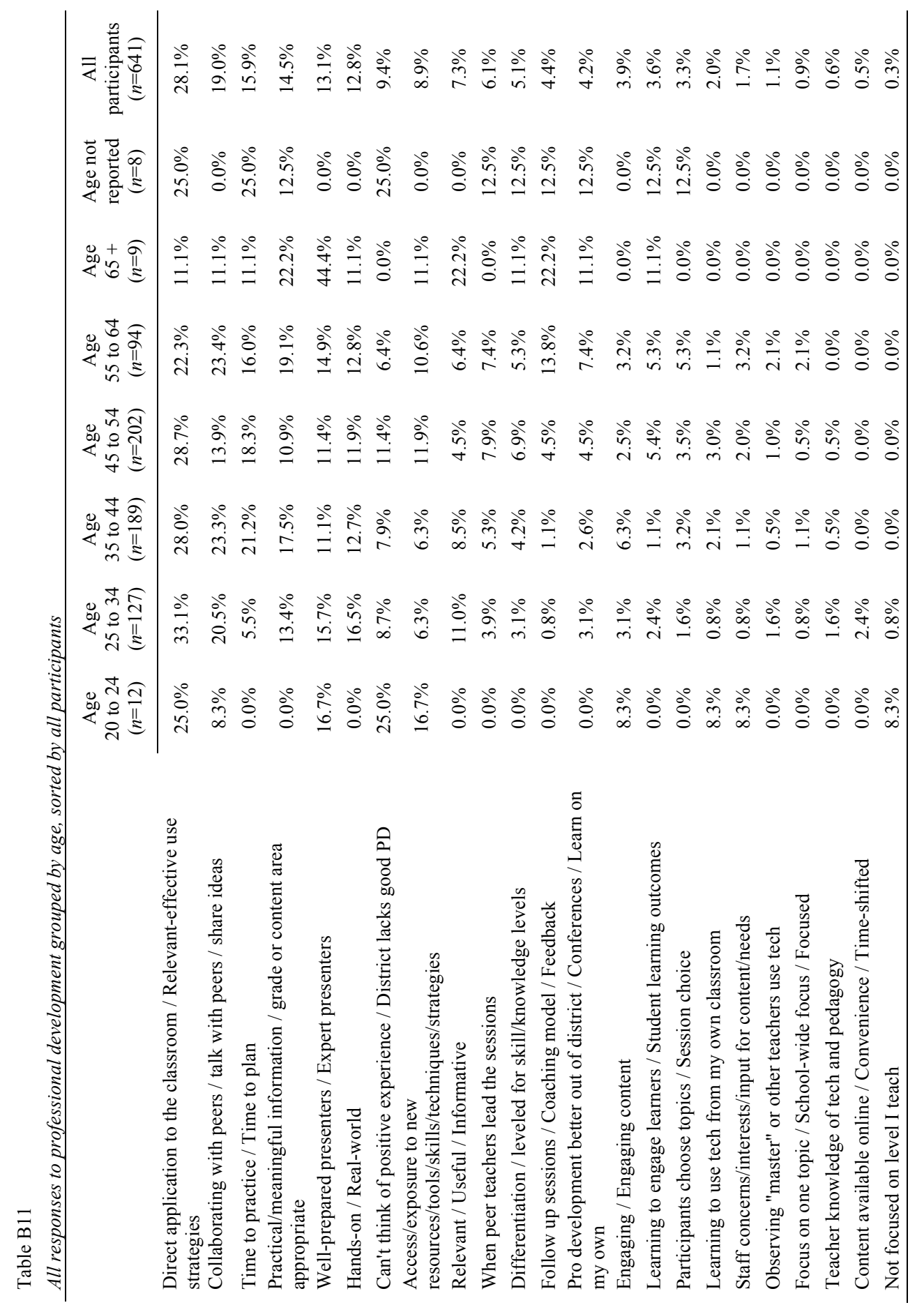


Table B12

Results of quantile regression model for Technology Frequency

\begin{tabular}{|c|c|c|c|c|}
\hline \multirow{2}{*}{ Covariates } & \multirow{2}{*}{$\begin{array}{c}\text { OLS } \\
\text { Estimate }\end{array}$} & \multicolumn{3}{|c|}{$\tau=0.50$} \\
\hline & & $\beta$ & $S E$ & $p$ \\
\hline Intercept & $0.911 * *$ & $1.500 * * *$ & 0.302 & .000 \\
\hline Choice & 0.065 & 0.000 & 0.045 & 1.000 \\
\hline Technology Ratio & $0.515 * * *$ & $0.500 *$ & 0.232 & .032 \\
\hline Teacher Influence & $0.103 * *$ & 0.000 & 0.021 & 1.000 \\
\hline Minority & 0.017 & 0.000 & 0.210 & 1.000 \\
\hline Female & 0.054 & 0.000 & 0.028 & 1.000 \\
\hline Age & 0.011 & 0.000 & 0.015 & 1.000 \\
\hline Experience & -0.018 & 0.000 & 0.022 & 1.000 \\
\hline Free/Reduced Lunch Students & 0.025 & 0.000 & 0.005 & 1.000 \\
\hline Non-White Students & 0.012 & 0.000 & 0.007 & 1.000 \\
\hline
\end{tabular}

Note. Model quality indicators for the OLS regression are $\mathrm{R}^{2}=0.203$ and $F(9,457)=13.010, p<.001$. $* \mathrm{p}<.05 . * * \mathrm{p}<.01 . * * * \mathrm{p}<.001$.

Table B13

Results of quantile regression model for Challenge (Combined)

\begin{tabular}{lcccc} 
& & & & $\tau=0.50$ \\
& OLS & & & \\
\cline { 2 - 4 } Covariates & Estimate & $\beta$ & $S E$ & .000 \\
\hline Intercept & & & & .370 \\
Administration & $1.860^{* *}$ & $1.799^{* * *}$ & 0.128 & .312 \\
Technology Support Staff & 0.088 & 0.077 & 0.086 & .094 \\
Minority & 0.044 & 0.096 & 0.095 & .158 \\
Female & -0.050 & -0.145 & 0.086 & .003 \\
Age & 0.050 & 0.095 & 0.067 & .063 \\
Free/Reduced Lunch Students & $0.048^{* *}$ & $0.081^{* *}$ & 0.027 & .147 \\
Non-White Students & $-0.024^{*}$ & -0.035 & 0.019 & 0.026 \\
\hline
\end{tabular}

Note. Model quality indicators for the OLS regression are $\mathrm{R}^{2}=0.036$ and $F(7,525)=2.835, p=.007$. $* \mathrm{p}<.05 . * * \mathrm{p}<.01 . * * * \mathrm{p}<.001$. 
Table B14

Results of quantile regression model for Technological Knowledge

\begin{tabular}{lcccc}
\hline & & & \multicolumn{3}{c}{$\tau=0.50$} \\
\cline { 3 - 5 } Covariates & Estimate & $\beta$ & $S E$ & $p$ \\
\hline & & & & \\
& & & & \\
Intercept & $3.884^{* * *}$ & $3.749^{* * *}$ & 0.206 & .000 \\
Administration & $-0.700^{* * *}$ & $-0.697^{* * *}$ & 0.126 & .000 \\
Technology Support Staff & $-1.056^{* * *}$ & $-1.249^{* * *}$ & 0.245 & .000 \\
Technology Frequency & $0.130^{* * *}$ & $0.149^{* *}$ & 0.053 & .005 \\
Technology Ratio & 0.033 & 0.080 & 0.072 & .265 \\
Minority & $0.257^{*}$ & 0.284 & 0.148 & .056 \\
Female & $-0.372^{* * *}$ & $-0.370^{* * *}$ & 0.093 & .000 \\
Age & $-0.161^{* * *}$ & $-0.123^{* *}$ & 0.046 & .008 \\
Free/Reduced Lunch Students & $0.058^{* *}$ & $0.065^{*}$ & 0.030 & .032 \\
Non-White Students & -0.033 & -0.046 & 0.031 & .141 \\
& & & & \\
\hline Note. Model quality indicators for the OLS regression are $\mathrm{R}^{2}=0.200$ and $F(9,588)=16.400, p<.001$. \\
$* \mathrm{p}<.05 . * * \mathrm{p}<.01 .{ }^{* * *} \mathrm{p}<.001$. & & & &
\end{tabular}

Table B15

Results of quantile regression model for Technological Content Knowledge

\begin{tabular}{|c|c|c|c|c|}
\hline \multirow{2}{*}{ Covariates } & \multirow{2}{*}{$\begin{array}{c}\text { OLS } \\
\text { Estimate }\end{array}$} & \multicolumn{3}{|c|}{$\tau=0.50$} \\
\hline & & $\beta$ & $S E$ & $p$ \\
\hline Intercept & $3.116^{* * *}$ & $4.000 * * *$ & 0.107 & .000 \\
\hline Administration & $-0.643 * * *$ & $-1.000 * *$ & 0.317 & .008 \\
\hline Technology Support Staff & $-0.974 * * *$ & $-1.000 *$ & 0.458 & .029 \\
\hline Technology Frequency & $0.173 * * *$ & 0.000 & 0.024 & 1.000 \\
\hline Technology Ratio & $0.142 *$ & 0.000 & 0.020 & 1.000 \\
\hline Minority & 0.174 & 0.000 & 0.381 & 1.000 \\
\hline Female & $-0.208 *$ & 0.000 & 0.031 & 1.000 \\
\hline Age & -0.021 & 0.000 & 0.005 & 1.000 \\
\hline Free/Reduced Lunch Students & $0.085^{* * *}$ & 0.000 & 0.018 & 1.000 \\
\hline Non-White Students & -0.049 & 0.000 & 0.012 & 1.000 \\
\hline
\end{tabular}

Note. Model quality indicators for the OLS regression are $\mathrm{R}^{2}=0.160$ and $F(9,583)=12.340, p<.001$. $* \mathrm{p}<.05 . * * \mathrm{p}<.01 . * * * \mathrm{p}<.001$ 
Table B16

Results of quantile regression model Technological Pedagogical Knowledge

\begin{tabular}{|c|c|c|c|c|}
\hline \multirow{2}{*}{ Covariates } & \multirow{2}{*}{$\begin{array}{c}\text { OLS } \\
\text { Estimate }\end{array}$} & \multicolumn{3}{|c|}{$\tau=0.50$} \\
\hline & & $\beta$ & $S E$ & $p$ \\
\hline Intercept & $3.308 * * *$ & $4.000 * * *$ & 0.181 & .000 \\
\hline Administration & $-0.570 * * *$ & -0.500 & 0.291 & .086 \\
\hline Technology Support Staff & $-0.867 * * *$ & $-1.000 * * *$ & 0.229 & .000 \\
\hline Technology Frequency & $0.170 * * *$ & 0.000 & 0.050 & 1.000 \\
\hline Technology Ratio & $0.199 * * *$ & 0.000 & 0.065 & 1.000 \\
\hline Minority & 0.179 & 0.000 & 0.082 & 1.000 \\
\hline Female & $-0.312 * * *$ & 0.000 & 0.112 & 1.000 \\
\hline Age & -0.038 & 0.000 & 0.020 & 1.000 \\
\hline Free/Reduced Lunch Students & 0.031 & 0.000 & 0.021 & 1.000 \\
\hline Non-White Students & -0.016 & 0.000 & 0.013 & 1.000 \\
\hline
\end{tabular}

Table B17

Results of quantile regression model for Technological Pedagogical Content Knowledge

\begin{tabular}{|c|c|c|c|c|}
\hline \multirow{2}{*}{ Covariates } & \multirow{2}{*}{$\begin{array}{c}\text { OLS } \\
\text { Estimate }\end{array}$} & \multicolumn{3}{|c|}{$\tau=0.50$} \\
\hline & & $\beta$ & $S E$ & $p$ \\
\hline Intercept & $3.242 * * *$ & $3.714 * * *$ & 0.212 & .000 \\
\hline Administration & $-0.562 * * *$ & $-0.500 *$ & 0.219 & .023 \\
\hline Technology Support Staff & $-0.872 * * *$ & $-0.762 * *$ & 0.239 & .002 \\
\hline Technology Frequency & $0.153 * * *$ & 0.071 & 0.048 & .133 \\
\hline Technology Ratio & $0.189 * * *$ & 0.095 & 0.071 & .182 \\
\hline Minority & 0.159 & 0.048 & 0.097 & .623 \\
\hline Female & $-0.231 * *$ & -0.143 & 0.091 & .118 \\
\hline Age & -0.002 & 0.000 & 0.028 & 1.000 \\
\hline Free/Reduced Lunch Students & 0.029 & 0.024 & 0.020 & .224 \\
\hline Non-White Students & -0.011 & -0.024 & 0.021 & .246 \\
\hline
\end{tabular}

Note. Model quality indicators for the OLS regression are $\mathrm{R}^{2}=0.167$ and $F(9,578)=12.860, p<.001$. $* \mathrm{p}<.05 . * \mathrm{p}<.01 . * * \mathrm{p}<.001$ 


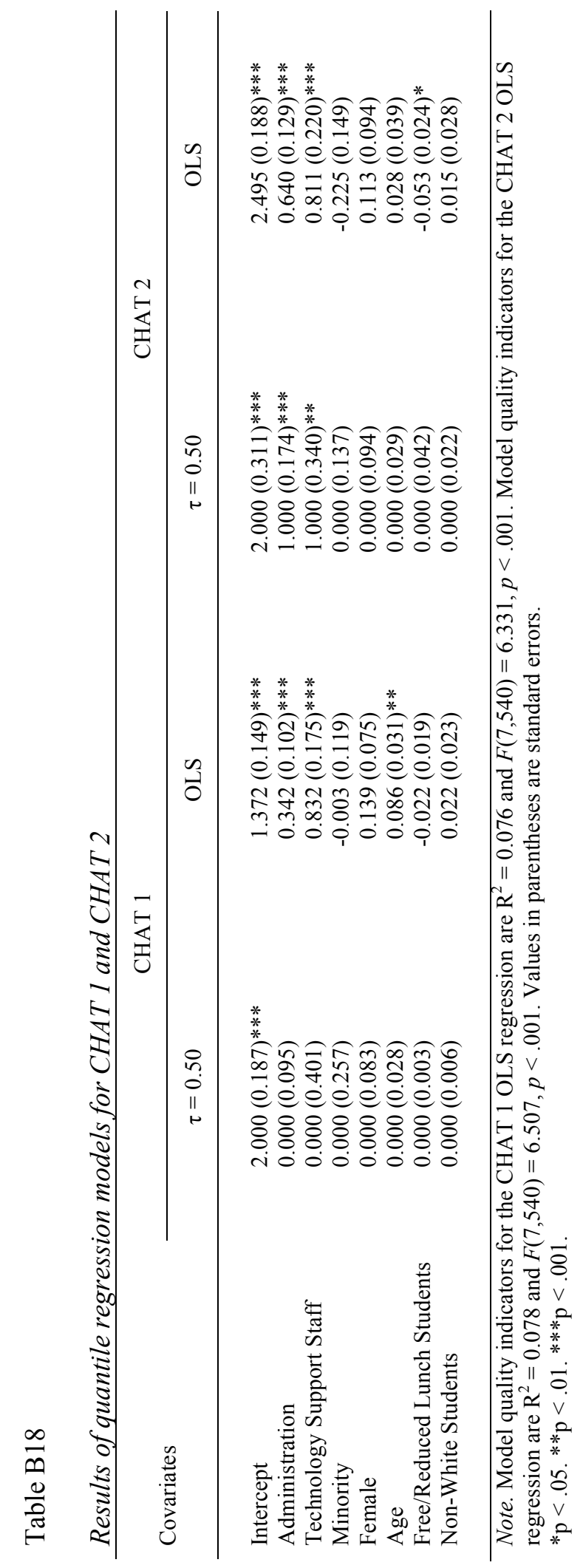




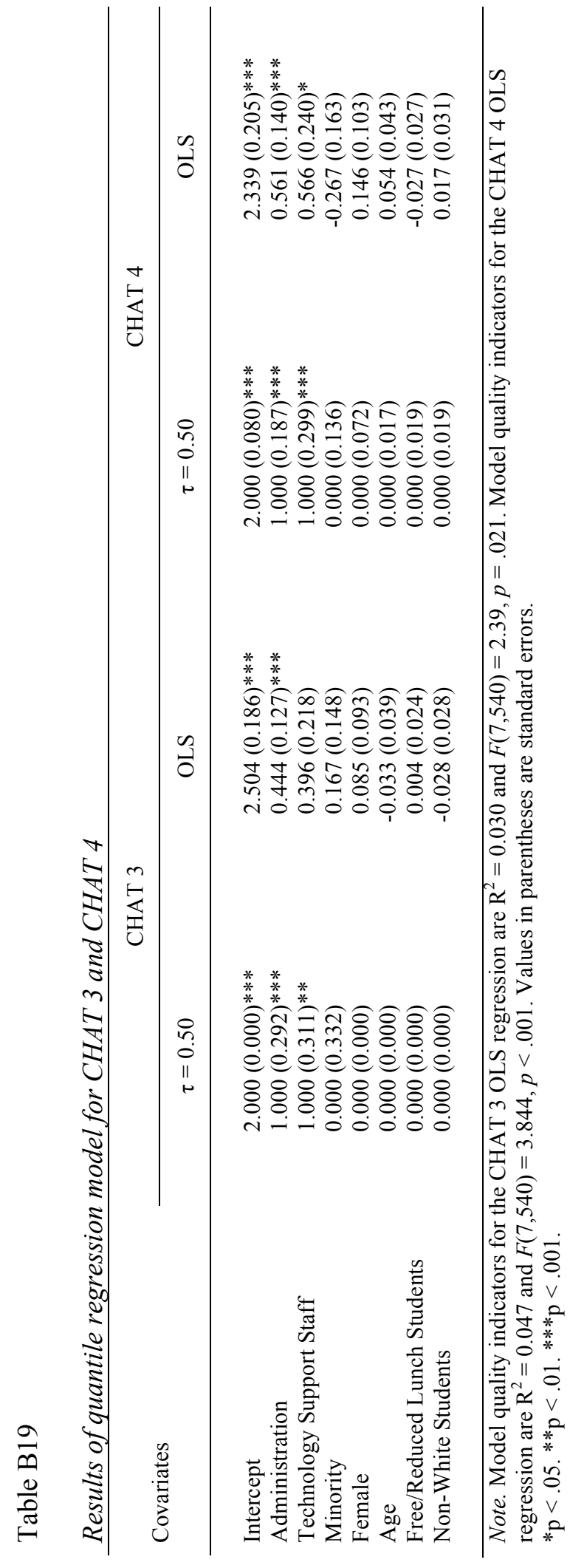




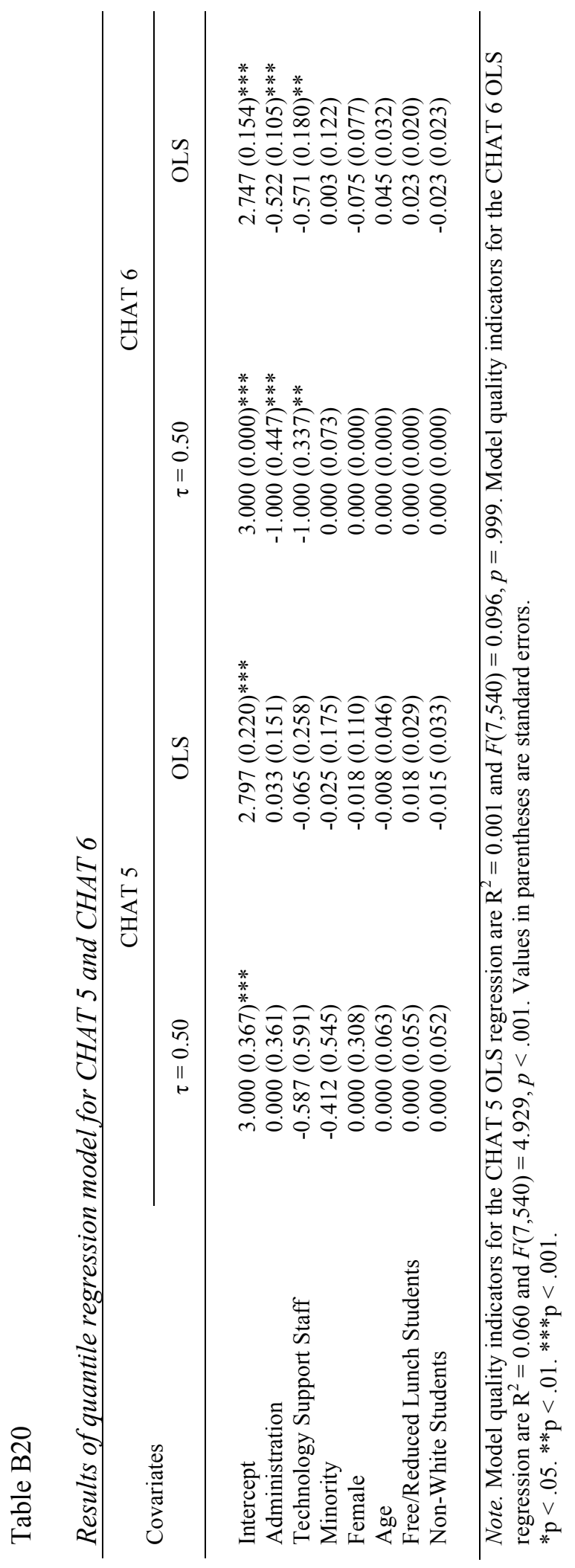




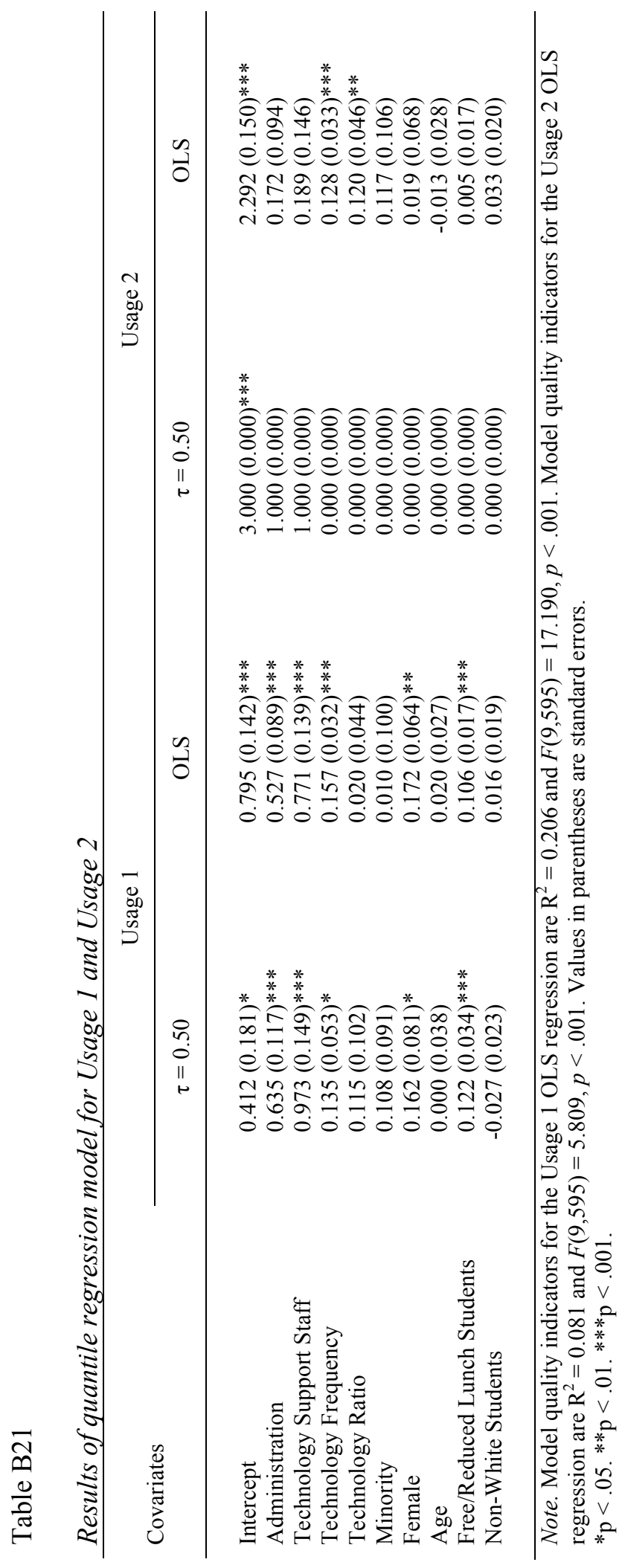




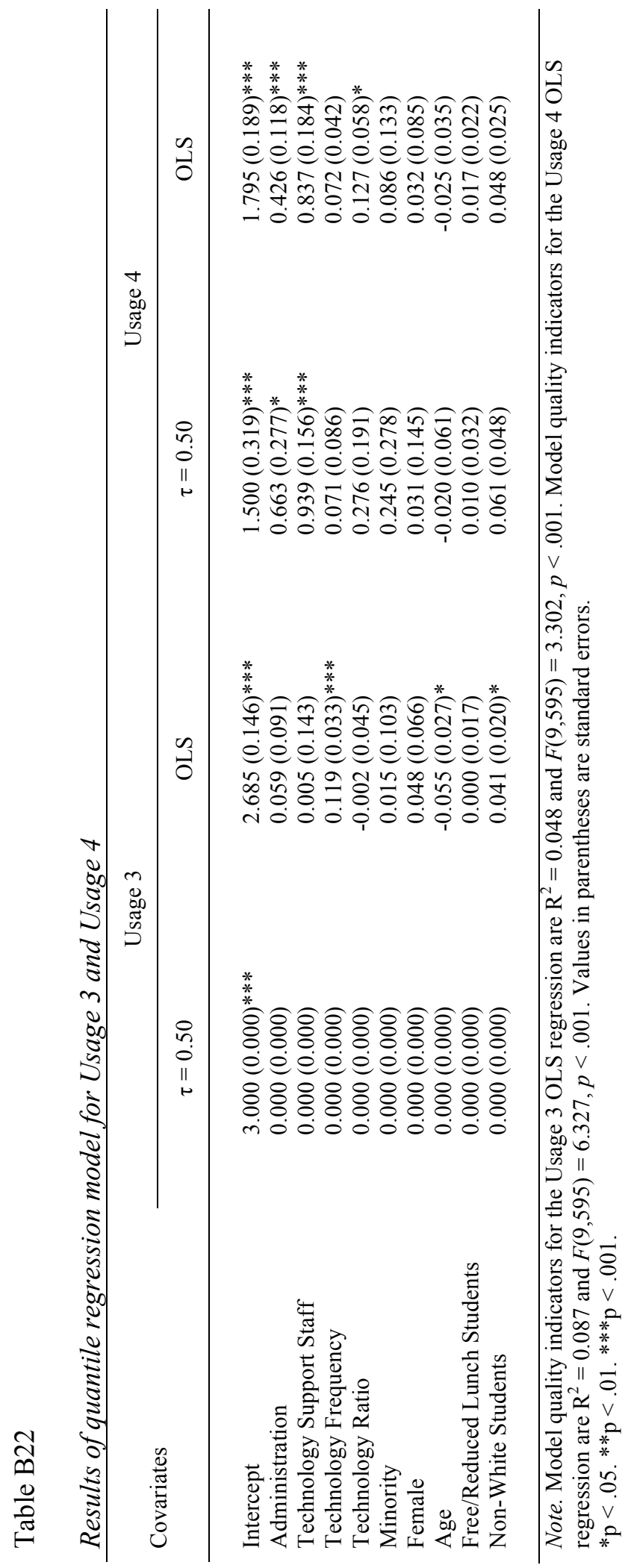




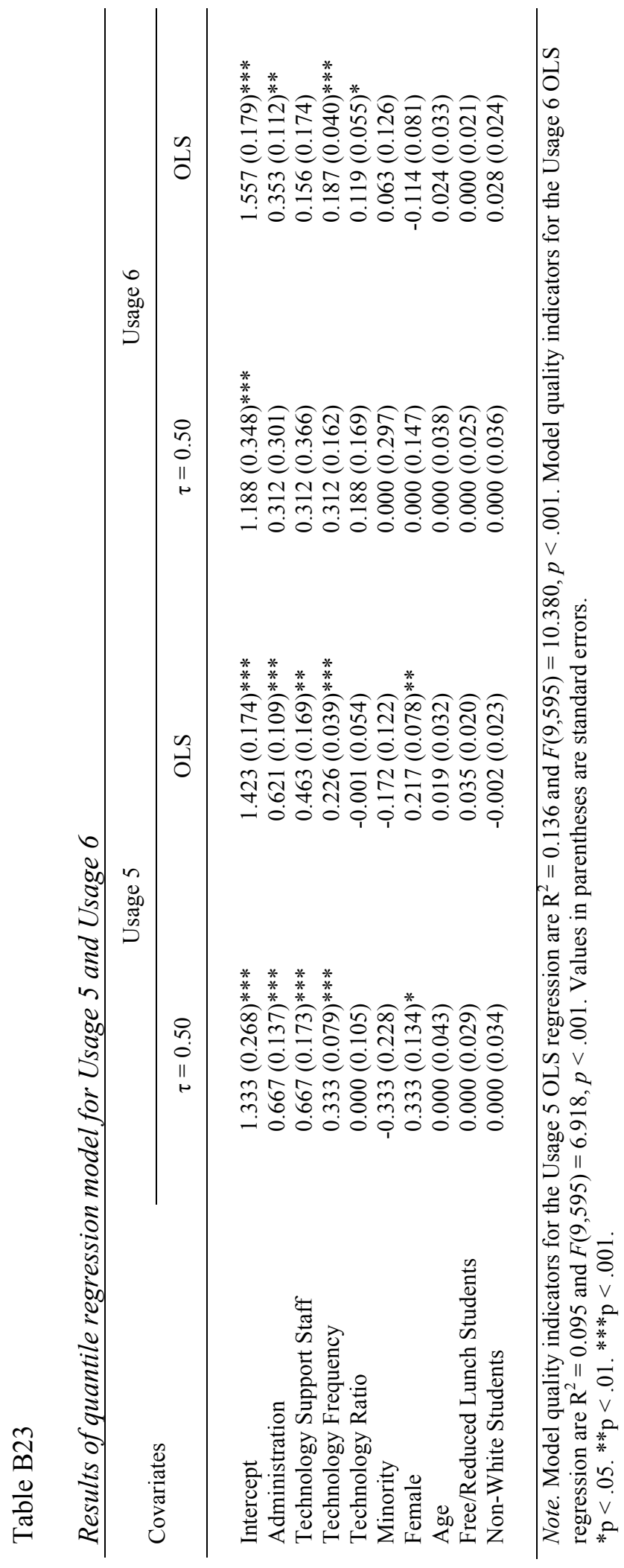




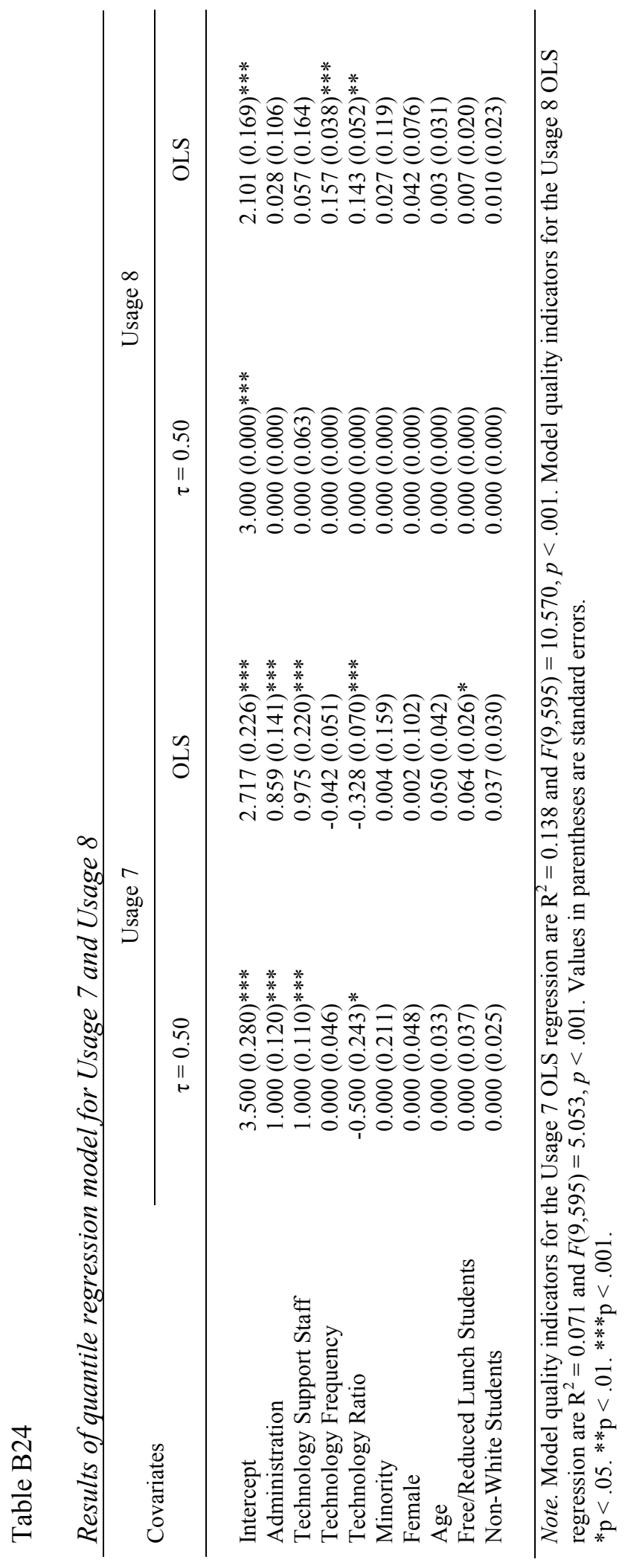


Table B25

Results of quantile regression model for Usage 9

\begin{tabular}{lcccc}
\hline & & & & $\tau=0.50$ \\
& OLS & & & \\
\cline { 3 - 5 } Covariates & & $\beta$ & $S E$ & $p$ \\
\hline & & & & \\
Intercept & $1.591^{* * *}$ & $1.219^{* * *}$ & 0.323 & .000 \\
Administration & 0.007 & -0.201 & 0.144 & .164 \\
Technology Support Staff & -0.032 & -0.146 & 0.187 & .435 \\
Technology Frequency & $0.217^{* * *}$ & $0.324^{* * *}$ & 0.057 & .000 \\
Technology Ratio & $0.254^{* * *}$ & $0.274^{* *}$ & 0.082 & .001 \\
Minority & 0.003 & 0.146 & 0.170 & .390 \\
Female & -0.040 & -0.046 & 0.111 & .682 \\
Age & $0.070^{*}$ & $0.119^{*}$ & 0.046 & .010 \\
Free/Reduced Lunch Students & -0.022 & -0.027 & 0.030 & .360 \\
Non-White Students & 0.012 & 0.018 & 0.032 & .571 \\
& & & & \\
\hline
\end{tabular}

Note. Model quality indicators for the OLS regression are $\mathrm{R}^{2}=0.143$ and $F(9,595)=11.050, p<.001$. $* \mathrm{p}<.05 . * * \mathrm{p}<.01 . * * * \mathrm{p}<.001$. 
Table B26

Advantages and disadvantages to using technology with students, sorted by all participants

\begin{tabular}{|c|c|c|c|c|}
\hline & $\begin{array}{l}\text { Admin } \\
(n=78)\end{array}$ & $\begin{array}{l}\text { Teacher } \\
(n=537)\end{array}$ & $\begin{array}{l}\text { Tech } \\
(n=26)\end{array}$ & $\begin{array}{c}\text { All } \\
(n=641)\end{array}$ \\
\hline Access information easily / current resources & $30.8 \%$ & $29.6 \%$ & $30.8 \%$ & $29.8 \%$ \\
\hline Availability of technology / Money / Funding & $23.1 \%$ & $29.4 \%$ & $3.8 \%$ & $27.6 \%$ \\
\hline Student academics / Organization & $32.1 \%$ & $26.6 \%$ & $26.9 \%$ & $27.3 \%$ \\
\hline Student engagement / Interest / Motivation & $25.6 \%$ & $26.6 \%$ & $23.1 \%$ & $26.4 \%$ \\
\hline $\begin{array}{l}\text { Tech support lacking / tech not working / network slow / } \\
\text { tech old }\end{array}$ & $15.4 \%$ & $22.2 \%$ & $3.8 \%$ & $20.6 \%$ \\
\hline Student individualization / personalization & $23.1 \%$ & $19.6 \%$ & $26.9 \%$ & $20.3 \%$ \\
\hline Building student skills / Preparing for future & $21.8 \%$ & $19.0 \%$ & $34.6 \%$ & $20.0 \%$ \\
\hline Distractions / Inappropriate use / Social media & $10.3 \%$ & $17.5 \%$ & $19.2 \%$ & $16.7 \%$ \\
\hline Student practice & $7.7 \%$ & $12.5 \%$ & $15.4 \%$ & $12.0 \%$ \\
\hline Student (project) creation / demonstration of learning & $7.7 \%$ & $11.7 \%$ & $19.2 \%$ & $11.5 \%$ \\
\hline Student communication or collaboration tool & $9.0 \%$ & $9.7 \%$ & $11.5 \%$ & $9.7 \%$ \\
\hline Not used effectively for learning/teaching & $11.5 \%$ & $7.8 \%$ & $23.1 \%$ & $8.9 \%$ \\
\hline $\begin{array}{l}\text { Feedback loop / Data collection (teacher) / real time } \\
\text { monitoring }\end{array}$ & $7.7 \%$ & $8.8 \%$ & $7.7 \%$ & $8.6 \%$ \\
\hline Access to real-world experiences (or info) & $7.7 \%$ & $7.8 \%$ & $15.4 \%$ & $8.1 \%$ \\
\hline Students have low tech skill level & $1.3 \%$ & $8.8 \%$ & $7.7 \%$ & $7.8 \%$ \\
\hline Less teacher control / supervision or management issues & $5.1 \%$ & $7.8 \%$ & $3.8 \%$ & $7.3 \%$ \\
\hline Equity (low access) to tech or tech experience (home) & $7.7 \%$ & $6.0 \%$ & $0.0 \%$ & $5.9 \%$ \\
\hline Time to prep / Time & $1.3 \%$ & $6.1 \%$ & $0.0 \%$ & $5.3 \%$ \\
\hline $\begin{array}{l}\text { Teacher PD (training) needed / Low teacher ability w/ } \\
\text { tech }\end{array}$ & $12.8 \%$ & $2.8 \%$ & $11.5 \%$ & $4.4 \%$ \\
\hline $\begin{array}{l}\text { Less teacher prep / less paper / enhance teaching } \\
\text { practices }\end{array}$ & $2.6 \%$ & $3.7 \%$ & $15.4 \%$ & $4.1 \%$ \\
\hline Equity (access) for students (home) & $6.4 \%$ & $3.5 \%$ & $0.0 \%$ & $3.7 \%$ \\
\hline Student sees tech as toy/entertainment, not learning tool & $1.3 \%$ & $3.2 \%$ & $0.0 \%$ & $2.8 \%$ \\
\hline Time used for assessments & $0.0 \%$ & $2.6 \%$ & $0.0 \%$ & $2.2 \%$ \\
\hline Screen time / Anti-social behavior / Isolation & $0.0 \%$ & $2.4 \%$ & $0.0 \%$ & $2.0 \%$ \\
\hline Student creativity & $0.0 \%$ & $0.9 \%$ & $3.8 \%$ & $0.9 \%$ \\
\hline
\end{tabular}

Note. Shaded items are considered "disadvantages" and non-shaded items are considered "advantages." 


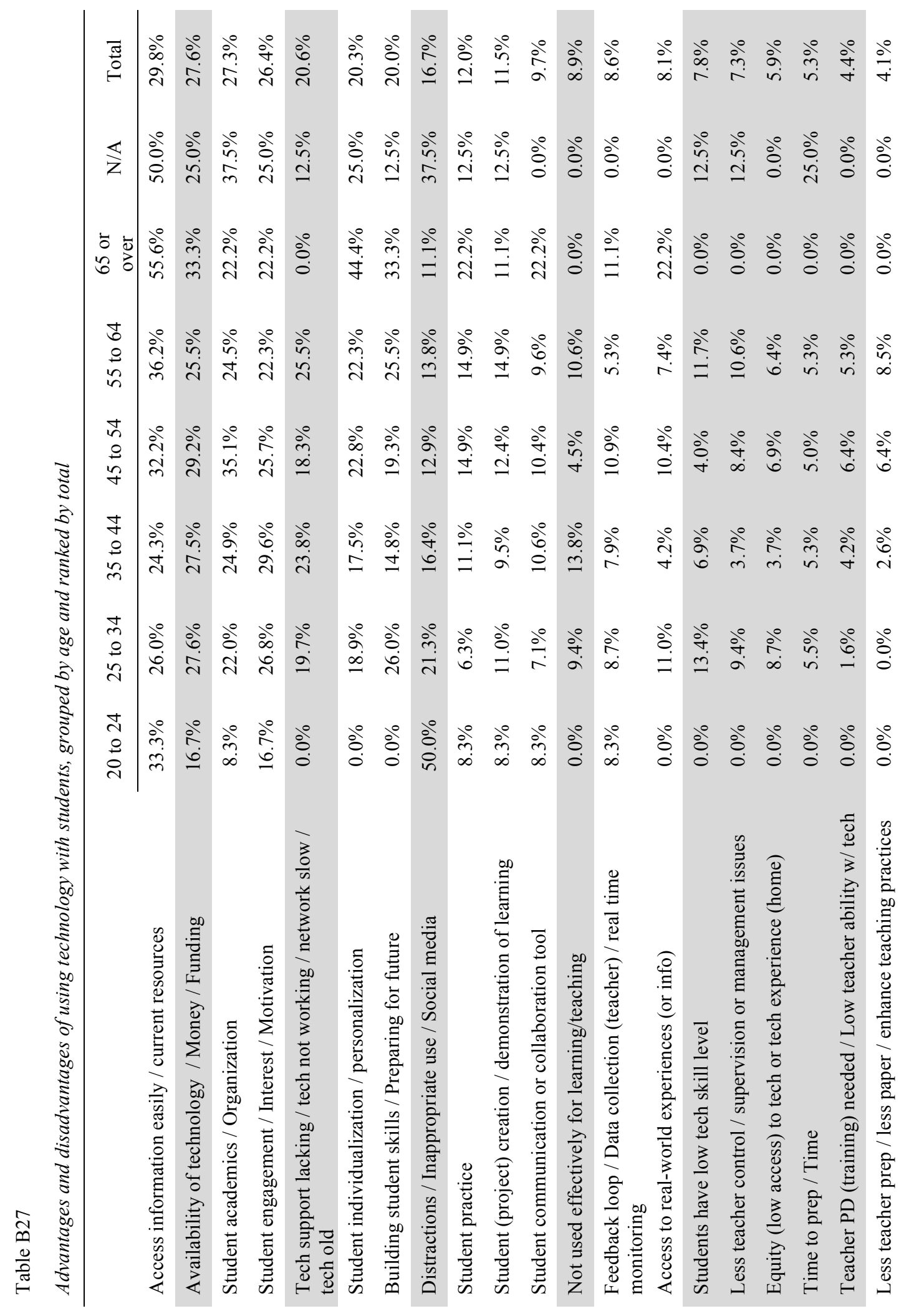




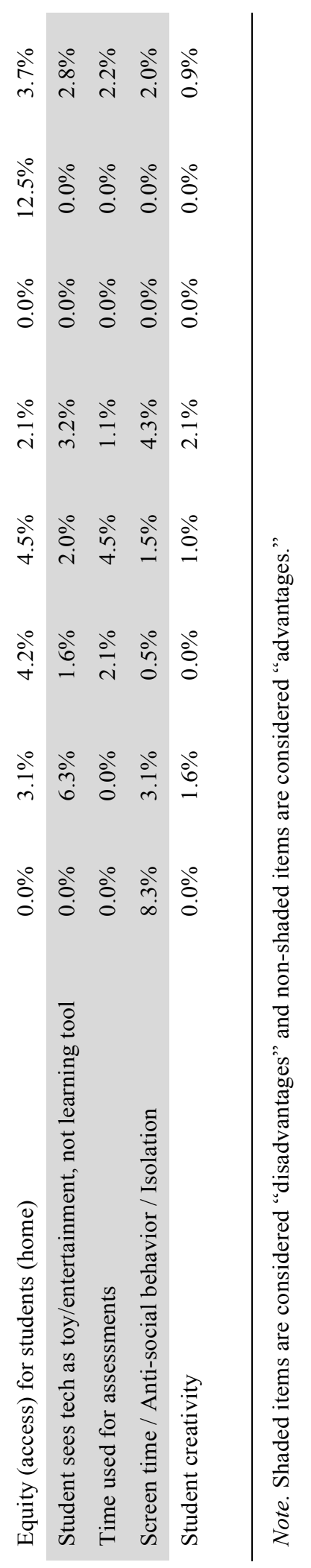




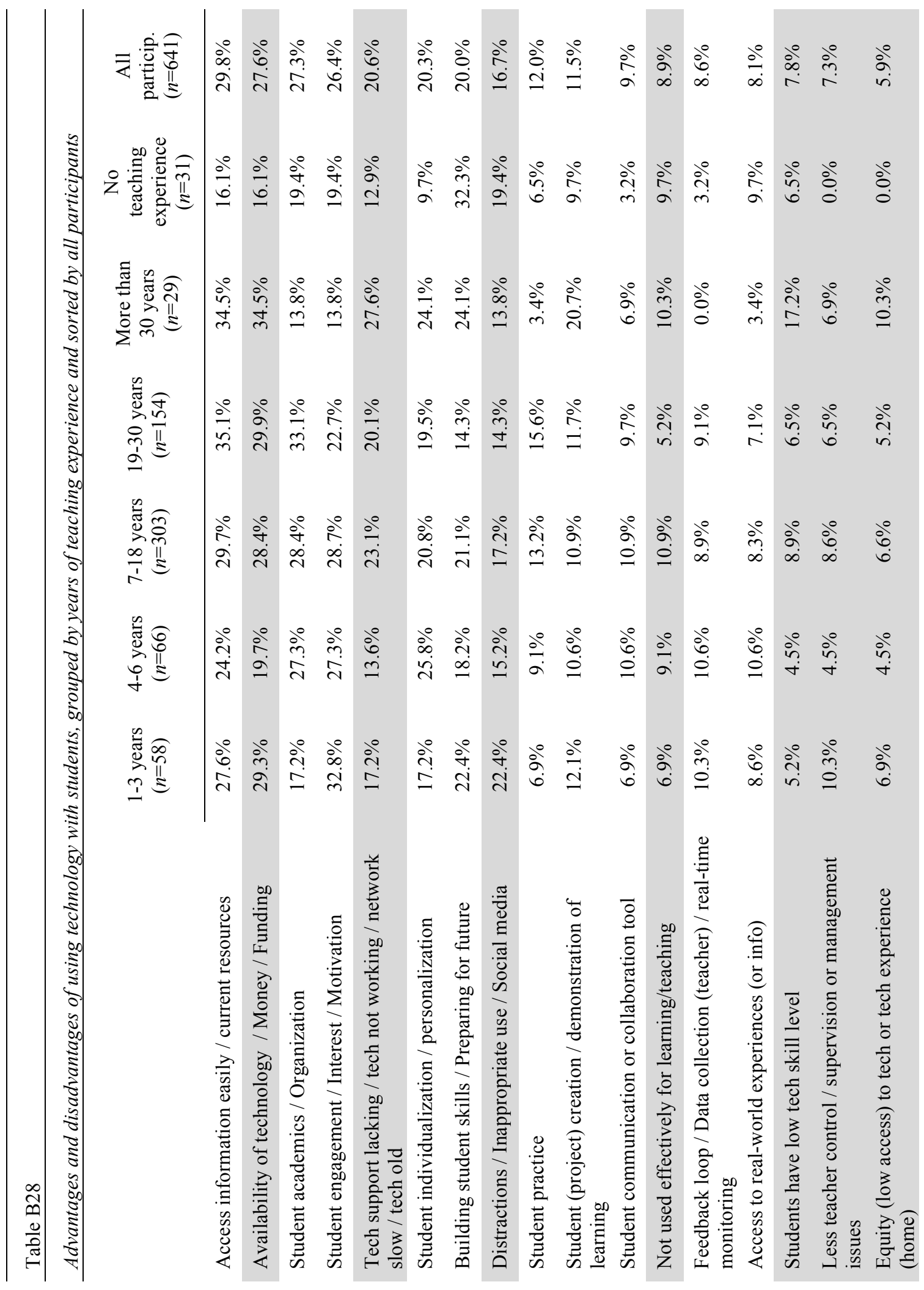




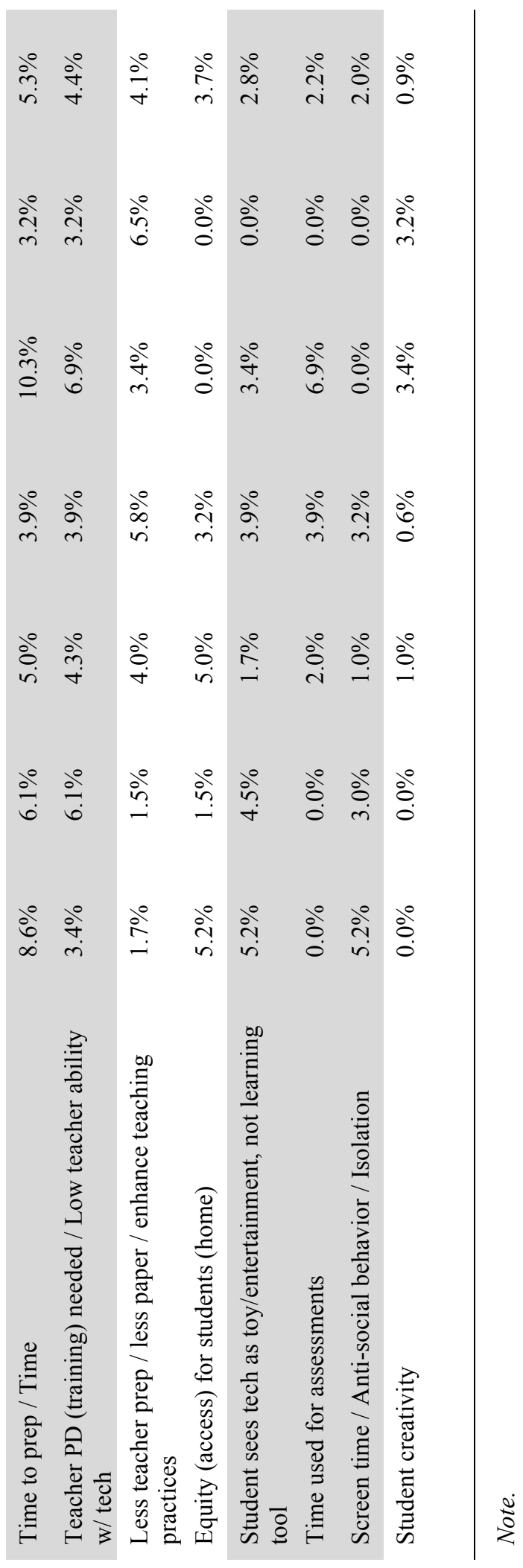


Table B29

All obstacles that influence technology integration grouped by role and sorted by all participants

\begin{tabular}{|c|c|c|c|c|}
\hline & $\begin{array}{l}\text { Admin } \\
(n=78)\end{array}$ & $\begin{array}{l}\text { Teacher } \\
(n=537)\end{array}$ & $\begin{array}{c}\text { Tech } \\
(n=26)\end{array}$ & $\underset{(n=641)}{\text { All }}$ \\
\hline Lack of access to devices & $24.4 \%$ & $35.2 \%$ & $23.1 \%$ & $33.4 \%$ \\
\hline Lack of time & $10.3 \%$ & $17.5 \%$ & $19.2 \%$ & $16.7 \%$ \\
\hline Teacher professional development missing & $23.1 \%$ & $11.7 \%$ & $38.5 \%$ & $14.2 \%$ \\
\hline Teacher knowledge of tech and pedagogy & $7.7 \%$ & $10.6 \%$ & $7.7 \%$ & $10.1 \%$ \\
\hline Costs/Funding & $21.8 \%$ & $8.6 \%$ & $7.7 \%$ & $10.1 \%$ \\
\hline Outdated/old tech & $6.4 \%$ & $7.3 \%$ & $7.7 \%$ & $7.2 \%$ \\
\hline Tech support/lack of & $6.4 \%$ & $7.3 \%$ & $7.7 \%$ & $7.2 \%$ \\
\hline Internet/network slow/unreliable & $9.0 \%$ & $5.8 \%$ & $23.1 \%$ & $6.9 \%$ \\
\hline Equity of student access & $9.0 \%$ & $6.1 \%$ & $0.0 \%$ & $6.2 \%$ \\
\hline Tech doesn't work & $1.3 \%$ & $6.0 \%$ & $3.8 \%$ & $5.3 \%$ \\
\hline District/school systems/vision & $6.4 \%$ & $4.7 \%$ & $7.7 \%$ & $5.0 \%$ \\
\hline Lack of resource & $5.1 \%$ & $4.5 \%$ & $3.8 \%$ & $4.5 \%$ \\
\hline Other tech policy/practice & $3.8 \%$ & $3.4 \%$ & $7.7 \%$ & $3.6 \%$ \\
\hline Student behaviors & $1.3 \%$ & $3.0 \%$ & $3.8 \%$ & $2.8 \%$ \\
\hline Teacher not knowing how to choose tech & $10.3 \%$ & $1.5 \%$ & $7.7 \%$ & $2.8 \%$ \\
\hline Log in time/Lab management & $0.0 \%$ & $3.2 \%$ & $0.0 \%$ & $2.7 \%$ \\
\hline Student training or education & $2.6 \%$ & $2.0 \%$ & $7.7 \%$ & $2.3 \%$ \\
\hline Filtering/blocking policy/practice & $1.3 \%$ & $2.0 \%$ & $3.8 \%$ & $2.0 \%$ \\
\hline Student distraction & $0.0 \%$ & $2.2 \%$ & $0.0 \%$ & $1.9 \%$ \\
\hline Lack of accessories/Peripheral devices & $0.0 \%$ & $2.0 \%$ & $3.8 \%$ & $1.9 \%$ \\
\hline Students misuse tech & $0.0 \%$ & $1.1 \%$ & $0.0 \%$ & $0.9 \%$ \\
\hline Student tech issues & $0.0 \%$ & $1.1 \%$ & $0.0 \%$ & $0.9 \%$ \\
\hline Assessment/SBAC/CCSS & $1.3 \%$ & $0.9 \%$ & $0.0 \%$ & $0.9 \%$ \\
\hline Keeping tech current & $0.0 \%$ & $0.9 \%$ & $0.0 \%$ & $0.8 \%$ \\
\hline Student-to-device ratio (negative) & $0.0 \%$ & $0.7 \%$ & $0.0 \%$ & $0.6 \%$ \\
\hline Teacher reluctance/resistance & $1.3 \%$ & $0.2 \%$ & $7.7 \%$ & $0.6 \%$ \\
\hline No obstacles / None ${ }^{a}$ & $0.0 \%$ & $0.4 \%$ & $0.0 \%$ & $0.3 \%$ \\
\hline
\end{tabular}

Note. "Some respondents specifically used "no obstacles" or "none" in their response. 


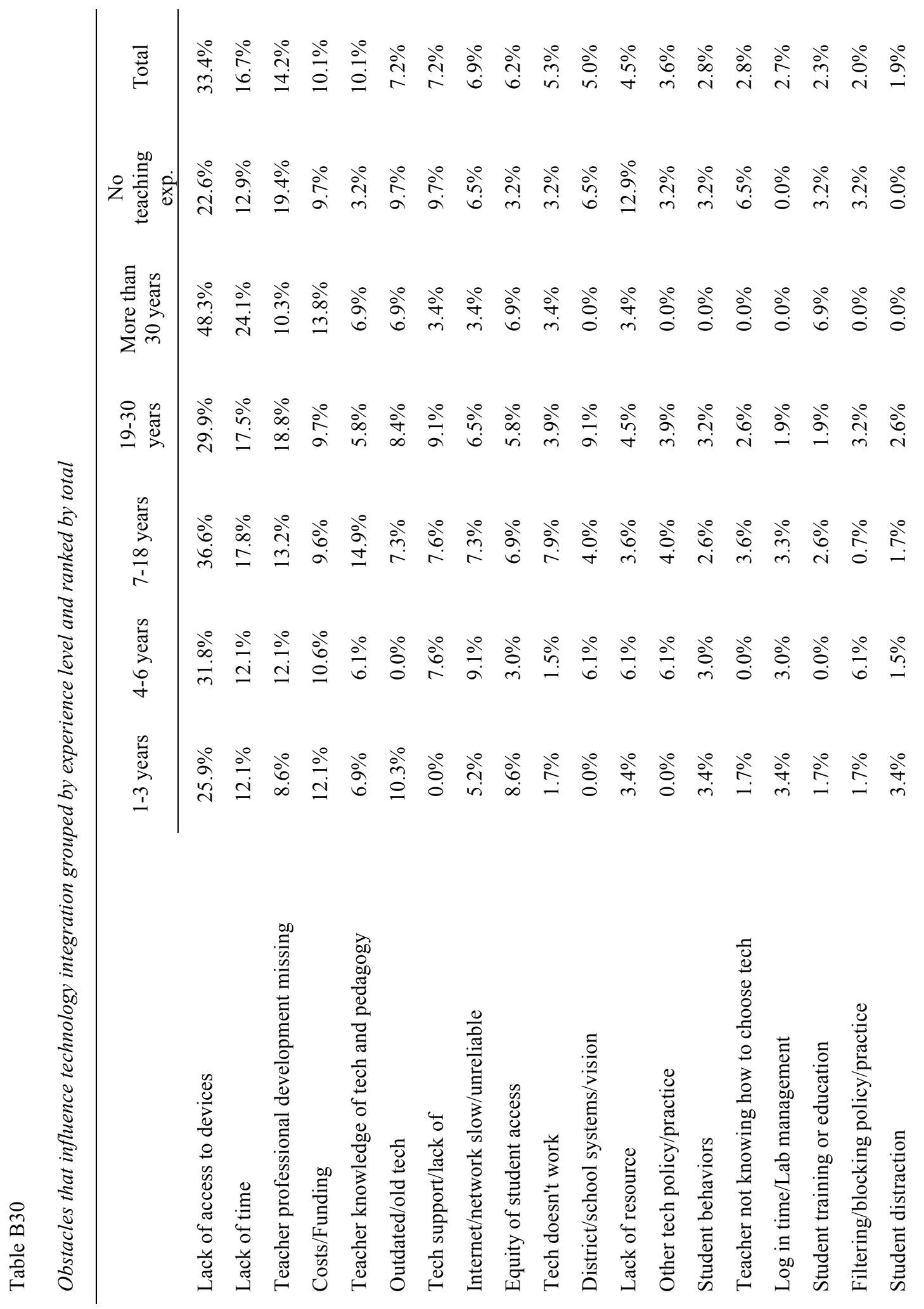




$$
\begin{aligned}
& \text { ఏे }
\end{aligned}
$$

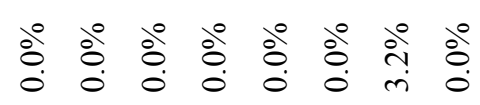

$$
\begin{aligned}
& \text { ठํ }
\end{aligned}
$$

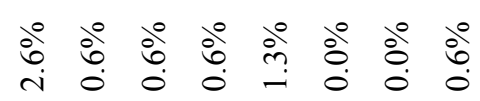

$$
\begin{aligned}
& \text { i̊̀ } \\
& \text { 官 施 } \\
& \text { ठे. }
\end{aligned}
$$

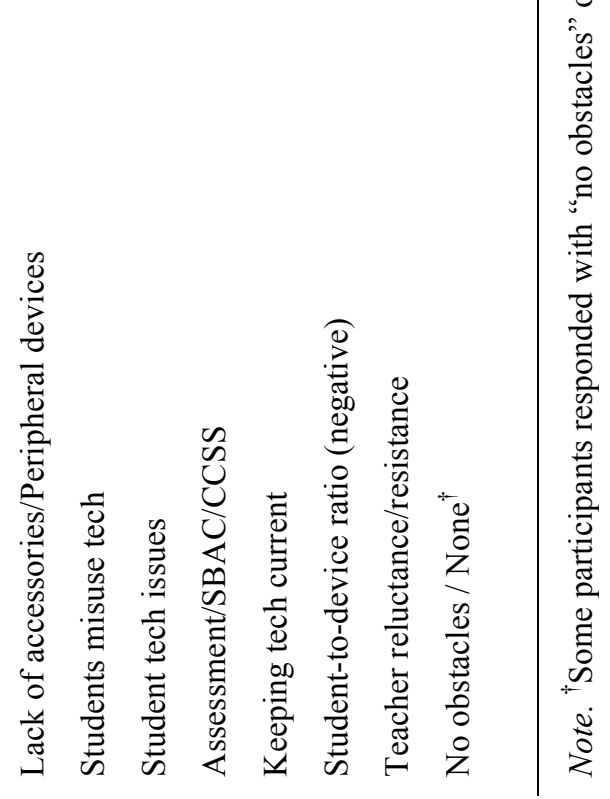


Table B31

Support statements that influence technology integration, grouped by role

\begin{tabular}{|c|c|c|c|c|}
\hline Support statement & $\%$ & Teachers & Admin & $\begin{array}{c}\text { Tech } \\
\text { Support }\end{array}$ \\
\hline \multirow{3}{*}{$\begin{array}{l}\text { (Teachers) } \\
\text { I feel that my school leadership } \\
\text { supports my use of technology } \\
\text { with students }\end{array}$} & Strongly agree & $26.4 \%$ & $16.4 \%$ & $34.6 \%$ \\
\hline & Agree & $50.9 \%$ & $61.6 \%$ & $42.3 \%$ \\
\hline & $\begin{array}{l}\text { Neither Agree } \\
\text { nor Disagree }\end{array}$ & $14.4 \%$ & $13.7 \%$ & $11.5 \%$ \\
\hline \multirow{2}{*}{$\begin{array}{l}\text { (Admin \& Tech Support) } \\
\text { I feel that my leadership supports } \\
\text { our teachers' use of technology } \\
\text { with students }\end{array}$} & Disagree & $5.2 \%$ & $8.2 \%$ & $7.7 \%$ \\
\hline & $\begin{array}{l}\text { Strongly } \\
\text { disagree }\end{array}$ & $3.1 \%$ & $0.0 \%$ & $3.9 \%$ \\
\hline \multirow{3}{*}{$\begin{array}{l}\text { (Teachers) } \\
\text { I feel that my teaching peers } \\
\text { support my use of technology with } \\
\text { students. }\end{array}$} & Strongly agree & $23.3 \%$ & $16.4 \%$ & $19.2 \%$ \\
\hline & Agree & $55.1 \%$ & $67.2 \%$ & $46.2 \%$ \\
\hline & $\begin{array}{l}\text { Neither Agree } \\
\text { nor Disagree }\end{array}$ & $17.3 \%$ & $11.0 \%$ & $30.8 \%$ \\
\hline \multirow{2}{*}{$\begin{array}{l}\text { (Admin \& Tech Support) } \\
\text { I feel that teachers' peers support } \\
\text { the use of technology with } \\
\text { students. }\end{array}$} & Disagree & $3.1 \%$ & $4.1 \%$ & $0.0 \%$ \\
\hline & $\begin{array}{l}\text { Strongly } \\
\text { disagree }\end{array}$ & $1.3 \%$ & $1.4 \%$ & $3.9 \%$ \\
\hline \multirow{3}{*}{$\begin{array}{l}\text { (Teachers) } \\
\text { I can get adequate technology } \\
\text { support for issues that arise for me } \\
\text { or for my students. }\end{array}$} & Strongly agree & $13.5 \%$ & $6.9 \%$ & $7.7 \%$ \\
\hline & Agree & $35.6 \%$ & $49.3 \%$ & $53.9 \%$ \\
\hline & $\begin{array}{l}\text { Neither Agree } \\
\text { nor Disagree }\end{array}$ & $17.5 \%$ & $20.6 \%$ & $19.2 \%$ \\
\hline \multirow{2}{*}{$\begin{array}{l}\text { (Admin \& Tech Support) } \\
\text { I feel that teachers can get } \\
\text { adequate technology support for } \\
\text { issues that arise for themselves or } \\
\text { for their students. }\end{array}$} & Disagree & $24.3 \%$ & $17.8 \%$ & $19.2 \%$ \\
\hline & $\begin{array}{l}\text { Strongly } \\
\text { disagree }\end{array}$ & $9.2 \%$ & $5.5 \%$ & $0.0 \%$ \\
\hline
\end{tabular}

Note. 
Table B32

Top responses to obstacles that influence technology integration, grouped by role

\begin{tabular}{|c|c|c|}
\hline Role & $\%$ & Category of response \\
\hline \multirow{8}{*}{$\begin{array}{l}\text { Teacher } \\
(n=537)\end{array}$} & $35.2 \%$ & Lack of access to devices \\
\hline & $17.5 \%$ & Lack of time \\
\hline & $11.7 \%$ & Teacher professional development missing \\
\hline & $10.6 \%$ & Teacher knowledge of tech and pedagogy \\
\hline & $8.6 \%$ & Costs/Funding \\
\hline & $7.3 \%$ & Outdated/old tech \\
\hline & $7.3 \%$ & Tech support/lack of \\
\hline & $6.1 \%$ & Equity of student access \\
\hline \multirow{8}{*}{$\begin{array}{l}\text { Administrator } \\
\qquad(n=78)\end{array}$} & $24.4 \%$ & Lack of access to devices \\
\hline & $23.1 \%$ & Teacher professional development missing \\
\hline & $21.8 \%$ & Costs/Funding \\
\hline & $10.3 \%$ & Lack of time \\
\hline & $10.3 \%$ & Teacher not knowing how to choose tech \\
\hline & $9.0 \%$ & Equity of student access \\
\hline & $9.0 \%$ & Internet/network slow/unreliable \\
\hline & $7.7 \%$ & Teacher knowledge of tech and pedagogy \\
\hline \multirow{8}{*}{$\begin{array}{l}\text { Tech Support } \\
\qquad(n=26)\end{array}$} & $38.5 \%$ & Teacher professional development missing \\
\hline & $23.1 \%$ & Lack of access to devices \\
\hline & $23.1 \%$ & Internet/network slow/unreliable \\
\hline & $19.2 \%$ & Lack of time \\
\hline & $7.7 \%$ & Teacher knowledge of tech and pedagogy \\
\hline & $7.7 \%$ & Costs/Funding \\
\hline & $7.7 \%$ & Outdated/old tech \\
\hline & $7.7 \%$ & Tech support/lack of \\
\hline
\end{tabular}

Note. 
Table B33

Top responses to obstacles to using technology with students, grouped by years of teaching experience

\begin{tabular}{|c|c|c|}
\hline Experience & $\%$ & Category of response \\
\hline \multirow{3}{*}{$\begin{array}{l}1-3 \text { years teaching } \\
(n=58)\end{array}$} & $25.9 \%$ & Lack of access to devices \\
\hline & $12.1 \%$ & Lack of time \\
\hline & $12.1 \%$ & Costs/Funding \\
\hline \multirow{3}{*}{$\begin{array}{l}\text { 4-6 years teaching } \\
\qquad(n=66)\end{array}$} & $31.8 \%$ & Lack of access to devices \\
\hline & $12.1 \%$ & Lack of time \\
\hline & $12.1 \%$ & Teacher professional development missing \\
\hline \multirow{3}{*}{$\begin{array}{l}\text { 7-18 years teaching } \\
(n=303)\end{array}$} & $36.6 \%$ & Lack of access to devices \\
\hline & $17.8 \%$ & Lack of time \\
\hline & $14.9 \%$ & Teacher knowledge of tech and pedagogy \\
\hline \multirow{3}{*}{$\begin{array}{c}19-30 \text { years teaching } \\
(n=154)\end{array}$} & $29.9 \%$ & Lack of access to devices \\
\hline & $18.8 \%$ & Teacher professional development missing \\
\hline & $17.5 \%$ & Lack of time \\
\hline \multirow{3}{*}{$\begin{array}{l}\text { More than } 30 \text { years } \\
\text { teaching }(n=29)\end{array}$} & $48.3 \%$ & Lack of access to devices \\
\hline & $24.1 \%$ & Lack of time \\
\hline & $13.8 \%$ & Costs/Funding \\
\hline \multirow{3}{*}{$\begin{array}{l}\text { No teaching } \\
\text { experience } \\
\quad(n=31)\end{array}$} & $22.6 \%$ & Lack of access to devices \\
\hline & $19.4 \%$ & Teacher professional development missing \\
\hline & $12.9 \%$ & Lack of time $^{a}$ \\
\hline
\end{tabular}

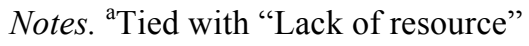


Table B34

Top responses to district- or school-provided professional development, grouped by participant role

\begin{tabular}{|c|c|c|}
\hline Role & $\%$ & Category of response \\
\hline \multirow{9}{*}{$\begin{array}{l}\text { Administrator } \\
\quad(\mathrm{n}=78)\end{array}$} & $30.8 \%$ & Direct application to the classroom / Relevant-effective use strategies \\
\hline & $20.5 \%$ & Practical/meaningful information / grade or content area appropriate \\
\hline & $21.8 \%$ & Collaborating with peers / talk with peers / share ideas \\
\hline & $15.4 \%$ & Access/exposure to new resources, tools, skills, techniques, strategies \\
\hline & $15.4 \%$ & Hands-on / Real-world \\
\hline & $12.8 \%$ & Relevant / useful / informative \\
\hline & $12.8 \%$ & Engaging / engaging content \\
\hline & $9.0 \%$ & Follow up sessions / coaching model / feedback \\
\hline & $9.0 \%$ & Time to practice / Time to plan \\
\hline \multirow{9}{*}{$\begin{array}{l}\text { Teacher } \\
(\mathrm{n}=537)\end{array}$} & $28.3 \%$ & Direct application to the classroom / Relevant-effective use strategies \\
\hline & $18.1 \%$ & Collaborating with peers / talk with peers / share ideas \\
\hline & $17.1 \%$ & Time to practice / Time to plan \\
\hline & $13.6 \%$ & Practical/meaningful information / grade or content area appropriate \\
\hline & $13.2 \%$ & Well-prepared presenters / Expert presenters \\
\hline & $12.8 \%$ & Hands-on / Real-world \\
\hline & $9.7 \%$ & Can't think of positive experience / District lacks good PD \\
\hline & $7.8 \%$ & Access/exposure to new resources/tools/skills/techniques/ strategies \\
\hline & $6.5 \%$ & Relevant / useful / informative \\
\hline \multirow{9}{*}{$\begin{array}{l}\text { Tech Support } \\
\quad(\mathrm{n}=26)\end{array}$} & $30.8 \%$ & Collaborating with peers / talk with peers / share ideas \\
\hline & $23.1 \%$ & Can't think of positive experience / District lacks good PD \\
\hline & $15.4 \%$ & Direct application to the classroom / Relevant-effective use strategies \\
\hline & $15.4 \%$ & Practical/meaningful information / grade or content area appropriate \\
\hline & $15.4 \%$ & Well-prepared presenters / Expert presenters \\
\hline & $11.5 \%$ & Time to practice / Time to plan \\
\hline & $11.5 \%$ & Access/exposure to new resources/tools/skills/techniques/ strategies \\
\hline & $11.5 \%$ & Participants choose topics / session choice \\
\hline & $11.5 \%$ & Staff concerns/interests/input for content/needs \\
\hline
\end{tabular}

Note. 
Table B35

Top responses to district- or school-provided professional development, grouped by years of teaching experience

\begin{tabular}{|c|c|c|}
\hline Experience & $\%$ & Category of response \\
\hline \multirow{4}{*}{$\begin{array}{c}1-3 \text { years } \\
\text { teaching } \\
(n=58)\end{array}$} & $24.1 \%$ & $\begin{array}{l}\text { Direct application to the classroom / Relevant-effective use } \\
\text { strategies }\end{array}$ \\
\hline & $20.7 \%$ & Collaborating with peers / talk with peers / share ideas \\
\hline & $19.0 \%$ & Hands-on / Real-world \\
\hline & $19.0 \%$ & $\begin{array}{l}\text { Access/exposure to new resources, tools, skills, techniques, } \\
\text { strategies }\end{array}$ \\
\hline \multirow{4}{*}{$\begin{array}{c}4-6 \text { years } \\
\text { teaching } \\
(n=66)\end{array}$} & $27.3 \%$ & $\begin{array}{l}\text { Direct application to the classroom / Relevant-effective use } \\
\text { strategies }\end{array}$ \\
\hline & $18.2 \%$ & Well-prepared presenters / Expert presenters \\
\hline & $15.2 \%$ & Relevant / Useful / Informative \\
\hline & $13.6 \%$ & Collaborating with peers / talk with peers / share ideas \\
\hline \multirow{4}{*}{$\begin{array}{l}7-18 \text { years } \\
\text { teaching } \\
(n=303)\end{array}$} & $32.0 \%$ & $\begin{array}{l}\text { Direct application to the classroom / Relevant-effective use } \\
\text { strategies }\end{array}$ \\
\hline & $21.8 \%$ & Collaborating with peers / talk with peers / share ideas \\
\hline & $19.8 \%$ & Time to practice / Time to plan \\
\hline & $17.2 \%$ & Practical/meaningful information / grade or content area appropriate \\
\hline \multirow{4}{*}{$\begin{array}{c}\text { 19-30 years } \\
\text { teaching } \\
(n=154)\end{array}$} & $26.6 \%$ & $\begin{array}{l}\text { Direct application to the classroom / Relevant-effective use } \\
\text { strategies }\end{array}$ \\
\hline & $18.8 \%$ & Time to practice / Time to plan \\
\hline & $14.3 \%$ & Practical/meaningful information / grade or content area appropriate \\
\hline & $13.0 \%$ & Collaborating with peers / talk with peers / share ideas \\
\hline \multirow{4}{*}{$\begin{array}{l}\text { More than } 30 \\
\text { years teaching } \\
\quad(n=29)\end{array}$} & $27.6 \%$ & Collaborating with peers / talk with peers / share ideas \\
\hline & $24.1 \%$ & $\begin{array}{l}\text { Direct application to the classroom / Relevant-effective use } \\
\text { strategies }\end{array}$ \\
\hline & $24.1 \%$ & Well-prepared presenters / Expert presenters \\
\hline & $20.7 \%$ & Time to practice / Time to plan \\
\hline \multirow{4}{*}{$\begin{array}{l}\text { No teaching } \\
\text { experience } \\
\quad(n=31)\end{array}$} & $32.3 \%$ & Can't think of positive experience / District lacks good PD \\
\hline & $22.6 \%$ & Collaborating with peers / talk with peers / share ideas \\
\hline & $16.1 \%$ & Well-prepared presenters / Expert presenters \\
\hline & $16.1 \%$ & Collaborating with peers \\
\hline
\end{tabular}

Notes. 
Table B36

Top responses to district- or school-provided professional development, grouped participant age group

\begin{tabular}{|c|c|c|}
\hline Participant age & $\%$ & Category of response \\
\hline \multirow{3}{*}{$\begin{array}{c}\text { Age } \\
20 \text { to } 24 \\
(n=12)\end{array}$} & $25.0 \%$ & $\begin{array}{l}\text { Direct application to the classroom / Relevant-effective use } \\
\text { strategies }\end{array}$ \\
\hline & $25.0 \%$ & Can't think of positive experience / District lacks good PD \\
\hline & $16.7 \%^{\mathrm{a}}$ & $\begin{array}{l}\text { Access/exposure to new resources, tools, skills, techniques, } \\
\text { strategies }\end{array}$ \\
\hline \multirow{3}{*}{$\begin{array}{c}\text { Age } \\
25 \text { to } 34 \\
(n=127)\end{array}$} & $33.1 \%$ & $\begin{array}{l}\text { Direct application to the classroom / Relevant-effective use } \\
\text { strategies }\end{array}$ \\
\hline & $16.5 \%$ & Hands-on / Real-world \\
\hline & $15.7 \%$ & Well-prepared presenters / Expert presenters \\
\hline \multirow{3}{*}{$\begin{array}{c}\text { Age } \\
35 \text { to } 44 \\
(n=189)\end{array}$} & $28.0 \%$ & $\begin{array}{l}\text { Direct application to the classroom / Relevant-effective use } \\
\text { strategies }\end{array}$ \\
\hline & $21.2 \%$ & Time to practice / Time to plan \\
\hline & $18.5 \%$ & Collaborating with peers \\
\hline \multirow{3}{*}{$\begin{array}{c}\text { Age } \\
45 \text { to } 54 \\
(n=202)\end{array}$} & $28.7 \%$ & $\begin{array}{l}\text { Direct application to the classroom / Relevant-effective use } \\
\text { strategies }\end{array}$ \\
\hline & $18.3 \%$ & Time to practice / Time to plan \\
\hline & $11.9 \%{ }^{\mathrm{b}}$ & $\begin{array}{l}\text { Access/exposure to new resources, tools, skills, techniques, } \\
\text { strategies }\end{array}$ \\
\hline \multirow{3}{*}{$\begin{array}{c}\text { Age } \\
55 \text { to } 64 \\
(n=94)\end{array}$} & $22.3 \%$ & $\begin{array}{l}\text { Direct application to the classroom / Relevant-effective use } \\
\text { strategies }\end{array}$ \\
\hline & $19.1 \%$ & $\begin{array}{l}\text { Practical/meaningful information / grade or content area } \\
\text { appropriate }\end{array}$ \\
\hline & $16.0 \%$ & Time to practice / Time to plan \\
\hline \multirow{3}{*}{$\begin{array}{l}\text { Age } \\
65+ \\
(n=9)\end{array}$} & $44.4 \%$ & Well-prepared presenters / Expert presenters \\
\hline & $22.2 \%$ & $\begin{array}{l}\text { Practical/meaningful information / grade or content area } \\
\text { appropriate }\end{array}$ \\
\hline & $22.2 \%^{\mathrm{c}}$ & Follow up sessions / coaching model / feedback \\
\hline
\end{tabular}

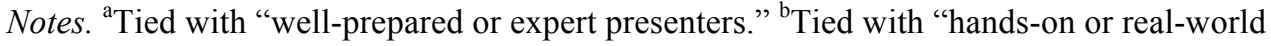
experiences." "Tied with "relevant, useful, or informative." 
APPENDIX C - Figures for Quantitative Results 

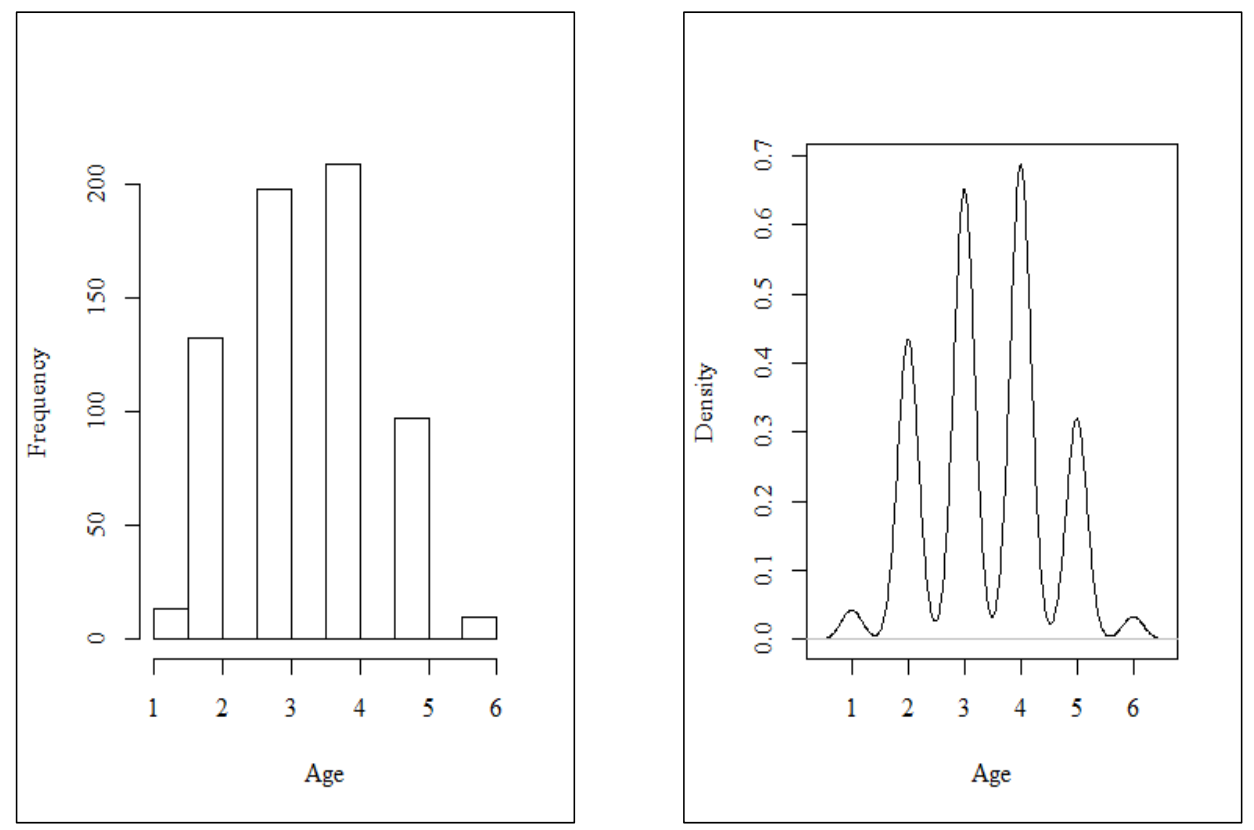

Figure C1. Frequency and density distribution for the Age variable.
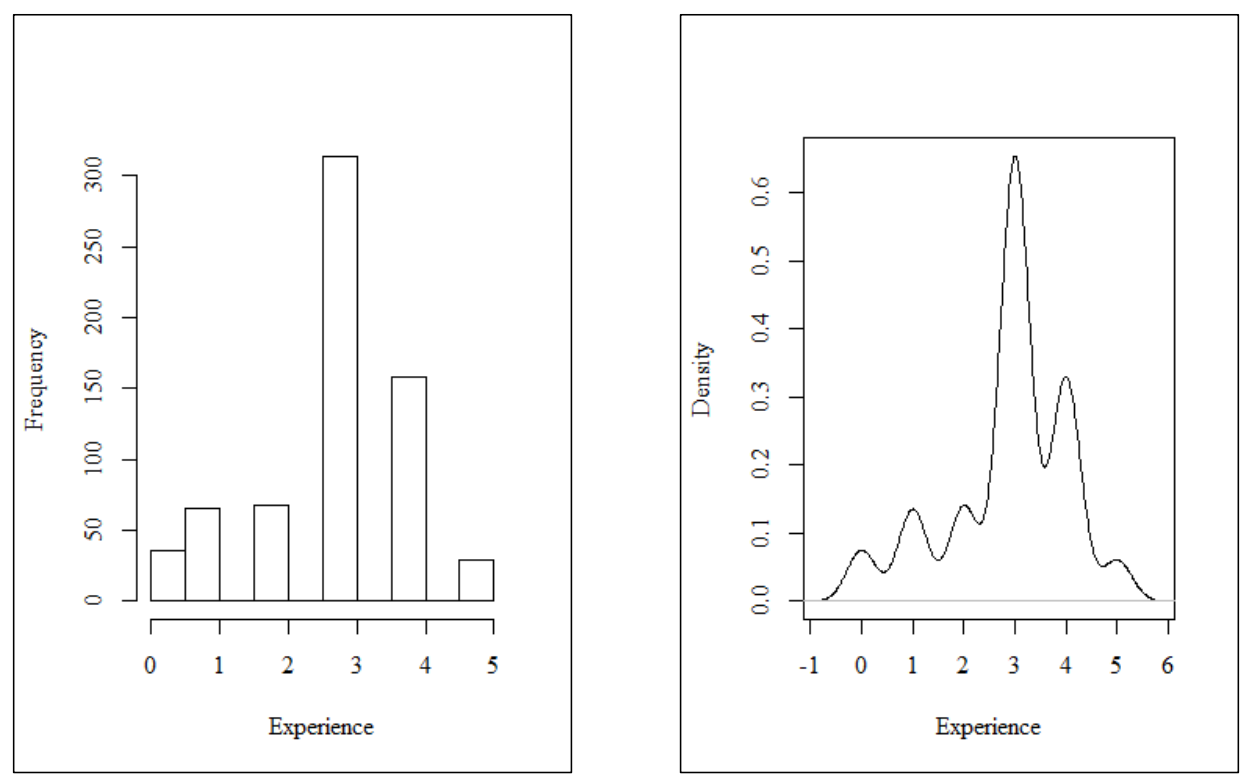

Figure C2. Frequency and density distribution for the teaching Experience variable. 

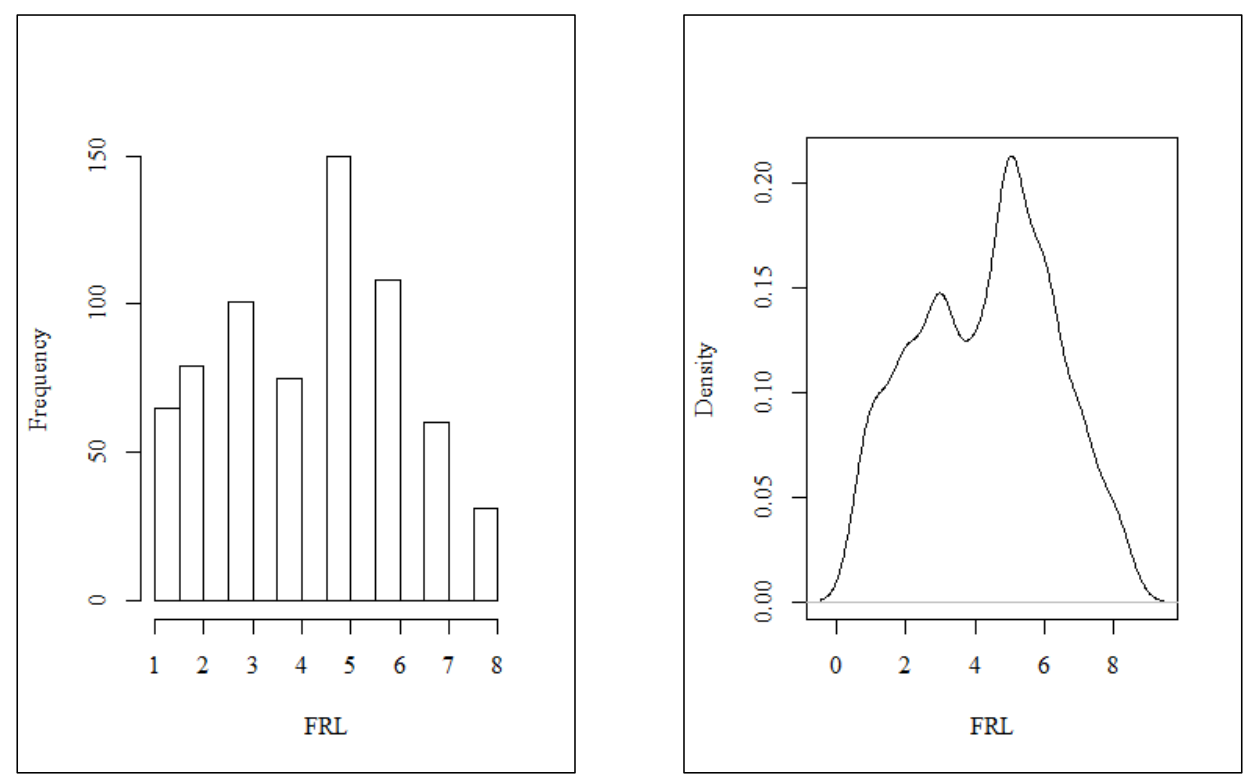

Figure C3. Frequency and density distribution for the Free and Reduced Lunch variable.
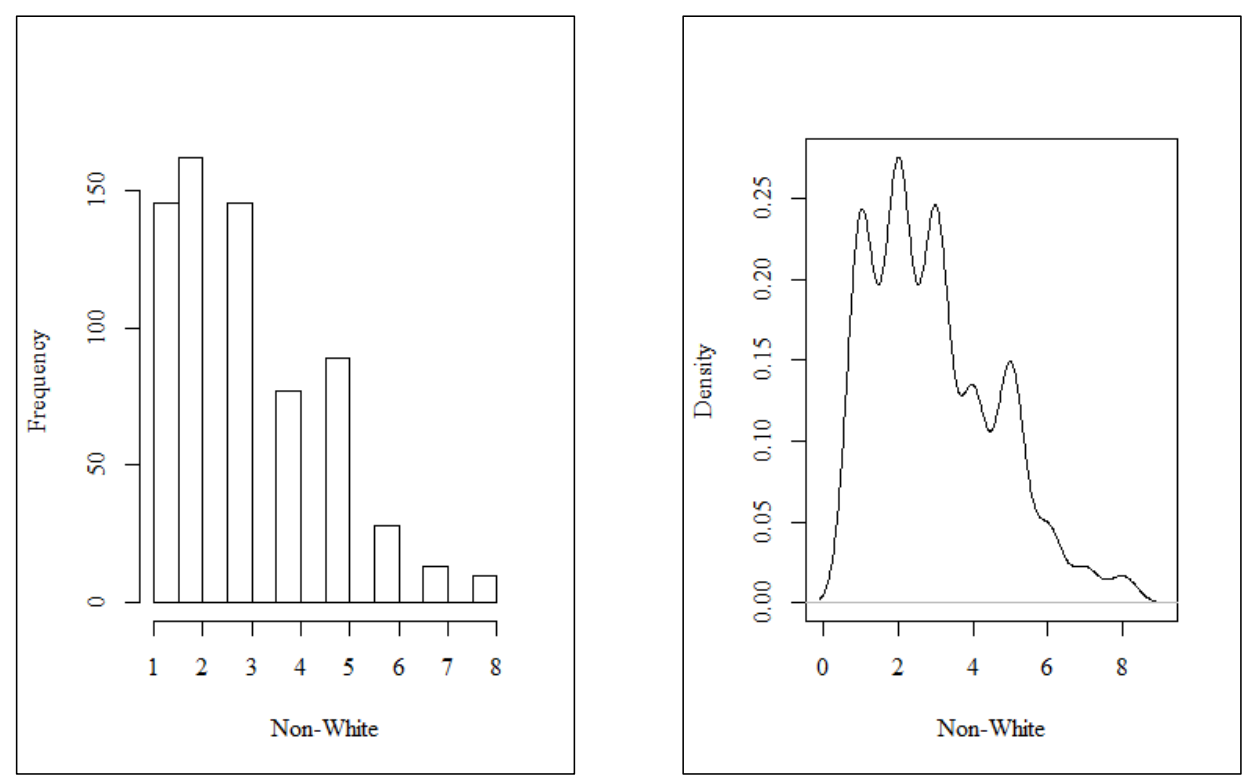

Figure C4. Frequency and density distribution for the Non-White variable. 

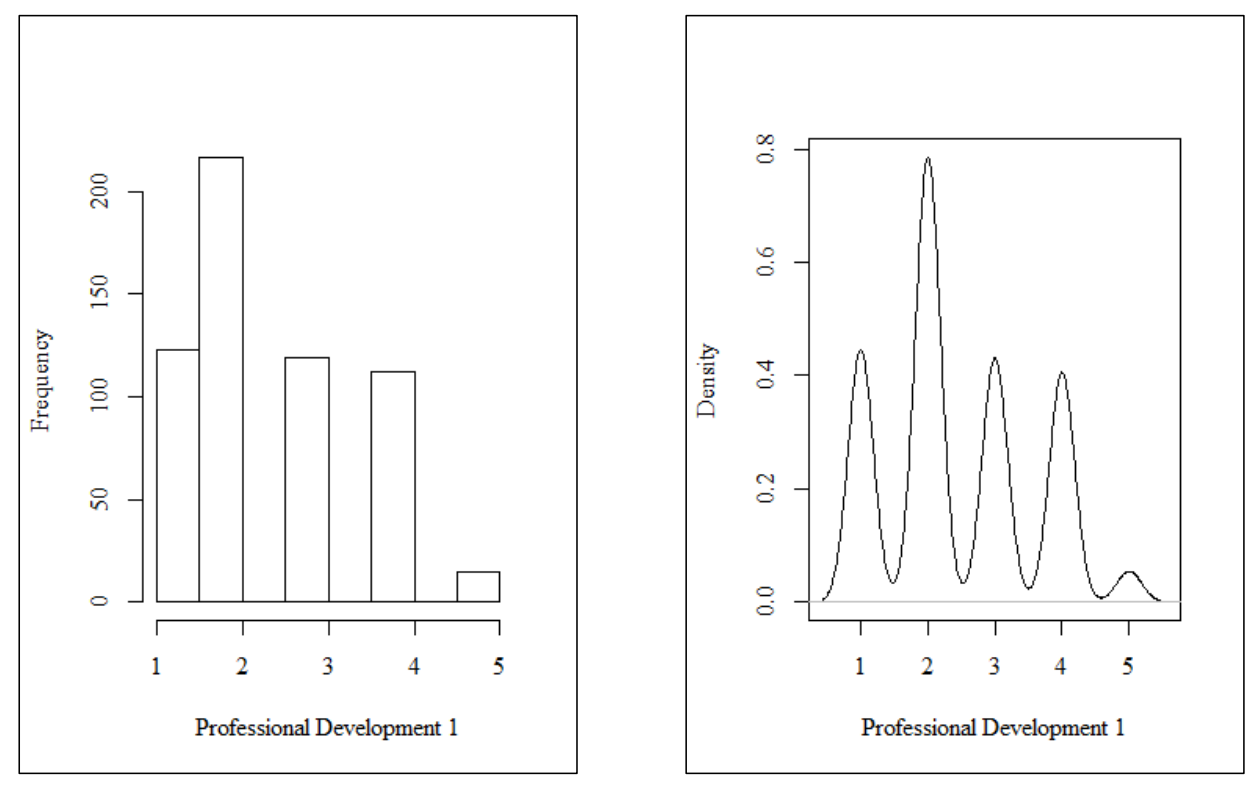

Figure C5. Frequency and density distribution for the Professional Development 1 variable.
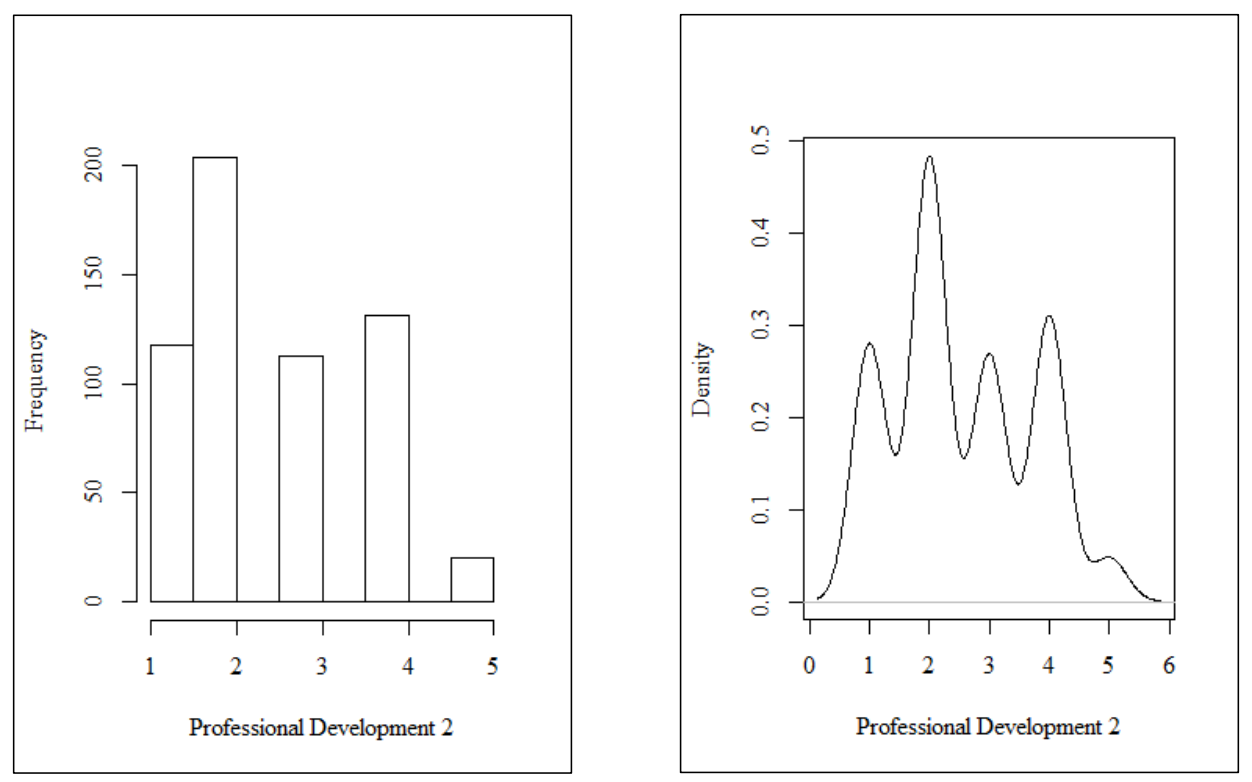

Figure C6. Frequency and density distribution for the Professional Development 2 variable. 

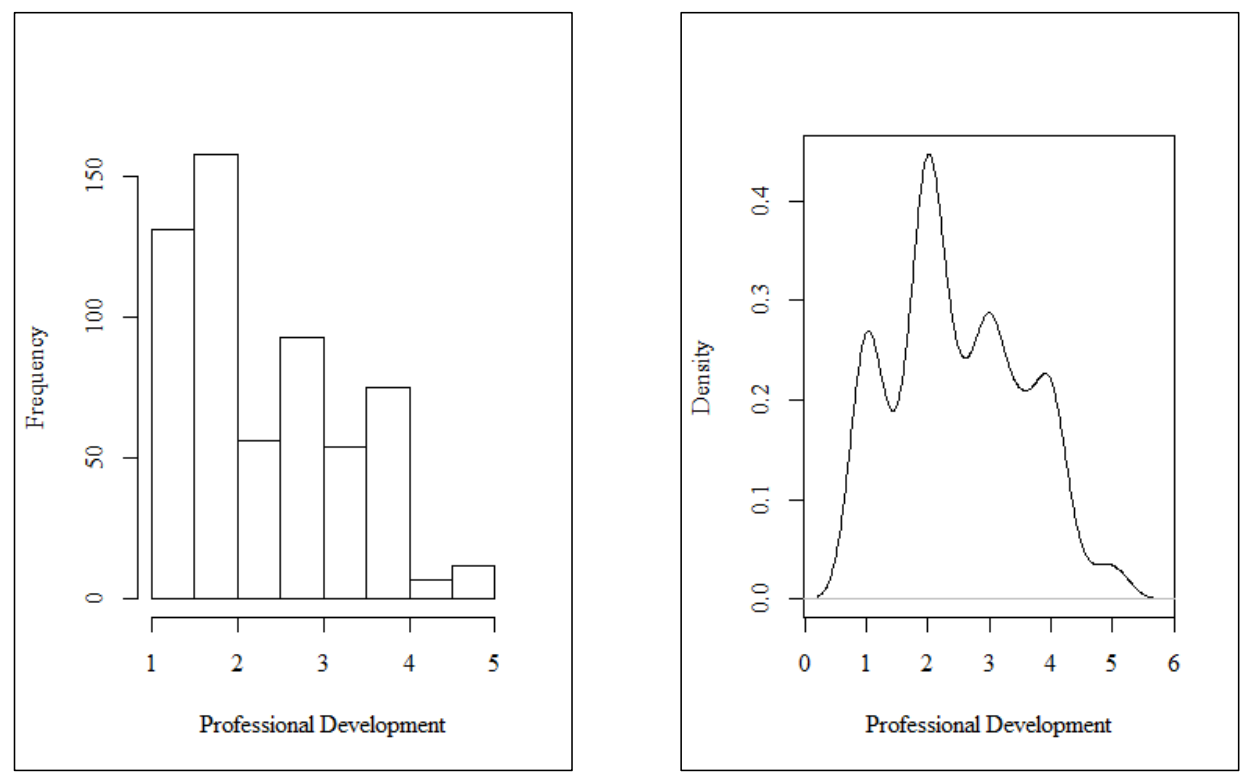

Figure C7. Frequency and density distribution for the Professional Development (Combined) variable.
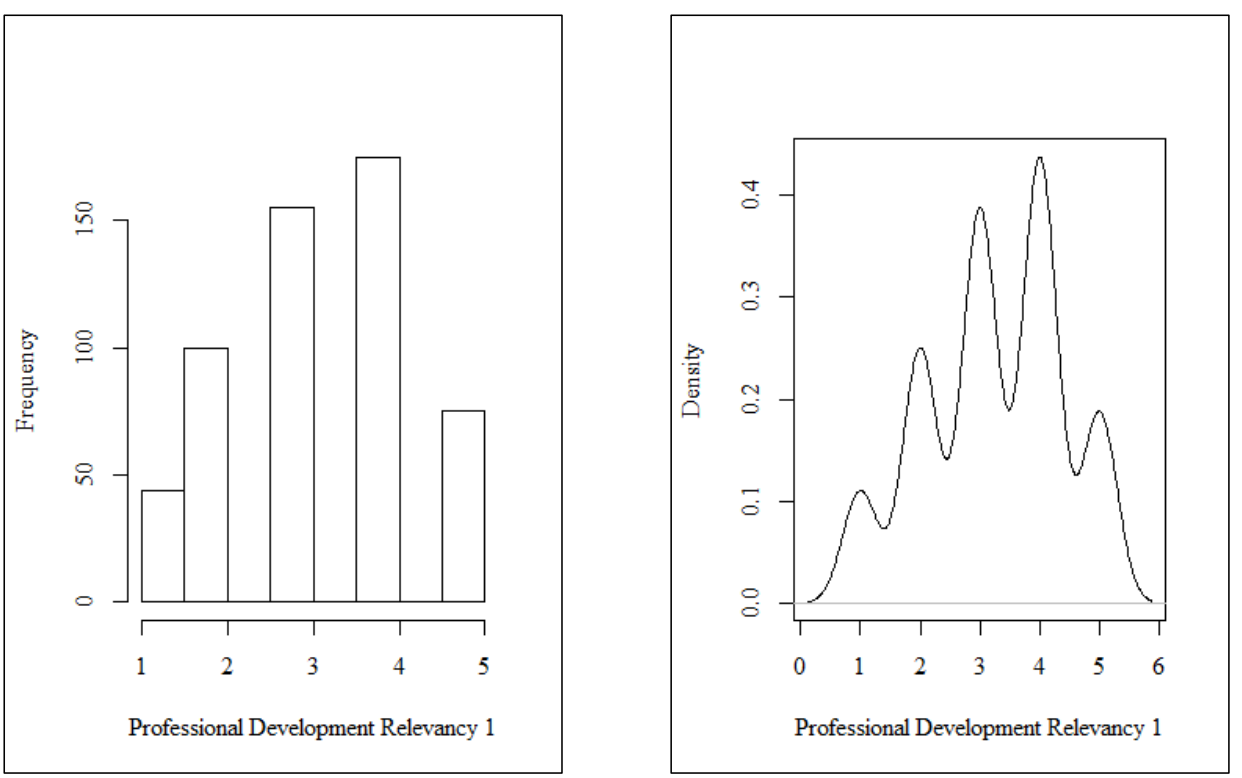

Figure C8. Frequency and density distribution for the Professional Development Relevancy 1 variable. 

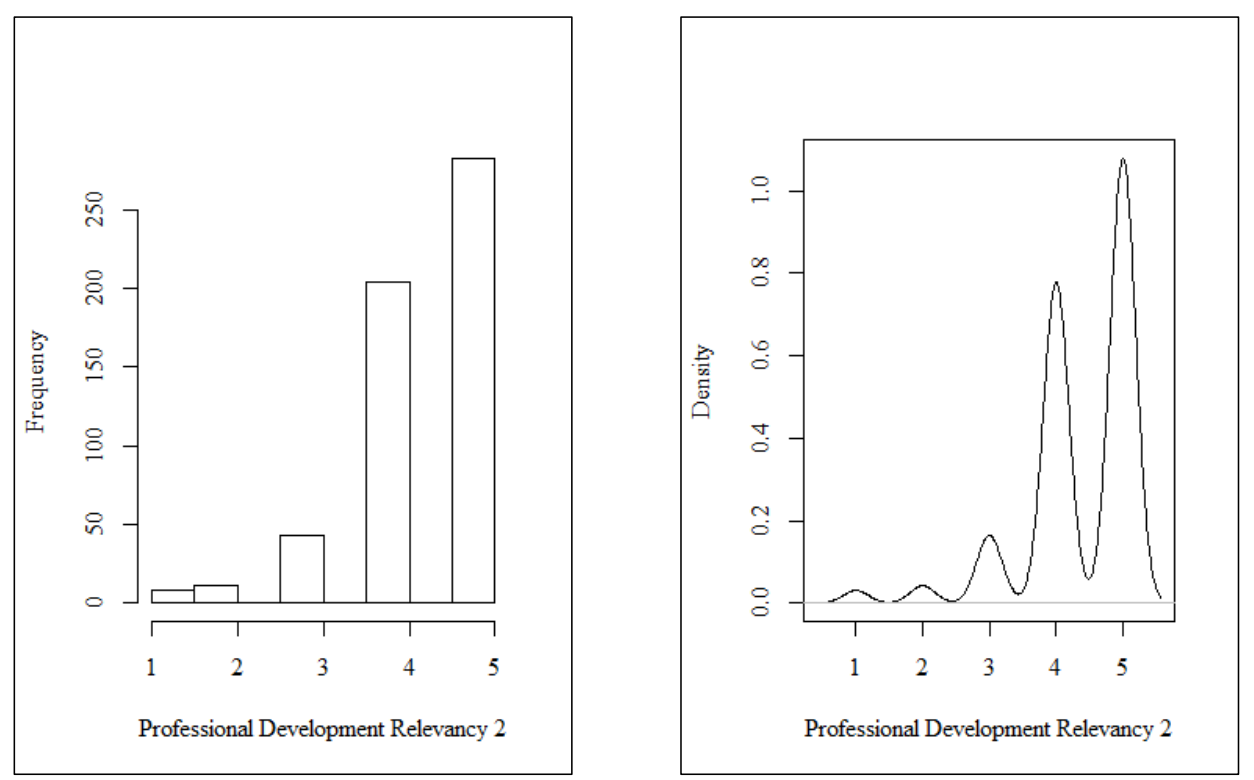

Figure C9. Frequency and density distribution for the Professional Development Relevancy 2 variable.
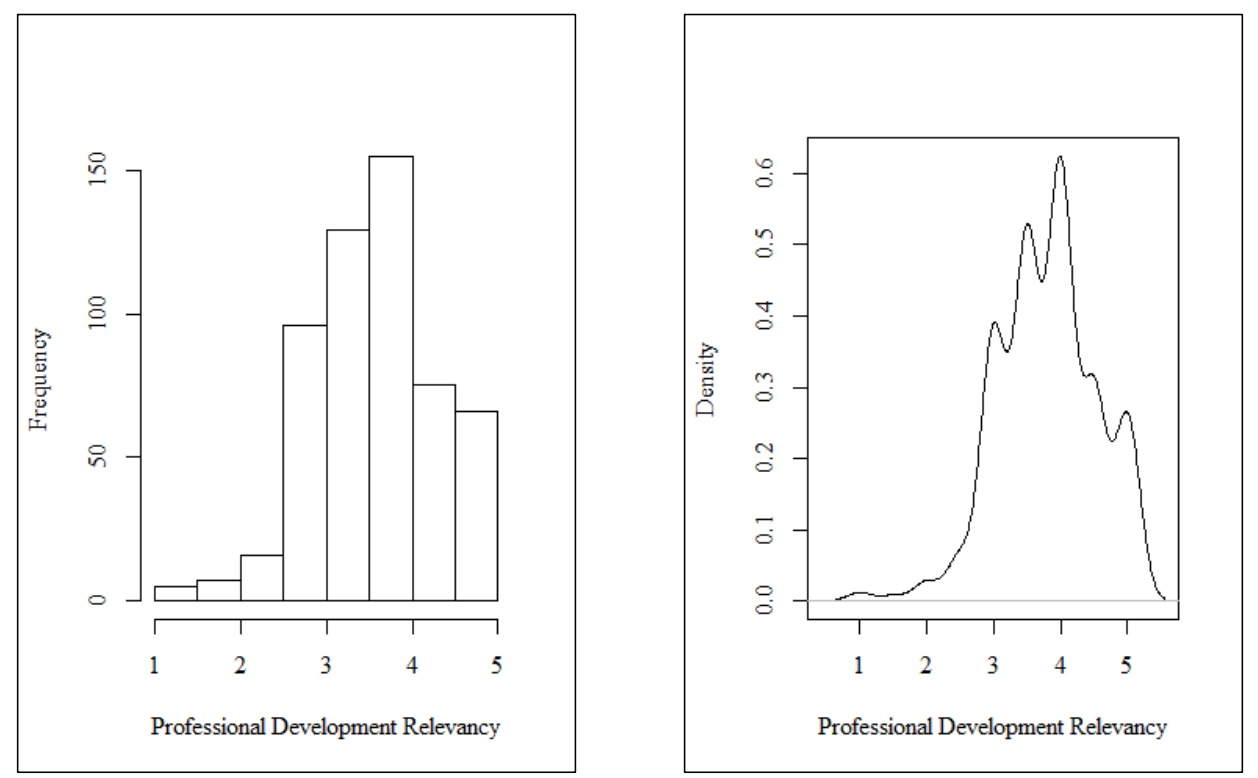

Figure C10. Frequency and density distribution for the Professional Development Relevancy (Combined) variable. 

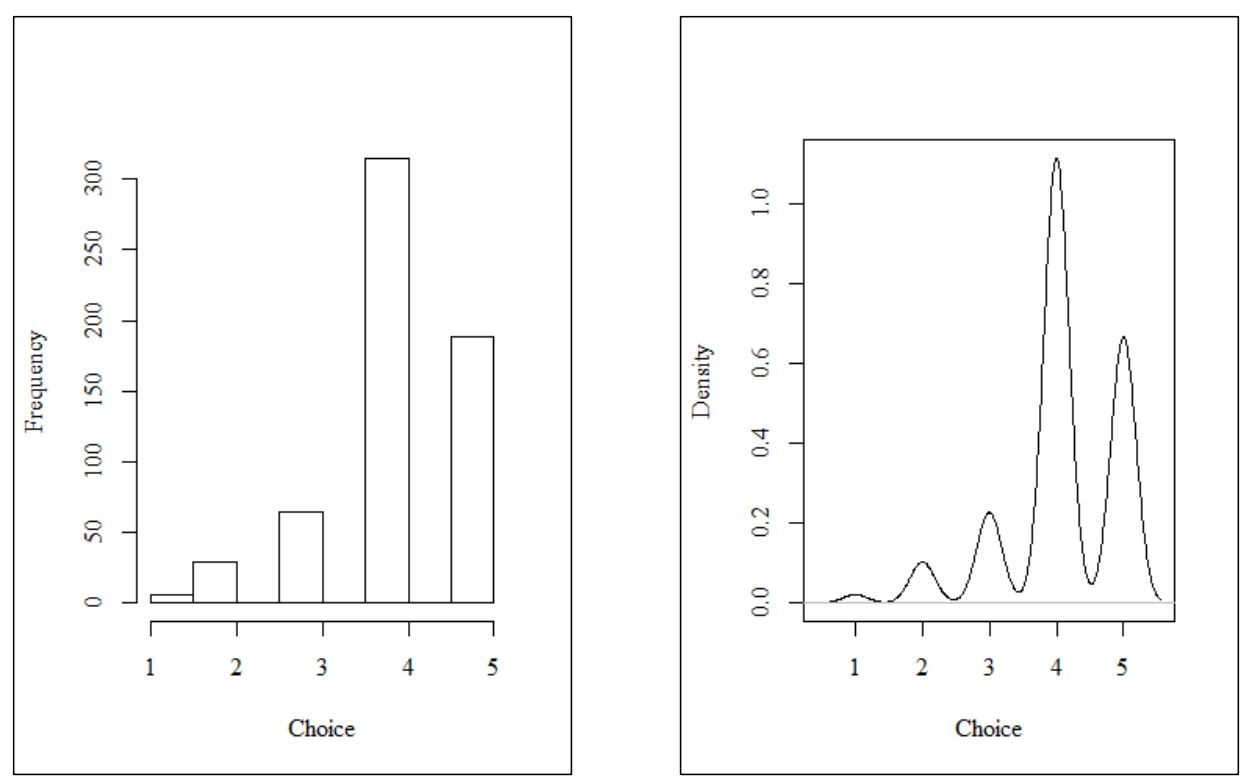

Figure C11. Frequency and density distribution for the teacher Choice variable.
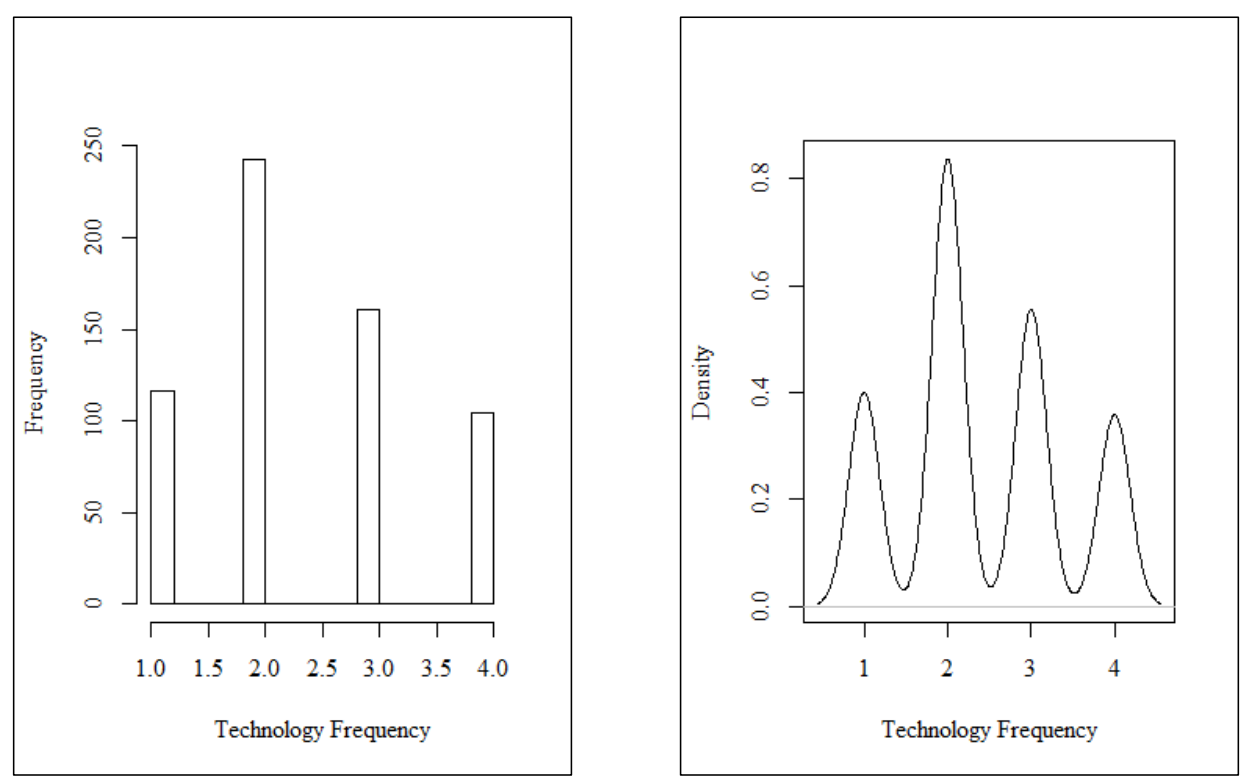

Figure C12. Frequency and density distribution for the Technology Frequency variable. 

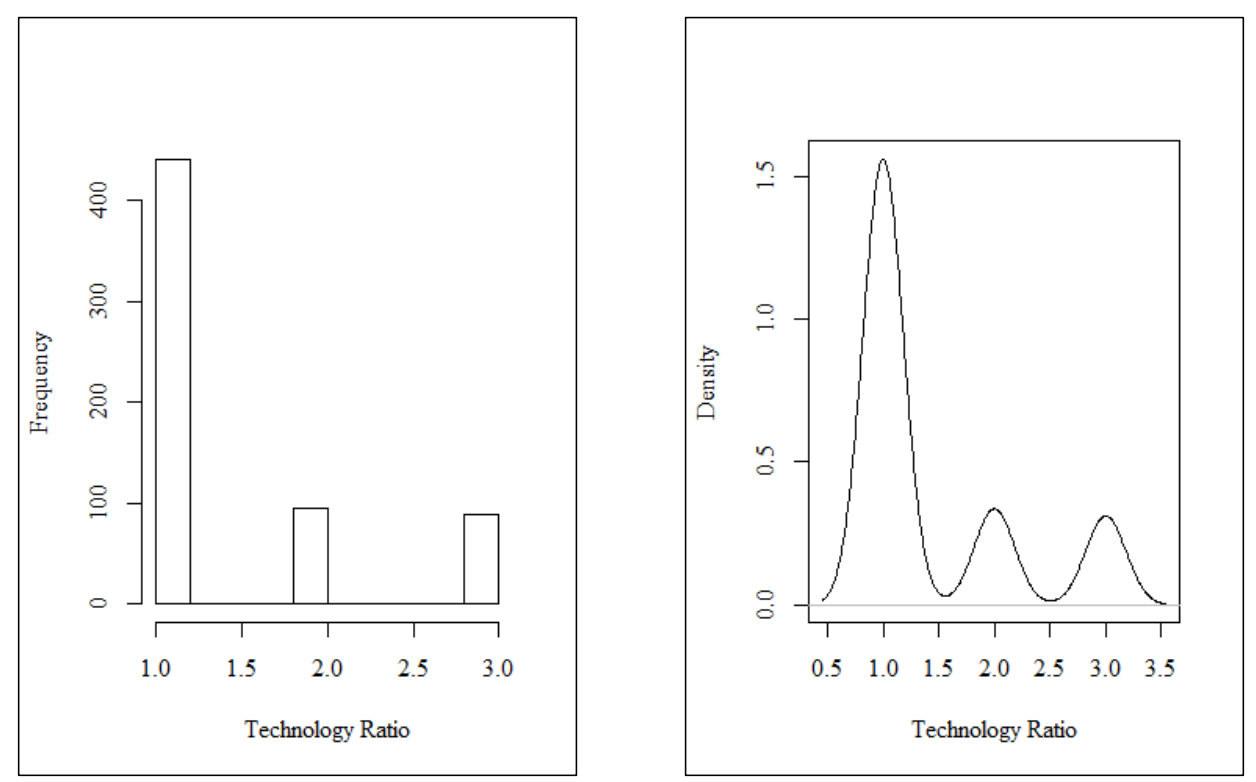

Figure C13. Frequency and density distribution for the Technology Ratio variable.
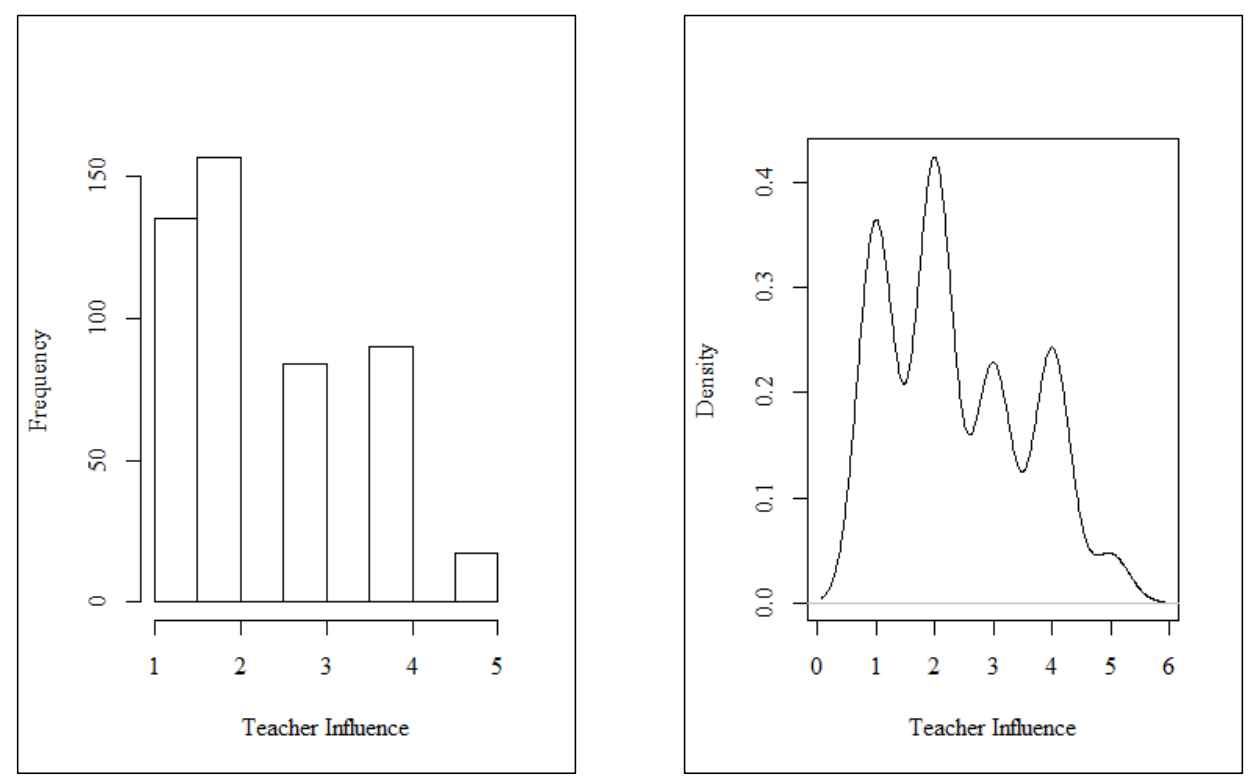

Figure C14. Frequency and density distribution for the Teacher Influence variable 

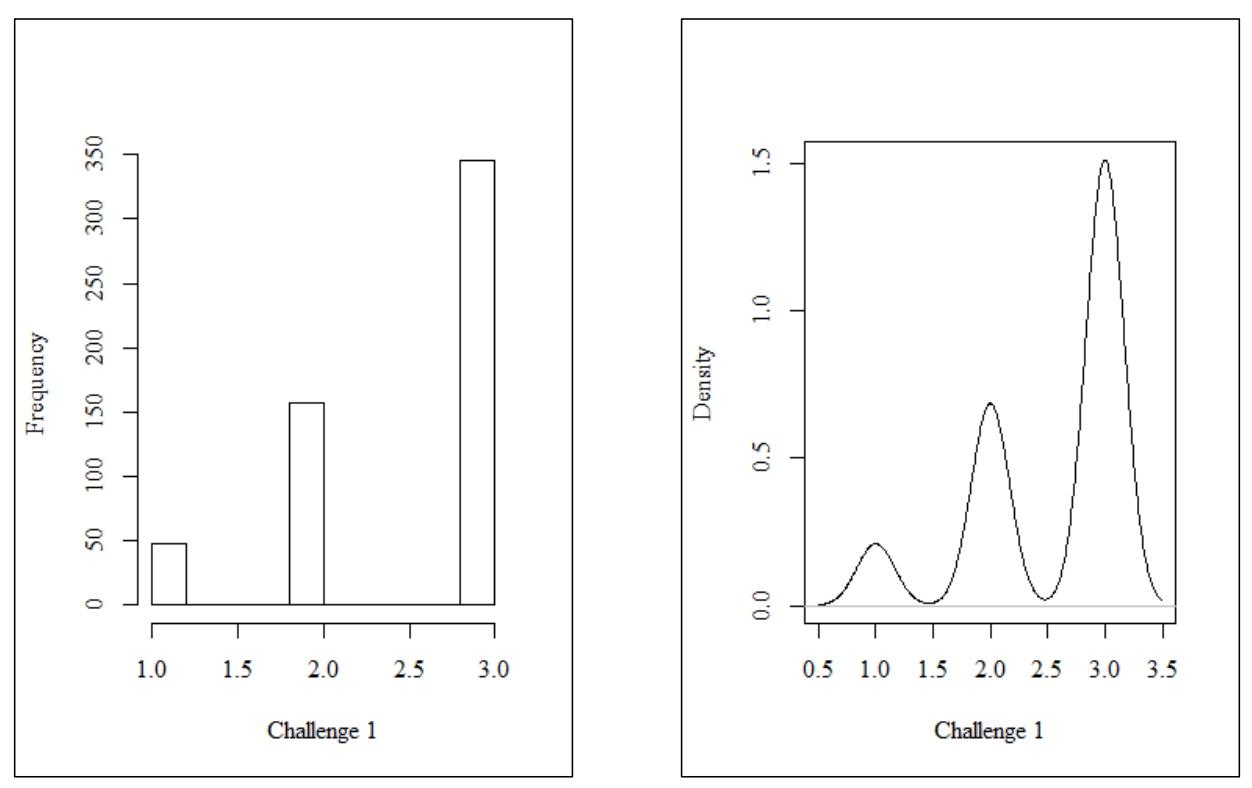

Figure C15. Frequency and density distribution for the Challenge 1 variable.
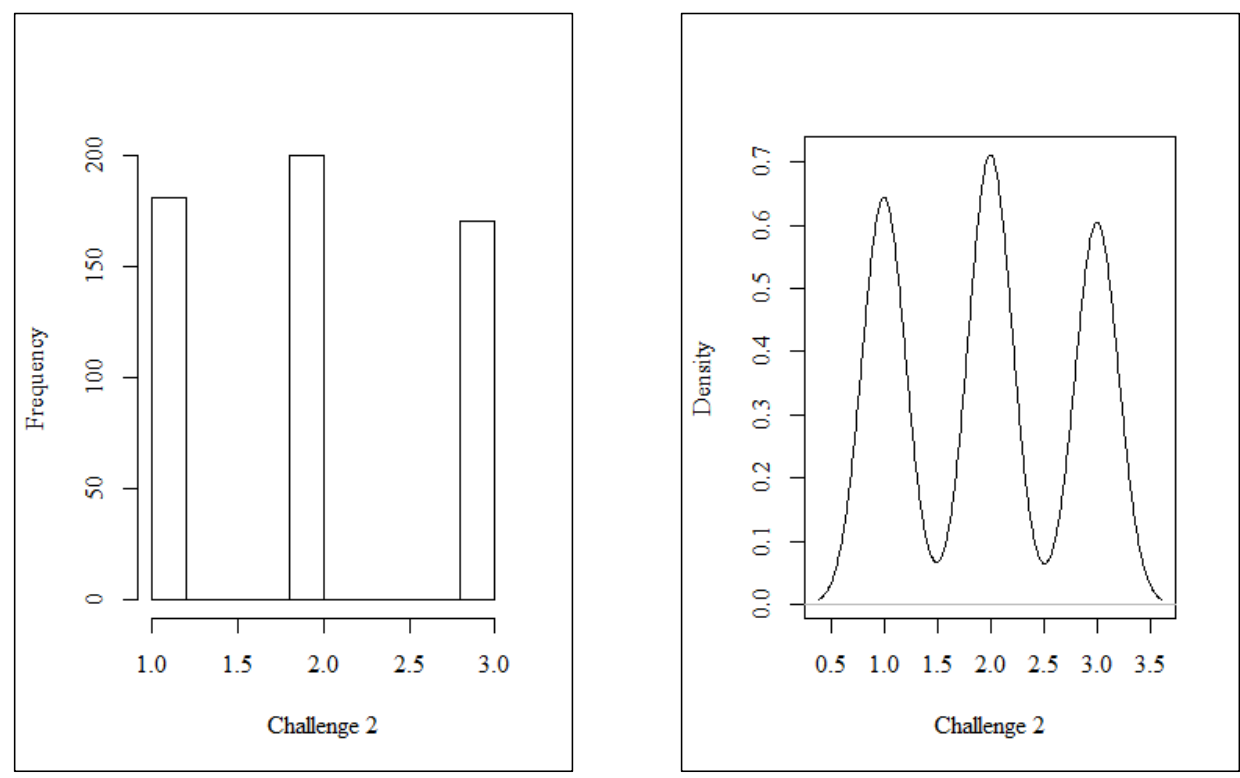

Figure C16. Frequency and density distribution for the Challenge 2 variable. 

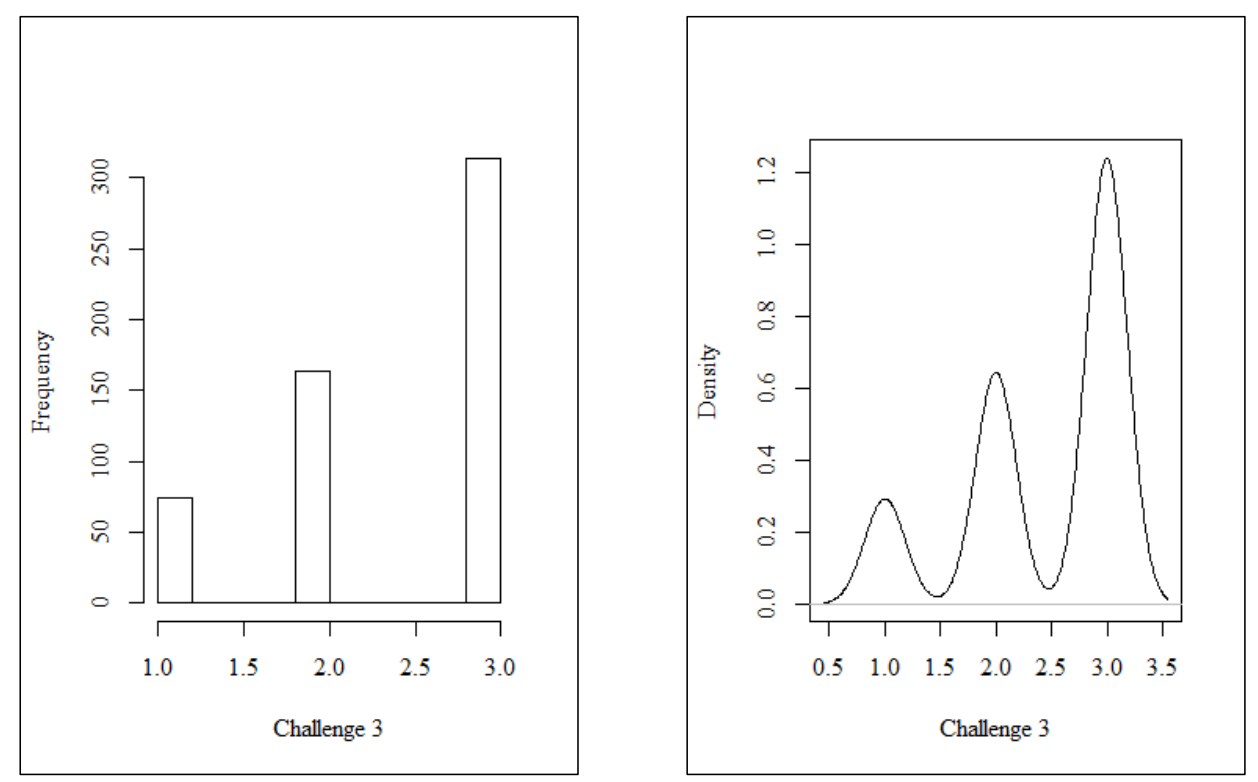

Figure C17. Frequency and density distribution for the Challenge 3 variable.
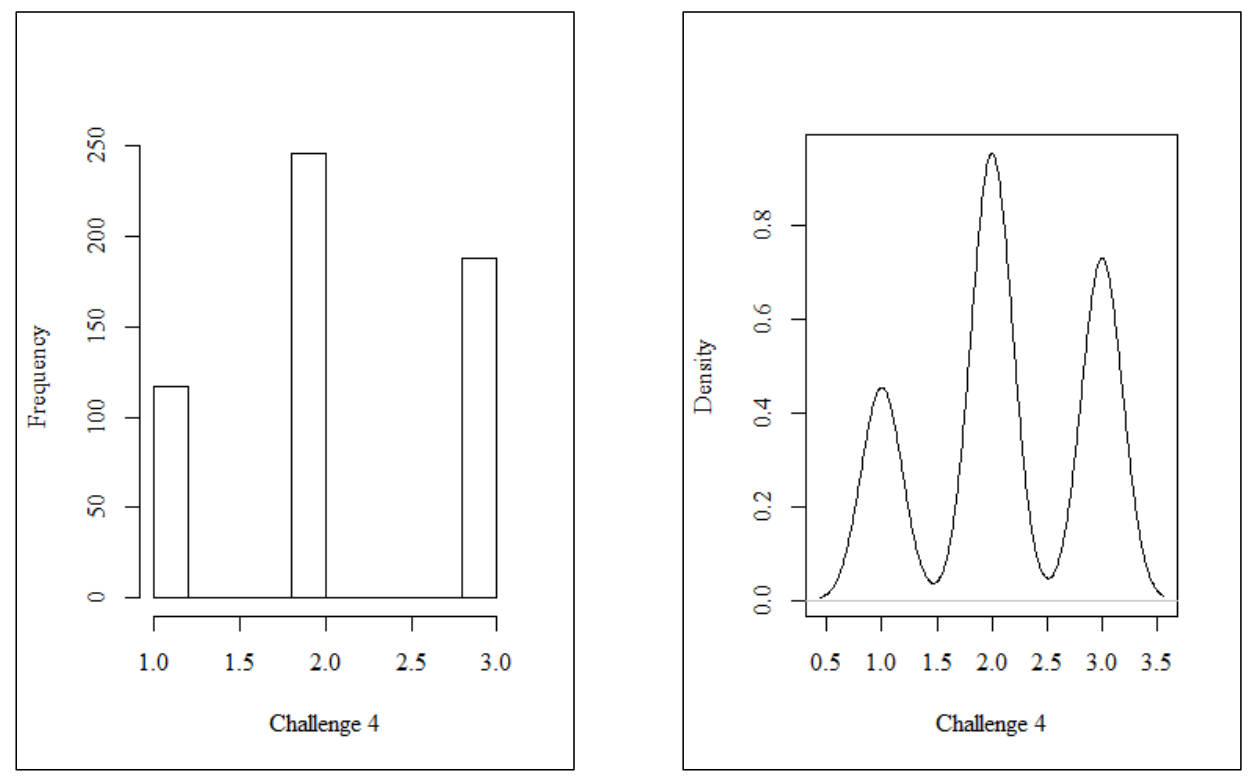

Figure C18. Frequency and density distribution for the Challenge 4 variable. 

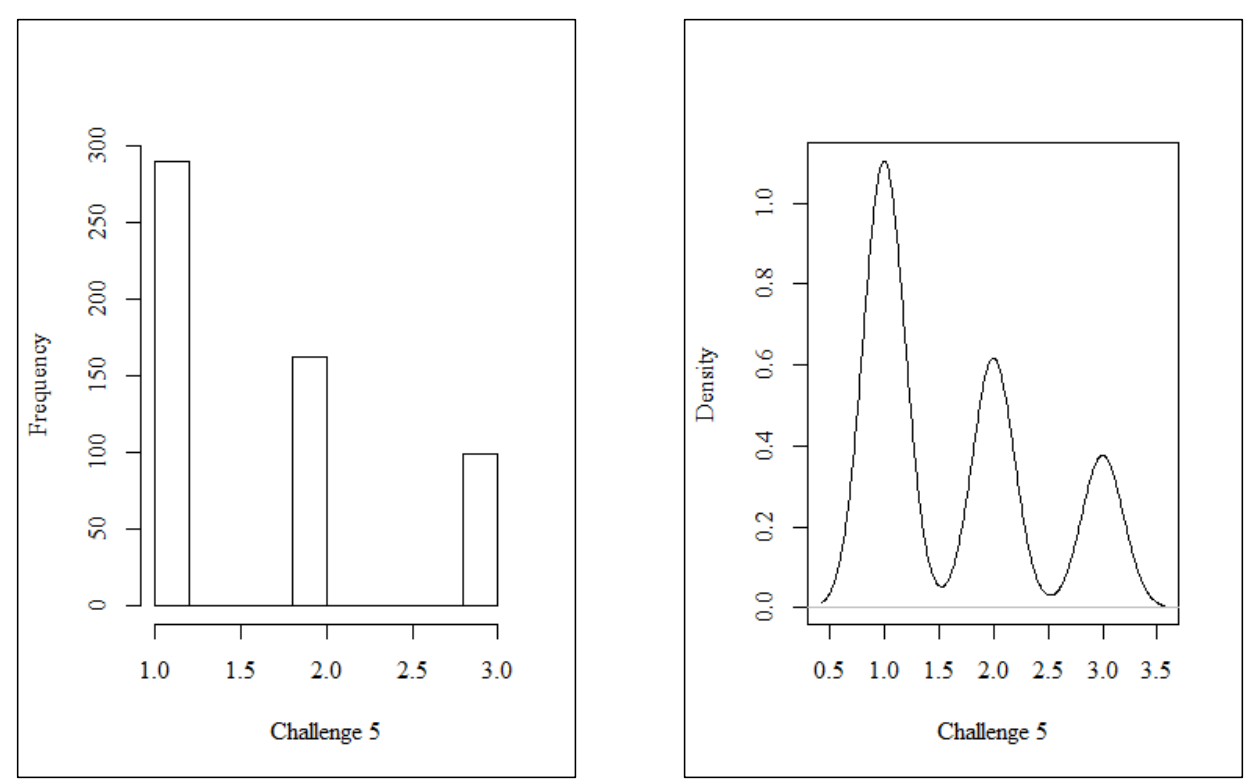

Figure C19. Frequency and density distribution for the Challenge 5 variable.
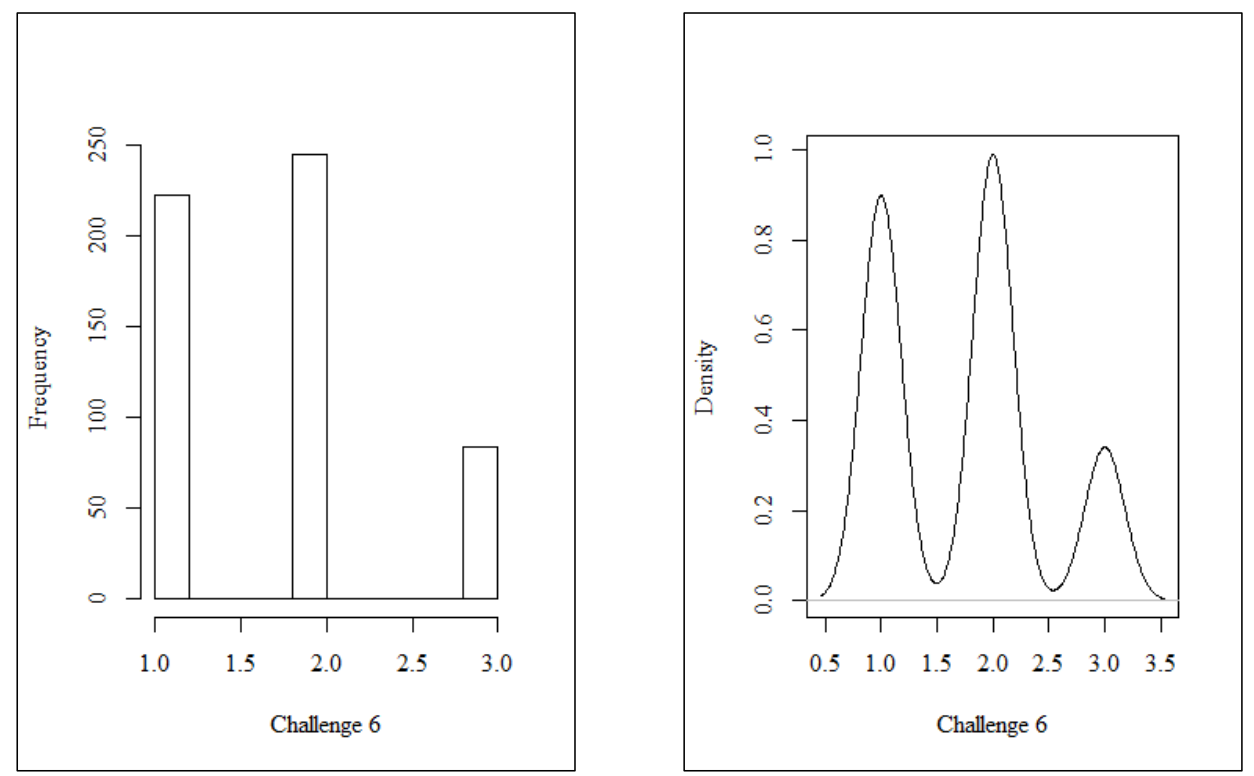

Figure C20. Frequency and density distribution for the Challenge 6 variable. 

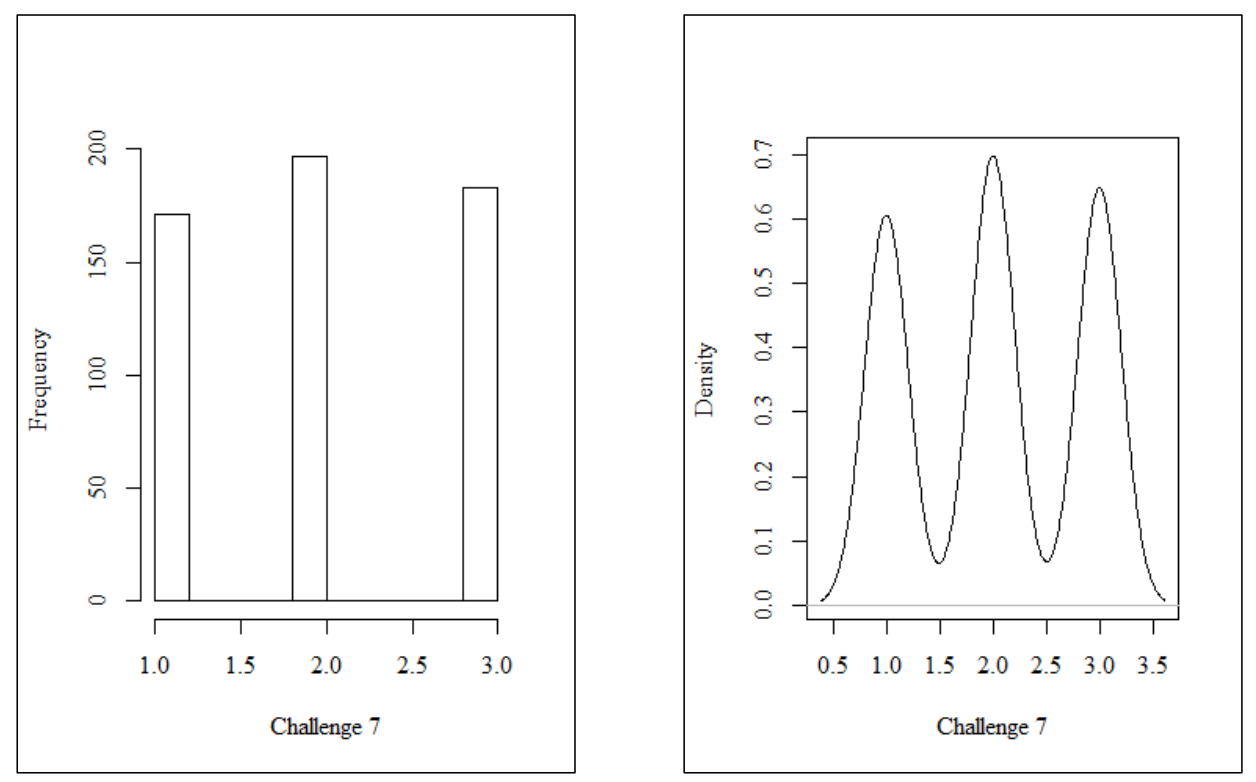

Figure C21. Frequency and density distribution for the Challenge 7 variable.
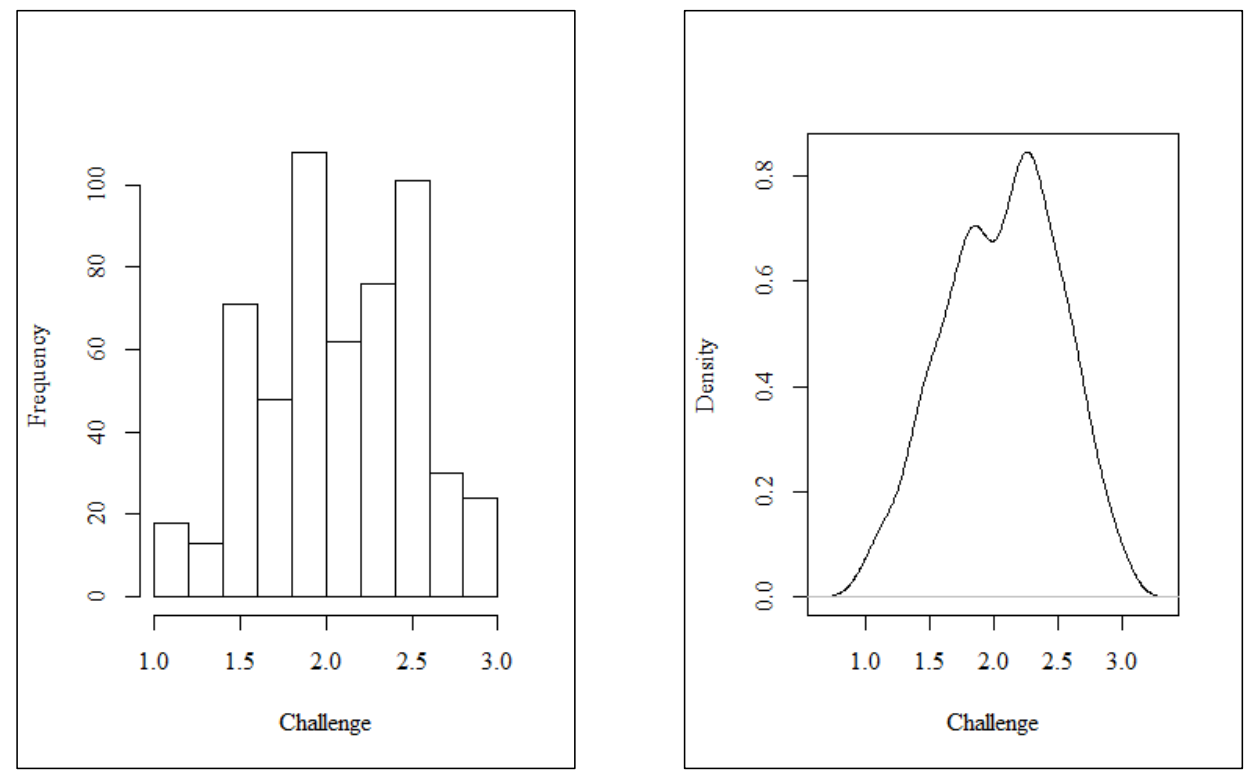

Figure C22. Frequency and density distribution for the Challenge (Combined) variable. 

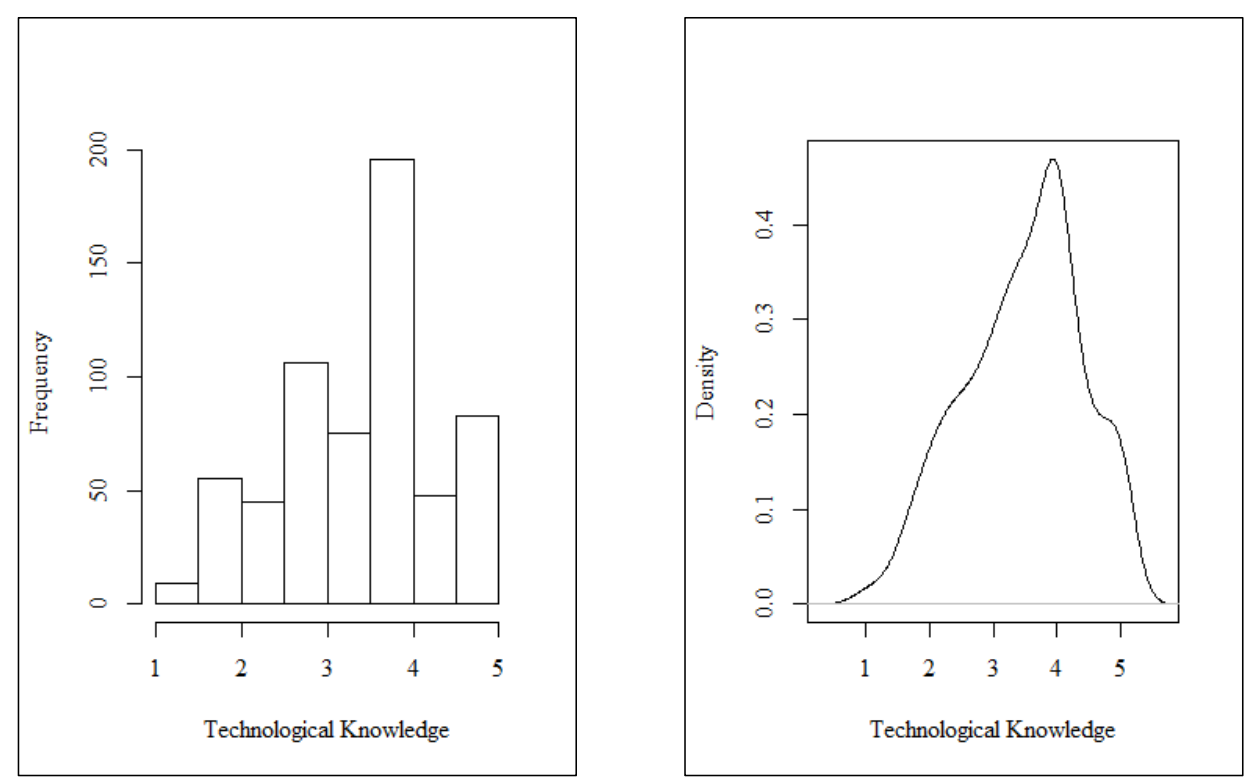

Figure C23. Frequency and density distribution for the Technological Knowledge variable.
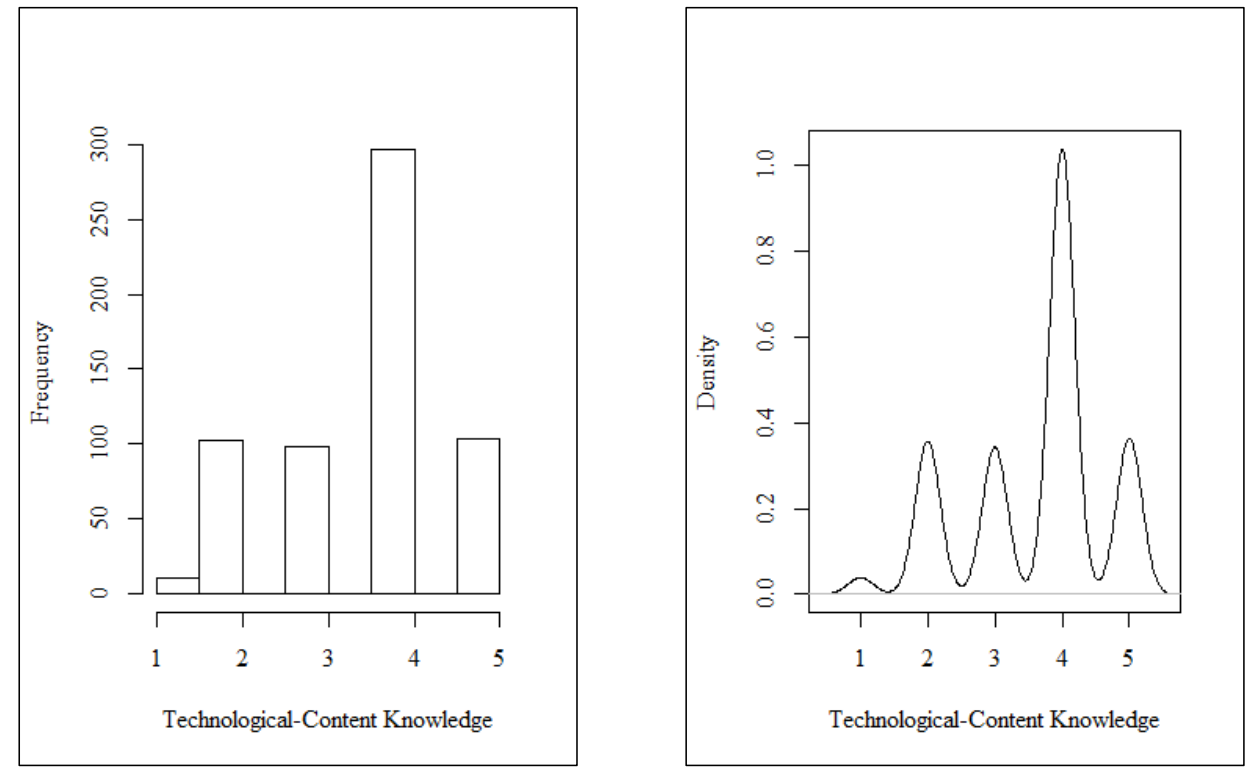

Figure C24. Frequency and density distribution for the Technological Content Knowledge variable. 

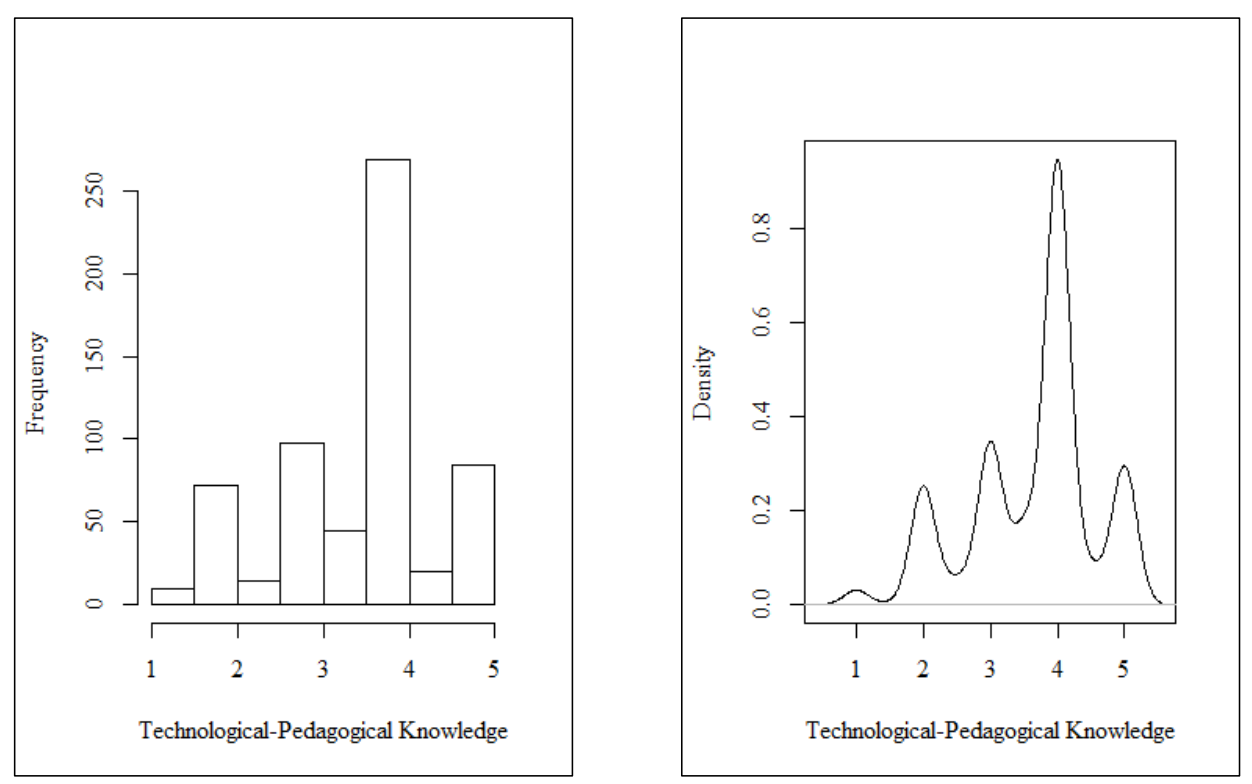

Figure C25. Frequency and density distribution for the Technological Pedagogical Knowledge variable.
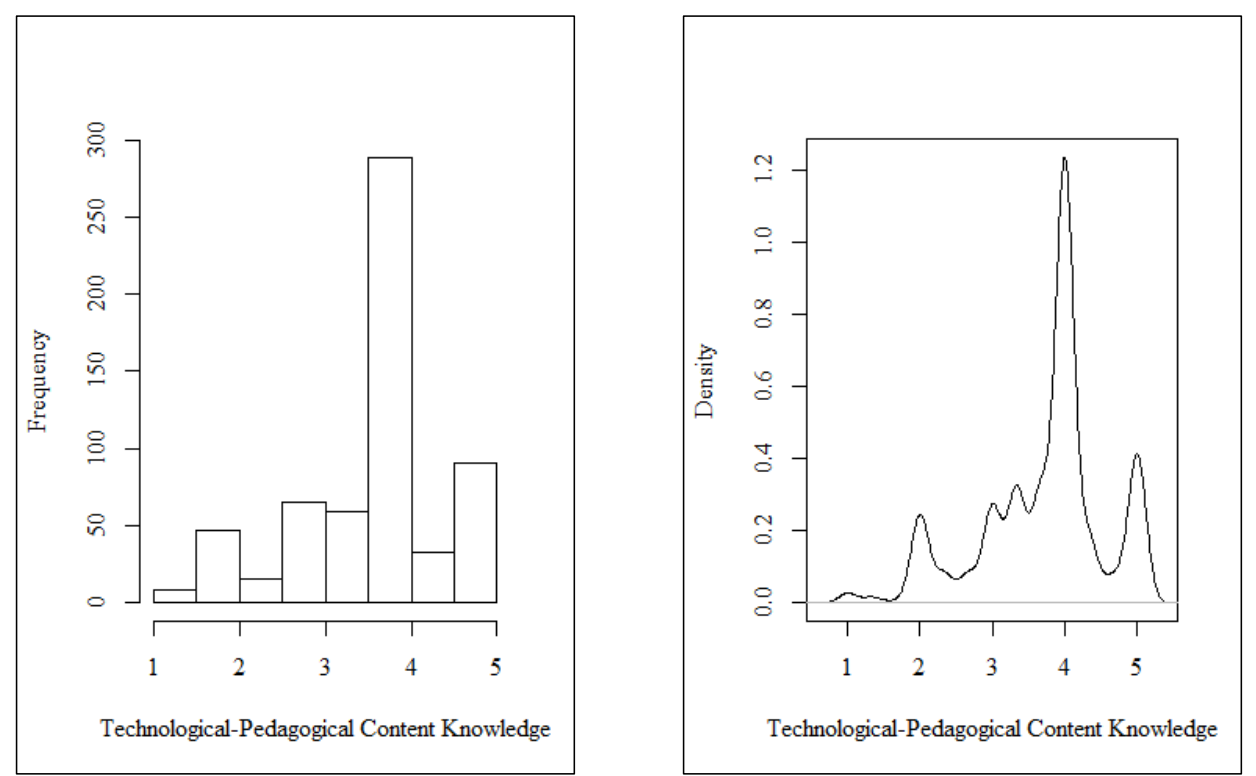

Figure C26. Frequency and density distribution for the Technological Pedagogical Content Knowledge variable. 

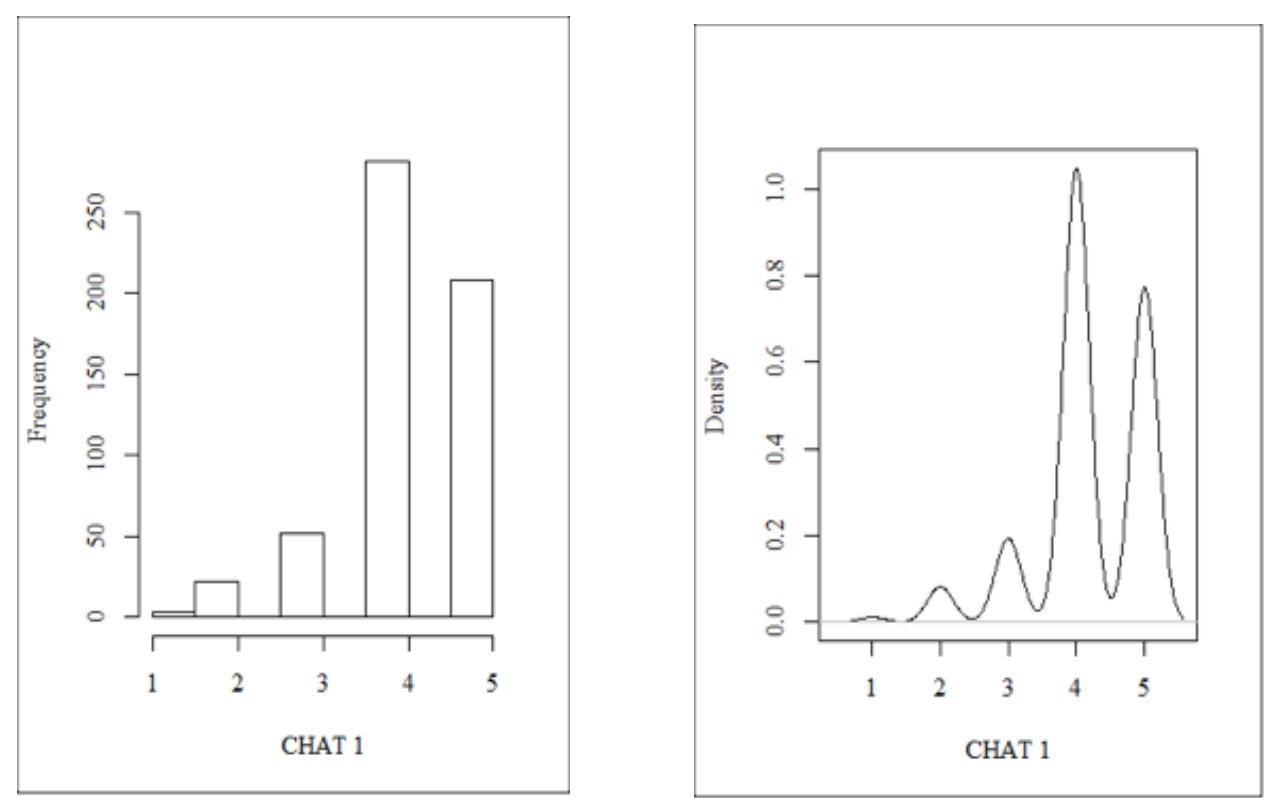

Figure C27. Frequency and density distribution for the Chat 1 variable.
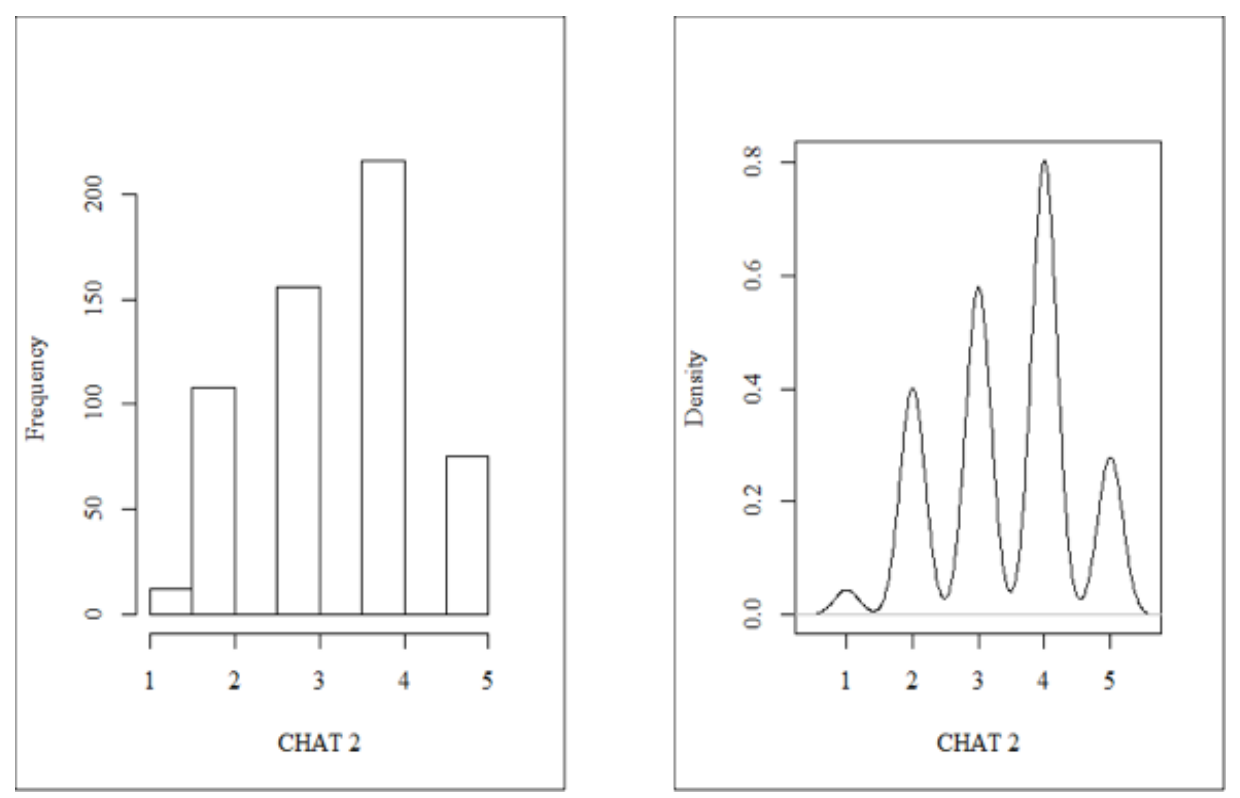

Figure $(28$. Frequency and density distribution tor the Chat 2 variable. 

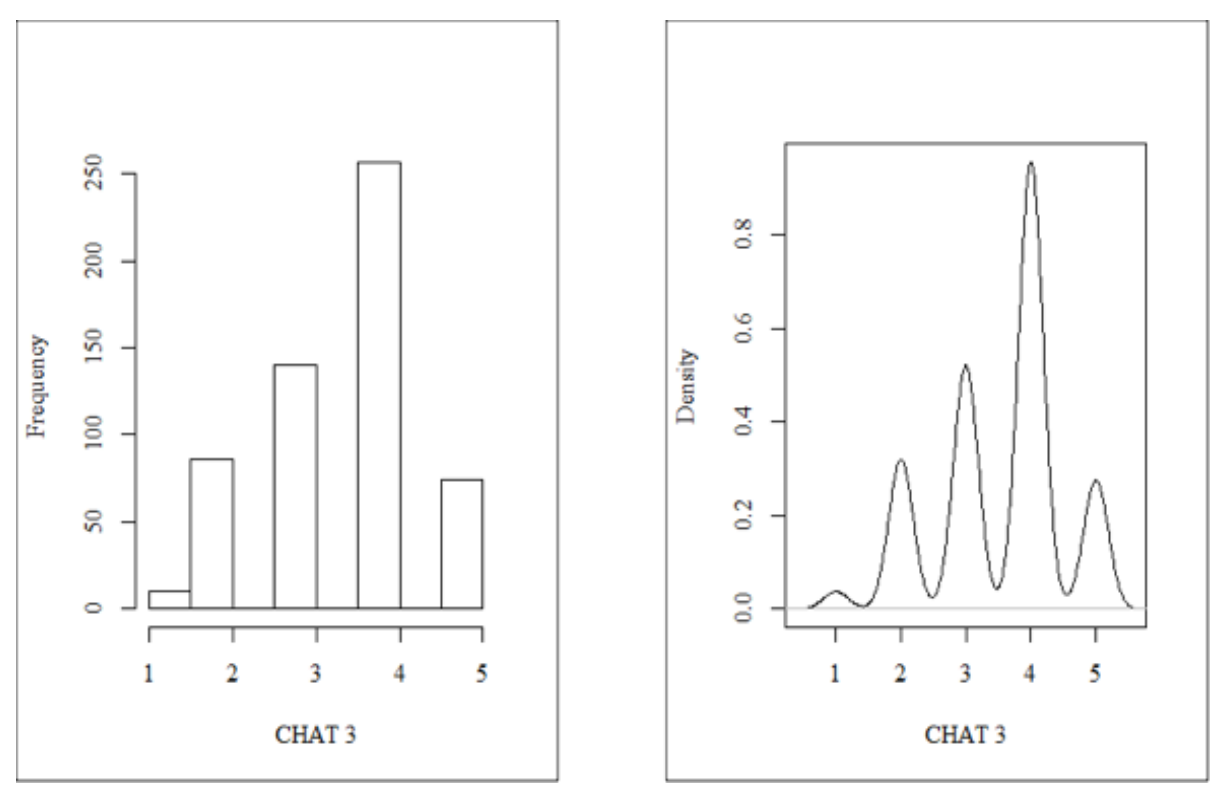

Figure C29. Frequency and density distribution for the Chat 3 variable.
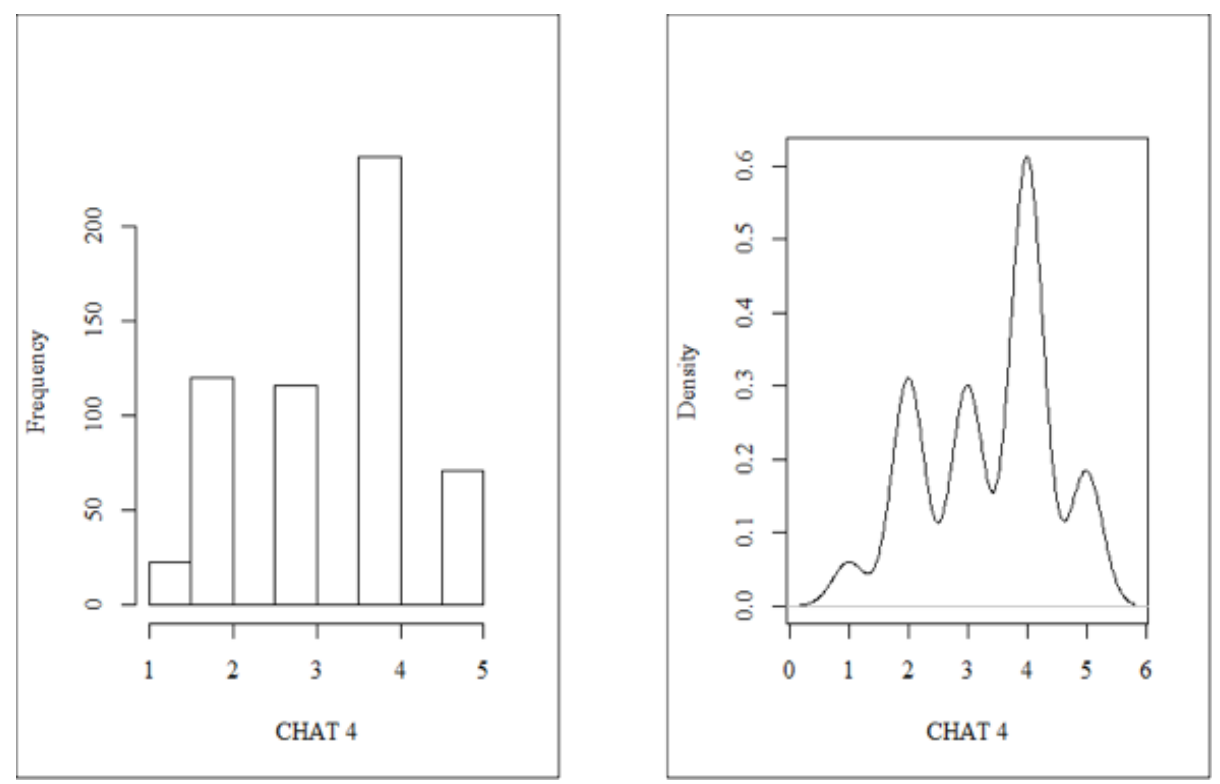

Figure C30. Frequency and density distribution for the Chat 4 variable. 

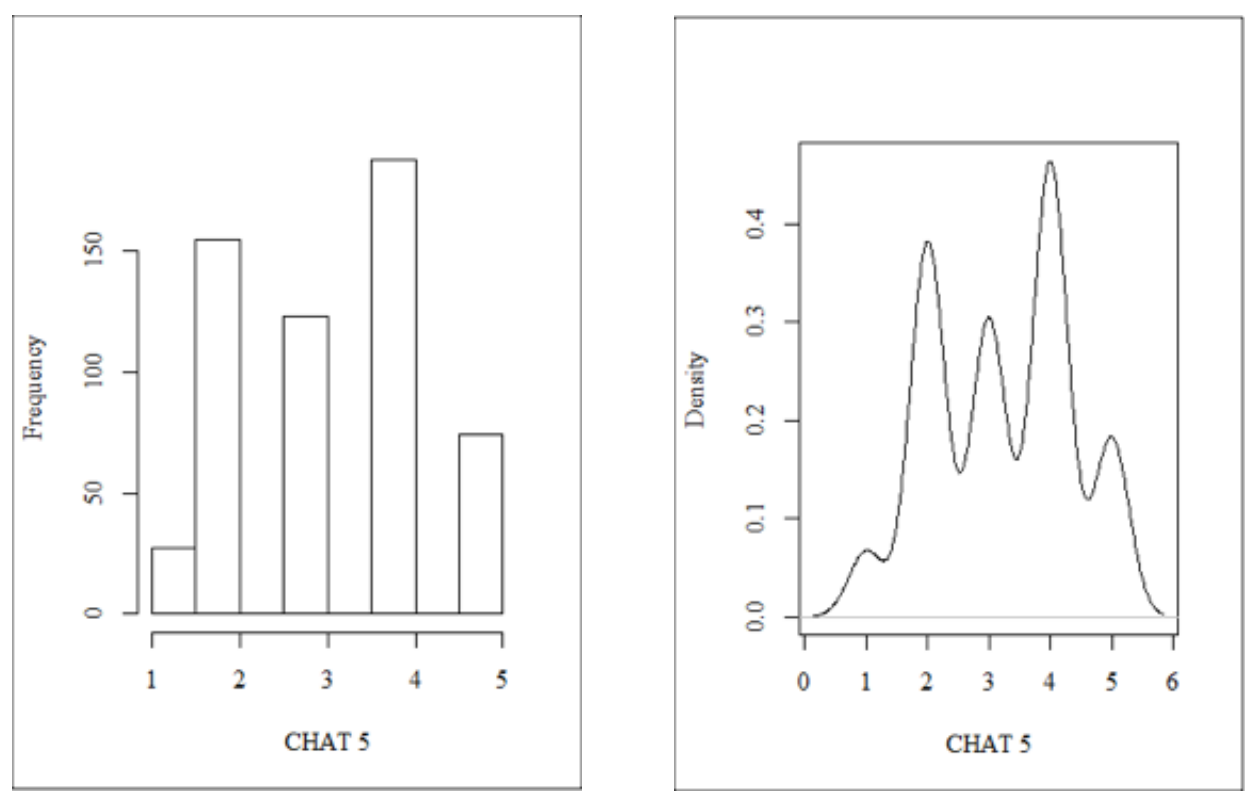

Figure C31. Frequency and density distribution for the Chat 5 variable.
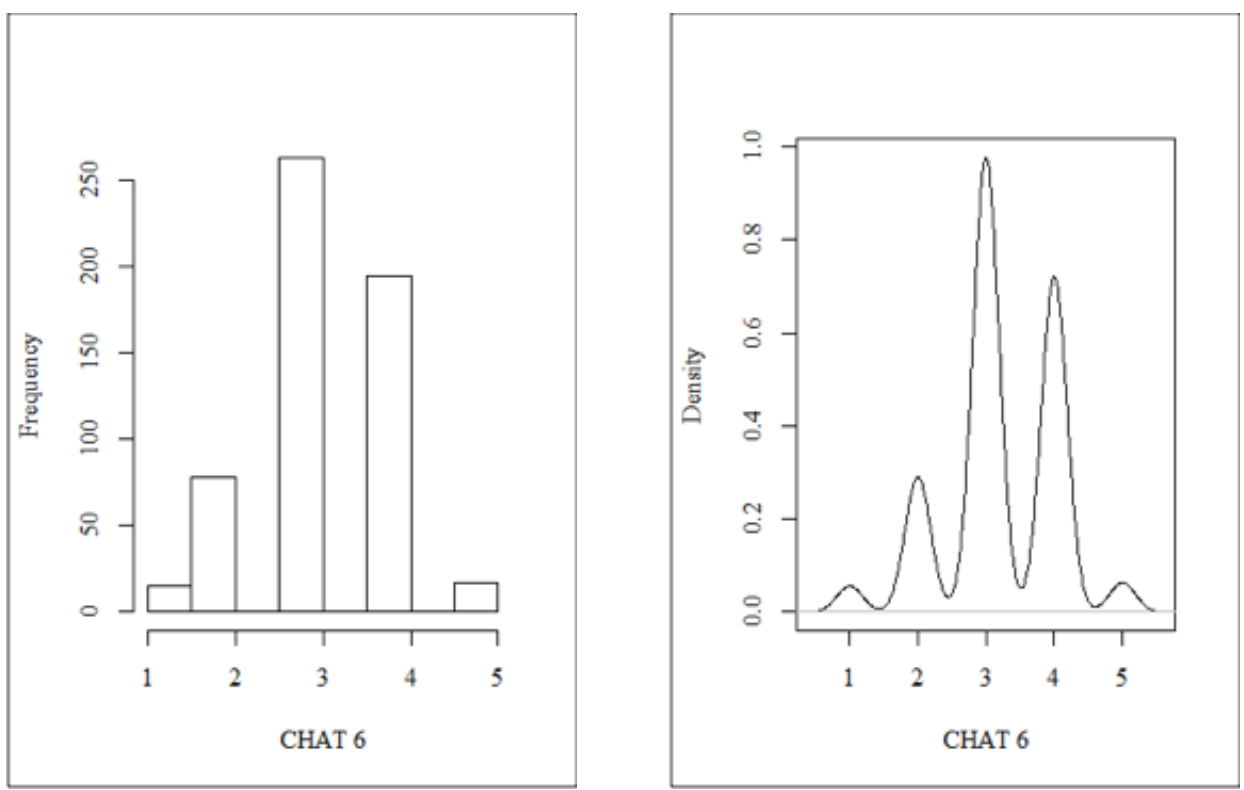

Figure $(3 L$. Frequency and density distribution tor the Chat 0 variable. 

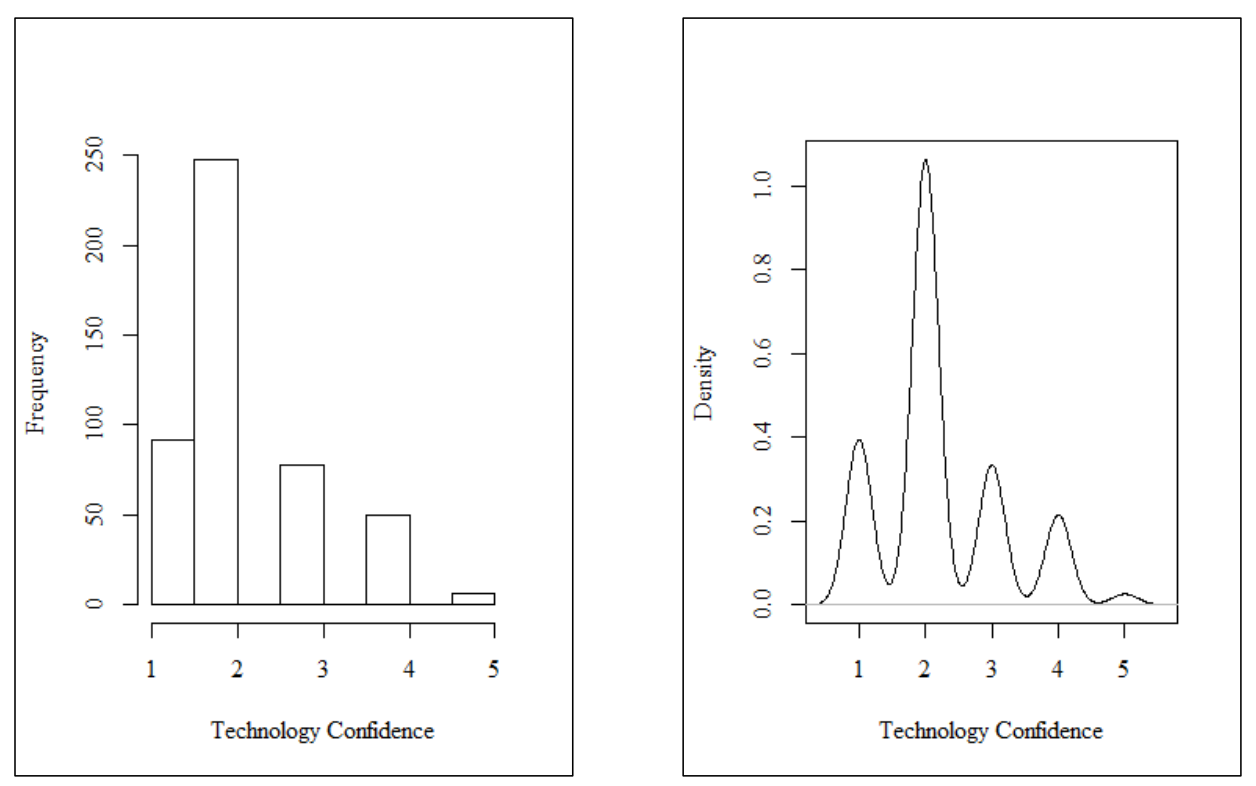

Figure C33. Frequency and density distribution for the Technology Confidence variable.
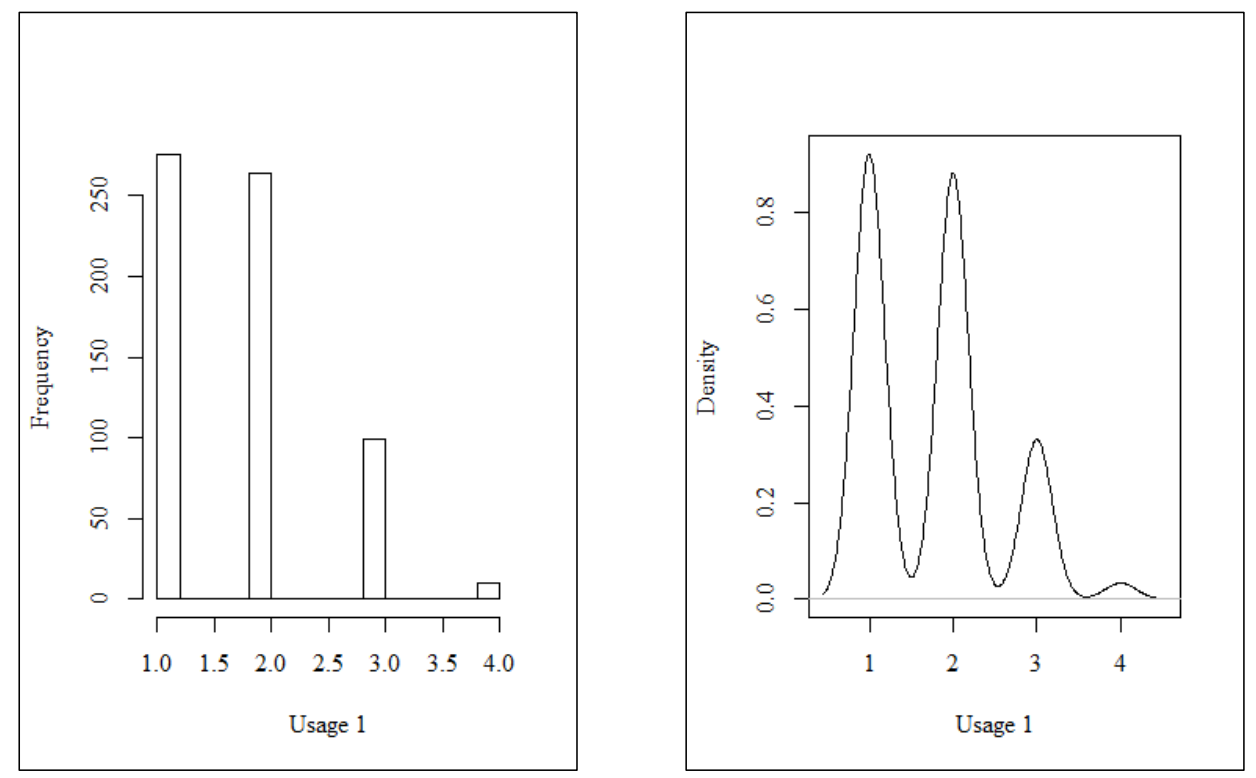

Figure C34. Frequency and density distribution for the Usage 1 variable. 

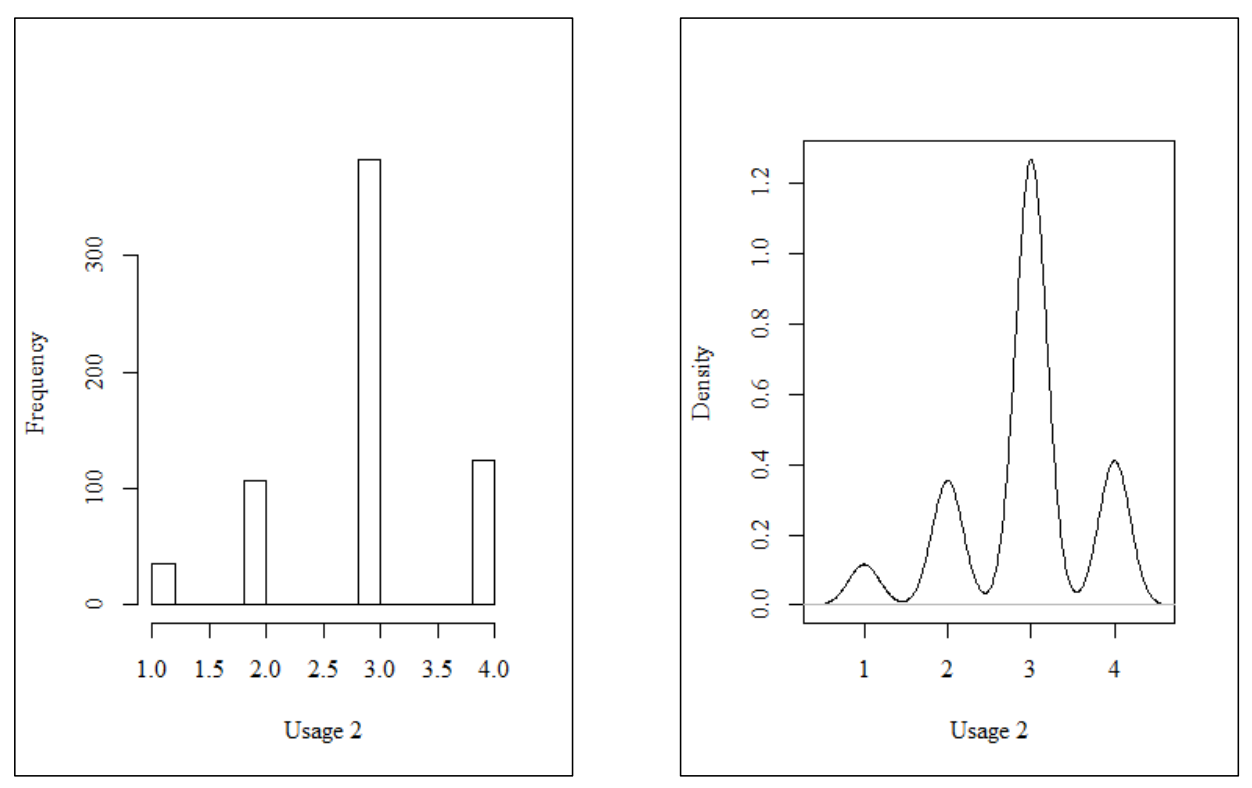

Figure C35. Frequency and density distribution for the Usage 2 variable.
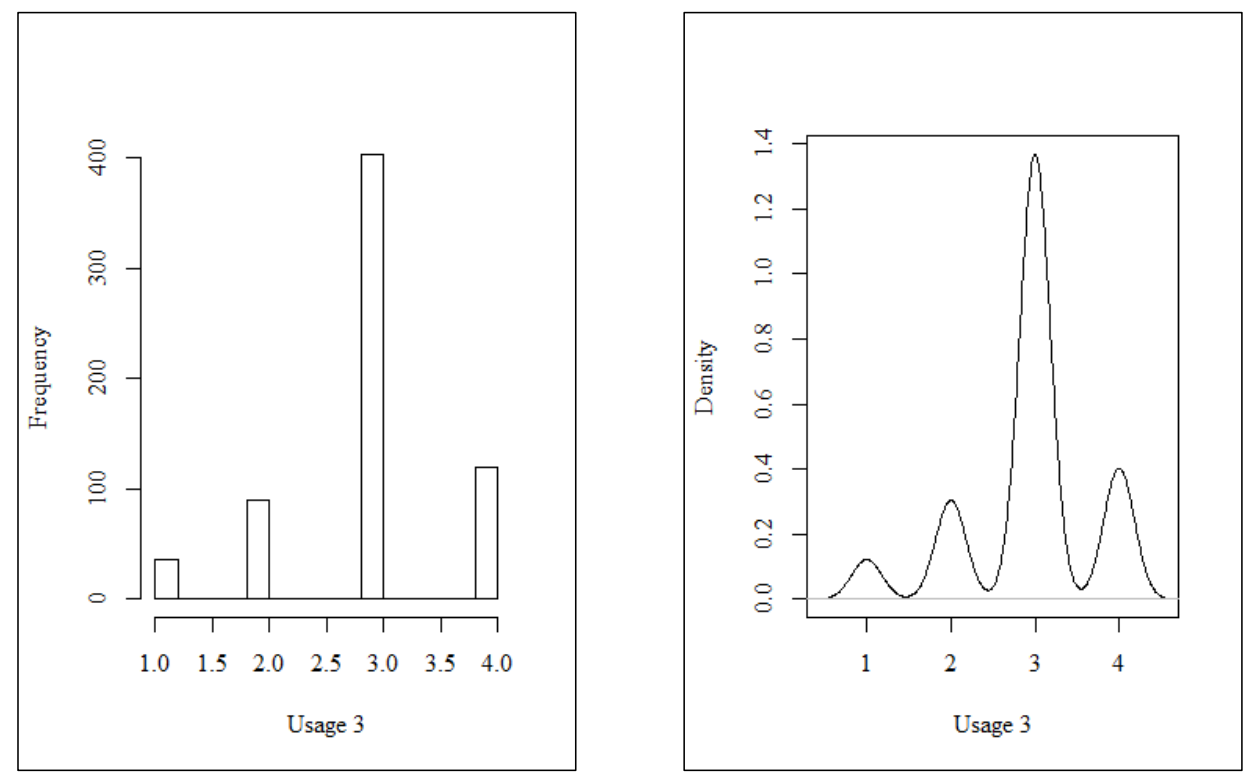

Figure C36. Frequency and density distribution for the Usage 3 variable. 

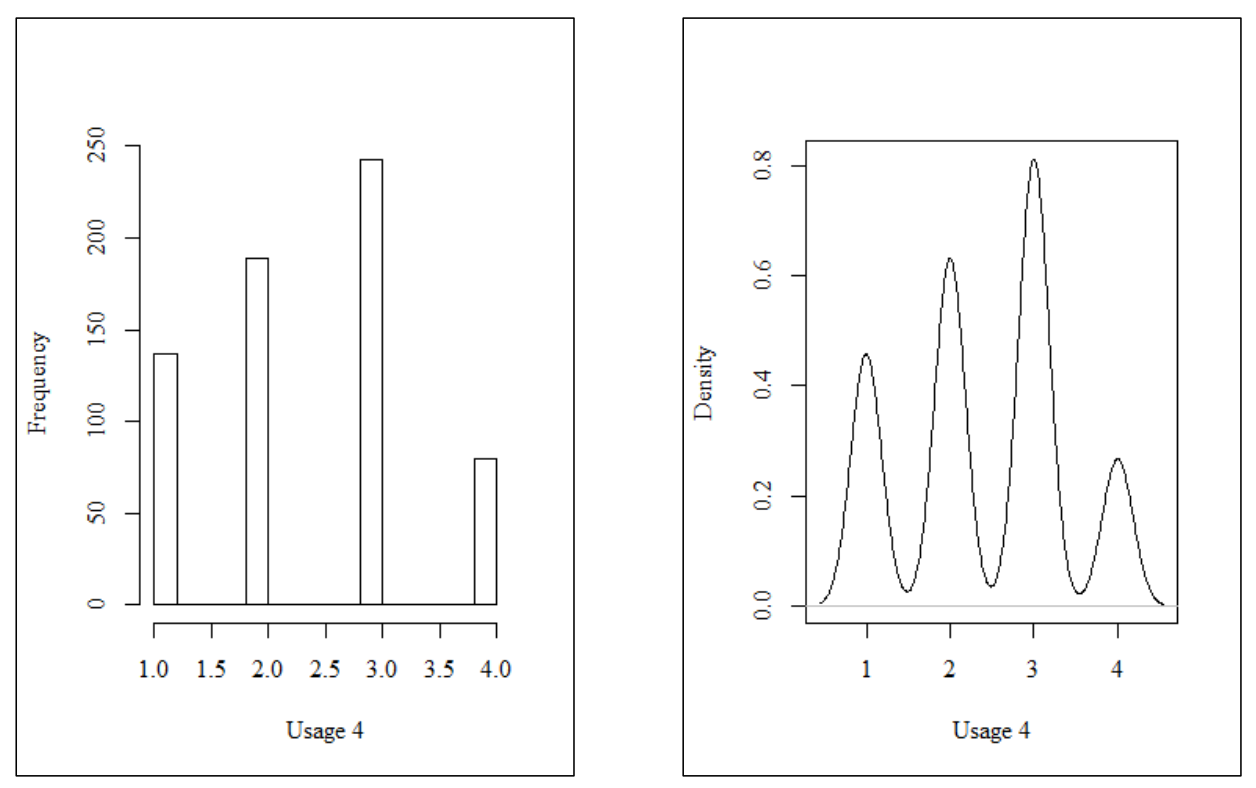

Figure C37. Frequency and density distribution for the Usage 4 variable.
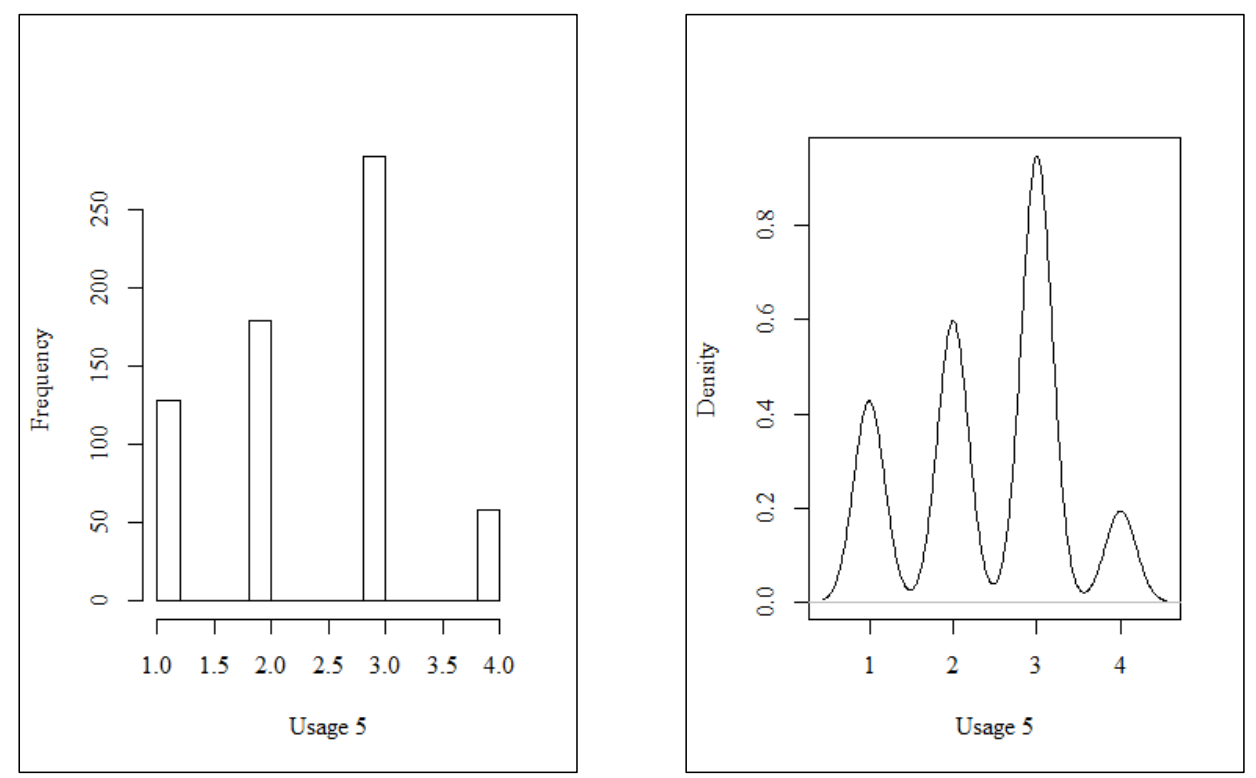

Figure C38. Frequency and density distribution for the Usage 5 variable. 

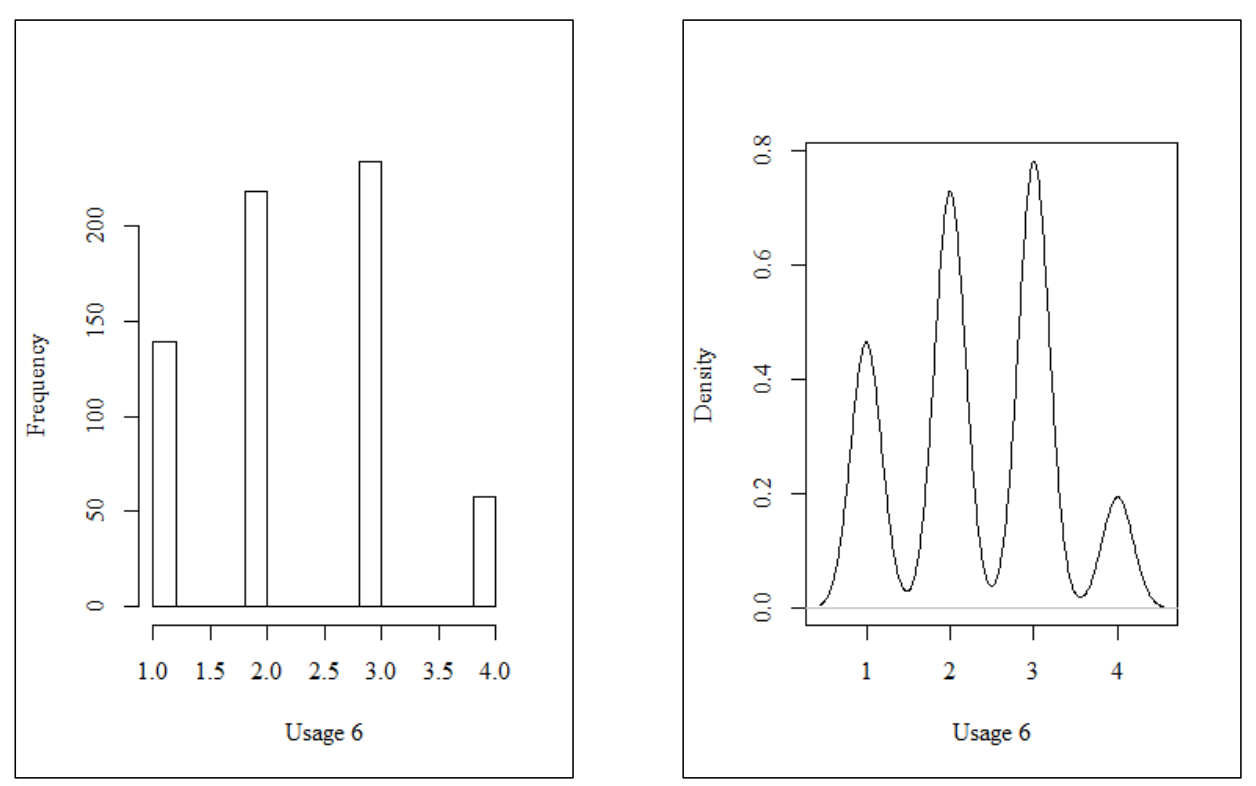

Figure C39. Frequency and density distribution for the Usage 6 variable.
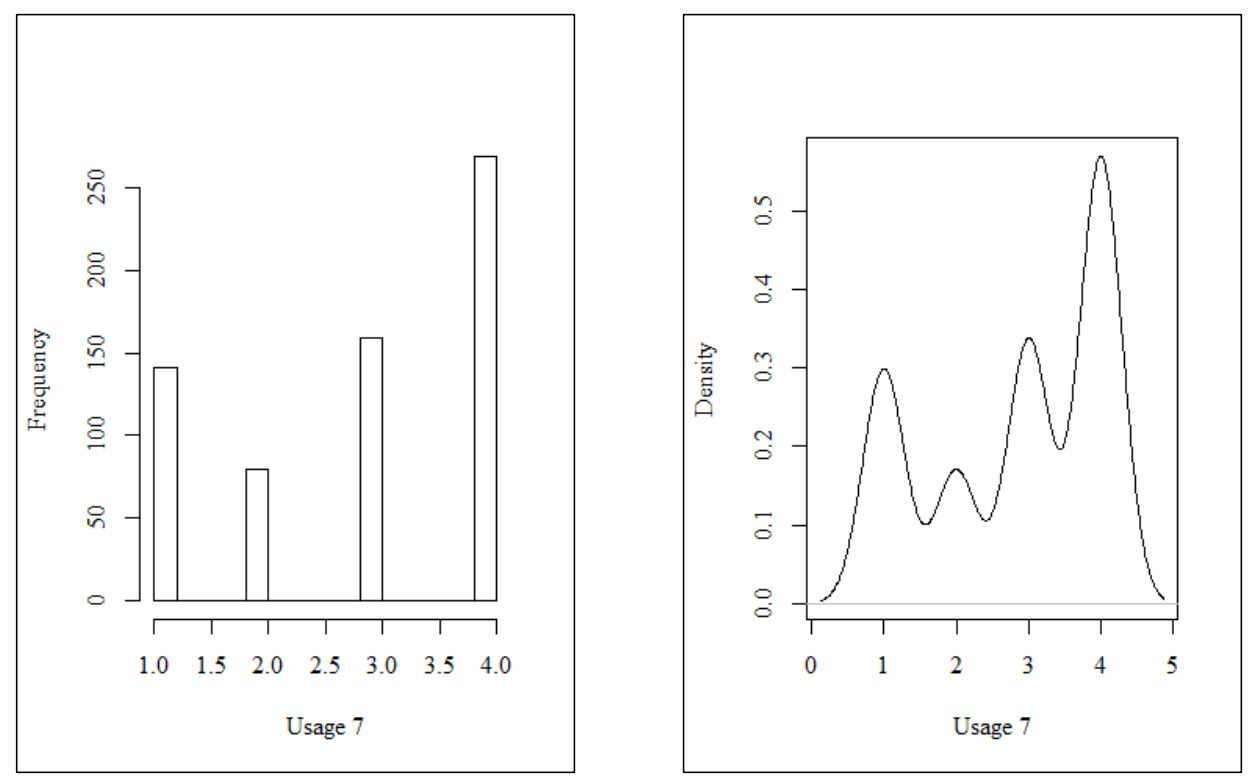

Figure C40. Frequency and density distribution for the Usage 7 variable. 

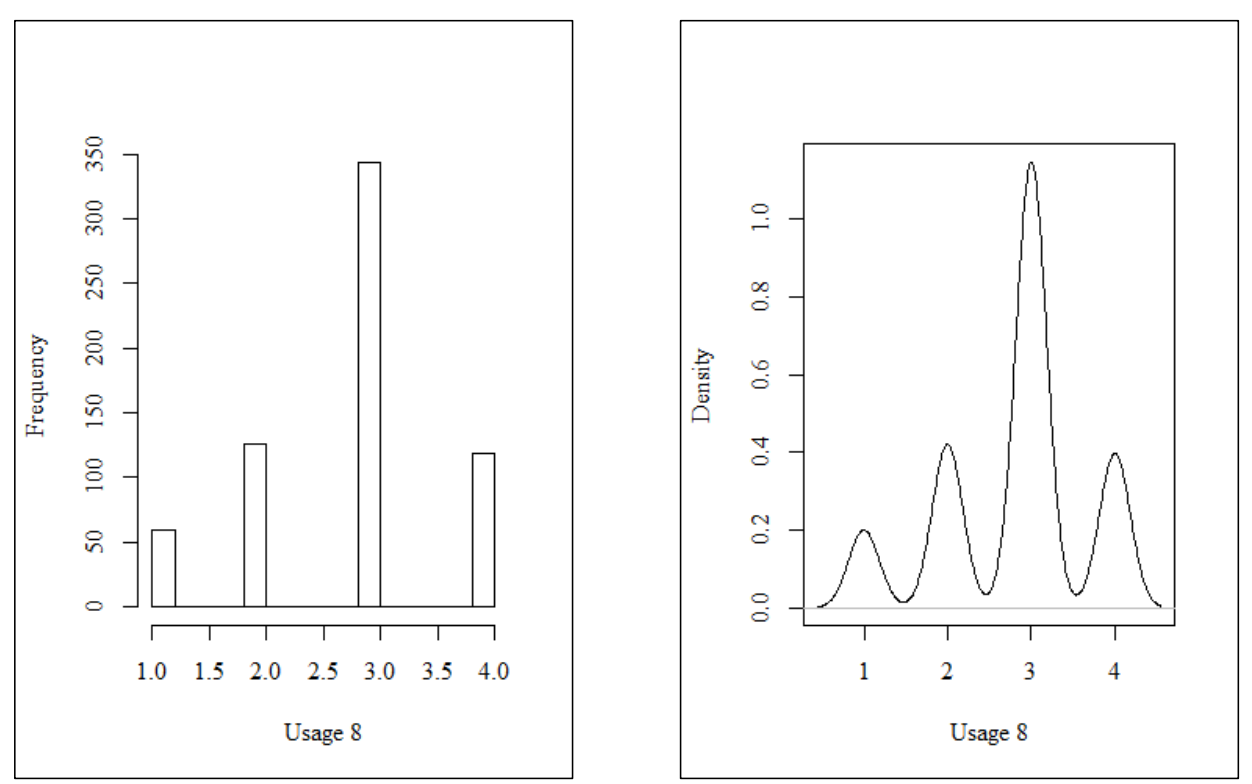

Figure C41. Frequency and density distribution for the Usage 8 variable.
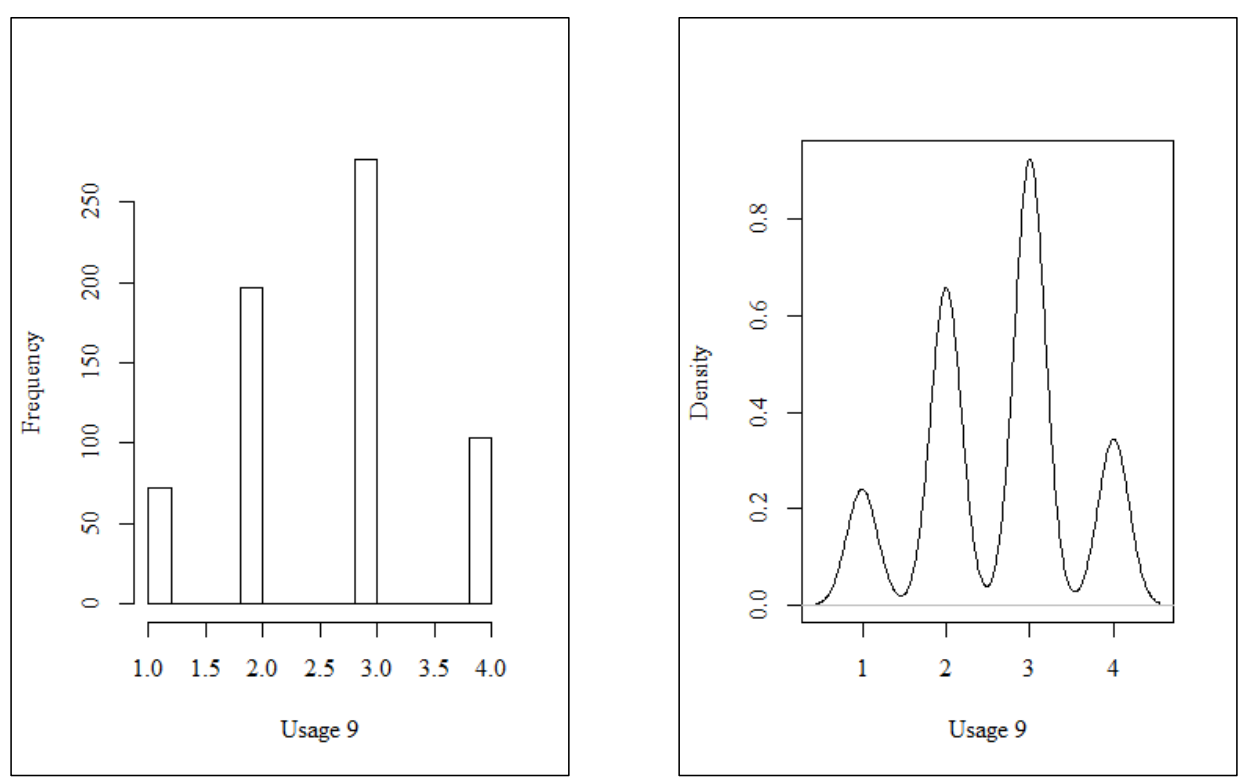

Figure C42. Frequency and density distribution for the Usage 9 variable. 
APPENDIX D - Correlation Matrices for Quantitative Results 
Table D1

Correlation matrix for Professional Development (Combined)

\begin{tabular}{|c|c|c|c|c|c|c|c|c|}
\hline Variables & 1 & 2 & 3 & 4 & 5 & 6 & 7 & 8 \\
\hline 1. Professional Development & & & & & & & & \\
\hline 2. Administration & .132 & & & & & & & \\
\hline 3. Technology Support Staff & .005 & -.082 & & & & & & \\
\hline 4. Minority & .026 & .005 & .039 & & & & & \\
\hline 5. Female & -.068 & -.186 & -.085 & .011 & & & & \\
\hline 6. Age & .053 & .055 & .085 & -.019 & -.023 & & & \\
\hline 7. Free/Reduced Lunch Students & .129 & -.024 & -.011 & .057 & .063 & -.046 & & \\
\hline 8. Non-White Students & .033 & -.059 & .028 & .103 & .113 & -.064 & .468 & \\
\hline
\end{tabular}

Table D2

Correlation matrix for Professional Development Relevancy (Combined)

\begin{tabular}{|c|c|c|c|c|c|c|c|c|}
\hline Variables & 1 & 2 & 3 & 4 & 5 & 6 & 7 & 8 \\
\hline $\begin{array}{l}\text { 1. Professional Development } \\
\text { Relevancy }\end{array}$ & & & & & & & & \\
\hline 2. Administration & .155 & & & & & & & \\
\hline 3. Technology Support Staff & .138 & -.082 & & & & & & \\
\hline 4. Minority & -.011 & .005 & .039 & & & & & \\
\hline 5. Female & -.027 & -.186 & -.085 & .011 & & & & \\
\hline 6. Age & .064 & .055 & .085 & -.019 & -.023 & & & \\
\hline 7. Free/Reduced Lunch Students & .054 & -.024 & -.011 & .057 & .063 & -.046 & & \\
\hline 8. Non-White Students & .060 & -.059 & .028 & .103 & .113 & -.064 & .468 & \\
\hline
\end{tabular}




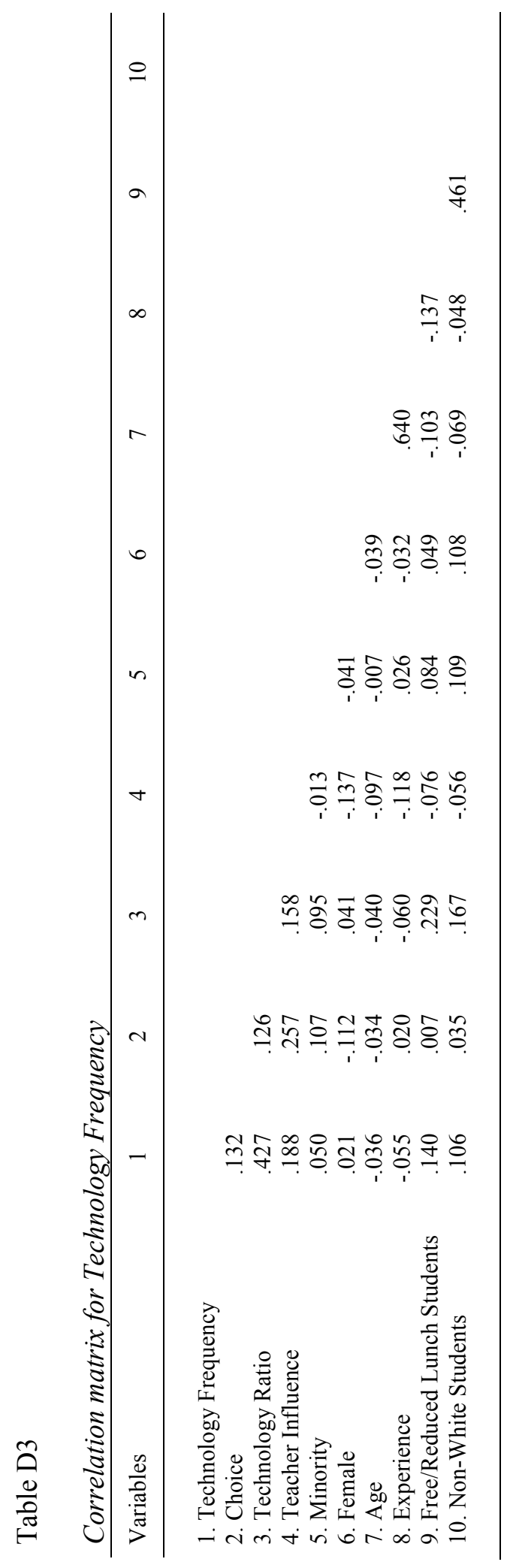


Table D4

Correlation matrix for Challenge (Combined)

\begin{tabular}{lrrrrrrrr}
\hline Variables & 1 & 2 & 3 & 4 & 5 & 6 & 7 & 8 \\
\hline 1. Challenge (Combined) & & & & & & & & \\
2. Administration & .056 & & & & & & & \\
3. Technology Support & & & & & & & & \\
Staff & .023 & -.074 & & & & & \\
4. Minority & -.027 & .009 & .011 & & & & & \\
5. Female & .042 & -.189 & -.108 & -.007 & & & \\
6. Age & .117 & .067 & .068 & -.034 & -.034 & & & \\
7. Free/Reduced Lunch & & & & & & & & \\
Students & -.052 & -.018 & -.051 & .046 & .060 & -.066 & & \\
8. Non-White Students & .076 & -.058 & .009 & .095 & .111 & -.078 & .455 & \\
& & & & & & & & \\
\hline
\end{tabular}



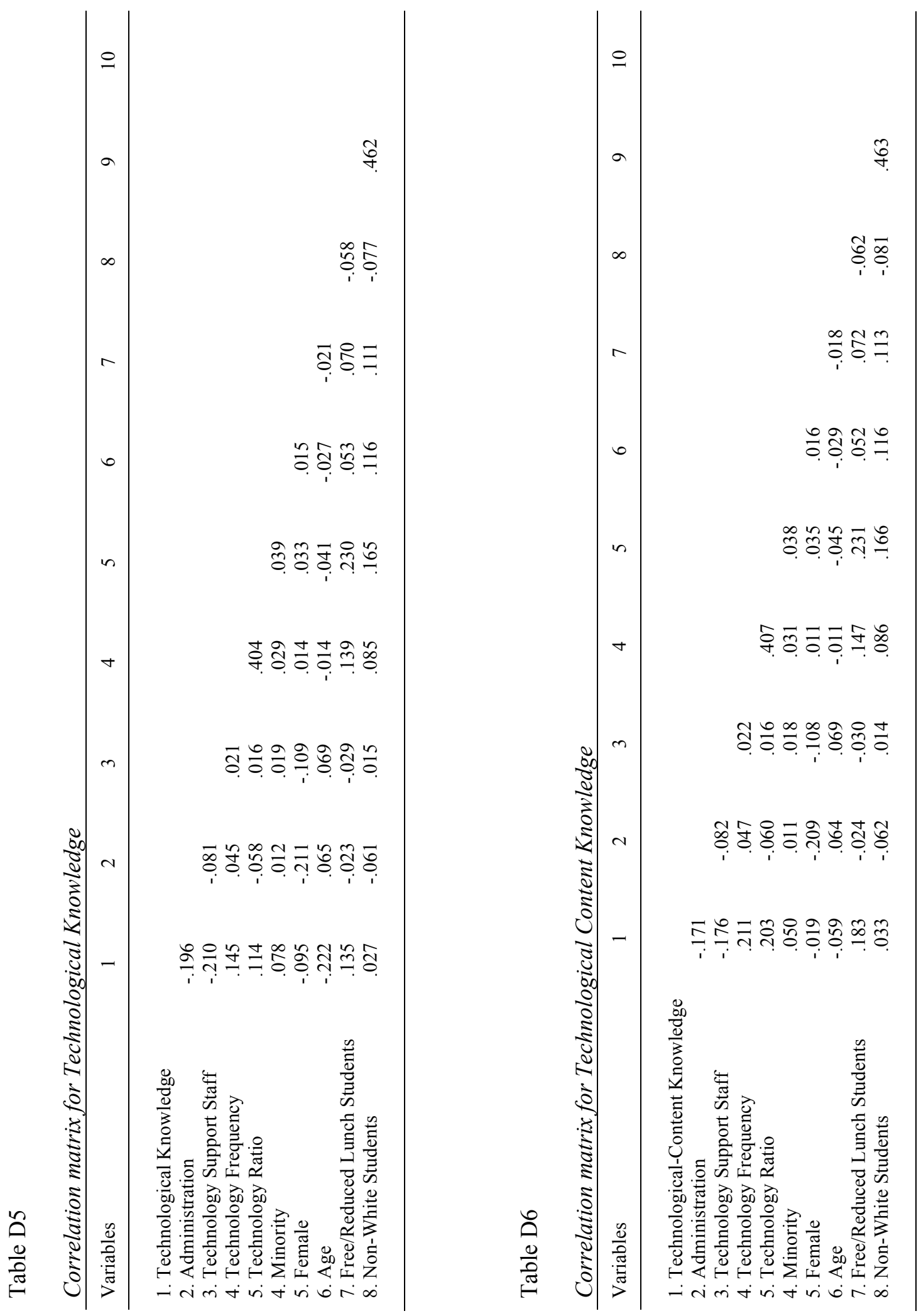

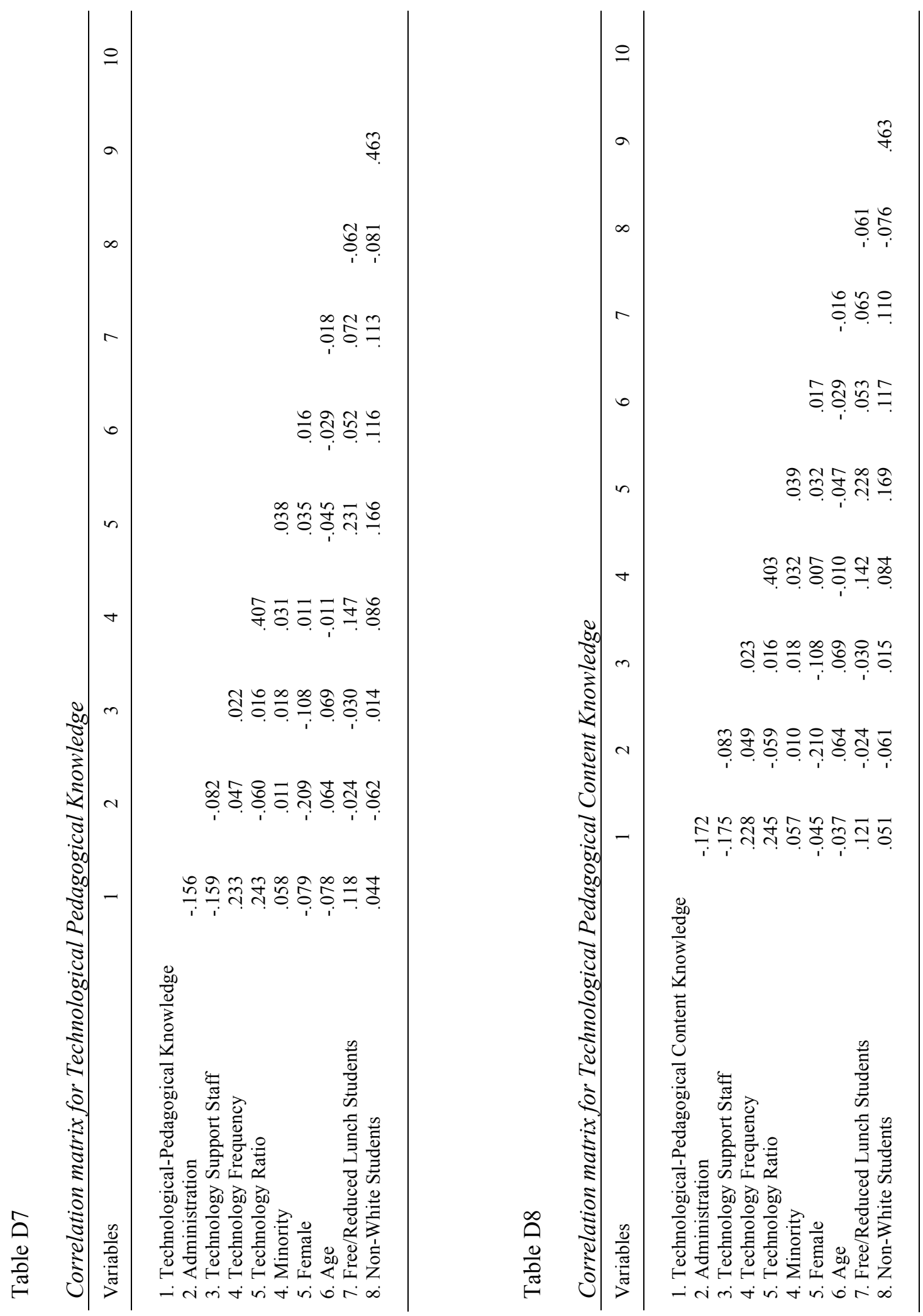
PERCEPTIONS OF EFFECTIVE TECHNOLOGY IMPLEMENTATION

Table D9

Correlation matrix for CHAT 1

\begin{tabular}{lrrrrrrrr}
\hline Variables & 1 & \multicolumn{1}{c}{2} & \multicolumn{1}{c}{3} & \multicolumn{1}{c}{4} & 5 & 6 & 7 & 8 \\
\hline 1. CHAT 1 & & & & & & & & \\
2. Administration & -.118 & & & & & & & \\
3. Technology Support Staff & -.191 & -.076 & & & & & & \\
4. Minority & .001 & .002 & .007 & & & & & \\
5. Female & -.025 & -.198 & -.120 & .000 & & & & \\
6. Age & -.135 & .070 & .063 & -.024 & -.032 & & & \\
7. Free/Reduced Lunch & & & & & & & & \\
Students & .047 & -.017 & -.058 & .065 & .072 & -.067 & & \\
8. Non-White Students & .018 & -.049 & .009 & .112 & .110 & -.065 & .455 & \\
& & & & & & & & \\
\hline
\end{tabular}

Table D10

Correlation matrix for CHAT 2

\begin{tabular}{|c|c|c|c|c|c|c|c|c|}
\hline Variables & 1 & 2 & 3 & 4 & 5 & 6 & 7 & 8 \\
\hline \multicolumn{9}{|l|}{ 1. CHAT 2} \\
\hline 2. Administration & -.192 & & & & & & & \\
\hline 3. Technology Support Staff & -.141 & -.076 & & & & & & \\
\hline 4. Minority & .066 & .002 & .007 & & & & & \\
\hline 5. Female & .015 & -.198 & -.120 & .000 & & & & \\
\hline 6. Age & -.060 & .070 & .063 & -.024 & -.032 & & & \\
\hline \multicolumn{9}{|l|}{ 7. Free/Reduced Lunch } \\
\hline Students & .106 & -.017 & -.058 & .065 & .072 & -.067 & & \\
\hline 8. Non-White Students & .034 & -.049 & .009 & .112 & .110 & -.065 & .455 & \\
\hline
\end{tabular}


Table D1 1

Correlation matrix for CHAT 3

\begin{tabular}{lrrrrrrrr}
\hline Variables & 1 & 2 & 3 & 4 & 5 & 6 & 7 & 8 \\
\hline 1. CHAT 3 & & & & & & & & \\
2. Administration & -.138 & & & & & & & \\
3. Technology Support Staff & -.059 & -.076 & & & & & & \\
4. Minority & -.045 & .002 & .007 & & & & & \\
5. Female & .003 & -.198 & -.120 & .000 & & & & \\
6. Age & .020 & .070 & .063 & -.024 & -.032 & & & \\
7. Free/Reduced Lunch & & & & & & & & \\
Students & .012 & -.017 & -.058 & .065 & .072 & -.067 & & \\
8. Non-White Students & .038 & -.049 & .009 & .112 & .110 & -.065 & .455 & \\
& & & & & & & & \\
\hline
\end{tabular}

Table D12

Correlation matrix for CHAT 4

\begin{tabular}{lrrrrrrrr}
\hline Variables & 1 & \multicolumn{1}{c}{2} & \multicolumn{1}{c}{3} & \multicolumn{1}{c}{4} & 5 & 6 & 7 & 8 \\
\hline 1. CHAT 4 & & & & & & & & \\
2. Administration & -.156 & & & & & & & \\
3. Technology Support Staff & -.086 & -.076 & & & & & & \\
4. Minority & .070 & .002 & .007 & & & & & \\
5. Female & -.013 & -.198 & -.120 & .000 & & & & \\
6. Age & -.073 & .070 & .063 & -.024 & -.032 & & & \\
7. Free/Reduced Lunch & & & & & & & & \\
Students & .049 & -.017 & -.058 & .065 & .072 & -.067 & & \\
8. Non-White Students & .008 & -.049 & .009 & .112 & .110 & -.065 & .455 & \\
& & & & & & & & \\
\hline
\end{tabular}


Table D13

Correlation matrix for CHAT 5

\begin{tabular}{lccccccc}
\hline Variables & 1 & 2 & 3 & 4 & 5 & 6 & 7 \\
\hline & & & & & & & \\
1. CHAT 5 & & & & & & & \\
2. Administration & -.012 & & & & & & \\
3. Technology Support Staff & .013 & -.076 & & & & & \\
4. Minority & .007 & .002 & .007 & & & & \\
5. Female & .008 & -.198 & -.120 & .000 & & & \\
6. Age & .008 & .070 & .063 & -.024 & -.032 & & \\
7. Free/Reduced Lunch & & & & & & & \\
Students & -.021 & -.017 & -.058 & .065 & .072 & -.067 & \\
8. Non-White Students & .009 & -.049 & .009 & .112 & .110 & -.065 & .455 \\
& & & & & & & \\
\hline
\end{tabular}

\section{Table D14}

Correlation matrix for CHAT 6

\begin{tabular}{|c|c|c|c|c|c|c|c|c|}
\hline Variables & 1 & 2 & 3 & 4 & 5 & 6 & 7 & 8 \\
\hline \multicolumn{9}{|l|}{ 1. CHAT 6} \\
\hline 2. Administration & .189 & & & & & & & \\
\hline 3. Technology Support Staff & .113 & -.076 & & & & & & \\
\hline 4. Minority & .003 & .002 & .007 & & & & & \\
\hline 5. Female & -.013 & -.198 & -.120 & .000 & & & & \\
\hline 6. Age & -.037 & .070 & .063 & -.024 & -.032 & & & \\
\hline \multicolumn{9}{|l|}{ 7. Free/Reduced Lunch } \\
\hline Students & -.038 & -.017 & -.058 & .065 & .072 & -.067 & & \\
\hline 8. Non-White Students & .021 & -.049 & .009 & .112 & .110 & -.065 & .455 & \\
\hline
\end{tabular}




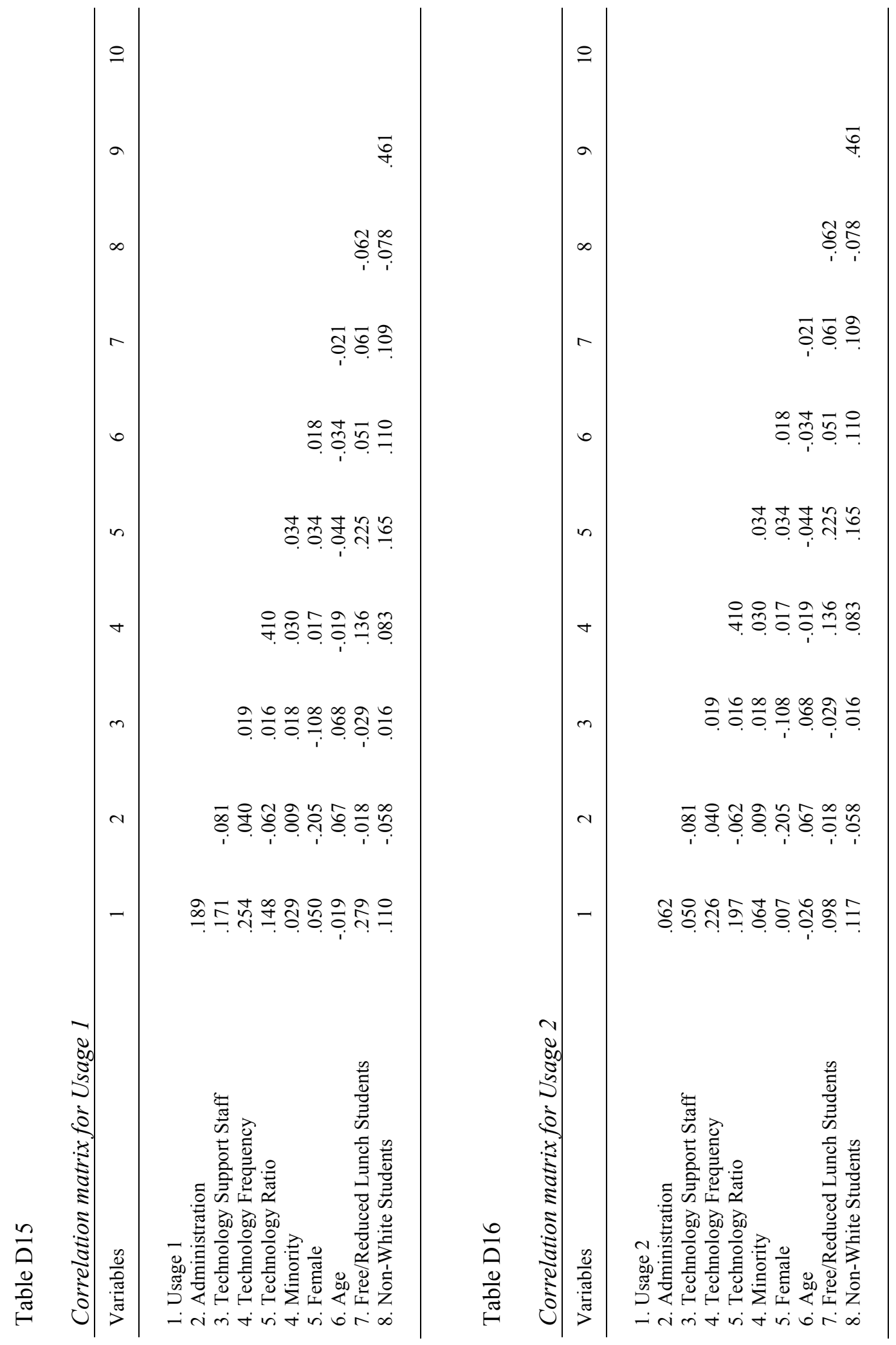




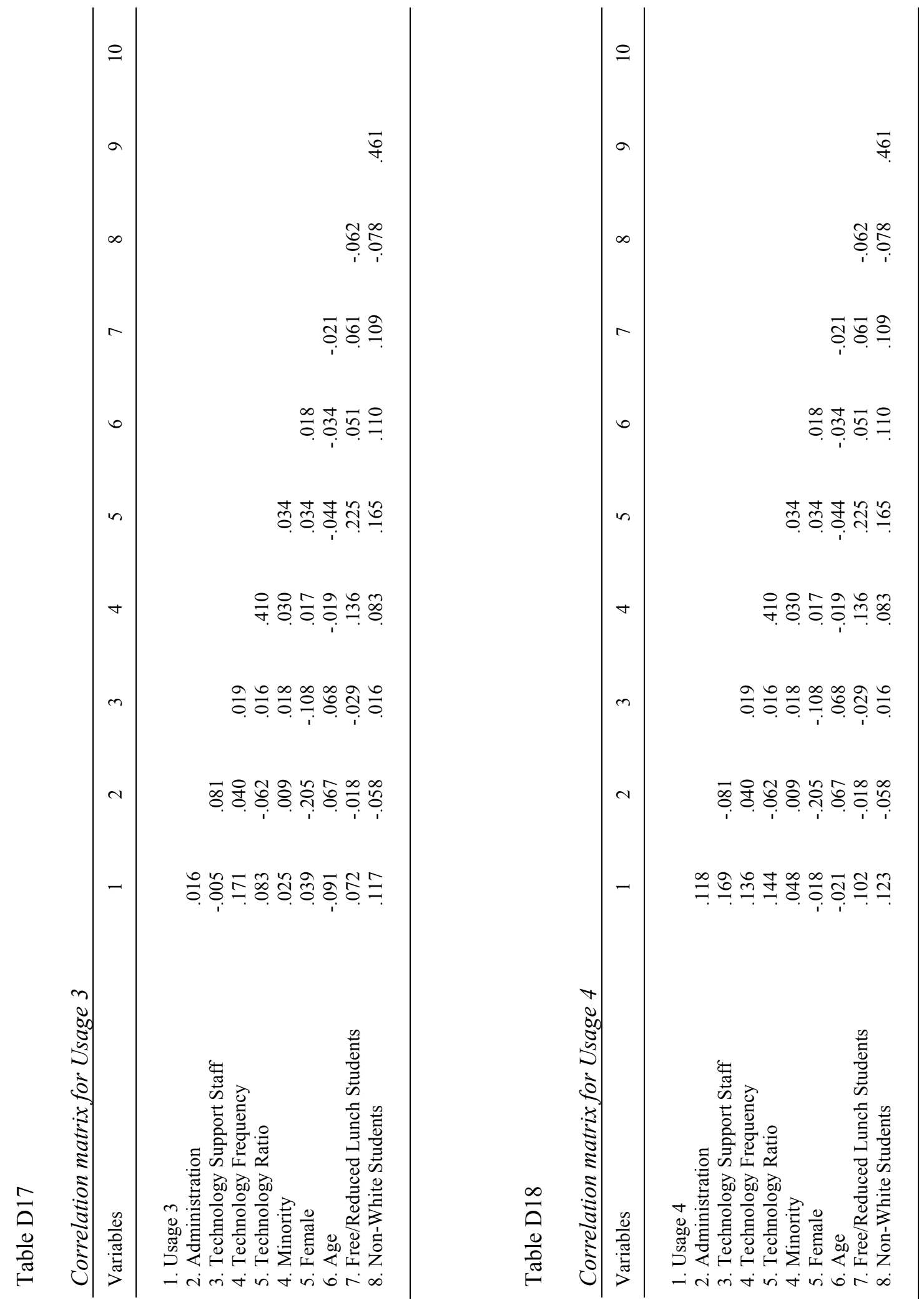



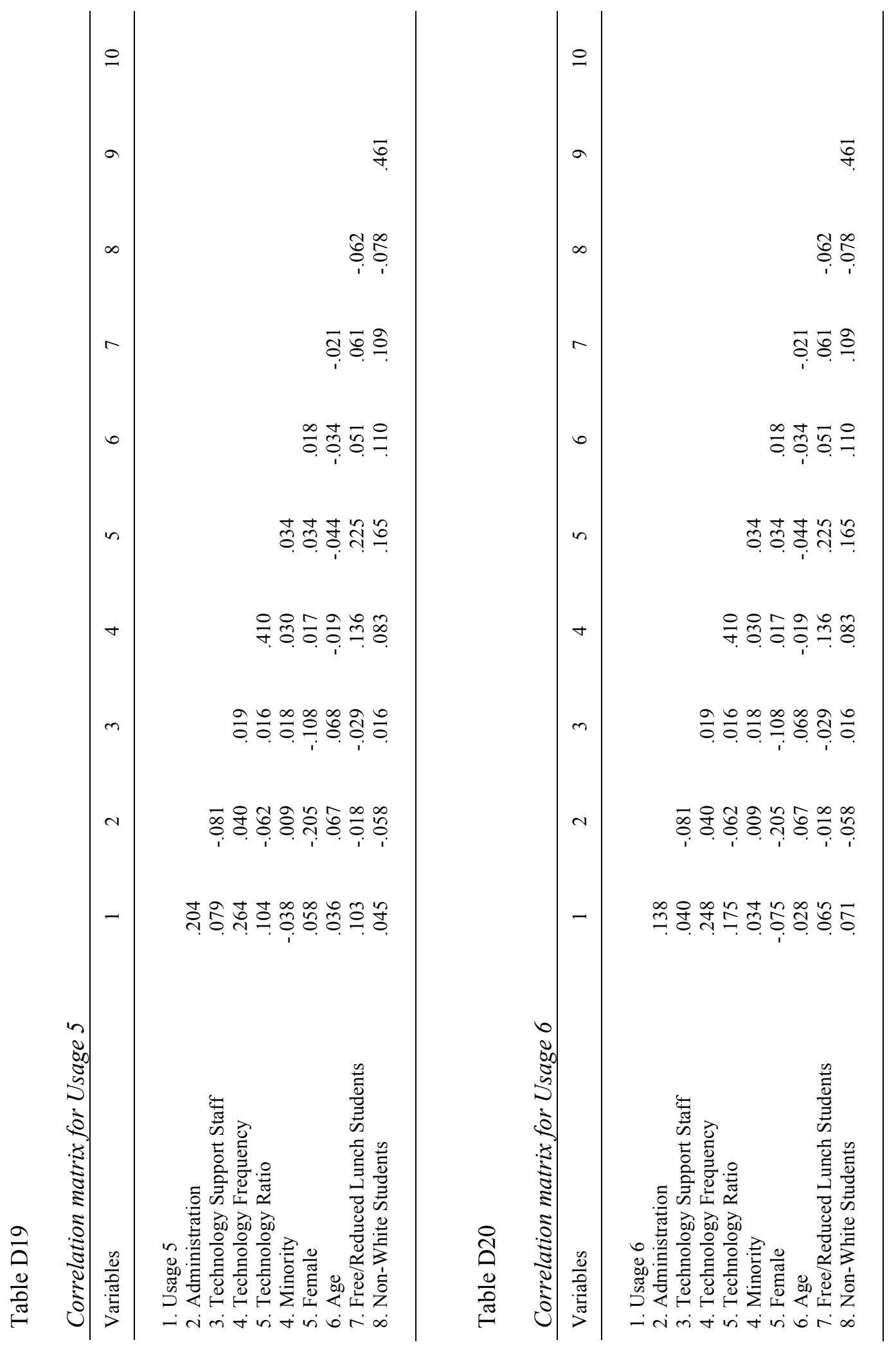


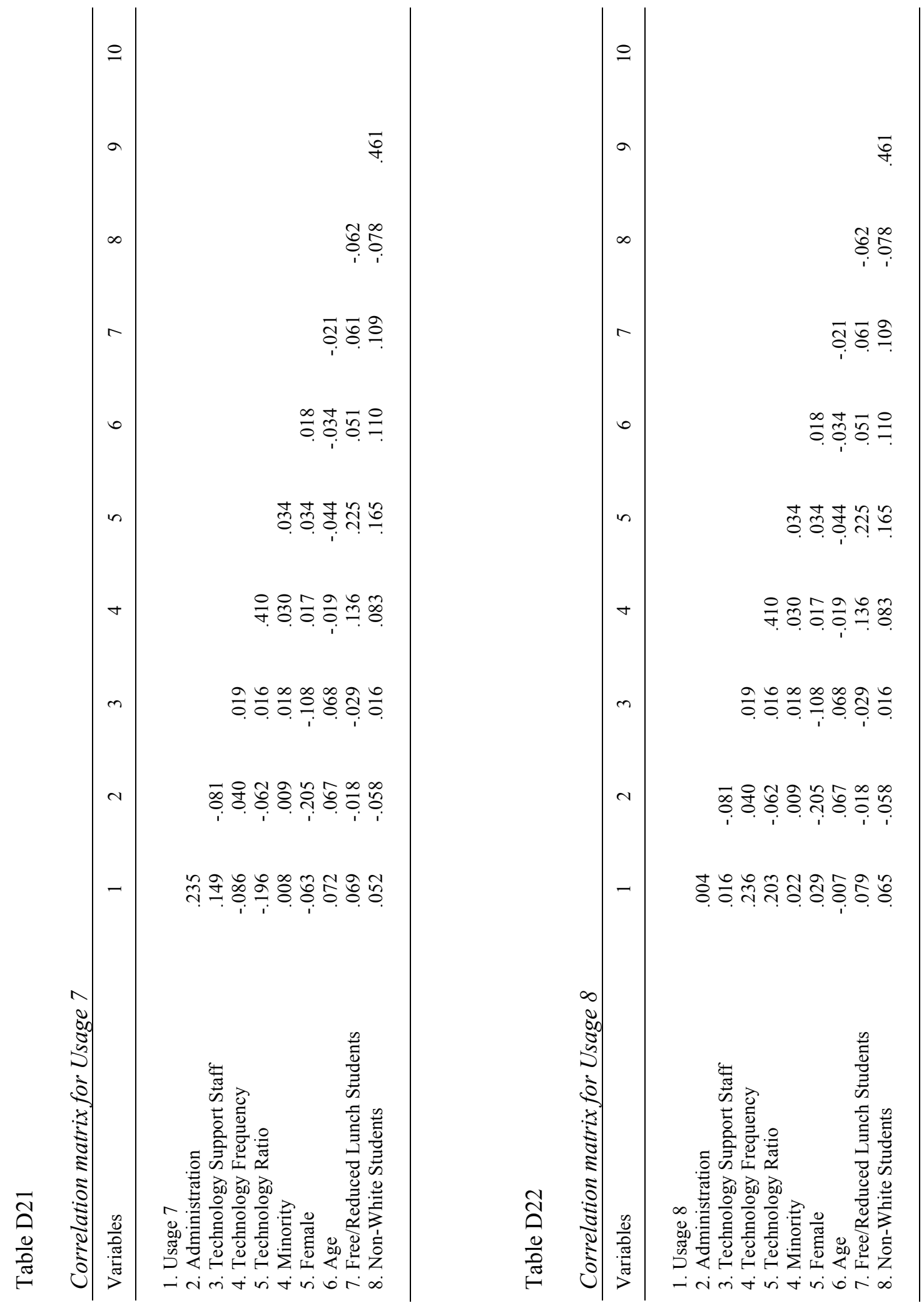




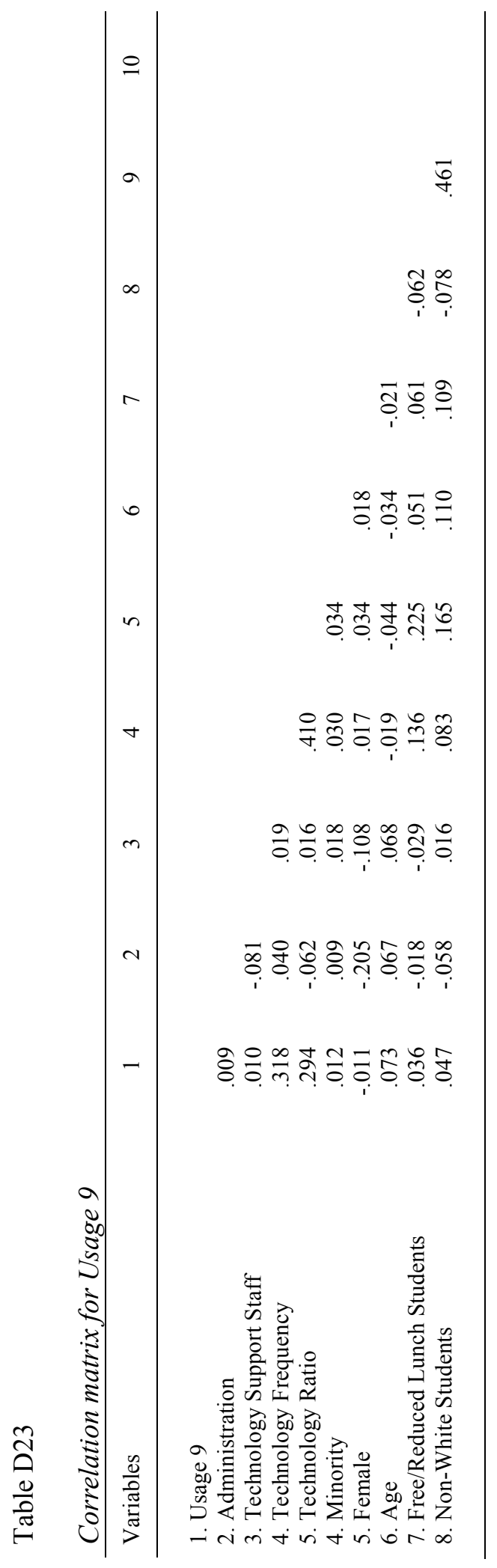


APPENDIX E - Survey Instrument 


\section{Q1 Informed Consent Form}

\section{Introduction}

This study attempts to measure the impact of leadership practices and teacher knowledge upon the successful integration of technology in the classroom.

\section{Procedures}

You will take part in a 26-question survey that should take approximately 15 minutes to complete. This questionnaire will be conducted with an online Qualtrics@-created survey.

\section{Risks}

Risks are minimal for involvement in this study. Supervisors will not know who has or has not done survey, and all data presented will be in an aggregate format (all the results will be combined, no individual responses will be reported).

\section{Benefits}

There are no direct benefits for participants. Participation in this study is voluntary, and by participating, respondents will not gain benefit in their workplace. However, it is hoped that through your participation, researchers will learn more about which practices and actions from administrators and teachers result in more successful technology integration projects.

\section{Confidentiality}

All data obtained from participants will be confidential and will only be reported in an aggregate format (by reporting only combined results and never reporting individual ones). Survey items which ask for state and district names will only be used by the researcher to pair responses to student demographic information available from the National Center for Education Statistics (NCES) and the US Census Bureau.

All questionnaires will be concealed, and no one other than the primary investigator and doctoral research supervisor listed below will have access to them. The data collected will be stored in a Qualtrics-secure database until the primary investigator has deleted it.

\section{Compensation}

There is no direct compensation for participation in this study.

\section{Participation}

Participation in this research study is completely voluntary. You have the right to withdraw at anytime or refuse to participate entirely without jeopardy to your employment. If you desire to withdraw before finishing the survey, please close your Internet browser and no other action is required. If you desire to withdraw after you have completed the questionnaire, please notify the principal investigator at this email: morelock@pdx.edu with your approximate time and date of submission. The researcher can then delete your responses, if any, to guarantee you confidentiality.

\section{Questions about the Research}

If you have questions regarding this study, you may contact the primary researcher, Joseph Morelock, at 503-305-xxxx, morelock@pdx.edu or his Portland State University 
doctoral candidate supervisor, Deborah Peterson, at (503) 725-xxxx, dpeterso@pdx.edu.

\section{Questions about your Rights as Research Participants}

If you have questions you do not feel comfortable asking the researcher, you may contact Deborah Peterson, at (503) 725-xxxx, dpeterso@pdx.edu or at the university address, 615 SW Harrison, Education Building, Office 506 U, Portland, OR 97207

Q2 I have read and understood the above consent form and desire of my own free will to participate in this study.

$\mathrm{O}$ Yes

O No

If No Is Selected, Then Skip To End of Survey

Q4 Thank you for agreeing to participate in this survey about technology and schools and the impact of teacher and leadership practices. All information you submit is confidential, and data that is presented in the final report will be in aggregate form and will not report district, school, or participant names. By selecting your state and district below, the researcher will be able to examine correlational data and conduct other statistical analyses.

Q80 Please select your state and your district from the choices below.

Oregon

[all Oregon school district names listed in drop-down menu] 
Q11 The following questions are related to your personal demographic information. Please be aware that your responses are optional for the following four questions; however your willingness to provide the information will allow the researcher to better understand trends and findings as they relate to gender, race, and ethnicity.

Q10 The following question asks about your ethnicity. This question is optional. Please select your ethnicity selecting one of the two choices:

O Hispanic or Latino: A person of Cuban, Mexican, Puerto Rican, South or Central American, or other Hispanic or Latino culture or origin, regardless of race (including Brazil).

Not Hispanic or Latino

Q13 The following question asks about your race. This question is optional. Please select your race from the following list. Please select all that apply:

$\square$ American Indian or Alaska Native

$\square$ Asian

$\square$ Black or African American

$\square$ Native Hawaiian or Other Pacific Islander

$\square$ White

Q12 The age categories below are based upon the 2010 U.S. Census. This question is optional. What is your current age?
O 20 to 24
○ 25 to 34
○ 35 to 44
O 45 to 54
O 55 to 64
O 65 or over

Q109 This question is optional. Please select your gender:

\section{O Male}

O Female 
Q12 How long have you been a classroom teacher, or if in a different role (administrator or technology coach), how long did you teach? If you were never a classroom teacher, please select "I have never been a classroom teacher"

1-3 years

4-6 years

7-18 years

O 19-30 years

More than 30 years

I have never been a classroom teacher

Q9 Please select the option below that best describes your primary ROLE at your school or district:

Classroom Teacher (including general education, special education, English Language Learners, teachers on special assignment)

Odministrator (not related to technology)

Technology staff (CIO, CTO, technology support, technology coordinator, technology coach/mentor, etc.) 
The following questions are shown only to respondents who select "Classroom Teacher (including general education, special education, English Language Learners, teachers on special assignment)" in Q9 above.

Q14 The following three questions relate to the ratio of technology devices to students and its general use at school from your own perspective.

Q15 The ratio of technology devices to students is most closely aligned with the statement (select one item only):

I have one (or more) computing device (computer, tablet, other mobile) for every student in my classroom. (ratio is 1 student per 1 device).

I have one (or more) computing device (computer, tablet, other mobile) for every two students in my classroom. (ratio is 2 students per 1 device).

O My school/district has available only shared devices (computer labs, laptop carts, tablet carts, etc.) for all teachers and students to share in my classroom/school (ratio is more than 2 students per 1 device). 
Q16 Technology devices in my classroom or used by my students are generally used for/as (select ALL that apply):

\begin{tabular}{|c|c|c|c|c|}
\hline & $\begin{array}{l}\text { Always used } \\
\text { for }\end{array}$ & $\begin{array}{l}\text { Most likely used } \\
\text { for }\end{array}$ & $\begin{array}{l}\text { Least likely used } \\
\text { for }\end{array}$ & $\begin{array}{l}\text { Never used } \\
\text { for }\end{array}$ \\
\hline $\begin{array}{c}\text { Reward for } \\
\text { completing other } \\
\text { work }\end{array}$ & 0 & 0 & 0 & 0 \\
\hline $\begin{array}{l}\text { Understanding } \\
\text { their academic } \\
\text { work }\end{array}$ & 0 & 0 & 0 & 0 \\
\hline $\begin{array}{l}\text { Supplementary or } \\
\text { enrichment tool }\end{array}$ & 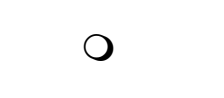 & 0 & 0 & 0 \\
\hline $\begin{array}{l}\text { Teaching about } \\
\text { computers and } \\
\text { other technology } \\
\text { tools and how to } \\
\text { use them }\end{array}$ & 0 & O & 0 & $\mathrm{O}$ \\
\hline $\begin{array}{l}\text { Remediation of } \\
\text { academic } \\
\text { deficiencies }\end{array}$ & 0 & 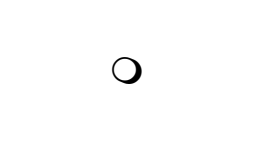 & 0 & 0 \\
\hline $\begin{array}{l}\text { Challenging the } \\
\text { brightest students }\end{array}$ & 0 & 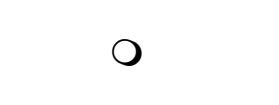 & 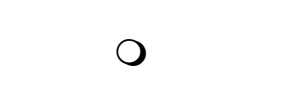 & 0 \\
\hline $\begin{array}{l}\text { State or local } \\
\text { assessments }\end{array}$ & 0 & 0 & 0 & 0 \\
\hline $\begin{array}{l}\text { Motivating } \\
\text { interest in school, } \\
\text { schoolwork, or } \\
\text { class projects }\end{array}$ & 0 & 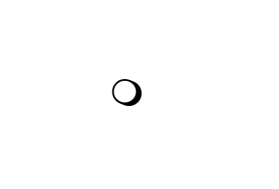 & 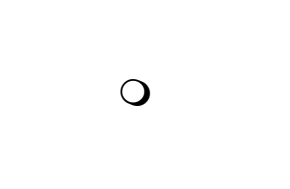 & $\mathrm{O}$ \\
\hline $\begin{array}{l}\text { Significantly } \\
\text { changing the } \\
\text { nature of learning } \\
\text { projects and the } \\
\text { way students } \\
\text { interact with } \\
\text { information, } \\
\text { contexts, and real- } \\
\text { world projects }\end{array}$ & 0 & 0 & 0 & 0 \\
\hline
\end{tabular}


Q19 In general, the frequency with which technology is used BY STUDENTS in my school or district is (select one only):

O every day / every day the class meets (1)

nearly every day / nearly every day the class meets (2)

throughout the school year, but not every day (3)

once or twice per week (5)

$\bigcirc$ less than once per week (6) 
Q17 The following questions focus on your perceptions about your own grasp of the content you teach, the way you teach it, and how you use technology in your teaching. Each question uses a 5-point scale, ranging from a "Strongly Agree" to "Strongly Disagree."

Q18 Please indicate the degree to which you agree or disagree for each of the statements listed on the left. "Technologies" refer to digital technology resources such as computers, tablets, small mobile devices, interactive white boards, etc.

\begin{tabular}{|c|c|c|c|c|c|}
\hline & $\begin{array}{c}\text { Strongly } \\
\text { Agree }\end{array}$ & Agree & $\begin{array}{l}\text { Neither } \\
\text { Agree nor } \\
\text { Disagree }\end{array}$ & Disagree & $\begin{array}{l}\text { Strongly } \\
\text { Disagree }\end{array}$ \\
\hline $\begin{array}{l}\text { I know how to } \\
\text { solve my own } \\
\text { technical } \\
\text { problems. }\end{array}$ & 0 & 0 & $\mathrm{O}$ & 0 & 0 \\
\hline $\begin{array}{l}\text { I can learn } \\
\text { technology } \\
\text { easily. }\end{array}$ & 0 & $\mathrm{O}$ & 0 & 0 & 0 \\
\hline $\begin{array}{l}\text { I have the } \\
\text { technical skills } \\
\text { I need to use } \\
\text { technology. }\end{array}$ & O & $\mathrm{O}$ & O & $\mathrm{O}$ & O \\
\hline $\begin{array}{l}\text { I have had } \\
\text { sufficient } \\
\text { opportunities } \\
\text { to work with } \\
\text { different } \\
\text { technologies. }\end{array}$ & 0 & O & $\mathrm{O}$ & 0 & 0 \\
\hline
\end{tabular}


Q23 Please indicate the degree to which you agree or disagree for each of the statements listed on the left.

\begin{tabular}{|c|c|c|c|c|c|}
\hline $\begin{array}{c}\text { I know about } \\
\text { Agree }\end{array}$ & Agree & $\begin{array}{c}\text { Neither } \\
\text { Agree nor } \\
\text { Disagree }\end{array}$ & Disagree & $\begin{array}{c}\text { Strongly } \\
\text { Disagree }\end{array}$ \\
$\begin{array}{c}\text { that I can use } \\
\text { for }\end{array}$ & & & 0 & \\
$\begin{array}{c}\text { understanding } \\
\text { and working in } \\
\text { the primary } \\
\text { subject area(s) } \\
\text { or grade } \\
\text { level(s) I } \\
\text { teach. }\end{array}$ & 0 & 0 & 0 & 0 \\
\hline
\end{tabular}

Q24 Please indicate the degree to which you agree or disagree for each of the statements listed on the left.

\begin{tabular}{|c|c|c|c|c|c|}
\hline & $\begin{array}{l}\text { Strongly } \\
\text { Agree }\end{array}$ & Agree & $\begin{array}{l}\text { Neither } \\
\text { Agree nor } \\
\text { Disagree }\end{array}$ & Disagree & $\begin{array}{l}\text { Strongly } \\
\text { Disagree }\end{array}$ \\
\hline $\begin{array}{l}\text { I can choose } \\
\text { technologies } \\
\text { that enhance } \\
\text { the teaching } \\
\text { approaches for } \\
\text { a lesson. }\end{array}$ & $\mathrm{O}$ & O & 0 & O & $\mathrm{O}$ \\
\hline $\begin{array}{l}\text { I can choose } \\
\text { technologies } \\
\text { that enhance } \\
\text { students' } \\
\text { learning for a } \\
\text { lesson. }\end{array}$ & $\mathrm{O}$ & 0 & $\mathrm{O}$ & $\mathrm{O}$ & $\mathrm{O}$ \\
\hline
\end{tabular}


Q25 Please indicate the degree to which you agree or disagree for each of the statements listed on the left.

\begin{tabular}{|c|c|c|c|c|c|}
\hline & $\begin{array}{c}\text { Strongly } \\
\text { Agree }\end{array}$ & Agree & $\begin{array}{l}\text { Neither } \\
\text { Agree nor } \\
\text { Disagree }\end{array}$ & Disagree & $\begin{array}{l}\text { Strongly } \\
\text { Disagree }\end{array}$ \\
\hline $\begin{array}{l}\text { I can choose } \\
\text { technologies } \\
\text { that enhance } \\
\text { the content for } \\
\text { a lesson. }\end{array}$ & $\mathrm{O}$ & 0 & $\mathrm{O}$ & 0 & 0 \\
\hline $\begin{array}{c}\text { I can select } \\
\text { technologies } \\
\text { to use in my } \\
\text { classroom that } \\
\text { enhance what } \\
\text { I teach, how I } \\
\text { teach, and } \\
\text { what students } \\
\text { learn. }\end{array}$ & $\mathrm{O}$ & 0 & $\mathrm{O}$ & O & 0 \\
\hline $\begin{array}{l}\text { I can teach } \\
\text { lessons that } \\
\text { appropriately } \\
\text { combine my } \\
\text { subject area(s) } \\
\text { or grade } \\
\text { level(s), } \\
\text { technologies, } \\
\text { and teaching } \\
\text { approaches. }\end{array}$ & $\mathrm{O}$ & 0 & $\mathrm{O}$ & 0 & 0 \\
\hline
\end{tabular}


Q26 The following questions relate to your perceptions of leadership, teacher selfefficacy, and support.

Q27 Please indicate the degree to which you agree or disagree for each of the statements listed on the left.

\begin{tabular}{|c|c|c|c|c|c|}
\hline & $\begin{array}{c}\text { Strongly } \\
\text { Agree }\end{array}$ & Agree & $\begin{array}{l}\text { Neither } \\
\text { Agree nor } \\
\text { Disagree }\end{array}$ & Disagree & $\begin{array}{l}\text { Strongly } \\
\text { Disagree }\end{array}$ \\
\hline $\begin{array}{l}\text { I use } \\
\text { technology in } \\
\text { my instruction } \\
\text { because it's } \\
\text { my own } \\
\text { choice to do } \\
\text { so. } \\
\text { I use } \\
\text { technology in } \\
\text { my instruction } \\
\text { because it's } \\
\text { expected by } \\
\text { school or } \\
\text { district } \\
\text { leaders. } \\
\text { I use } \\
\text { technology in } \\
\text { my instruction } \\
\text { because } \\
\text { some/many of } \\
\text { my peers do } \\
\text { so. } \\
\text { I use } \\
\text { technology in } \\
\text { my instruction } \\
\text { because } \\
\text { students } \\
\text { request it. } \\
\text { I use } \\
\text { technology in } \\
\text { my instruction } \\
\text { because } \\
\text { families or } \\
\text { parents expect } \\
\text { it. }\end{array}$ & 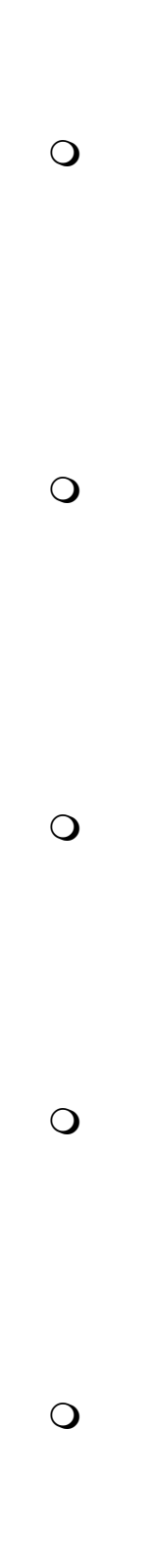 & 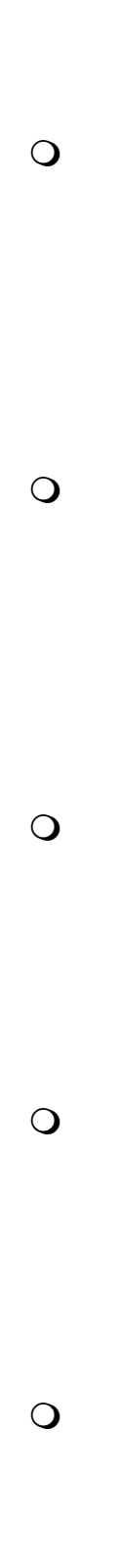 & $\mathrm{O}$ & 0 & O \\
\hline
\end{tabular}


Q28 Please indicate the degree to which you agree or disagree for each of the statements listed on the left.

\begin{tabular}{|c|c|c|c|c|c|}
\hline & $\begin{array}{c}\text { Strongly } \\
\text { Agree }\end{array}$ & Agree & $\begin{array}{l}\text { Neither } \\
\text { Agree nor } \\
\text { Disagree }\end{array}$ & Disagree & $\begin{array}{l}\text { Strongly } \\
\text { Disagree }\end{array}$ \\
\hline $\begin{array}{l}\text { The school } \\
\text { leadership or } \\
\text { district } \\
\text { leadership } \\
\text { provides } \\
\text { adequate } \\
\text { training or } \\
\text { professional } \\
\text { development } \\
\text { for using } \\
\text { technology in } \\
\text { instruction. }\end{array}$ & $\mathrm{O}$ & 0 & $\mathrm{O}$ & $\mathrm{O}$ & $\mathrm{O}$ \\
\hline $\begin{array}{l}\text { The school } \\
\text { leadership or } \\
\text { district } \\
\text { leadership } \\
\text { provides } \\
\text { training or } \\
\text { professional } \\
\text { development } \\
\text { which directly } \\
\text { influences my } \\
\text { use of } \\
\text { technology in } \\
\text { instruction }\end{array}$ & $\mathrm{O}$ & 0 & $\mathrm{O}$ & O & 0 \\
\hline
\end{tabular}


Q29 Please indicate the degree to which you agree or disagree for each of the statements listed on the left.

\begin{tabular}{|c|c|c|c|c|c|}
\hline & $\begin{array}{c}\text { Strongly } \\
\text { Agree }\end{array}$ & Agree & $\begin{array}{l}\text { Neither } \\
\text { Agree nor } \\
\text { Disagree }\end{array}$ & Disagree & $\begin{array}{l}\text { Strongly } \\
\text { Disagree }\end{array}$ \\
\hline $\begin{array}{c}\text { I feel that I am } \\
\text { able to } \\
\text { influence } \\
\text { technology } \\
\text { purchasing } \\
\text { decisions in } \\
\text { my } \\
\text { school/district. }\end{array}$ & $\mathrm{O}$ & O & $\mathrm{O}$ & $\mathrm{O}$ & 0 \\
\hline $\begin{array}{c}\text { My } \\
\text { school/district } \\
\text { has an } \\
\text { effective } \\
\text { method for me } \\
\text { to apply for } \\
\text { funding a } \\
\text { technology } \\
\text { project in my } \\
\text { classroom. }\end{array}$ & $\mathrm{O}$ & $\mathrm{O}$ & $\mathrm{O}$ & $\mathrm{O}$ & $\mathrm{O}$ \\
\hline
\end{tabular}


Q30 Please indicate the degree to which you agree or disagree for each of the statements listed on the left.

\begin{tabular}{|c|c|c|c|c|c|}
\hline $\begin{array}{c}\text { I feel that my } \\
\text { school } \\
\text { leadership } \\
\text { Aupports my } \\
\text { use of } \\
\text { technology } \\
\text { with students }\end{array}$ & O & $\begin{array}{c}\text { Agree } \\
\text { Agree nor } \\
\text { Disagree }\end{array}$ & Disagree & $\begin{array}{c}\text { Strongly } \\
\text { Disagree }\end{array}$ \\
$\begin{array}{c}\text { I feel that my } \\
\text { teaching peers } \\
\text { support my } \\
\text { use of }\end{array}$ & 0 & 0 & 0 & 0 & 0 \\
$\begin{array}{c}\text { technology } \\
\text { with students. } \\
\text { I can get } \\
\text { adequate } \\
\text { technology } \\
\text { support for } \\
\text { issues that } \\
\text { arise for me } \\
\text { or for my } \\
\text { students. }\end{array}$ & 0 & 0 & 0 & 0 & 0 \\
\hline
\end{tabular}


Q32 The following questions ask you about your attitudes and perceptions about your classroom uses of technology.

Q33 Please indicate the degree to which you agree or disagree for each of the statements listed on the left.

\begin{tabular}{|c|c|c|c|c|c|}
\hline & $\begin{array}{c}\text { Strongly } \\
\text { Agree }\end{array}$ & Agree & $\begin{array}{l}\text { Neither } \\
\text { Agree nor } \\
\text { Disagree }\end{array}$ & Disagree & $\begin{array}{l}\text { Strongly } \\
\text { Disagree }\end{array}$ \\
\hline $\begin{array}{l}\text { I learn by doing } \\
\text { and/or by using } \\
\text { technology tools } \\
\text { in an active way } \\
\text { on my own. }\end{array}$ & 0 & O & $\mathrm{O}$ & O & O \\
\hline $\begin{array}{c}\text { I prefer } \\
\text { professional } \\
\text { learning activities } \\
\text { that promote } \\
\text { active use with } \\
\text { technology tools. }\end{array}$ & 0 & O & 0 & 0 & $\mathrm{O}$ \\
\hline $\begin{array}{c}\text { I prefer } \\
\text { professional } \\
\text { learning activities } \\
\text { that focus on } \\
\text { theory and best } \\
\text { practices. }\end{array}$ & 0 & 0 & 0 & 0 & $O$ \\
\hline $\begin{array}{l}\text { I learn by } \\
\text { researching or } \\
\text { learning about } \\
\text { using technology } \\
\text { tools before I } \\
\text { start doing it or } \\
\text { using it in my } \\
\text { classroom/school. }\end{array}$ & 0 & 0 & 0 & $\mathrm{O}$ & 0 \\
\hline
\end{tabular}


Q34 Please indicate the degree to which you agree or disagree for each of the statements listed on the left.

\begin{tabular}{|c|c|c|c|c|c|}
\hline & $\begin{array}{c}\text { Strongly } \\
\text { Agree }\end{array}$ & Agree & $\begin{array}{l}\text { Neither } \\
\text { Agree nor } \\
\text { Disagree }\end{array}$ & Disagree & $\begin{array}{l}\text { Strongly } \\
\text { Disagree }\end{array}$ \\
\hline $\begin{array}{l}\text { I look for } \\
\text { models of } \\
\text { effective or } \\
\text { appropriate } \\
\text { use BEFORE } \\
\text { I start using } \\
\text { technology } \\
\text { tools with my } \\
\text { students. }\end{array}$ & 0 & 0 & 0 & 0 & $\mathrm{O}$ \\
\hline $\begin{array}{l}\text { I prefer to use } \\
\text { technology } \\
\text { tools in a } \\
\text { similar way as } \\
\text { my peers or } \\
\text { leaders do. }\end{array}$ & 0 & 0 & 0 & 0 & 0 \\
\hline $\begin{array}{l}\text { I need to } \\
\text { know how to } \\
\text { fully use a } \\
\text { technology } \\
\text { tool (device or } \\
\text { application) } \\
\text { BEFORE my } \\
\text { students begin } \\
\text { using it. }\end{array}$ & $\mathrm{O}$ & 0 & 0 & 0 & 0 \\
\hline $\begin{array}{l}\text { I prefer to try } \\
\text { out different } \\
\text { techniques of } \\
\text { using } \\
\text { technology } \\
\text { tools with } \\
\text { students } \\
\text { regardless of } \\
\text { how my peers } \\
\text { or leaders do } \\
\text { so. }\end{array}$ & 0 & 0 & 0 & 0 & 0 \\
\hline
\end{tabular}


Q35 Please indicate the degree to which you agree or disagree for each of the statements listed on the left.

\begin{tabular}{|c|c|c|c|c|c|}
\hline & $\begin{array}{c}\text { Strongly } \\
\text { Agree }\end{array}$ & Agree & $\begin{array}{l}\text { Neither } \\
\text { Agree nor } \\
\text { Disagree }\end{array}$ & Disagree & $\begin{array}{l}\text { Strongly } \\
\text { Disagree }\end{array}$ \\
\hline $\begin{array}{l}\text { I only use } \\
\text { technology } \\
\text { tools with my } \\
\text { students when } \\
\text { I know their } \\
\text { learning } \\
\text { product will } \\
\text { be } \\
\text { significantly } \\
\text { enhanced. }\end{array}$ & 0 & $\mathrm{O}$ & $\mathrm{O}$ & 0 & 0 \\
\hline $\begin{array}{l}\text { Knowing the } \\
\text { outcomes } \\
\text { and/or the } \\
\text { student } \\
\text { products or } \\
\text { goals for using } \\
\text { technology is } \\
\text { important to } \\
\text { me BEFORE I } \\
\text { start doing so. }\end{array}$ & 0 & 0 & 0 & $\mathrm{O}$ & 0 \\
\hline $\begin{array}{l}\text { I like to show } \\
\text { others what } \\
\text { my students } \\
\text { do with } \\
\text { technology in } \\
\text { the classroom }\end{array}$ & $\mathrm{O}$ & $\mathrm{O}$ & 0 & O & 0 \\
\hline
\end{tabular}


The following questions are shown only to respondents who select "Administrator (not related to technology)" in Q9 above.

Q45 The following three questions relate to the ratio of technology devices to students and its general use at school from your own perspective.

Q46 The ratio of technology devices to students is most closely aligned with the statement (select one item only):

O In general, we have one (or more) computing device (computer, tablet, other mobile) for every student in my district/school (ratio is 1 student per 1 device)

In general, we have one (or more) computing device (computer, tablet, other mobile) for every two students in my district/school (ratio is 2 students to 1 device)

O My school/district has available only shared devices (computer labs, laptop carts, tablet carts, etc.) for all students in a school to share (more than 2 students to 1 device) 
Q110 Technology devices in my school / school district are generally used for/as:

\begin{tabular}{|c|c|c|c|c|}
\hline & $\begin{array}{l}\text { Always used } \\
\text { for }\end{array}$ & $\begin{array}{l}\text { Most likely used } \\
\text { for }\end{array}$ & $\begin{array}{l}\text { Least likely used } \\
\text { for }\end{array}$ & $\begin{array}{l}\text { Never used } \\
\text { for }\end{array}$ \\
\hline $\begin{array}{c}\text { Reward for } \\
\text { completing other } \\
\text { work }\end{array}$ & 0 & 0 & 0 & 0 \\
\hline $\begin{array}{l}\text { Understanding } \\
\text { their academic } \\
\text { work }\end{array}$ & 0 & 0 & 0 & 0 \\
\hline $\begin{array}{l}\text { Supplementary or } \\
\text { enrichment tool }\end{array}$ & 0 & 0 & 0 & 0 \\
\hline $\begin{array}{l}\text { Teaching about } \\
\text { computers and } \\
\text { other technology } \\
\text { tools and how to } \\
\text { use them }\end{array}$ & 0 & 0 & 0 & 0 \\
\hline $\begin{array}{c}\text { Remediation of } \\
\text { academic } \\
\text { deficiencies }\end{array}$ & 0 & 0 & 0 & 0 \\
\hline $\begin{array}{l}\text { Challenging the } \\
\text { brightest students }\end{array}$ & 0 & 0 & 0 & 0 \\
\hline $\begin{array}{c}\text { State or local } \\
\text { assessments }\end{array}$ & 0 & 0 & 0 & 0 \\
\hline $\begin{array}{l}\text { Motivating } \\
\text { interest in school, } \\
\text { schoolwork, or } \\
\text { class projects }\end{array}$ & 0 & 0 & 0 & 0 \\
\hline $\begin{array}{l}\text { Significantly } \\
\text { changing the } \\
\text { nature of learning } \\
\text { projects and the } \\
\text { way students } \\
\text { interact with } \\
\text { information, } \\
\text { contexts, and real- } \\
\text { world projects }\end{array}$ & 0 & 0 & 0 & 0 \\
\hline
\end{tabular}


Q48 In general, the frequency with which technology is used BY STUDENTS in my school or district is (select one only):

$\mathrm{O}$ every day the class meets (1)

nearly every day the class meets (2)

throughout the school year, but not every day (3)

once or twice per week (5)

less than once per week (6) 
Q49 The following questions focus on your perceptions about your own grasp of the content you teach, the way you teach it, and how you use technology in your teaching. Each question uses a 5-point scale, ranging from a "Strongly Agree" to a "Strongly Disagree."

Q50 Please indicate the degree to which you agree or disagree for each of the statements listed on the left. "Technologies" refer to digital technology resources such as computers, tablets, small mobile devices, interactive white boards, etc.

\begin{tabular}{|c|c|c|c|c|c|}
\hline & $\begin{array}{c}\text { Strongly } \\
\text { Agree }\end{array}$ & Agree & $\begin{array}{c}\text { Neither } \\
\text { Agree nor } \\
\text { Disagree }\end{array}$ & Disagree & $\begin{array}{l}\text { Strongly } \\
\text { Disagree }\end{array}$ \\
\hline $\begin{array}{l}\text { The majority } \\
\text { of the teachers } \\
\text { in my school } \\
\text { or district } \\
\text { know how to } \\
\text { solve their } \\
\text { own technical } \\
\text { problems. }\end{array}$ & 0 & 0 & 0 & 0 & 0 \\
\hline $\begin{array}{l}\text { The majority } \\
\text { of the teachers } \\
\text { in my school } \\
\text { or district can } \\
\text { learn } \\
\text { technology } \\
\text { easily. }\end{array}$ & $\mathrm{O}$ & 0 & 0 & 0 & 0 \\
\hline $\begin{array}{l}\text { The majority } \\
\text { of the teachers } \\
\text { in my school } \\
\text { or district have } \\
\text { the technical } \\
\text { skills they } \\
\text { need to use } \\
\text { technology. }\end{array}$ & 0 & 0 & 0 & 0 & 0 \\
\hline $\begin{array}{l}\text { The majority } \\
\text { of the teachers } \\
\text { in my school } \\
\text { or district have } \\
\text { had sufficient } \\
\text { opportunities } \\
\text { to work with } \\
\text { different } \\
\text { technologies. }\end{array}$ & 0 & 0 & 0 & 0 & 0 \\
\hline
\end{tabular}


Q54 Please indicate the degree to which you agree or disagree for each of the statements listed on the left.

\begin{tabular}{|c|c|c|c|c|c|}
\hline & $\begin{array}{c}\text { Strongly } \\
\text { Agree }\end{array}$ & Agree & $\begin{array}{l}\text { Neither } \\
\text { Agree nor } \\
\text { Disagree }\end{array}$ & Disagree & $\begin{array}{l}\text { Strongly } \\
\text { Disagree }\end{array}$ \\
\hline $\begin{array}{l}\text { The majority } \\
\text { of the teachers } \\
\text { in my school } \\
\text { or district } \\
\text { know about } \\
\text { technologies } \\
\text { that they can } \\
\text { use for } \\
\text { understanding } \\
\text { and working in } \\
\text { the primary } \\
\text { subject area(s) } \\
\text { or grade } \\
\text { level(s) they } \\
\text { teach. }\end{array}$ & $\mathrm{O}$ & $\mathrm{O}$ & $\mathrm{O}$ & $\mathrm{O}$ & $\mathrm{O}$ \\
\hline
\end{tabular}


Q55 Please indicate the degree to which you agree or disagree for each of the statements listed on the left.

\begin{tabular}{|c|c|c|c|c|c|}
\hline & $\begin{array}{c}\text { Strongly } \\
\text { Agree }\end{array}$ & Agree & $\begin{array}{l}\text { Neither } \\
\text { Agree nor } \\
\text { Disagree }\end{array}$ & Disagree & $\begin{array}{l}\text { Strongly } \\
\text { Disagree }\end{array}$ \\
\hline $\begin{array}{l}\text { The majority } \\
\text { of the teachers } \\
\text { in my school } \\
\text { or district can } \\
\text { choose } \\
\text { technologies } \\
\text { that enhance } \\
\text { the teaching } \\
\text { approaches for } \\
\text { a lesson. }\end{array}$ & 0 & $\mathrm{O}$ & O & $\mathrm{O}$ & $\mathrm{O}$ \\
\hline $\begin{array}{l}\text { The majority } \\
\text { of the teachers } \\
\text { in my school } \\
\text { or district can } \\
\text { choose } \\
\text { technologies } \\
\text { that enhance } \\
\text { students' } \\
\text { learning for a } \\
\text { lesson. }\end{array}$ & 0 & 0 & $\mathrm{O}$ & O & $\mathrm{O}$ \\
\hline
\end{tabular}


Q56 Please indicate the degree to which you agree or disagree for each of the statements listed on the left.

\begin{tabular}{|c|c|c|c|c|c|}
\hline & $\begin{array}{c}\text { Strongly } \\
\text { Agree }\end{array}$ & Agree & $\begin{array}{l}\text { Neither } \\
\text { Agree nor } \\
\text { Disagree }\end{array}$ & Disagree & $\begin{array}{l}\text { Strongly } \\
\text { Disagree }\end{array}$ \\
\hline $\begin{array}{l}\text { The majority } \\
\text { of the teachers } \\
\text { in my school } \\
\text { or district can } \\
\text { choose } \\
\text { technologies } \\
\text { that enhance } \\
\text { the content for } \\
\text { a lesson. }\end{array}$ & 0 & 0 & 0 & 0 & 0 \\
\hline $\begin{array}{c}\text { The majority } \\
\text { of the teachers } \\
\text { in my school } \\
\text { or district can } \\
\text { select } \\
\text { technologies } \\
\text { to use in their } \\
\text { classroom that } \\
\text { enhance what } \\
\text { they teach, } \\
\text { how they } \\
\text { teach, and } \\
\text { what students } \\
\text { learn. }\end{array}$ & $\mathrm{O}$ & 0 & 0 & $\mathrm{O}$ & 0 \\
\hline $\begin{array}{l}\text { The majority } \\
\text { of the teachers } \\
\text { in my school } \\
\text { or district can } \\
\text { teach lessons } \\
\text { that } \\
\text { appropriately } \\
\text { combine their } \\
\text { subject area(s) } \\
\text { or grade } \\
\text { level(s), } \\
\text { technologies, } \\
\text { and teaching } \\
\text { approaches. }\end{array}$ & $\mathrm{O}$ & 0 & 0 & 0 & 0 \\
\hline
\end{tabular}


Q57 The following questions relate to your perceptions of leadership, teacher selfefficacy, and support.

Q58 Please indicate the degree to which you agree or disagree for each of the statements listed on the left.

\begin{tabular}{|c|c|c|c|c|c|}
\hline & $\begin{array}{c}\text { Strongly } \\
\text { Agree }\end{array}$ & Agree & $\begin{array}{l}\text { Neither } \\
\text { Agree nor } \\
\text { Disagree }\end{array}$ & Disagree & $\begin{array}{l}\text { Strongly } \\
\text { Disagree }\end{array}$ \\
\hline $\begin{array}{c}\text { The majority } \\
\text { of the teachers } \\
\text { in my school } \\
\text { or district use } \\
\text { technology in } \\
\text { their } \\
\text { instruction } \\
\text { because it's } \\
\text { their own } \\
\text { choice to do } \\
\text { so. }\end{array}$ & 0 & 0 & $\mathrm{O}$ & 0 & 0 \\
\hline $\begin{array}{c}\text { The majority } \\
\text { of the teachers } \\
\text { in my school } \\
\text { or district use } \\
\text { technology in } \\
\text { their } \\
\text { instruction } \\
\text { because it's an } \\
\text { expectation of } \\
\text { school or } \\
\text { district } \\
\text { leaders. }\end{array}$ & 0 & 0 & $\mathrm{O}$ & 0 & 0 \\
\hline $\begin{array}{l}\text { The majority } \\
\text { of the teachers } \\
\text { in my school } \\
\text { or district use } \\
\text { technology in } \\
\text { their } \\
\text { instruction } \\
\text { because } \\
\text { some/many of } \\
\text { their peers do } \\
\text { so. }\end{array}$ & 0 & 0 & 0 & 0 & 0 \\
\hline $\begin{array}{l}\text { The majority } \\
\text { of the teachers } \\
\text { in my school } \\
\text { or district use } \\
\text { technology in }\end{array}$ & 0 & 0 & 0 & 0 & O \\
\hline
\end{tabular}




\begin{tabular}{|c|c|c|c|c|c|}
\hline $\begin{array}{l}\text { their } \\
\text { instruction } \\
\text { because } \\
\text { students } \\
\text { request it. } \\
\text { The majority } \\
\text { of the teachers } \\
\text { in my school } \\
\text { or district use } \\
\text { technology in } \\
\text { their } \\
\text { instruction } \\
\text { because } \\
\text { families or } \\
\text { parents expect } \\
\text { it. }\end{array}$ & 0 & 0 & 0 & 0 & 0 \\
\hline
\end{tabular}


Q59 Please indicate the degree to which you agree or disagree for each of the statements listed on the left.

\begin{tabular}{|c|c|c|c|c|c|}
\hline & $\begin{array}{c}\text { Strongly } \\
\text { Agree }\end{array}$ & Agree & $\begin{array}{l}\text { Neither } \\
\text { Agree nor } \\
\text { Disagree }\end{array}$ & Disagree & $\begin{array}{l}\text { Strongly } \\
\text { Disagree }\end{array}$ \\
\hline $\begin{array}{l}\text { The school } \\
\text { leadership or } \\
\text { district } \\
\text { leadership } \\
\text { provides } \\
\text { adequate } \\
\text { training or } \\
\text { professional } \\
\text { development } \\
\text { for using } \\
\text { technology in } \\
\text { instruction. }\end{array}$ & $\mathrm{O}$ & 0 & 0 & 0 & 0 \\
\hline $\begin{array}{l}\text { The school } \\
\text { leadership or } \\
\text { district } \\
\text { leadership } \\
\text { provides } \\
\text { training or } \\
\text { professional } \\
\text { development } \\
\text { which directly } \\
\text { influences the } \\
\text { use of } \\
\text { technology in } \\
\text { instruction }\end{array}$ & $\mathrm{O}$ & $\mathrm{O}$ & $\mathrm{O}$ & O & 0 \\
\hline
\end{tabular}


Q60 Please indicate the degree to which you agree or disagree for each of the statements listed on the left.

\begin{tabular}{|c|c|c|c|c|c|}
\hline & $\begin{array}{l}\text { Strongly } \\
\text { Agree }\end{array}$ & Agree & $\begin{array}{l}\text { Neither } \\
\text { Agree nor } \\
\text { Disagree }\end{array}$ & Disagree & $\begin{array}{l}\text { Strongly } \\
\text { Disagree }\end{array}$ \\
\hline $\begin{array}{c}\text { Teachers are } \\
\text { able to } \\
\text { influence } \\
\text { technology } \\
\text { purchasing } \\
\text { decisions in } \\
\text { their school } \\
\text { and/or our } \\
\text { district. }\end{array}$ & O & O & O & O & O \\
\hline $\begin{array}{l}\text { Our school or } \\
\text { district has an } \\
\text { effective } \\
\text { method for } \\
\text { teachers to } \\
\text { apply for } \\
\text { funding a } \\
\text { technology } \\
\text { project in } \\
\text { their } \\
\text { classroom. }\end{array}$ & 0 & O & 0 & O & 0 \\
\hline
\end{tabular}


Q61 Please indicate the degree to which you agree or disagree for each of the statements listed on the left.

\begin{tabular}{|c|c|c|c|c|c|}
\hline $\begin{array}{c}\text { Strongly } \\
\text { Agree }\end{array}$ & Agree & $\begin{array}{c}\text { Neither } \\
\text { Agree nor } \\
\text { Disagree }\end{array}$ & Disagree & $\begin{array}{c}\text { Strongly } \\
\text { Disagree }\end{array}$ \\
\hline $\begin{array}{c}\text { I feadership } \\
\text { supports our } \\
\text { teachers' use } \\
\text { of technology } \\
\text { with students }\end{array}$ & 0 & 0 & 0 & 0 & 0 \\
$\begin{array}{c}\text { I feel that } \\
\text { teachers' peers } \\
\text { support the } \\
\text { use of }\end{array}$ & 0 & 0 & 0 & 0 & 0 \\
technology \\
with students. \\
$\begin{array}{c}\text { I feel that } \\
\text { teachers can } \\
\text { get adequate } \\
\text { technology } \\
\text { support for } \\
\text { issues that } \\
\text { arise for } \\
\text { themselves or } \\
\text { for their } \\
\text { students. }\end{array}$ & 0 & 0 & 0 & 0 & 0 \\
\hline
\end{tabular}


Q63 The following questions ask you about your attitudes and perceptions about your classroom uses of technology.

Q64 Please indicate the degree to which you agree or disagree for each of the statements listed on the left.

\begin{tabular}{|c|c|c|c|c|c|}
\hline & $\begin{array}{c}\text { Strongly } \\
\text { Agree }\end{array}$ & Agree & $\begin{array}{l}\text { Neither } \\
\text { Agree nor } \\
\text { Disagree }\end{array}$ & Disagree & $\begin{array}{l}\text { Strongly } \\
\text { Disagree }\end{array}$ \\
\hline $\begin{array}{l}\text { The majority } \\
\text { of the teachers } \\
\text { in my school } \\
\text { or district } \\
\text { learn by doing } \\
\text { and/or by } \\
\text { using } \\
\text { technology } \\
\text { tools in an } \\
\text { active way on } \\
\text { their own. }\end{array}$ & O & O & $\mathrm{O}$ & O & O \\
\hline $\begin{array}{l}\text { The majority } \\
\text { of the teachers } \\
\text { in my school } \\
\text { or district } \\
\text { prefer } \\
\text { professional } \\
\text { learning } \\
\text { activities that } \\
\text { promote } \\
\text { active use } \\
\text { with } \\
\text { technology } \\
\text { tools. }\end{array}$ & $\mathrm{O}$ & 0 & 0 & 0 & 0 \\
\hline $\begin{array}{l}\text { The majority } \\
\text { of the teachers } \\
\text { in my school } \\
\text { or district } \\
\text { prefer } \\
\text { professional } \\
\text { learning } \\
\text { activities that } \\
\text { focus on } \\
\text { theory and } \\
\text { best practices. }\end{array}$ & $\mathrm{O}$ & O & O & O & O \\
\hline $\begin{array}{l}\text { The majority } \\
\text { of the teachers } \\
\text { in my school } \\
\text { or district }\end{array}$ & 0 & O & 0 & $\mathrm{O}$ & $\mathrm{O}$ \\
\hline
\end{tabular}




\begin{tabular}{|c|l|l|l|l|}
\hline learn by & & & \\
researching or & & & \\
learning about & & & \\
using & & & \\
technology & & & \\
tools before I & & & \\
start doing it & & & \\
or using it in & & & \\
my district or & & & \\
school. & & & \\
\hline
\end{tabular}


Q65 Please indicate the degree to which you agree or disagree for each of the statements listed on the left.

\begin{tabular}{|c|c|c|c|c|c|}
\hline & $\begin{array}{c}\text { Strongly } \\
\text { Agree }\end{array}$ & Agree & $\begin{array}{c}\text { Neither } \\
\text { Agree nor } \\
\text { Disagree }\end{array}$ & Disagree & $\begin{array}{l}\text { Strongly } \\
\text { Disagree }\end{array}$ \\
\hline $\begin{array}{l}\text { The majority } \\
\text { of the teachers } \\
\text { in my school } \\
\text { or district look } \\
\text { for models of } \\
\text { effective or } \\
\text { appropriate } \\
\text { use BEFORE } \\
\text { they start } \\
\text { using } \\
\text { technology } \\
\text { tools with } \\
\text { their students. }\end{array}$ & O & O & O & O & O \\
\hline $\begin{array}{l}\text { The majority } \\
\text { of the teachers } \\
\text { in my school } \\
\text { or district } \\
\text { prefer to use } \\
\text { technology } \\
\text { tools in a } \\
\text { similar way as } \\
\text { their peers or } \\
\text { leaders do. }\end{array}$ & O & 0 & O & O & 0 \\
\hline $\begin{array}{l}\text { The majority } \\
\text { of the teachers } \\
\text { in my school } \\
\text { or district } \\
\text { need to know } \\
\text { how to fully } \\
\text { use a } \\
\text { technology } \\
\text { tool (device or } \\
\text { application) } \\
\text { BEFORE their } \\
\text { students begin } \\
\text { using it. }\end{array}$ & O & 0 & O & O & O \\
\hline $\begin{array}{l}\text { The majority } \\
\text { of the teachers } \\
\text { in my school } \\
\text { or district } \\
\text { prefer to try }\end{array}$ & 0 & O & O & O & O \\
\hline
\end{tabular}




\begin{tabular}{|c|l|l|l|l|}
\hline out different & & & \\
techniques of & & & \\
using & & & \\
technology & & & \\
tools with & & & \\
students & & & \\
regardless of & & & \\
how their & & & \\
peers or & & & \\
leaders do so. & & & \\
\hline
\end{tabular}


Q66 Please indicate the degree to which you agree or disagree for each of the statements listed on the left.

\begin{tabular}{|c|c|c|c|c|c|}
\hline & $\begin{array}{c}\text { Strongly } \\
\text { Agree }\end{array}$ & Agree & $\begin{array}{l}\text { Neither } \\
\text { Agree nor } \\
\text { Disagree }\end{array}$ & Disagree & $\begin{array}{l}\text { Strongly } \\
\text { Disagree }\end{array}$ \\
\hline $\begin{array}{l}\text { The majority } \\
\text { of the teachers } \\
\text { in my school } \\
\text { or district only } \\
\text { use } \\
\text { technology } \\
\text { tools with } \\
\text { their students } \\
\text { when they } \\
\text { know their } \\
\text { learning } \\
\text { product will } \\
\text { be } \\
\text { significantly } \\
\text { enhanced. }\end{array}$ & $\mathrm{O}$ & $\mathrm{O}$ & $\mathrm{O}$ & 0 & $\mathrm{O}$ \\
\hline $\begin{array}{l}\text { Knowing the } \\
\text { outcomes } \\
\text { and/or the } \\
\text { student } \\
\text { products or } \\
\text { goals for using } \\
\text { technology is } \\
\text { important to } \\
\text { the majority of } \\
\text { the teachers in } \\
\text { my school or } \\
\text { district } \\
\text { BEFORE they } \\
\text { start doing so. }\end{array}$ & 0 & 0 & 0 & 0 & 0 \\
\hline $\begin{array}{l}\text { The majority } \\
\text { of the teachers } \\
\text { in my school } \\
\text { or district like } \\
\text { to show others } \\
\text { what their } \\
\text { students do } \\
\text { with } \\
\text { technology in } \\
\text { the classroom }\end{array}$ & 0 & 0 & O & $\mathrm{O}$ & $\mathrm{O}$ \\
\hline
\end{tabular}


The following questions are shown only to respondents who select "Technology staff

(CIO, CTO, technology support, technology coordinator, technology coach/mentor, etc.)" in Q9 above.

Q68 The following three questions relate to the ratio of technology devices to students and its general use at school from your own perspective.

Q69 The ratio of technology devices to students is most closely aligned with the statement (select one item only):

In general, we have one (or more) computing device (computer, tablet, other mobile) for every students in my district/school (ratio is 1 student per 1 device)

In general, we have one (or more) computing device (computer, tablet, other mobile) for every two students in my district/school (ratio is 2 students per 1 device)

My school/district has available only shared devices (computer labs, laptop carts, tablet carts, etc.) for all students in a school to share (ratio is more than 2 students per 1 device) 
Q111 Technology devices in my school / school district are generally used for/as:

\begin{tabular}{|c|c|c|c|c|}
\hline & $\begin{array}{l}\text { Always used } \\
\text { for }\end{array}$ & $\begin{array}{l}\text { Most likely used } \\
\text { for }\end{array}$ & $\begin{array}{l}\text { Least likely used } \\
\text { for }\end{array}$ & $\begin{array}{l}\text { Never used } \\
\text { for }\end{array}$ \\
\hline $\begin{array}{c}\text { Reward for } \\
\text { completing other } \\
\text { work }\end{array}$ & 0 & 0 & 0 & $\mathrm{O}$ \\
\hline $\begin{array}{l}\text { Understanding } \\
\text { their academic } \\
\text { work }\end{array}$ & 0 & 0 & 0 & 0 \\
\hline $\begin{array}{l}\text { Supplementary or } \\
\text { enrichment tool }\end{array}$ & 0 & 0 & 0 & 0 \\
\hline $\begin{array}{l}\text { Teaching about } \\
\text { computers and } \\
\text { other technology } \\
\text { tools and how to } \\
\text { use them }\end{array}$ & 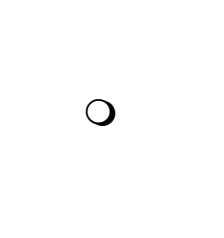 & 0 & 0 & O \\
\hline $\begin{array}{c}\text { Remediation of } \\
\text { academic } \\
\text { deficiencies }\end{array}$ & 0 & 0 & 0 & 0 \\
\hline $\begin{array}{l}\text { Challenging the } \\
\text { brightest students }\end{array}$ & 0 & 0 & $O$ & 0 \\
\hline $\begin{array}{l}\text { State or local } \\
\text { assessments }\end{array}$ & 0 & 0 & 0 & 0 \\
\hline $\begin{array}{l}\text { Motivating } \\
\text { interest in school, } \\
\text { schoolwork, or } \\
\text { class projects }\end{array}$ & 0 & 0 & 0 & 0 \\
\hline $\begin{array}{l}\text { Significantly } \\
\text { changing the } \\
\text { nature of learning } \\
\text { projects and the } \\
\text { way students } \\
\text { interact with } \\
\text { information, } \\
\text { contexts, and real- } \\
\text { world projects }\end{array}$ & 0 & 0 & 0 & 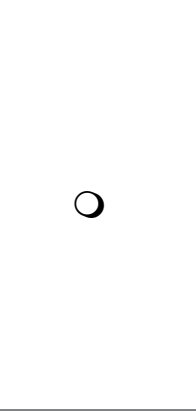 \\
\hline
\end{tabular}


Q71 In general, the frequency with which technology is used BY STUDENTS in my school or district is (select one only):

$O$ every day the class meets (1)

nearly every day the class meets (2)

throughout the school year, but not every day (3)

once or twice per week (5)

$\bigcirc$ less than once per week (6) 
Q72 The following questions focus on your perceptions about your own grasp of the content you teach, the way you teach it, and how you use technology in your teaching. Each question uses a 5-point scale, ranging from a "Strongly Agree" to "Strongly Disagree."

Q73 Please indicate the degree to which you agree or disagree for each of the statements listed on the left. "Technologies" refer to digital technology resources such as computers, tablets, small mobile devices, interactive white boards, etc.

\begin{tabular}{|c|c|c|c|c|c|}
\hline & $\begin{array}{c}\text { Strongly } \\
\text { Agree }\end{array}$ & Agree & $\begin{array}{l}\text { Neither } \\
\text { Agree nor } \\
\text { Disagree }\end{array}$ & Disagree & $\begin{array}{l}\text { Strongly } \\
\text { Disagree }\end{array}$ \\
\hline $\begin{array}{l}\text { The majority } \\
\text { of the teachers } \\
\text { in my school } \\
\text { or district } \\
\text { know how to } \\
\text { solve their } \\
\text { own technical } \\
\text { problems. }\end{array}$ & 0 & 0 & $\mathrm{O}$ & O & O \\
\hline $\begin{array}{l}\text { The majority } \\
\text { of the teachers } \\
\text { in my school } \\
\text { or district can } \\
\text { learn } \\
\text { technology } \\
\text { easily. }\end{array}$ & $\mathrm{O}$ & O & $\mathrm{O}$ & O & 0 \\
\hline $\begin{array}{l}\text { The majority } \\
\text { of the teachers } \\
\text { in my school } \\
\text { or district have } \\
\text { had sufficient } \\
\text { opportunities } \\
\text { to work with } \\
\text { different } \\
\text { technologies. }\end{array}$ & 0 & 0 & $\mathrm{O}$ & 0 & 0 \\
\hline
\end{tabular}


Q77 Please indicate the degree to which you agree or disagree for each of the statements listed on the left.

\begin{tabular}{|c|c|c|c|c|c|}
\hline & $\begin{array}{c}\text { Strongly } \\
\text { Agree }\end{array}$ & Agree & $\begin{array}{l}\text { Neither } \\
\text { Agree nor } \\
\text { Disagree }\end{array}$ & Disagree & $\begin{array}{l}\text { Strongly } \\
\text { Disagree }\end{array}$ \\
\hline $\begin{array}{l}\text { The majority } \\
\text { of the teachers } \\
\text { in my school } \\
\text { or district } \\
\text { know about } \\
\text { technologies } \\
\text { that they can } \\
\text { use for } \\
\text { understanding } \\
\text { and working in } \\
\text { the primary } \\
\text { subject area(s) } \\
\text { or grade } \\
\text { level(s) they } \\
\text { teach. }\end{array}$ & $\mathrm{O}$ & $\mathrm{O}$ & $\mathrm{O}$ & $\mathrm{O}$ & $\mathrm{O}$ \\
\hline
\end{tabular}


Q78 Please indicate the degree to which you agree or disagree for each of the statements listed on the left.

\begin{tabular}{|c|c|c|c|c|c|}
\hline & $\begin{array}{c}\text { Strongly } \\
\text { Agree }\end{array}$ & Agree & $\begin{array}{l}\text { Neither } \\
\text { Agree nor } \\
\text { Disagree }\end{array}$ & Disagree & $\begin{array}{l}\text { Strongly } \\
\text { Disagree }\end{array}$ \\
\hline $\begin{array}{l}\text { The majority } \\
\text { of the teachers } \\
\text { in my school } \\
\text { or district can } \\
\text { choose } \\
\text { technologies } \\
\text { that enhance } \\
\text { the teaching } \\
\text { approaches for } \\
\text { a lesson. }\end{array}$ & 0 & $\mathrm{O}$ & O & $\mathrm{O}$ & $\mathrm{O}$ \\
\hline $\begin{array}{l}\text { The majority } \\
\text { of the teachers } \\
\text { in my school } \\
\text { or district can } \\
\text { choose } \\
\text { technologies } \\
\text { that enhance } \\
\text { students' } \\
\text { learning for a } \\
\text { lesson. }\end{array}$ & 0 & 0 & $\mathrm{O}$ & O & $\mathrm{O}$ \\
\hline
\end{tabular}


Q79 Please indicate the degree to which you agree or disagree for each of the statements listed on the left.

\begin{tabular}{|c|c|c|c|c|c|}
\hline & $\begin{array}{c}\text { Strongly } \\
\text { Agree }\end{array}$ & Agree & $\begin{array}{l}\text { Neither } \\
\text { Agree nor } \\
\text { Disagree }\end{array}$ & Disagree & $\begin{array}{l}\text { Strongly } \\
\text { Disagree }\end{array}$ \\
\hline $\begin{array}{l}\text { The majority } \\
\text { of the teachers } \\
\text { in my school } \\
\text { or district can } \\
\text { choose } \\
\text { technologies } \\
\text { that enhance } \\
\text { the content for } \\
\text { a lesson. }\end{array}$ & 0 & 0 & 0 & 0 & 0 \\
\hline $\begin{array}{l}\text { The majority } \\
\text { of the teachers } \\
\text { in my school } \\
\text { or district can } \\
\text { select } \\
\text { technologies } \\
\text { to use in their } \\
\text { classroom that } \\
\text { enhance what } \\
\text { they teach, } \\
\text { how they } \\
\text { teach, and } \\
\text { what students } \\
\text { learn. }\end{array}$ & 0 & 0 & O & O & 0 \\
\hline $\begin{array}{c}\text { The majority } \\
\text { of the teachers } \\
\text { in my school } \\
\text { or district can } \\
\text { teach lessons } \\
\text { that } \\
\text { appropriately } \\
\text { combine their } \\
\text { subject area(s) } \\
\text { or grade } \\
\text { level(s), } \\
\text { technologies, } \\
\text { and teaching } \\
\text { approaches. }\end{array}$ & 0 & 0 & 0 & O & O \\
\hline
\end{tabular}


Q80 The following questions relate to your perceptions of leadership, teacher selfefficacy, and support.

Q81 Please indicate the degree to which you agree or disagree for each of the statements listed on the left.

\begin{tabular}{|c|c|c|c|c|c|}
\hline & $\begin{array}{c}\text { Strongly } \\
\text { Agree }\end{array}$ & Agree & $\begin{array}{l}\text { Neither } \\
\text { Agree nor } \\
\text { Disagree }\end{array}$ & Disagree & $\begin{array}{l}\text { Strongly } \\
\text { Disagree }\end{array}$ \\
\hline $\begin{array}{c}\text { The majority } \\
\text { of the teachers } \\
\text { in my school } \\
\text { or district use } \\
\text { technology in } \\
\text { their } \\
\text { instruction } \\
\text { because it's } \\
\text { their own } \\
\text { choice to do } \\
\text { so. }\end{array}$ & 0 & 0 & 0 & 0 & 0 \\
\hline $\begin{array}{c}\text { The majority } \\
\text { of the teachers } \\
\text { in my school } \\
\text { or district use } \\
\text { technology in } \\
\text { their } \\
\text { instruction } \\
\text { because it's an } \\
\text { expectation of } \\
\text { school or } \\
\text { district } \\
\text { leaders. }\end{array}$ & 0 & 0 & O & $\mathrm{O}$ & 0 \\
\hline $\begin{array}{c}\text { The majority } \\
\text { of the teachers } \\
\text { in my school } \\
\text { or district use } \\
\text { technology in } \\
\text { their } \\
\text { instruction } \\
\text { because } \\
\text { some/many of } \\
\text { their peers do } \\
\text { so. }\end{array}$ & $\mathrm{O}$ & 0 & $\mathrm{O}$ & 0 & 0 \\
\hline $\begin{array}{l}\text { The majority } \\
\text { of the teachers } \\
\text { in my school } \\
\text { or district use } \\
\text { technology in }\end{array}$ & O & $\mathrm{O}$ & $\mathrm{O}$ & 0 & $\mathrm{O}$ \\
\hline
\end{tabular}




\begin{tabular}{|c|c|c|c|c|c|}
\hline $\begin{array}{c}\text { their } \\
\text { instruction } \\
\text { because } \\
\text { students } \\
\text { request it. } \\
\text { The majority } \\
\text { of the teachers } \\
\text { in my school } \\
\text { or district use } \\
\text { technology in } \\
\text { their } \\
\text { instruction } \\
\text { because } \\
\text { families or } \\
\text { parents expect } \\
\text { it. }\end{array}$ & $O$ & 0 & 0 & 0 & 0 \\
\hline
\end{tabular}


Q82 Please indicate the degree to which you agree or disagree for each of the statements listed on the left.

\begin{tabular}{|c|c|c|c|c|c|}
\hline & $\begin{array}{c}\text { Strongly } \\
\text { Agree }\end{array}$ & Agree & $\begin{array}{l}\text { Neither } \\
\text { Agree nor } \\
\text { Disagree }\end{array}$ & Disagree & $\begin{array}{l}\text { Strongly } \\
\text { Disagree }\end{array}$ \\
\hline $\begin{array}{l}\text { The school } \\
\text { leadership or } \\
\text { district } \\
\text { leadership } \\
\text { provides } \\
\text { adequate } \\
\text { training or } \\
\text { professional } \\
\text { development } \\
\text { for using } \\
\text { technology in } \\
\text { instruction. }\end{array}$ & $\mathrm{O}$ & 0 & 0 & 0 & 0 \\
\hline $\begin{array}{l}\text { The school } \\
\text { leadership or } \\
\text { district } \\
\text { leadership } \\
\text { provides } \\
\text { training or } \\
\text { professional } \\
\text { development } \\
\text { which directly } \\
\text { influences the } \\
\text { use of } \\
\text { technology in } \\
\text { instruction }\end{array}$ & $\mathrm{O}$ & $\mathrm{O}$ & $\mathrm{O}$ & O & 0 \\
\hline
\end{tabular}


Q83 Please indicate the degree to which you agree or disagree for each of the statements listed on the left.

\begin{tabular}{|c|c|c|c|c|c|}
\hline & $\begin{array}{c}\text { Strongly } \\
\text { Agree }\end{array}$ & Agree & $\begin{array}{l}\text { Neither } \\
\text { Agree nor } \\
\text { Disagree }\end{array}$ & Disagree & $\begin{array}{l}\text { Strongly } \\
\text { Disagree }\end{array}$ \\
\hline $\begin{array}{l}\text { Teachers are } \\
\text { able to } \\
\text { influence } \\
\text { technology } \\
\text { purchasing } \\
\text { decisions in } \\
\text { their school } \\
\text { and/or our } \\
\text { district. }\end{array}$ & $\mathrm{O}$ & O & $\mathrm{O}$ & 0 & O \\
\hline $\begin{array}{l}\text { Our school or } \\
\text { district has an } \\
\text { effective } \\
\text { method for } \\
\text { teachers to } \\
\text { apply for } \\
\text { funding a } \\
\text { technology } \\
\text { project in } \\
\text { their } \\
\text { classroom. }\end{array}$ & O & $\mathrm{O}$ & 0 & 0 & O \\
\hline
\end{tabular}


Q84 Please indicate the degree to which you agree or disagree for each of the statements listed on the left.

\begin{tabular}{|c|c|c|c|c|c|}
\hline & $\begin{array}{c}\text { Strongly } \\
\text { Agree }\end{array}$ & Agree & $\begin{array}{l}\text { Neither } \\
\text { Agree nor } \\
\text { Disagree }\end{array}$ & Disagree & $\begin{array}{l}\text { Strongly } \\
\text { Disagree }\end{array}$ \\
\hline $\begin{array}{l}\text { I feel that my } \\
\text { leadership } \\
\text { supports our } \\
\text { teachers' use } \\
\text { of technology } \\
\text { with students }\end{array}$ & O & O & O & 0 & O \\
\hline $\begin{array}{l}\text { I feel that } \\
\text { teachers' peers } \\
\text { support the } \\
\text { use of } \\
\text { technology } \\
\text { with students. }\end{array}$ & O & O & O & O & O \\
\hline $\begin{array}{l}\text { I feel that } \\
\text { teachers can } \\
\text { get adequate } \\
\text { technology } \\
\text { support for } \\
\text { issues that } \\
\text { arise for } \\
\text { themselves or } \\
\text { for their } \\
\text { students. }\end{array}$ & 0 & O & O & O & 0 \\
\hline
\end{tabular}


Q86 The following questions ask you about your attitudes and perceptions about your classroom uses of technology.

Q87 Please indicate the degree to which you agree or disagree for each of the statements listed on the left.

\begin{tabular}{|c|c|c|c|c|c|}
\hline & $\begin{array}{c}\text { Strongly } \\
\text { Agree }\end{array}$ & Agree & $\begin{array}{l}\text { Neither } \\
\text { Agree nor } \\
\text { Disagree }\end{array}$ & Disagree & $\begin{array}{l}\text { Strongly } \\
\text { Disagree }\end{array}$ \\
\hline $\begin{array}{l}\text { The majority } \\
\text { of the teachers } \\
\text { in my school } \\
\text { or district } \\
\text { learn by doing } \\
\text { and/or by } \\
\text { using } \\
\text { technology } \\
\text { tools in an } \\
\text { active way on } \\
\text { their own. }\end{array}$ & 0 & 0 & $\mathrm{O}$ & 0 & 0 \\
\hline $\begin{array}{l}\text { The majority } \\
\text { of the teachers } \\
\text { in my school } \\
\text { or district } \\
\text { prefer to try } \\
\text { out different } \\
\text { techniques of } \\
\text { using } \\
\text { technology } \\
\text { tools with } \\
\text { students } \\
\text { regardless of } \\
\text { how their } \\
\text { peers or } \\
\text { leaders do so. }\end{array}$ & 0 & O & O & O & $\mathrm{O}$ \\
\hline $\begin{array}{l}\text { The majority } \\
\text { of the teachers } \\
\text { in my school } \\
\text { or district look } \\
\text { for models of } \\
\text { effective or } \\
\text { appropriate } \\
\text { use BEFORE } \\
\text { they start } \\
\text { using } \\
\text { technology } \\
\text { tools with }\end{array}$ & O & 0 & $\mathrm{O}$ & 0 & $\mathrm{O}$ \\
\hline
\end{tabular}




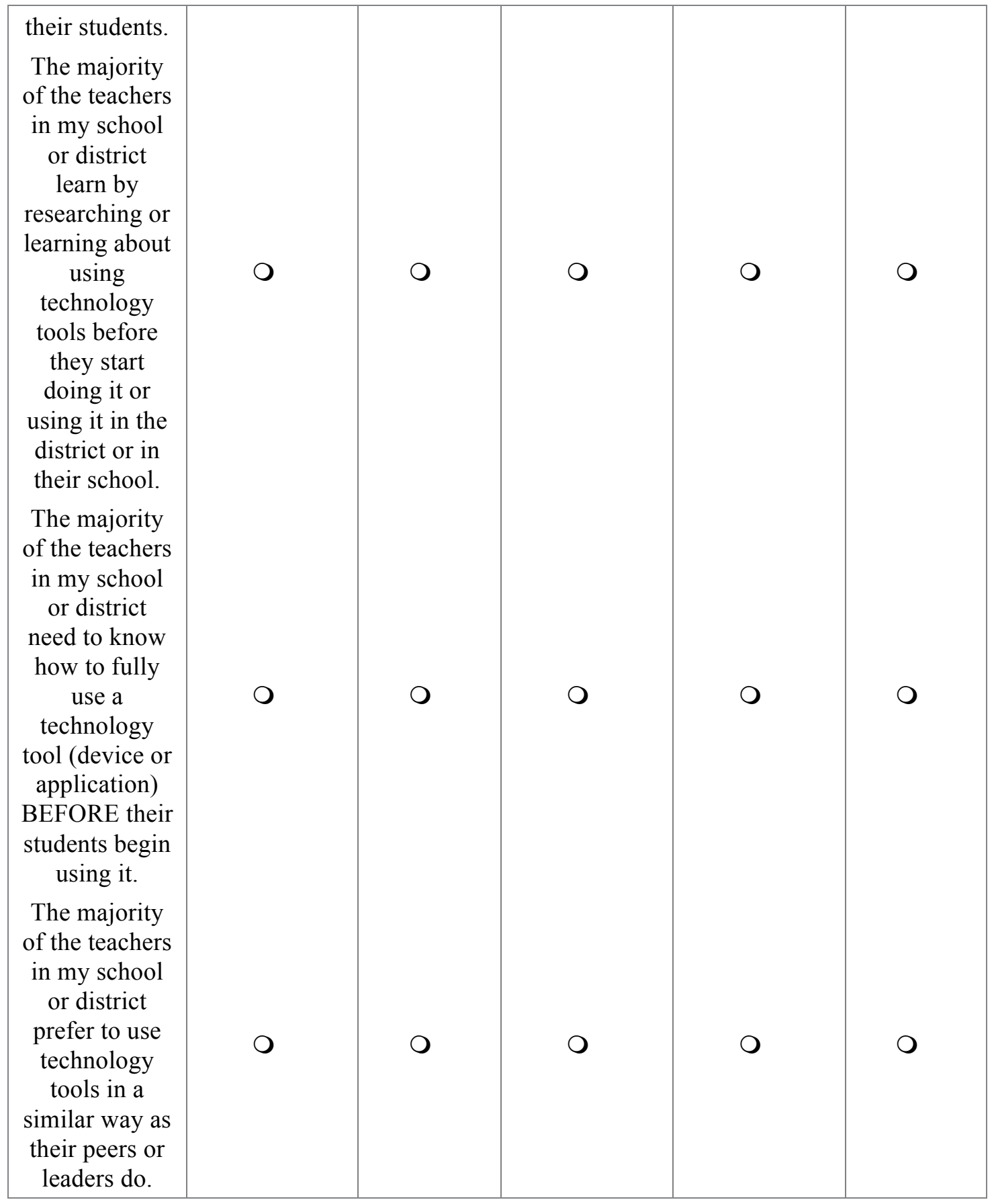


Q106 Please indicate the degree to which you agree or disagree for each of the statements listed on the left.

\begin{tabular}{|c|c|c|c|c|c|}
\hline & $\begin{array}{l}\text { Strongly } \\
\text { Agree }\end{array}$ & Agree & $\begin{array}{l}\text { Neither } \\
\text { Agree nor } \\
\text { Disagree }\end{array}$ & Disagree & $\begin{array}{l}\text { Strongly } \\
\text { Disagree }\end{array}$ \\
\hline $\begin{array}{l}\text { The majority } \\
\text { of the teachers } \\
\text { in my school } \\
\text { or district look } \\
\text { for models of } \\
\text { effective or } \\
\text { appropriate } \\
\text { use BEFORE } \\
\text { they start } \\
\text { using } \\
\text { technology } \\
\text { tools with } \\
\text { their students. }\end{array}$ & O & O & $O$ & O & O \\
\hline $\begin{array}{l}\text { The majority } \\
\text { of the teachers } \\
\text { in my school } \\
\text { or district } \\
\text { prefer to use } \\
\text { technology } \\
\text { tools in a } \\
\text { similar way as } \\
\text { their peers or } \\
\text { leaders do. }\end{array}$ & O & O & 0 & 0 & 0 \\
\hline $\begin{array}{l}\text { The majority } \\
\text { of the teachers } \\
\text { in my school } \\
\text { or district } \\
\text { need to know } \\
\text { how to fully } \\
\text { use a } \\
\text { technology } \\
\text { tool (device or } \\
\text { application) } \\
\text { BEFORE their } \\
\text { students begin } \\
\text { using it. }\end{array}$ & O & 0 & O & O & O \\
\hline $\begin{array}{l}\text { The majority } \\
\text { of the teachers } \\
\text { in my school } \\
\text { or district } \\
\text { prefer to try }\end{array}$ & 0 & O & 0 & 0 & 0 \\
\hline
\end{tabular}




\begin{tabular}{|c|l|l|l|l|}
\hline out different & & & \\
techniques of & & & \\
using & & & \\
technology & & & \\
tools with & & & \\
students & & & \\
regardless of & & & \\
how their & & & \\
peers or & & & \\
leaders do so. & & & \\
\hline
\end{tabular}


Q107 Please indicate the degree to which you agree or disagree for each of the statements listed on the left.

\begin{tabular}{|c|c|c|c|c|c|}
\hline & $\begin{array}{c}\text { Strongly } \\
\text { Agree }\end{array}$ & Agree & $\begin{array}{l}\text { Neither } \\
\text { Agree nor } \\
\text { Disagree }\end{array}$ & Disagree & $\begin{array}{l}\text { Strongly } \\
\text { Disagree }\end{array}$ \\
\hline $\begin{array}{l}\text { The majority } \\
\text { of the teachers } \\
\text { in my school } \\
\text { or district only } \\
\text { use } \\
\text { technology } \\
\text { tools with } \\
\text { their students } \\
\text { when they } \\
\text { know their } \\
\text { learning } \\
\text { product will } \\
\text { be } \\
\text { significantly } \\
\text { enhanced. }\end{array}$ & $\mathrm{O}$ & $\mathrm{O}$ & $\mathrm{O}$ & 0 & 0 \\
\hline $\begin{array}{l}\text { Knowing the } \\
\text { outcomes } \\
\text { and/or the } \\
\text { student } \\
\text { products or } \\
\text { goals for using } \\
\text { technology is } \\
\text { important to } \\
\text { the majority of } \\
\text { the teachers in } \\
\text { my school or } \\
\text { district } \\
\text { BEFORE they } \\
\text { start doing so. }\end{array}$ & 0 & 0 & 0 & 0 & 0 \\
\hline $\begin{array}{l}\text { The majority } \\
\text { of the teachers } \\
\text { in my school } \\
\text { or district like } \\
\text { to show others } \\
\text { what their } \\
\text { students do } \\
\text { with } \\
\text { technology in } \\
\text { the classroom }\end{array}$ & 0 & 0 & $\mathrm{O}$ & $\mathrm{O}$ & $\mathrm{O}$ \\
\hline
\end{tabular}


The following final questions are shown to all respondents regardless of group after they finish the appropriate block of questions above.

Q37 The following questions ask you about challenges for classroom technology use.

Q38 Is each of the following a MAJOR challenge, a MINOR challenge, or NOT a challenge at all for you to incorporate digital technologies into your classroom/school/district?

\begin{tabular}{|c|c|c|c|}
\hline $\begin{array}{c}\text { Time constraints } \\
\text { Pressure to "teach to } \\
\text { the test" }\end{array}$ & Major challenge & Minor challenge & Not a challenge \\
$\begin{array}{c}\text { Lack of access to } \\
\text { technology resources } \\
\text { for your students }\end{array}$ & 0 & 0 & 0 \\
$\begin{array}{c}\text { Lack of technology } \\
\text { support for issues that } \\
\text { arise }\end{array}$ & 0 & 0 & 0 \\
$\begin{array}{c}\text { Lack of support (or a } \\
\text { general resistance) by } \\
\text { school or district } \\
\text { leadership }\end{array}$ & 0 & 0 & \\
$\begin{array}{c}\text { Your own lack of } \\
\text { knowledge about or } \\
\text { comfort with } \\
\text { technology }\end{array}$ & 0 & & \\
\hline
\end{tabular}


Q40 Does your school or district have the following in place, AND how much of an impact, if any, does it have on your the of technology for students in school?

\begin{tabular}{|c|c|c|c|c|}
\hline & $\begin{array}{l}\text { Yes, major } \\
\text { impact }\end{array}$ & $\begin{array}{l}\text { Yes, minor } \\
\text { impact }\end{array}$ & Yes, NO impact & $\begin{array}{c}\text { School/district } \\
\text { does not have } \\
\text { this }\end{array}$ \\
\hline $\begin{array}{l}\text { Filters blocking } \\
\text { access to certain } \\
\text { websites or } \\
\text { online content }\end{array}$ & $\mathrm{O}$ & O & $\mathrm{O}$ & O \\
\hline $\begin{array}{l}\text { Rules governing } \\
\text { students using } \\
\text { personal } \\
\text { technology } \\
\text { devices on school } \\
\text { grounds }\end{array}$ & $\mathrm{O}$ & $\mathrm{O}$ & $\mathrm{O}$ & 0 \\
\hline $\begin{array}{l}\text { Acceptable Use } \\
\text { Policy governing } \\
\text { how and for what } \\
\text { purpose students } \\
\text { shall be granted } \\
\text { access to the } \\
\text { school's network } \\
\text { resources (i.e. } \\
\text { Internet, email, } \\
\text { etc.) }\end{array}$ & $\mathrm{O}$ & $\mathrm{O}$ & O & O \\
\hline
\end{tabular}


Q89 Do you agree or disagree with the following statements:

\begin{tabular}{|c|c|c|c|c|c|}
\hline & $\begin{array}{l}\text { Strongly } \\
\text { Agree }\end{array}$ & Agree & $\begin{array}{l}\text { Neither } \\
\text { Agree nor } \\
\text { Disagree }\end{array}$ & Disagree & $\begin{array}{l}\text { Strongly } \\
\text { Disagree }\end{array}$ \\
\hline $\begin{array}{l}\text { The } \\
\text { professional } \\
\text { development } \\
\text { activities for } \\
\text { teachers to } \\
\text { learn to use } \\
\text { technology in } \\
\text { the classroom } \\
\text { with students } \\
\text { are relevant } \\
\text { and useful. }\end{array}$ & 0 & 0 & O & 0 & 0 \\
\hline $\begin{array}{l}\text { There should } \\
\text { be more } \\
\text { professional } \\
\text { development } \\
\text { opportunities } \\
\text { for teachers to } \\
\text { learn to use } \\
\text { technology in } \\
\text { the classroom } \\
\text { with students. }\end{array}$ & 0 & 0 & 0 & 0 & 0 \\
\hline
\end{tabular}


Q41 Using the provided rating scale, how does your school or district do in providing teachers the resources and support they need to effectively incorporate the newest digital technologies into their curriculum and pedagogy?

\begin{tabular}{|c|c|c|c|c|c|}
\hline & Great job & Good job & $\begin{array}{c}\text { Neither good } \\
\text { nor bad }\end{array}$ & $\begin{array}{c}\text { Mediocre } \\
\text { job }\end{array}$ & Poor job \\
\hline $\begin{array}{c}\text { District/school } \\
\text { provides } \\
\text { resources and } \\
\text { supports }\end{array}$ & 0 & 0 & 0 & 0 & 0 \\
\hline
\end{tabular}

